Final Report

FHWA/IN/JTRP-2005/1

\title{
FILTER PERFORMANCE AND DESIGN FOR HIGHWAY DRAINS
}

\author{
By \\ Sangho Lee \\ Graduate Research Assistant \\ School of Civil Engineering \\ Purdue University \\ And \\ Philippe L. Bourdeau \\ Principal Investigator \\ Associate Professor of Civil Engineering \\ Purdue University
Joint Transportation Research Program
Project No. C-36-15O
File No. 6-9-15
SPR-2635
Conducted in Cooperation with
Federal Highway Administration \\ the Indiana Department of Transportation \\ and the U.S. Department of Transportation
}

The contents of this report reflect the views of the authors who are responsible for the fats and accuracy of the data presented herein. The contents do not necessarily reflect the official views of policies of the Indiana Department of Transportation and Federal Highway Administration.

This report does not constitute a standard, specification, or regulation.

Purdue University

West Lafayette, Indiana

May 2006 


\section{TECHNICAL Summary}

INDOT Research

Technology Transfer and Project Implementation Information

TRB Subject Code: 63-6 Subsurface Drainage

Publication No.: FHWA/IN/JTRP-2005/1, SPR-2635

May 2006

Final Report

\section{Filter Performance and Design for Highway Drains}

\section{Introduction}

The effectiveness of underdrain filters was investigated in order to make recommendations on selection criteria, design and installation guidelines that would improve the long-term performance of drainage systems in Indiana highways. Since significant savings in construction and maintenance cost can be achieved if geosynthetic filters are employed successfully, the study was focused on these types of filters, rather than on traditional mineral filters. The scope of the study was limited to hydro-mechanical filtration mechanisms of solid particles that is, biological and chemical aspects were not addressed to the exception of a test using recycled concrete aggregate. The investigating approach includes field data collection, laboratory experiments and analysis.

\section{Findings}

Soil filtration by geotextiles is a complex, multifaceted, process. Its successful application depends on physical compatibility between the geotextile filter and the soil to be retained. Therefore, no successful design can be achieved without considering, first the nature and characteristics of the soil present at the site, and then the range of geotextile products eligible. There is no universal solution where a unique geotextile filter would be compatible with all types of soils or even a broad range of soils. But design solutions can be devised where geotextiles would be compatible with soil types defined by simple parameters such as their particle size and state of compaction.

Geotechnical situations that are considered prone to filtration problems with highway underdrains and from which soil samples were analyzed are characterized by high silt content, but the presence of clay together with silt, plays also a role in filter clogging.

At a project site from which samples of exhumed filters were obtained, the soil was, typically, silty clay. The filter samples from this site exhibited variable degree of clogging after 15 years of service and, when quasi-intact specimens were tested in the laboratory, they were found incompatible with the soil.
Video recording of underdrain pipe nondestructive inspections from different INDOT projects show moderate to heavy sedimentation within pipes after one year of service, suggesting adequate filtration was lacking at this sites.

Testing in the laboratory suggests cement chemicals from recycled (rubbleized) concrete aggregates might also affect the integrity of geotextile filters, a conclusion already reached by Wukash and Siddiqui (1996) in an earlier JTRP study.

Laboratory testing results were obtained using the best available experimentation methods, the FWGR and the RRT, for a number of material combinations and testing parameters. During flexible wall gradient ratio tests, fine migration within the filter system could be traced indirectly by monitoring the precise pore pressure variation at different elevations along the soil column. Resulting data, gradient ratios and hydraulic head losses through the geotextiles, were consistent altogether to identify the different clogging mechanisms. In particular, they allowed differentiation between surface blocking by coarse particles and internal clogging by fines.

Among the most interesting findings from the testing program is the influence of the soil state of compaction on the filter response. In general, compaction increases interlocking 
between soil particles, reduces the pore space and, consequently, the internal stability of the soil is improved. This is contributing to good filter performance for soils made of a small to medium amount of silt mixed with coarser particles. But a positive effect was not observed with soils made essentially of silt. However, the effect of compaction is more complex if the soil surrounding the filter is compacted after the getextile has been installed. In this case compaction-induced pressure is applied to geotextile and can modify the fabric pore structure or force soil particles into its openings.

Another important factor is the geotextile thickness in connection with its opening size. The thicker is the geotextile, the more likely is a particle to encounter a constriction smaller than its size. High silt content soils can be effectively filtered by thick geotextiles with small FOS rather than by thin ones with large FOS. As described before, most commercially available non woven geotextiles have a FOS larger than silt particle size. Therefore, the fines need be filtered within the geotextile fabric instead of be retained outside To achieve this, a longer infiltration path, characteristic of a thick non-woven geotextile, will offer to a traveling particle more opportunities for small constriction encounter than a thin fabric would. If the soil is to be compacted, a thick geotextile is also less likely to have its porosity decreased and fabric structure disturbed by the compaction process than a thin geotextile.

Filtration tests were performed with different types of soils, including low silt content soil, gap-graded soil and high silt content soil. With low silt content soil (10\%wt silt) it is generally agreed that the filter should be a geotextile with large AOS (>1 mm), but it was observed in this study that, if the soil has been compacted, a thick geotextile with much smaller AOS $(0.15 \mathrm{~mm})$ can also be adequate. Gapgraded soil with $20 \%$ wt silt was successfully filtered using a geotextile with large opening size $(0.21 \mathrm{~mm})$ without need for compaction.

Of paramount importance is the relationship between filter opening size and soil grain size distribution. Uniformly graded soils
$(\mathrm{Cu}<3)$ can be filtered by the geotextiles with large FOS because a self-filtration zone of soil builds itself at the filter interface and forms bridges over filter openings that may be larger than individual particles. On the other hand, well graded or gap-graded soils need to be filtered by geotextiles with FOS smaller than the representative particle size, $\mathrm{D}_{50}$ or the lower limit of the GSD gap $D_{G}$, respectively.

Another important relationship is between the geotextile manufacturing style (producing different modes of fiber bonding and fabric porosities) and the soil type of GSD (e.g. gap graded, well graded or pure fine). If the soil is internally unstable and has small silt content (< $20 \%$ wt silt), an even pattern at the surface of the filter facilitates penetration of the loose fines through the openings that still left free from coarse particle blockage. In case of high silt content soil (> 50\%wt silt) where particles assemblies are more likely to be in a in loose state, the geotextile porosity should be large in order to limit the risk of plugging by localized fine intrusion. For soils that are the most problematic with respect to geotextile filter design $(20 \%<$ silt wt $<50 \%$ ), selection of a geotextile style will depend on both grain size distribution and state of compaction since these factors control the soil internal stability.

Presence of small amounts of clay in silty soils contributes to filter clogging. It was observed from the experiments that the cohesiveness of clay mineral plays a role in accelerating the filter internal clogging especially at low flow rate (below 1.0E-6 cm/sec). A solution for filtering silty soils with small clay content $(<20 \% \mathrm{wt})$ is to associate a thick geotextile and a layer of sand placed upstream of the filter.

The magnitude of the hydraulic gradient across the filter zone influences the time rate of the clogging process but not its result. Application of high gradients in filtration tests had the effect of accelerating the process, as compared to tests performed under smaller gradients, but the ultimate state of the system, in terms of gradient ratios and hydraulic conductivity at steady state, was not significantly different.

\section{Implementation}

Detailed recommendations are presented in Sections 7.2 and 7.3 of the report.

Geotextile filter selection guidelines

The guidelines for selecting geotextile filter in function of soil characteristics that are the grain size composition of the soil, its Atterberg's limits and for clay soils, the hydraulic conductivity, are summarized in Table 7-1 of the report which also includes a number of explanatory notes. Only non-woven geotextiles are recommended. The output consists for each situation, in a recommendation of opening size 
range that would be adequate (defined in function of soil grain size), bonding type and fabric thickness. An indication of the effect of soil compaction is also provided.

For the solutions recommended, it is generally assumed, when a filter is required, that the geotextile will be installed as a liner on the bottom, sides and top boundaries of the drainage trench. A difference between this design and current INDOT practice is that, in the present recommendation, the geotextile is wrapped over the drainage trench top after backfilling. It is believed this configuration is better than current practice in which the trench top is left without filter and allows infiltration of fines or recycled concrete chemicals driven by vertical downwards gradients. There is one exception, when a combination of geotextile and sand filters are recommended. In this case, because the sand component of the filter has to be located upstream of the geotextile, the practical solution is to install the geotextile as a wrapping around the drainage pipe, and then backfill the lower part of the trench with sand, at least up to 4" above the pipe (the remaining part can be backfilled with coarser aggregate if this is more economical).

\section{Survivability criteria}

Selection of geotextile filter based on filter criteria addresses the primary function of the geotextile where retention and permeability requirements are met. Another important criterion for the selection of a particular geotextile is based on its ability to survive the mechanical constraints imposed during installation, construction of the roadway and later in service. It has been observed that a number of failures of geotextiles occur during installation and construction rather than in service. This problem was addressed by AASTO and FHWA through a Task Force Committee mission. The resulting criteria and methodology are empirical and are explained in Appendix B of the report. Current INDOT Specifications Sect. 913.19 should be updated accordingly. The recommended revisions are listed in Page 178 of the report.

Step-by-step procedure

Section 7.3 of the report describes a stepby-step procedure to help with implementation of the recommended guidelines.

\section{Contacts}

For more information:

\section{Prof. Philippe Bourdeau}

Principal Investigator

School of Civil Engineering

Purdue University

West Lafayette IN 47907

Phone: (765) 494-5031

Fax: (765) 496-1364

E-mail: bourdeau@ecn.purdue.edu

\section{Indiana Department of Transportation}

Division of Research

1205 Montgomery Street

P.O. Box 2279

West Lafayette, IN 47906

Phone: (765) 463-1521

Fax: (765) 497-1665

\section{Purdue University}

Joint Transportation Research Program

School of Civil Engineering

West Lafayette, IN 47907-1284

Phone: (765) 494-9310

Fax: (765) 496-7996

E-mail: jtrp@ecn.purdue.edu

http://www.purdue.edu/jtrp 
TECHNICAL REPORT STANDARD TITLE PAGE

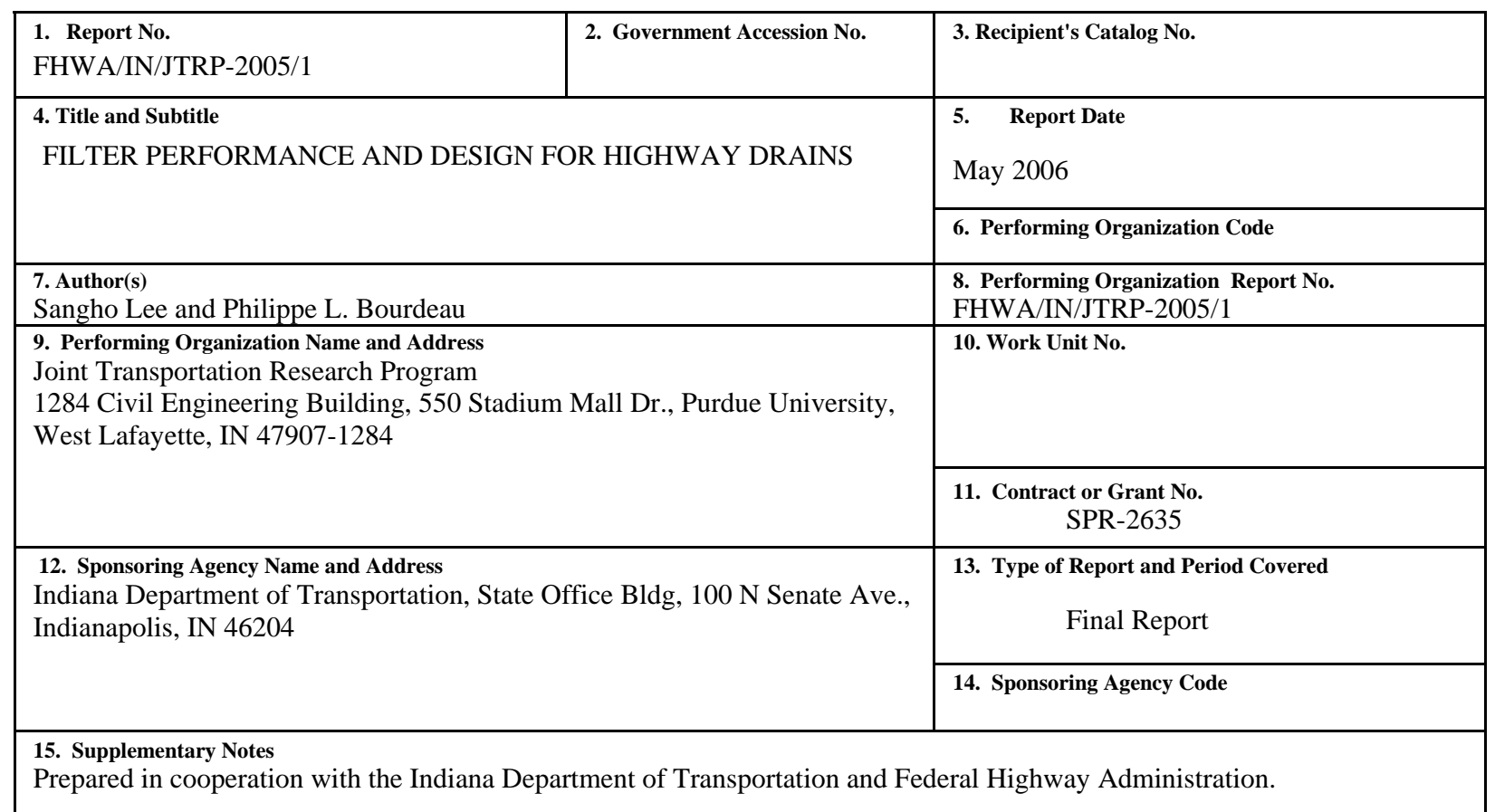

\section{Abstract}

The research is an investigation of soil filtration by geotextile fabrics, with the ultimate objective of improving design and long-term performance of underdrain systems in Indiana highways. Experiments were conducted in the laboratory using the best available techniques, Flexible Wall Gradient Ratio Test and Rapid Retention Test, in order to assess soil-filter compatibility and monitor geotextile clogging, for a range of materials and testing conditions. Field information was also collected and samples from highway reconstruction project were examined for their long-term performance. The main findings relate to the influence of the amounts of silt and clay and the state of compaction of the subgrade. Controlling parameters of the geotextile effectiveness are its opening size, thickness and manufacturing style. Based on these findings and information already available from the literature, new design and installation guidelines including filter selection criteria are proposed for non-woven geotextile filters in Indiana highway edge underdrain systems

\section{Key Words}

Underdrain, edge drain, filter, clogging, non-woven, geotextiles, filter criterion, flexible wall gradient ratio, rapid retention test

\section{Distribution Statement}

No restrictions. This document is available to the public through the National Technical Information Service, Springfield, VA 22161

\begin{tabular}{|c|c|c|c|}
\hline $\begin{array}{c}\text { 19. Security Classif. (of this report) } \\
\text { Unclassified }\end{array}$ & 20. Security Classif. (of this page) & 21. No. of Pages & 22. Price \\
& Unclassified & 204 & \\
\hline
\end{tabular}

Form DOT F 1700.7 (8-69) 


\section{Table of Contents}

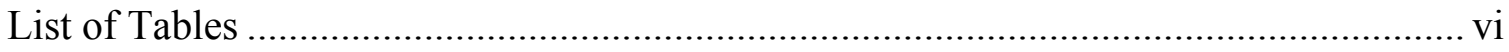

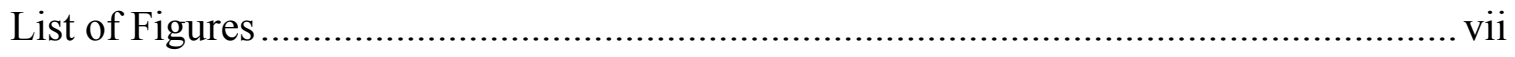

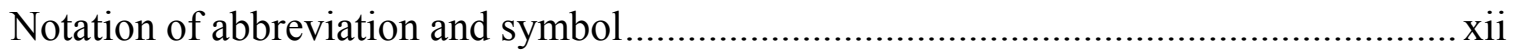

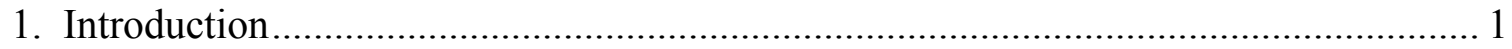

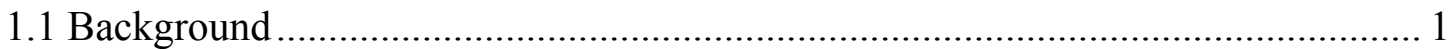

1.2 Statement of Problem............................................................................... 2

1.3 Scope of the Present Study ............................................................................. 5

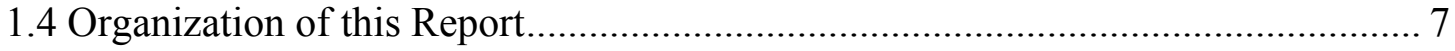

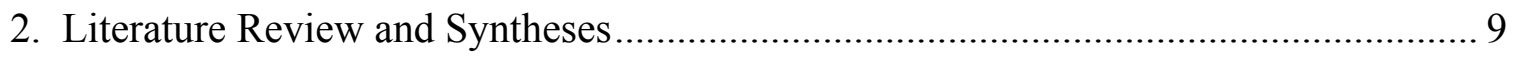

2.1 General Characteristics of Soil Filtration Using Geotextiles............................... 9

2.2 Mechanism of Geotextile Filtration and Physical Clogging .............................. 10

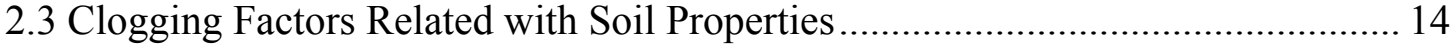

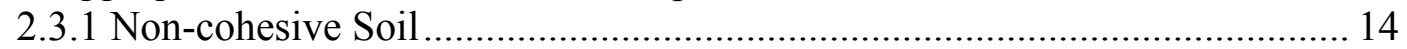

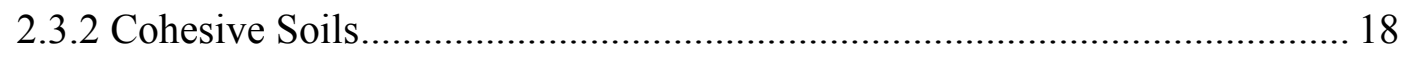

2.4 Clogging Factors Related to Geotextile Properties............................................. 20

2.4.1 Filter Opening Size and Constriction Size Distribution ............................. 21

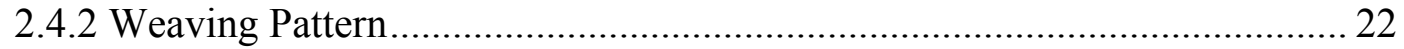

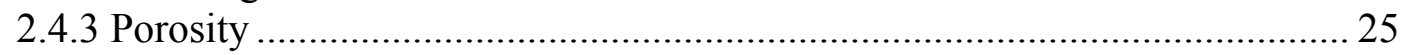

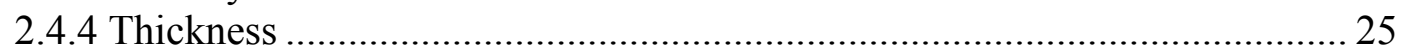

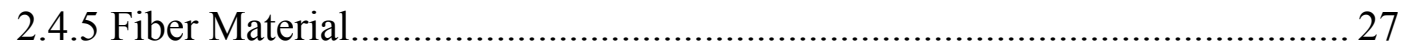

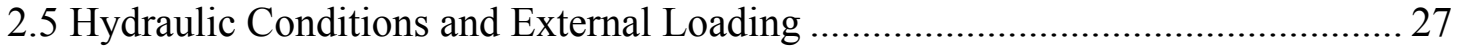

2.6 Test Methods for Geotextile Clogging Assessments ........................................ 29

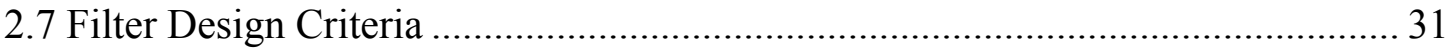

2.7.1 FHWA Criteria (Christopher and Holtz, 1985 and Christopher et al, 1995) 33

2.7.2 Geosyntec Group Criteria (Luettich et al, 1992) ...................................... 33

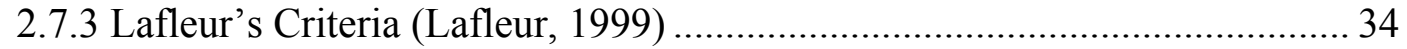

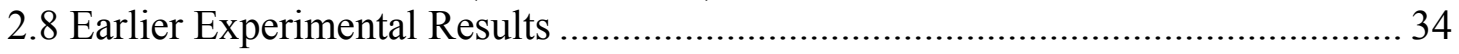

2.9 Earlier Field Performance Study .................................................................. 38

3. Investigation of Field Conditions and Long-Term Performance ............................. 40

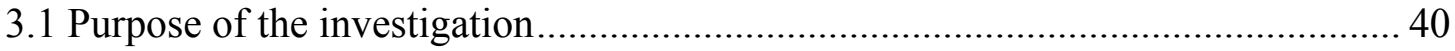

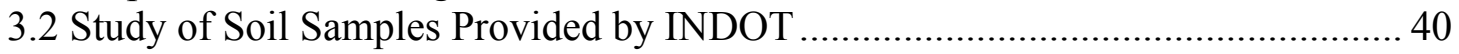

3.3 Field Evaluation of Filter Long-Term Performance .......................................... 42

3.3.1 Site Selection and Sampling .............................................................. 42

3.3.2 Analysis of Soil samples from the Sullivan Co. US 41 Site ........................ 44

3.3.3 Analysis of Geotextile Samples from the Sullivan Co. US 41 Site ............. 44

3.3.4 Analysis of Bloomington Clay Filtration with Geotextile Samples from the

Sullivan Co. US 41 Site .......................................................................... 45

3.3.5 Filtration Test of Recycled Concrete Aggregate from the Sullivan Co. US 


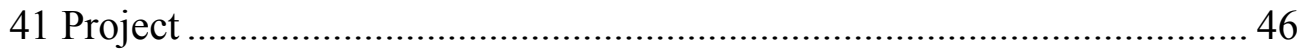

3.3.6 Video Inspection of Subdrainage Pipes ........................................................ 47

3.4 Summary of Field Studies Findings.................................................................. 50

4. Numerical Simulation of Hydraulic Conditions in Pavement ......................................59

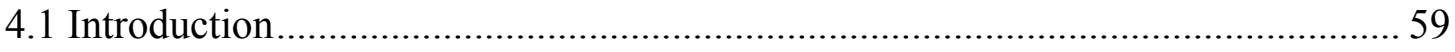

4.2 Analysis of Subsurface Flow Patterns Using PURDRAIN ………………….......... 61

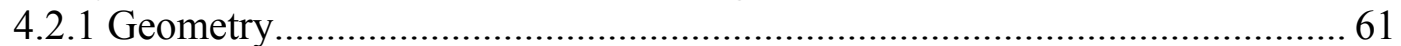

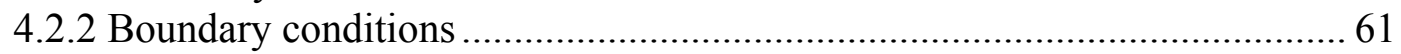

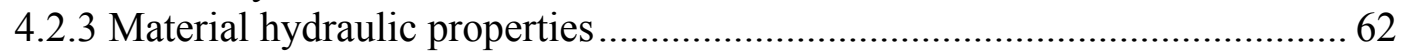

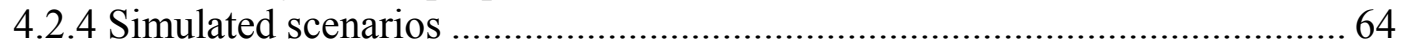

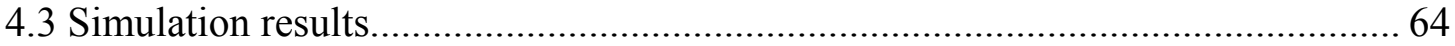

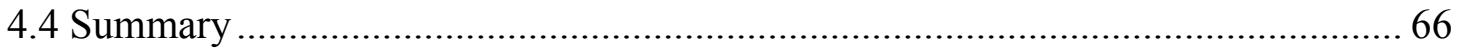

5. Laboratory Investigation of Geotextile Filtration by Flexible Gradient Ratio Test -

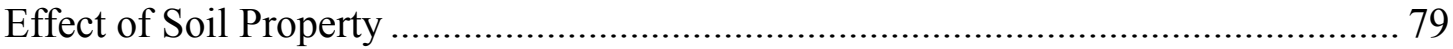

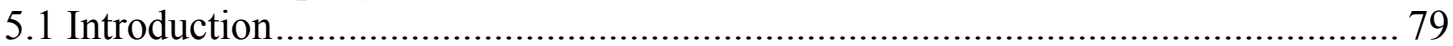

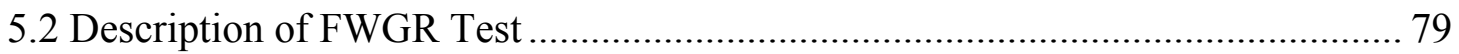

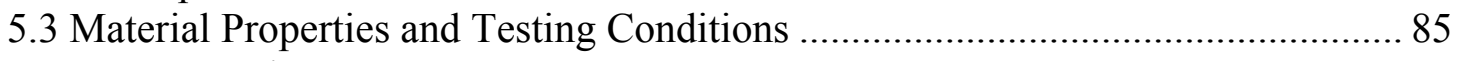

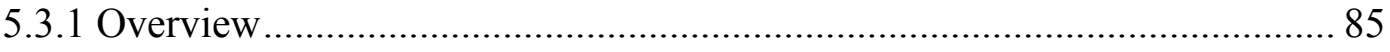

5.3.2 Soil Specimen Preparation ....................................................................... 85

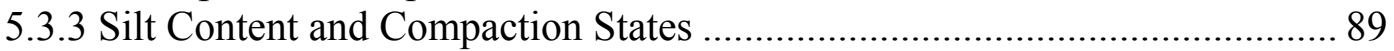

5.3.4 Geotextile Apparent Opening Size (AOS) ................................................... 91

5.3.5 Geotextile Constrained Compressibility and Thickness ................................. 92

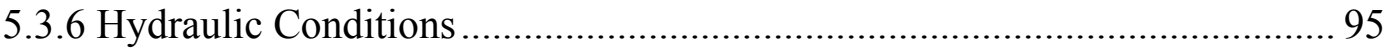

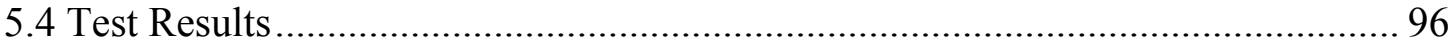

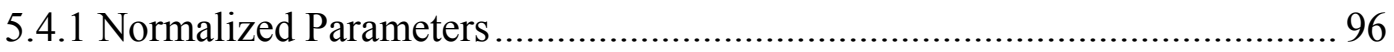

5.4.2 Filter Hydraulic Performance during Soil Filtration...................................... 98

5.4.3 Gradient Ratio and Geotextile Head Loss ................................................ 107

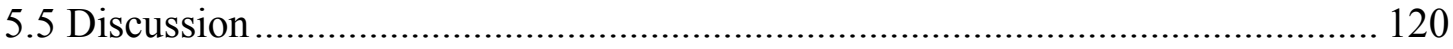

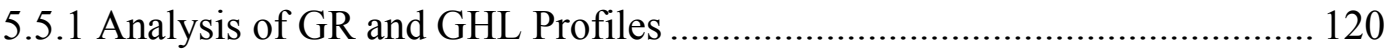

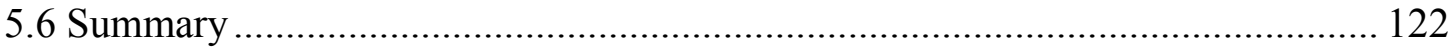

6. Laboratory Investigation of Geotextile Filtration by Rapid Retention Test - Effect of

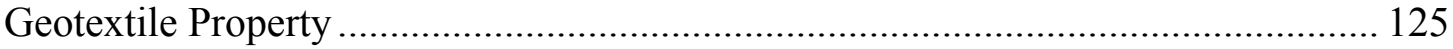

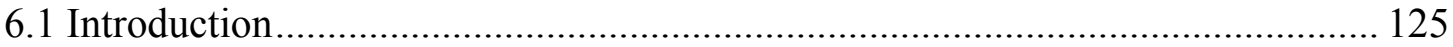

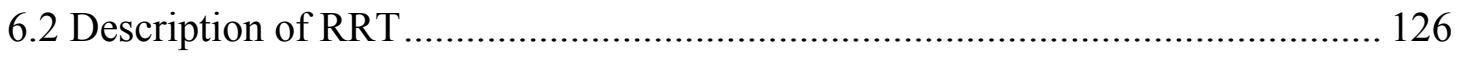

6.3 Soil Specimen Preparation.............................................................................. 129

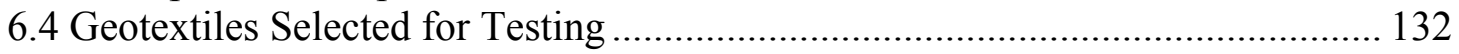

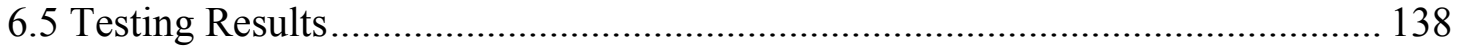

6.5.1 Compatibility of Tested Geotextiles and Soils ............................................ 138

6.5.2 Effect of Hydraulic Gradient Magnitude on RRT Outcomes ...................... 140

6.5.3 Influence of Soil Compaction on RRT Outcomes ...................................... 148

6.5.4 Effect of GT Thickness on the Clogging Process in RRT .......................... 152

6.5.5 Influence of Clay Content on GT Clogging............................................... 158

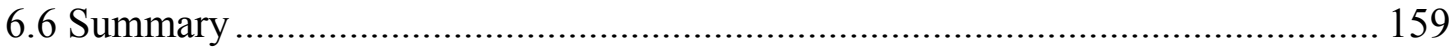


7. Conclusions and Recommendations of Geotextile Filter Selection Guidelines ........ 162

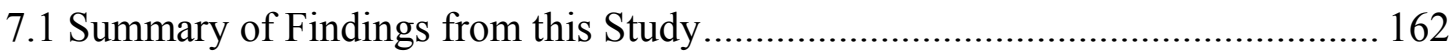

7.2 Recommendations for Filter Selection and Design ........................................ 169

7.2.1 Geotextile filter selection guidelines ................................................. 169

7.2.2 Examples of filter selection ........................................................ 175

7.2.3 Additional physical requirements for geotextiles: Survivability criteria ... 176

7.3 Implementation: Step-by-Step Procedure ...................................................... 178

7.4 Recommendations for Future Study .......................................................... 183

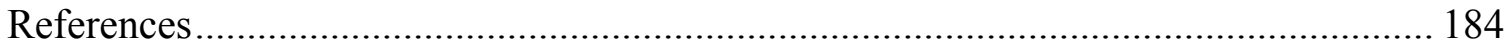

Appendix A

Geotextile Retention Criteria in Published Literature ................................................ 198

Appendix B

Geotextile Survivability Specifications. AASHTO-AGC-ARTBA, Task Force 25 and

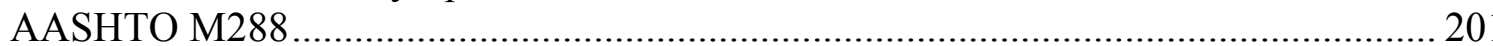




\section{List of Tables}

Table 2-1 Capability of selected geosynthetic filter design criteria to predict filter field performance, based on observation of exhumed samples at sites investigated by Koerner et al (1996) (after Wilson-Fahmy et al, 1996) 39

Table 3-1 Soil samples provided by INDOT

Table 3-2 Soil classifications for samples provided by INDOT

Table 3-3 General information on video inspections of drainage pipes 48

Table 4-1 Input parameters for the Brooks \& Corey partially saturated materials model 63

Table 4-2 Maximal gradient values from numerical simulations 67

Table 5-1 Void ratio and relative density values of test soil specimens 88

Table 5-2 Opening size values recommended from GT retention criteria. 91

Table 5-3 Specs of non woven geotextiles in the constraint compression test (GSE, 2003) 95

Table 5-4 Operational data and test results of flexible wall gradient ratio method 105

Table 6-1 Compositions of soil specimens used in RRT 130

Table 6-2 Specifications of geotextile specimens used in RRT 134

Table 6-3 Summary table for test program used in RRT 142

Table 7-1 Proposed filter selection guideline 171 


\section{List of Figures}

Figure 2-1 Piping(a), bridging(b) and blinding (c) mechanisms associated with Different geotextile opening size and soil behaviors (after Lafleur, 1999) - Left hand Side: soil grain size distribution (GSD) and its variation in the vicinity of the Geotextile (dotted curve: initial GSD; plain curve: final GSD; $\mathrm{R}_{\mathrm{R}}=\mathrm{O}_{\mathrm{f}} / \mathrm{d}_{\mathrm{i}} ; \mathrm{O}_{\mathrm{f}}$ : filter Opening size; $\mathrm{d}_{\mathrm{i}}$ : indicative particle size of protected soil) - Center-left: Schematics of resulting granular structure - Center-right: profile of resulting soil Hydraulic conductivity in function of distance to geotextile $\left(\overline{k_{B}}\right.$ : initial soil Hydraulic conductivity (dotted line)) - Right-hand side: evolution of system Average hydraulic conductivity in function of time, as compared to $\mathrm{k}_{\mathrm{F}}$ (virgin Hydraulic conductivity of geotextile

Figure 2-2 Soil grading influence on internal stability (Kenney and Lau, 1985) WG: soils widely graded in range $\mathrm{F}=0.2-1.0 ; \mathrm{NG}$ : soils narrowly graded in range

$\mathrm{F}=0.3-1.0$.

Figure 2-3 Typical variation of system flow rate during cohesive soil filtration (after Rollin and Lombard, 1988)

Figure 2-4 Different weaving patterns for non woven and woven geotextiles $\left(\mathrm{T}_{\mathrm{e}}\right.$ : elementary thickness) 24

Figure 2-5 Relationship between hydraulic gradient and effective confining stress for soil internal stability in dynamic flow condition (after Cazzuffi et al, 1999).... 30

Figure 2-6 Conceptual representation of the main types of geotextile clogging tests 32

Figure 2-7 Summary of clogging test results in function of material parameters, based on literature review. Large values of $\mathrm{K}_{\mathrm{i}} / \mathrm{K}_{\mathrm{f}}$ ratio indicates clogging of filter system, where $\mathrm{K}_{\mathrm{i}}$ and $\mathrm{K}_{\mathrm{f}}$ are initial and final system hydraulic conductivities respectively.... 36

Figure 2-8 Multi-parameter visualization of clogging test results, based on literature review $\left(\mathrm{K}_{\mathrm{i}}\right.$ : initial hydraulic conductivity, $\mathrm{K}_{\mathrm{f}}$ : final hydraulic conductivity, FOS: filtration opening size of geotextile, $\mathrm{D}_{10}, \mathrm{D}_{85}$ : sizes (diameter) of grains at 10 and $85 \%$ in cumulative soil GSD

Figure 3-1 Grain size distribution of the silty soil samples provided by INDOT.... 51

Figure 3-2 Particle size distribution of the clayey soil samples provided by INDOT52

Figure 3-3 Atterberg's limit analysis for soil samples provided by INDOT .... 53 Figure 3-4 Two samples of the same geotextile filter from the Sullivan Co. US 41 site exhumed after 15 years of service: heavily clogged (left-hand side) and almost intact (righthand side). 
Figure 3-5 Rubbleized concrete aggregates after crushing (LHS: with stabilizer, RHS: after stabilizer is removed) 55

Figure 3-6 Installation of 3-layer non woven geotextile filter prior to testing with rubbleized concrete aggreagate 56

Figure 3-7 Testing device for chemical clogging of geotextile filters with rubbleized concrete aggregate 57

Figure 3-8 Chemical stains or deposits on geotextile filters after 2 weeks of testing with rubbleized concrete aggregates 58

Figure 4-1 Simple flow models in subdrainage: (a) uniform vertical flow toward drainage layer and (b) radial flow toward drainage pipe.... 68

Figure 4-2 Design example cross-section for pavement-shoulder joint area and edge drain in Indiana roadways

Figure 4-3 Simplified cross-section and boundary conditions used in numerical simulations using PURDRAIN 70

Figure 4-4 Brooks and Corey (1964) model for water retention and hydraulic conductivity functions. 71

Figure 4-5 Simulated initial conditions and rainfall scenarios: (A) Drainage from fully submerged condition, (B) Rainfall infiltration following very dry period and (C) Rainfall infiltration following wet period with high water table in subgrade

Figure 4-6 Simulation results for Scenario A1: drainage from fully submerged condition with low permeability contrast between subgrade and aggregate layers (a) hydraulic head distribution in $\mathrm{cm}$ (the elevation datum plane is at bottom boundary); (b) saturation degree distribution 73

Figure 4-7 Simulation results for Scenario A2: drainage from fully submerged condition with high permeability contrast between subgrade and aggregate layers (a) hydraulic head distribution in $\mathrm{cm}$ (the elevation datum plane is at bottom boundary); (b) saturation degree distribution 74

Figure 4-8 Simulation results for Scenario B1: rainfall infiltration following very dry period with low permeability contrast between subgrade and aggregate layers (a) hydraulic head distribution in $\mathrm{cm}$ (the elevation datum plane is at bottom boundary); (b) saturation degree distribution .... 75

Figure 4-9 Simulation results for Scenario B2: rainfall infiltration following very dry period with high permeability contrast between subgrade and aggregate layers (a) hydraulic head 
distribution in $\mathrm{cm}$ (the elevation datum plane is at bottom boundary); (b) saturation degree distribution 76

Figure 4-10 Simulation results for Scenario $\mathrm{C} 1$ : rainfall infiltration following wet period with low permeability contrast between subgrade and aggregate layers (a) hydraulic head distribution in $\mathrm{cm}$ (the elevation datum plane is at bottom boundary); (b) saturation degree distribution 77

Figure 4-11 Simulation results for Scenario C2: rainfall infiltration following wet period with high permeability contrast between subgrade and aggregate layers (a) hydraulic head distribution in $\mathrm{cm}$ (the elevation datum plane is at bottom boundary); (b) saturation degree distribution 78

Figure 5-1 Port locations and soil column specs in FWGR test 84

Figure 5-2 (a) Grain size distribution (GSD) of soil specimens and (b) internal stability evaluation $\left(\mathrm{H}^{\prime}=1.3 \mathrm{~F}\right.$ where $\mathrm{F}$ is cumulative fraction of GSD in percentage (after Kenney and Lau, 1985)) 87

Figure 5-3 (a) Compaction test results for different fine contents by various method types and (b) the comparable reference data (Thevanayagam et al, 2002) 93

Figure 5-4 Constrained Compressibility of GT with Different Thickness (higher product number indicates larger GT thickness) 94

Figure 5-5 Conversion of real test data into relative parameters (for the loosely deposited soils filtered by a thick GT (GSE1202)). 104

Figure 5-6 System hydraulic conductivity variations of the different silt content . 106

Figure 5-7 Gradient ratio and GT head loss responses for 10\% silt with thick geotextile (GSE1202) 114

Figure 5-8 Gradient ratio and GT head loss responses for 10\% silt with thin geotextile (GSE 402). 115

Figure 5-9 Gradient ratio and GT head loss responses for $20 \%$ silt with thick geotextile (GSE 1202) 116

Figure 5-10 Gradient ratio and GT head loss responses for $20 \%$ silt with thin geotextile (GSE 402) 117

Figure 5-11 Gradient ratio and GT head loss responses for 50\% silt with thick geotextile (GSE 1202). 118

Figure 5-12 Gradient ratio and GT head loss responses for 50\% silt with thin geotextile (GSE 402). 
Figure 5-13 Summary of GR and GHL variations for each different clogging mechanism the filtration results are classified in Table 5.4) 122

Figure 6-1 Schematic of RRT cell components

Figure 6-2 Example of system hydraulic conductivity variations during RRT for Loose soils with different silt contents under gradient, $\mathrm{i}=40$. 135

Figure 6-3 Grain size distributions of soil specimens 136

Figure 6-4 Illustration of different in wettability between needle punched (A) and heat bonded (B) geotextiles. A water column of $1 \mathrm{~cm}$ stands above the heat bonded GT while none remains above the needle punched specimen

Figure 6-5 RRT results obtained in filtration ( $\mathrm{i}=40$ ) of uniformly graded dune sand in loose state with GT of different types

Figure 6-6 RRT ( $i=40)$ results for various GT types with loose soils of different silt contents (20\% wt gap graded, $50 \% \mathrm{wt}$ well graded and $100 \%$ wt silt pure fine) 144

Figure 6-7 Schematic plots of different surface properties between heat bonded (HB) and needle punched GT (NP) 145

Figure 6-8 RRT results for NP of thicknesses, $1.5 \mathrm{~mm}, 2.5 \mathrm{~mm}$ and $3.8 \mathrm{~mm}$ with dense $50 \%$ wt silt soil filtered under hydraulic gradients of 10 and 40 146

Figure 6-9 RRT results for NP of thicknesses, $1.5 \mathrm{~mm}, 2.5 \mathrm{~mm}$ and $3.8 \mathrm{~mm}$ with dense $100 \%$ wt silt soil filtered under hydraulic gradients of 10 and 40

Figure 6-10 Compaction influence on RRT performance of a thin HS filter (C-M60) with soils of different silt contents.... 150

Figure 6-11 Compaction influence on RRT performances of a thin NP filter (Linq125) with soils of different silt content 151

Figure 6-12 Distributions of piping and clogging particle masses in RRT of NP filters, different in AOS and thickness with 50\% wt and 100\% wt soils (Thickness and AOS increase from L125 to L350 GT, see Table 6.2).... 154

Figure 6-13 Distributions of piping and clogging particle masses in RRT of NP filters, different in AOS and thickness (Thickness and AOS increase from L125 to L350 GT, see Table 6.2) 155 Figure 6-14 GT thickness effect on rate of $\mathrm{K}_{\text {rel }}$ change in RRT for $50 \%$ wt silt soil under different system hydraulic gradients 156 
Figure 6-15 GT thickness effect on rate of $\mathrm{K}_{\mathrm{rel}}$ change for pure fine soil under

different system hydraulic gradients

Figure 6-16 Hydraulic performances in RRT under $i=40$ of thick NP, alone and in association with a fine sand layer, for filtration of dense soils with $10 \%$ wt or $20 \%$ wt clay (c: clay, m: silt and s: fine sand).

Figure 7-1 Schematic design cross sections for drainage and filter systems (A) General design, (B) special case of clay soil (see Table 7-1)

Figure 7-2 Example particle size distributions. (A) example 1, (B) example 2 .... 173

Figure 7-3 Selection examples. (A) example 1, (B) example 2 ...................174 


\section{Notation of Abbreviation and Symbol}

$\Delta \mathrm{h}:$ system hydraulic head difference [kPa],[psig]

AOS : apparent opening size of non woven geotextile specified in ASTM D 4751 [mm]

$\mathrm{Cu}^{*}$ : uniformity coefficient criteria varied by compaction degree in the filter design by Giroud

$\mathrm{D}_{\mathrm{C}}$ : constriction size of granular filter $[\mathrm{mm}]$

$\mathrm{D}_{\mathrm{G}}$ : the lower limit of gap range $[\mathrm{mm}]$

DHR : double hydrometer ratio (weight fraction of dispersed clay below $5 \mu \mathrm{m}$ in size)

$\mathrm{D}_{\mathrm{i}}$ : grain size of corresponding to $\mathrm{i} \%$ in cumulative soil GSD [mm]

$\mathrm{F}, \mathrm{F}_{\mathrm{D}}$ : cumulative mass fraction for a particle size, $\mathrm{D}$

FOS: filtration opening size of non woven geotextile measured by hydrodynamic sieving method [mm]

FWGR : flexible wall gradient ratio method suggested by Honey and Holtz (2001)

GHL : geotextile head loss [kPa],[psig]

GR : gradient ratio

$\mathrm{GR}_{\mathrm{ASTM}}$ : gradient ratio defined in ASTM D5101

$\mathrm{GR}_{\text {Mod }}$ : gradient ratio modified by Fannin et al (1994)

GSD : soil grain size distribution

GT : nonwoven geotextile

$\mathrm{H}$ : mass fraction of GSD defined by $\mathrm{F}_{4 \mathrm{D}}-\mathrm{F}_{\mathrm{D}}$

HCR : hydraulic conductivity ratio

HS : heat set type

$\mathrm{i}$ : hydraulic gradient

$\mathrm{i}_{\mathrm{x}-\mathrm{y}}$ : hydraulic gradient estimated between $\mathrm{x}$ and $\mathrm{y}$ elevation levels from filter interface

$\mathrm{K}$ : absolute hydraulic conductivity [cm/sec],[ft/min]

$\mathrm{K}_{\text {init }}, \mathrm{K}_{\text {final }}$ : initial/final system hydraulic conductivity values measured in FWGR test and RRT $[\mathrm{cm} / \mathrm{sec}],[\mathrm{ft} / \mathrm{min}]$

$\mathrm{K}_{\text {rel }}$ : relative system hydraulic conductivity defined by $\mathrm{K} / \mathrm{K}_{\text {init }}$

$\mathrm{n}$ : porosity

NP : needle punched type

$\mathrm{O}_{\chi}$ : opening size of $\chi \%$ in cumulative geotextile OSD [mm] 
$\mathrm{O}_{\mathrm{f}}{ }^{*}$ : the optimum geotextile opening size applied to filter design method [mm]

OSD : opening size distribution for geotextile

P.I. : plasticity index specified in ASTM D 4318

POA : percentage opening area for woven geotextile [\%]

PPT : pore pressure transducer

r.p.v. : relative pore volume

RRT : rapid retention test

$S_{a}:$ specific surface area $[\mathrm{m} / \mathrm{m}]$

SB : spun bonded type

$\mathrm{t}_{\mathrm{G}}$ : nonwoven geotextile thickness [cm],[in]

$\mathrm{w}$ : water content [\%] 


\section{Introduction}

\subsection{Background}

Adequate filters are critical to the long-term performance of highway drains. The role of a filter is to prevent soil and adjacent material particles from entering the drain, while still allowing water to flow freely. When the filter does not retain the particles, the drain is at high risk of becoming clogged with transported sediments. On the other hand, when the filter openings themselves become obstructed, water is unable to reach the drain.

A traditional technique in civil engineering infrastructures projects such as earth dams, retaining walls or roadways has been to use mineral filters made of selected granular material such as gravel and sand. A number of filter selection criteria were formulated, often in connection with earth dam construction problems, and are currently being used for a broad range of applications including roadways. These design criteria are empirical formulas relating the required filter grain size to that of the surrounding material (e.g. U.S.B.R., 1974, 1994). More recently, the technology of geosynthetic fabrics (i.e. geotextiles) has provided a cost-effective alternative to mineral filters. Geotextiles are made of plastic polymer fibers or threads and are highly permeable. They can be used to wrap drainage pipes or to line drainage trenches and function as filters (e.g. Koerner, 1998). Geotextiles are available in two broad categories according to their weaving process, woven fabrics and non-woven. A woven geotextile has a uniform microstructure made of parallel, regularly spaced fibers or threads in two perpendicular directions. Its porosity is characterized by openings that are uniform in size and spacing. In contrast, a non-woven geotextile has a spatially random microstructure made of a disorderly pattern 
of non-parallel and tortuous fibers. As a result, its porosity features a broad distribution in size and spacing as well as high degree of tortuosity. In a number of cases, geotextiles have performed successfully as filters while being easier to install, much thinner and more permeable than conventional granular filters (Giroud, 1996). Present practice for Indiana highways is to use geotextiles when filters are required.

\subsection{Statement of Problem}

Current design methods for selecting geotextile filters consider their capacity to (a) transmit fluid across the fabric plane, (b) retain solid particles and (c) survive to potential damage during and after installation. The first requirement relates to the permeability of the fabric, given the quantity of flow expected toward the drain (e.g. Koerner, 1998). Design with respect to the retention requirement is typically performed using empirical formulas in which index values of the surrounding material particle size and the fabric pore size (i.e. the apparent opening size, $\mathrm{AOS}^{1}$, according to ASTM-D4751) are being compared (e.g. Carroll, 1983, Giroud, 1988, Luettich et al., 1992). To satisfy the last requirement, survivability, the selected geotextile must have adequate mechanical and chemical characteristics, given the anticipated construction and site conditions (AASHTO, 1991).

\footnotetext{
${ }^{1}$ The Apparent Opening Size (AOS) or Equivalent Opening Size (EOS) of a geotextile are defined as the U.S. standard sieve number that has openings closest in size to the openings in the geotextile. The ASTM D4751 test uses known-diameter glass beads to determine the AOS by standard dry sieving. Sieving is done using beads of successively larger diameters until the weight fraction of beads passing through the test specimen is $5 \%$. The corresponding opening size (in $\mathrm{mm}$ ) is $\mathrm{O}_{95}$. Note that this procedure defines only one particular void size of the geotextile and not the total void-size distribution (Koerner, 1998).
} 
According to current guidelines and specifications for Indiana highway projects, a filter is needed when the soil adjacent to the drain consists mainly of silt. This means, a soil with more than $50 \%$ passing by weight the \#200 sieve (i.e. particle size lesser than $0.075 \mathrm{~mm}$ ), classified as fine-grained soil, but with less than $20 \%$ clay particles (i.e. smaller than $0.002 \mathrm{~mm})$. In such situations, a geotextile filter must be installed with the following main characteristics (INDOT Technical Specifications, 2000-02, Section 913):

Texture: Non-woven fabric (needle punched or heat bonded)

Apparent Opening Size (AOS): Sieve \#50 (300 microns) or smaller

Coefficient of permeability: $0.01 \mathrm{~cm} / \mathrm{s}$ or greater

Additional characteristics in chemical composition and mechanical index properties are specified in order to ensure survivability of the fabric.

INDOT's guidelines for typical pavement cross-sections include plans and filter installation procedures. A construction detail of interest is that, when the geotextile filter is installed as a liner inside the drainage trench, it is not wrapped over the granular backfill at the top of the trench, contrary to frequent practice and textbook recommendation (e.g. Koerner, 1998).

Over the past 20 years, design and performance of filters for subsurface drainage of highway pavements have been a constant concern to INDOT and have been the subject of substantial research effort through JHRP and JTRP. In 1988, a review of geotextile functions and selection criteria addressed filtration applications (Karcz and Holtz, 1988). The study resulted in selection guidelines adapted from the French Committee of 
Geotextiles and Geomembranes (1981) recommendations. Another study devoted exclusively to prefabricated geocomposite edge drains (Elsharief, 1992) addressed installation, structural integrity and filtration aspects of this type of drains that are made of a plastic drainage core wrapped in a geotextile filter. A filtration selection criterion was proposed as a result. It is noted that the technology of prefabricated geocomposite edge drains has since been discarded by INDOT because of problems with the structural reliability of these products but information accrued on their filter performance may still be relevant. In 1993, a broader-scope research project was completed on pavement drainage in Indiana highways (Ahmed et al., 1993, Espinoza et al., 1993). In conclusion, it was pointed out that infiltration of fines from base and subgrade soils surrounding edge drain trenches often resulted in clogged pipes, and further investigation was needed on designing filters to optimize pavement subdrainage performance. Chemical clogging of filters related to using recycled concrete aggregate in INDOT's pavement reconstruction projects was also investigated (Wukash and Siddiqui, 1996). Evidence was found that effluent from recycled concrete contains calcium hydroxide that can lead to the formation of calcium carbonate and its deposition in filters. Still today, a significant part of difficulties encountered by INDOT with insufficient drainage performance of highways is likely to be related to inadequate filters. The performance of filters installed in Indiana highways is often unsatisfactory and fails to meet long-term expectations.

A review of published literature using TRIS and other specialized bibliographic resources (see appended list of references) shows that, in spite of research efforts and accumulated experience with these techniques, the filtration process using geotextiles is complex and 
still not fully understood. For instance, there are experimental evidences that, when various types of soil are involved, geotextiles filters may become clogged much faster than granular filters (Koerner et al., 1996) and that non-woven fabrics are likely to perform better than woven- (Hoffman and Turgeon, 1983), but there is no clearly established theory to explain these differences. Such factors as, arching of solid particles across the fabric openings, magnitude of the hydraulic gradient (or flow rate) toward the drain and pore water pressure, fabric pattern of the geotextile and its thickness, magnitude of the confining pressure, have probably a noticeable influence on the filter performance, in addition to the soil grain and filter opening sizes. In this list of influence factors, the hydraulic and mechanical parameters are related to variations in the pavement environment (precipitations and fluctuations of groundwater) and traffic loads.

In summary, there is strong need for improved guidelines, based on better understanding of the filtration process and supported by testing and performance data, in order to select, design and construct drainage filters for Indiana highways. This is a necessary condition to avoid premature clogging and the resulting failure of highway drains.

\subsection{Scope of the Present Study}

The effectiveness of underdrain filters was investigated in order to make recommendations on selection criteria, design and installation guidelines that would improve the long-term performance of drainage systems in Indiana highways. Since significant savings in construction and maintenance cost can be achieved if geosynthetic filters are employed successfully, the study was focused on these types of filters, rather 
than on traditional mineral filters. Because of time frame and budget constraints, the scope of the study was limited to hydro-mechanical filtration mechanisms of solid particles that is, biological and chemical aspects were not addressed to the exception of a test using recycled concrete aggregate. The investigating approach includes field data collection, laboratory experiments and analysis.

Long-term performance and its relationship to design expectation are of particular importance. Attempt was made to assess the evolution in time and potential deterioration of the filter fabric properties. Several types of experiments (e.g. permeability test, filtration test) exist that allow determining in the laboratory the filtration capability of geotextiles and the compatibility of a particular combination of filter and interfacing material. Through these experimental procedures, it is possible to investigate systematically the influence of important soil, geotextile and hydraulic parameters, but the duration of one test is limited to a few days. This particular difficulty can be overcome by complementing laboratory testing with field information. In collaboration with the Study Advisory Committee and INDOT's district engineers, samples and other field information were obtained from sites where inadequate filter performance may have been the cause of insufficient drainage.

In order to relate the long-term performance to short-term design parameters, series of tests in the laboratory were performed on new, intact, samples of geotextile filters. The clogging potential of intact geotextile filters were investigated using the best currently available methods, the Flexible Wall Gradient Ratio Test (FWGRT) and the Rapid 
Retention Test (RRT). Characteristics and relative merits of these techniques are discussed in detail in subsequent sections of this report. In order to perform these tests, new equipment was developed or existing equipment was modified in the Bechtel Geotechnical Laboratories of Purdue University.

Soils that are the most prone to internal erosion and cause filtration problems often include significant amount of silt. In Indiana, such subgrade materials would likely be sandy silts or silty clays. Because of the preeminent role played by silt particles in filter clogging, a systematic study was performed by varying the amount of silt in reconstituted samples that were then tested with geotextile filters. This constituted the bulk of the experimental study in addition to tests conducted with samples from natural deposits. Other parameters whose influence was investigated included geotextile thickness and manufacturing style.

\subsection{Organization of this Report}

The following sections are found in this report:

- Chapter 1 presents the introduction, background and scope of the research study.

- Chapter 2 is a synthesis of literature review on geotextile filtration and clogging mechanisms, and the physical parameters involved. Current filter design methods are reviewed, as well as earlier experimental and field studies.

- Chapter 3 reports an investigation of field materials and filter performance. It also includes the analysis of video inspections of underdrains performed at INDOT project sites. 
- Chapter 4 is an assessment, by means of numerical simulation, of subsurface flow and hydraulic gradients filters are subjected to.

- Chapter 5 reports experiments using the Flexible Wall Gradient Ratio Test, with emphasis on the influence of soil properties.

- Chapter 6 reports experiments using the Rapid Retention Test, with emphasis on the influence of geotextile properties.

- In chapter 7, a synthesis of the results is used to develop tentative guidelines for filter selection and installation. Design examples are provided. 


\section{Literature review and synthesis}

\subsection{General Characteristics of Soil Filtration Using Geotextiles}

Geotextiles have been increasingly used as soil reinforcements, separators, drains or filters in various civil and environmental engineering application areas such as, earth retaining structures, shallow foundation bases, tunnel liners, embankments, breakwater systems, and landfill leachate collection systems and covers. Even when their primary usage is not drainage, geotextiles must be very permeable throughout their service life, so that they do not prevent free drainage nor contribute to excess pore pressure build-up in the adjacent soil. The open porous structure of geotextiles and its permanence is an essential property of this type of geosynthetics. It enables geotextiles to filter soil particles while allowing free flow of pore fluid. Geotextiles can perform better as filters than granular materials, and there is definite advantage provided by their easy installation and resulting low cost of construction (Giroud, 1996). Under unfavorable conditions encountered on landfill slopes or in breakwater systems, geotextile solutions can be more reliable than granular filters because the fiber fabric of geotextiles is less likely to be disturbed or destroyed by tensile drag or wave forces than the granular arrangement of mineral filters. However there is ample physical evidence that geotextile fabrics can be clogged by non cohesive particles from silty soils (e.g. Bhatia et al, 1998) and, to a lesser extent, by clay particles (Gardoni and Palmeira, 1998, Almeida et al, 1995). Clogging mechanisms belong to two broad types, related to either physical or bio-chemical processes. Often, physical clogging occurs first and then is followed by slower biochemical processes such as iron ochre deposition, carbonate/sulfate precipitation and bacterial growth (Rollin and Lombard, 1988). Furthermore, time rates of bio-chemical 
clogging depend on the pore size and, therefore, are affected by previous occurrence of physical clogging (Reddi and Bonala, 1997).

According to Giroud (1996) and Rollin and Lombard (1988) factors influencing the filtration performance of geotextiles can be classified into four main categories that are (1) properties of the adjacent subgrade soil or base material such as, coefficient of uniformity $(\mathrm{Cu})$, coefficient of gradation $(\mathrm{Cc})$, plasticity index $(\mathrm{PI})$, clay dispersivity (e.g. determined using the double hydrometer ratio, DHR, test), particle shape and grain hardness for granular soil, state of compaction and degree of saturation, (2) properties of the geotextile such as, filtration opening size $\left(\mathrm{FOS}^{2}\right)$ or apparent opening size (AOS), textile bulk density (mass/area), porosity, textile thickness, fiber density and diameter, and constitutive polymer(s), (3) hydro-mechanical conditions such as, hydraulic gradient, pore pressure and state of stress and (4) bio-chemical properties of the permeating fluid such as its $\mathrm{pH}$, hardness (e.g. [Fe], [Mn], [Mg], [Ca]), redox potential (Eh) in case of iron ochre, water BOD and COD (substrate type and concentration), osmotic pressure and dissolved oxygen.

In this chapter, background knowledge on the mechanism of physical filtration and clogging, and the roles played by the most influential factors are reviewed.

\subsection{Mechanism of Geotextile Filtration and Physical Clogging}

Soil filtration by geotextiles involves complex interaction between the filter and the contiguous soil. Under the action of seepage forces induced by groundwater flow toward

\footnotetext{
${ }^{2}$ The filtration opening size (FOS) of a geotextile is similar in concept to the apparent opening size (AOS) but is determined by wet hydrodynamic sieving (see the ISO/DIS 12956 test standard) which is a method more representative of field conditions than the dry sieving method used for the AOS.
} 
the filter (and the drain), soil particle movement and relocation lead to changes in grain size distribution, porosity and permeability within both the soil and the filter. Several mechanisms have been identified as piping, bridging, blinding, blocking (or plugging) and clogging (Rollin and Lombard, 1988, Lafleur, 1999). The first three are conceptually represented in Figure 2.1.

Piping is a typical case of soil internal erosion. Because a large fraction of soil particles is much smaller than the filter openings, they cannot be retained. As a result, the fine fraction disappears from the grain size distribution. In the affected zone, the soil porosity as well as its hydraulic conductivity increase dramatically and quasi-uniformly.

Bridging is a mechanism by which the soil forms a self-filtration structure at the interface with the geotextile. In this case, fine particles smaller than the geotextile openings are lost only within a thin layer in contact with the filter. Then, coarser particles arching over the geotextile openings prevent the process to extend beyond the interface zone. Eventually particle migration is contained and a state of equilibrium is reached where only the porosity and hydraulic conductivity of the interface zone have been locally increased as compared to the initial state. In consequence, the system average hydraulic conductivity increases slightly and stabilizes at a value, intermediate between the soil initial permeability and that of the geotextile.

Blinding occurs when fine particles migrating from a distance are retained and accumulate in the interface zone close to the geotextile. As porosity in the interface zone decreases and flow conduits are filled, hydraulic conductivity 
increases locally in the zone from where the fines originated but decreases in the interface zone with the geotextile. As a result, the system average permeability may decrease steadily without a satisfying equilibrium being reached.

The other two mechanisms, blocking and clogging, involve more locally or internally the geotextile.

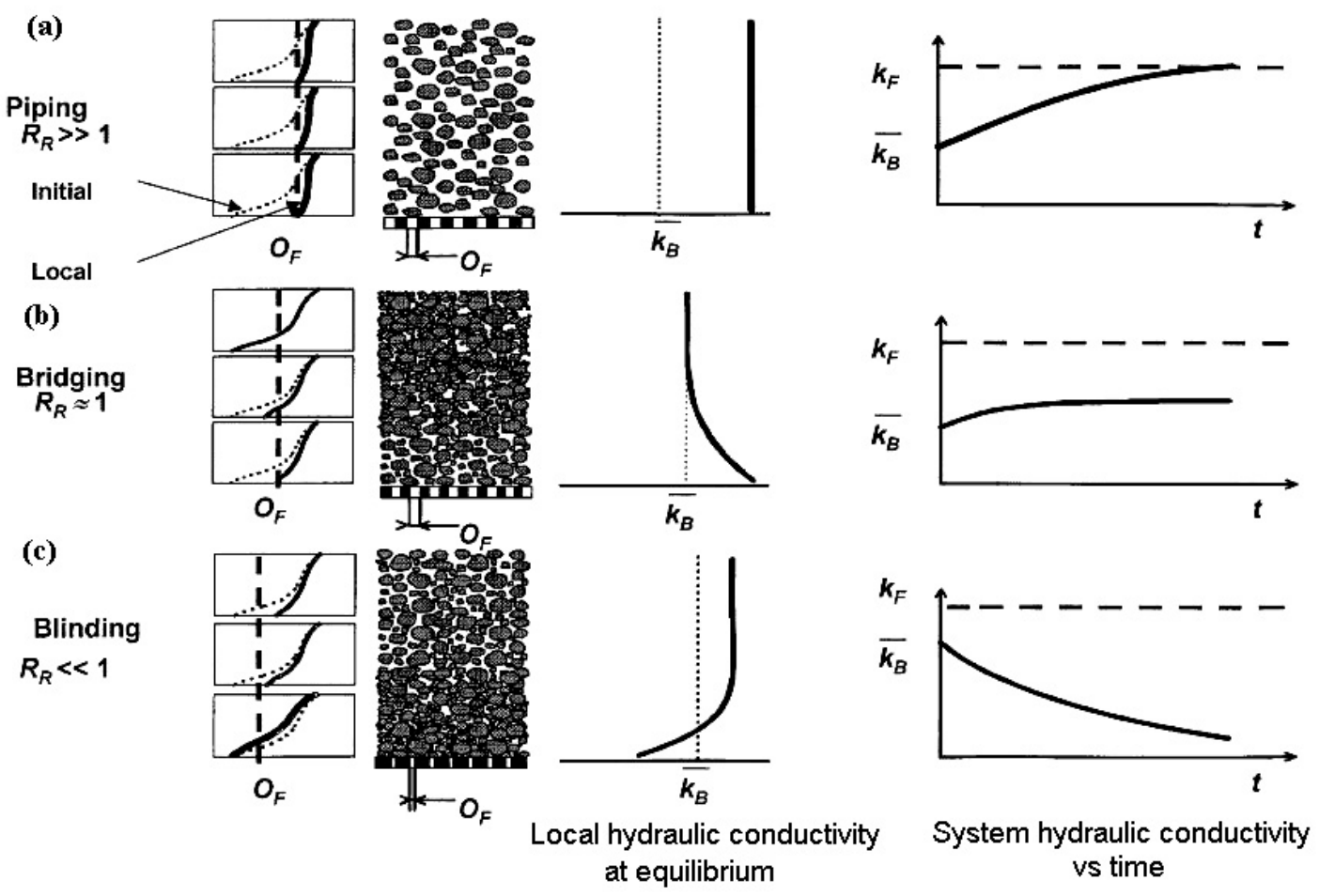

Figure 2.1 Piping(a), bridging(b) and blinding (c) mechanisms associated with different geotextile opening size and soil behaviors (after Lafleur, 1999) - Left hand side: soil grain size distribution (GSD) and its variation in the vicinity of the geotextile ( doted curve : initial GSD; plain curve : final GSD ; $R_{R}=\mathrm{O}_{\mathrm{f}} / \mathrm{d}_{\mathrm{i}} ; \mathrm{O}_{\mathrm{f}}$ :filter opening size; $\mathrm{d}_{\mathrm{i}}$ : indicative particle size of protected soil ) - Center-left: schematics of resulting granular structure - Center-right: profile of resulting soil hydraulic conductivity in function of distance to geotextile ( $\overline{k_{B}}$ : initial soil hydraulic conductivity (dotted line)) - Right-hand side: evolution of system average hydraulic conductivity in function of time, as compared to $k_{\mathrm{F}}$ (virgin hydraulic conductivity of geotextile). 
In the case of blocking, coarse particles directly in contact with the geotextile surface obstruct the filter openings, preventing fine particles as well as fluid to penetrate.

Internal clogging, instead, occurs when migrating fine particles penetrate the filter fabric and encounter fiber constrictions too narrow for traveling farther. Fines can then accumulate within the geotextile and obstruct its drainage channels.

In practice, the terminology of clogging is often extended to designate not only internal clogging of the geotextile but blocking and blinding as well (Rollin and Lombard, 1988). Another form of geotextile blocking, by fine particles instead of coarse ones, can also be observed in situations where fine pumping due to pulsing of excess pore pressure takes place. This could be the case in roadway or railway construction, for instance, when a geotextile is used as separator between aggregate base course or ballast and soft saturated silt subgrade (Alobaidi and Hoare, 1999). In the present study, this particular mechanism will be referred to as plugging in order to avoid confusion with the classical case where blocking is caused by coarse particles larger than the filter opening size.

It is noted that, of the five mechanisms described above, only bridging can be considered a highly desirable condition, all the other leading to either sediment being transported to the drains (piping) or the system hydraulic conductivity being possibly decreased down to a level insufficient for adequate drainage (blinding, blocking and clogging). For well graded soils, geotextile blocking or internal clogging are usually considered the most sever problems and more investigation of these types of filter failure is needed for various 
of soil and geotextile conditions.

The time required for physical clogging to stabilize in a particular situation varies with the hydraulic gradient magnitude: the greater the gradient, the faster the process. In the laboratory this often takes up to 1,000 hours when the gradient ratio test is used (Rollin and Lombard, 1988; Bhatia et al, 1995, Bhatia et al, 1998). As will be seen later, reliance on such long duration laboratory tests is due, to some extend, to the current lack of a general theory to integrating the various filtration mechanisms altogether.

\subsection{Clogging Factors Related with Soil Properties}

\subsubsection{Non-cohesive Soil}

Causes for physical clogging during filtration are not only related to geotextile properties but also to the soil (Bhatia and Huang, 1995). With non cohesive soils in particular, internal instability of their granular structure can make it very difficult to prescribe an optimal design opening size, $\mathrm{O}_{\mathrm{f}}{ }^{*}$, for the geotextile and to formulate filter criteria that would help prevent piping, blinding or internal clogging. The internal stability of granular soil structure has been investigated in depth by Kenney and Lau (1985) and Lafleur et al (1990). Their research focused on developing criteria for the internal stability of soil when seepage or vibration is applied. According to Kenney and Lau (1985) non-cohesive soils are internally stable if their GSD is such that $\mathrm{H}>1.3 \mathrm{~F}_{\mathrm{D}}$, where $F_{D}$ is the cumulative mass fraction relative to a particle size, $D$, and $H=F_{4 D}-F_{D}$. A graphic representation of the criterion is given in Figure 2.2 together with curves representative of (a) unstable and (b) stable grading. The reason for these authors to use $\mathrm{H}=\mathrm{F}_{4 \mathrm{D}}-\mathrm{F}_{\mathrm{D}}$ as the characteristic particle size interval is that, in a stable granular soil, 


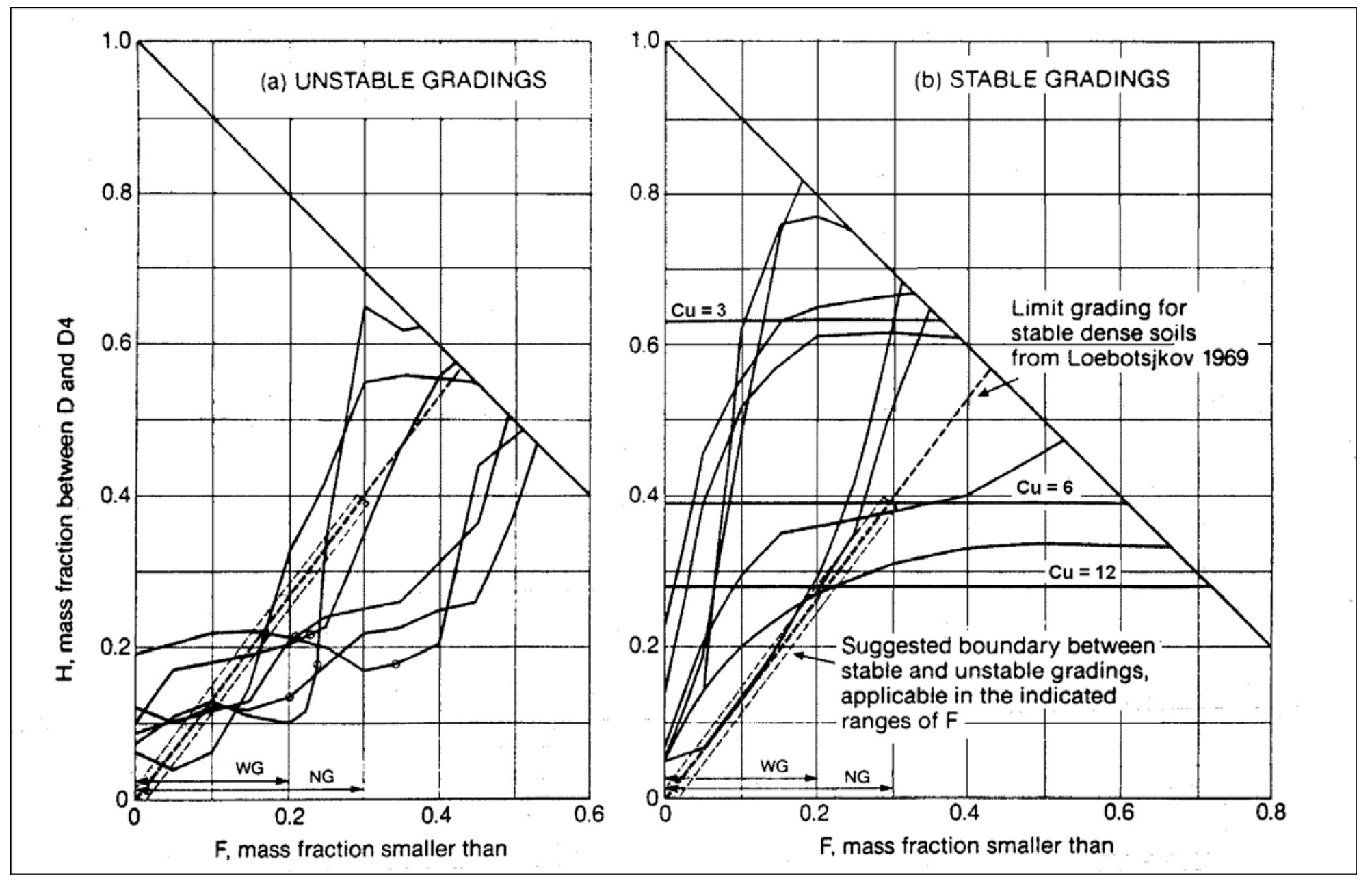

Figure 2.2 Soil grading influence on internal stability (Kenney and Lau, 1985) WG: soils widely graded in range F=0.2-1.0; NG: soils narrowly graded in range $\mathrm{F}=0.3-1.0$ 
predominant constrictions of the void network are approximately four times smaller than the small particles (Kenney et al, 1985). The resulting granular filter design criterion, $\mathrm{D}_{5}$ $<4 \mathrm{D}_{50}$ or $\mathrm{D}_{15}<5 \mathrm{D}_{50}$ for soils with $\mathrm{Cu}<6$ is more conservative than Terzaghi's (1922) classical formula.

In connection with granular filter design for broadly graded soils Lafleur et al (1989) took into account the bridging effect (i.e. self-filtration) which may exist also in this case. The behavior of linearly graded soils was compared with a model they proposed, but the model underestimated both the amount of fines lost and the bridging zone thickness observed in experiments. However, their screen test results indicated that the thickness of the self-filtration zone is proportional to the constriction size $\left(D_{c}\right)$ of the granular filter. Additionally, these authors suggested the granular filter opening size should be between $\mathrm{D}_{50}$ and $\mathrm{D}_{80}$ for linearly graded soil, and within the gap range in the case of gap-graded soil. It was also noted that, in absence of vibration, particle interlocking might contribute to limiting the loss of fines.

Particle size uniformity (as represented, for instance, by the coefficient of uniformity $\left.\mathrm{Cu}=\mathrm{D}_{60} / \mathrm{D}_{10}\right)$ can affect soil retention. This property plays a role in filter design through the ratio $\mathrm{O}_{\mathrm{f}} / \mathrm{D}_{1}$ where $\mathrm{O}_{\mathrm{f}}$ is the largest opening size of the filter and $\mathrm{D}_{1}$ is the largest size of particle retained. Watson and John (1999) studied the effect of $\mathrm{Cu}$ on particle bridging. They investigated which were the largest opening sizes compatible with stable granular bridging structures, for different cases of particle size gradation. They assumed a spherical particle shape and tested their model on the basis of the ratio, $\mathrm{O}_{90} / \mathrm{D}_{90}$. They found that the uniformity coefficient $(\mathrm{Cu})$ influences the smallest size of the particles that 
can form the granular bridging structure, and that particles smaller than $0.228 \mathrm{O}_{\mathrm{f}}$ are not associated with bridging formations regardless of the soil grain size uniformity. In general, as $\mathrm{Cu}$ increases, the ratio $\mathrm{O}_{90} / \mathrm{D}_{90}$ decreases. In practice, this means for piping be prevented the filter largest opening size, $\mathrm{O}_{\mathrm{f}}$, should be reduced when the soil is better graded. Giroud (1996) considered the selection of $\mathrm{O}_{\mathrm{f}}{ }^{*} / \mathrm{D}_{85}$ should take into account the soil uniformity coefficient $(\mathrm{Cu})$ and state of compaction. Three different density states of bridging granular structure were considered: hyperstable $\left(\mathrm{Cu}^{*}=3\right)$, mesostable $\left(\mathrm{Cu}^{*}=6.5\right)$ and hypostable $\left(\mathrm{Cu}^{*}=13\right)$, where $\mathrm{Cu}^{*}$ are the coefficients of uniformity, characteristic values related to soil internal stability. The relationship between $\mathrm{O}_{\mathrm{f}}$ and the finest size of bridging particles was derived for the two case, $\mathrm{Cu}>\mathrm{Cu}^{*}$ and $\mathrm{Cu} \leq \mathrm{Cu}^{*}$. Both approaches outlined above show similar trends such as relatively high values of $\mathrm{O}_{\mathrm{f}}{ }^{*} / \mathrm{D}_{85}$ obtained in dense conditions and relatively low values in loose condition. However, neither model was based on consideration of actual particle size distributions. Instead, idealized linearly graded soils were assumed.

The effect of particle shape on soil retention performance has been investigated, but without clear, quantitative conclusions being reached. Aberg (1992b) accounted for the particle shape in his investigation of void ratio for the various GSD types of soils. His experiments led to a linear relationship between the void ratio and the particle angularity. He also observed in compacted samples that the small grains were more angular than the large ones because, during sample preparation, compaction work had produced particle breakage. Lafleur et al (1989) suggested that in soil the angularity of fines particles contributes to making thicker the granular bridge formed in successful filtration cases. In 
connection with this idea, when actual soil was tested in comparison with glass beads, the later yielded lower critical ratio, $\mathrm{O}_{95} / \mathrm{D}_{85}$, and amount of piping which was more sensitive to the opening size when the ratio is close to its critical value (Bhatia and Huang, 1995).

\subsubsection{Cohesive Soils}

Filtration experiments that performed with cohesive (i.e. mainly clay) soils and geotextiles consistently show the same variations in system hydraulic conductivity (Rollin and Lombard, 1988, Mlynarek et al,1991, Bergado et al, 1996, Haegeman and Van,1999). These variations (Figure 2.3) correspond to four main stages: (1) seepageinduced compression or consolidation, (2) piping of fine particles, (3) build-up of a filter

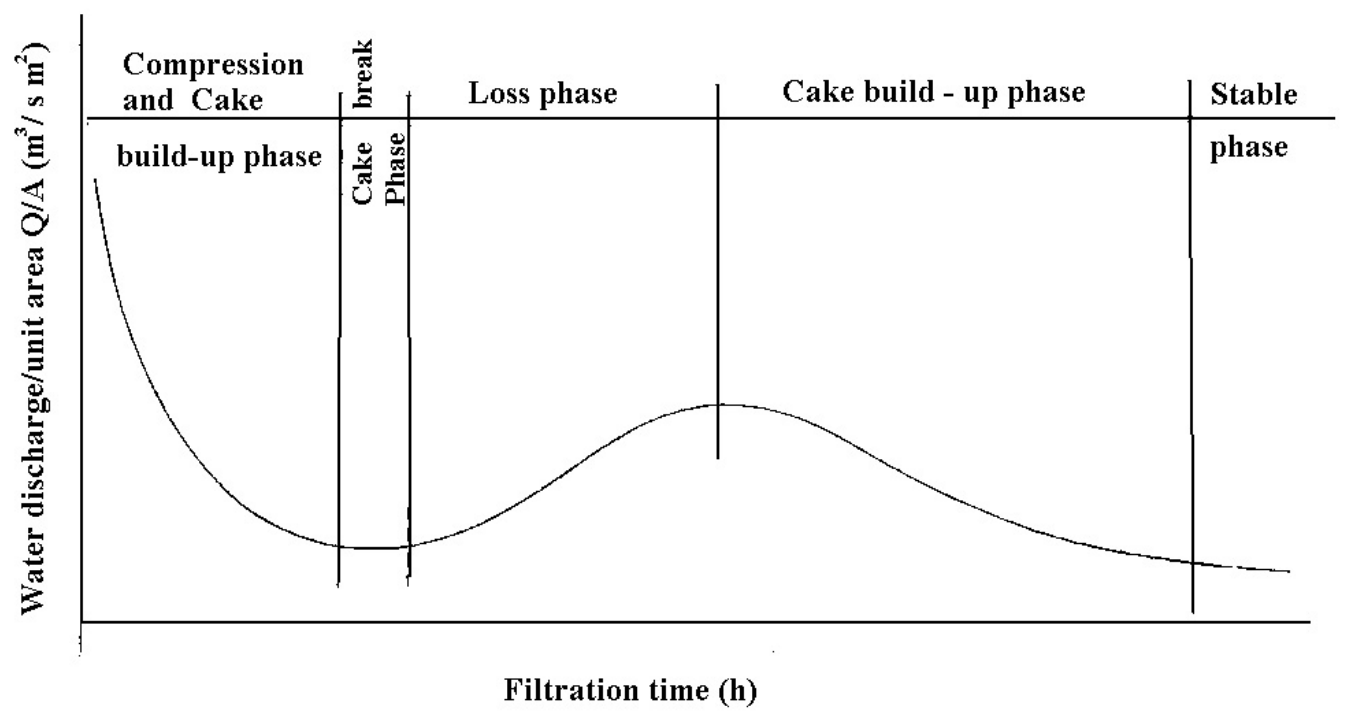

Figure 2.3 Typical variation of system flow rate during cohesive soil filtration (after Rollin and Lombard, 1988) 
cake within the soil layer and (4) steady state. Haegeman and Van (1999) also reported that the dry unit weight of soil increases steadily during this sequence and the final steady state hydraulic conductivity is intermediate between the values of the soil slurry and the geotextile.

When a clayey soil initially saturated is being partially dried, thin discontinuities or cracks are likely to develop. In cohesive soils, particle piping through the pore structure is more difficult than in non cohesive soils because of capillary forces, but clay internal erosion through discontinuities or desiccation cracks is more likely to occur. This has not received much attention as a factor influencing filter designs. Attention should be paid to situations where the clay deflocculates easily and/or the fluid velocity within cracks is high enough for particle transport to occur. This would require appropriate testing methods be developed. From this standpoint, plastic soils are problematic in the case of dispersive clay which can be identified by the conditions, DHR $>0.5$ and PI $>5$ (Luettich et al, 1992) where DHR is the double hydrometer ratio. Clay deflocculating is influenced by several factors such as, electrolyte concentration, ion valence, temperature, dielectric constant, size of hydrate ion, $\mathrm{pH}$ and anion adsorption of clay and water system (Lambe and Whitman, 1979). More detail on these particular factors can be found elsewhere (Almeida et al, 1995, Gardoni and Palmeira, 1998).

In general, geotextiles intended to filter clay are too permeable for decelerating the velocity of flow leaking flow through dessication cracks. In such cases, the use of a granular layer between the clay and the geotextile was proposed by Kellner and Matei 
(1991). This would enable the clay to generate its own natural filter zone within granular

layer. It was also pointed out by Bourdeaux and Imaizumi (1977) that, at flow velocity below $10 \mathrm{~cm} / \mathrm{sec}(20 \mathrm{ft} / \mathrm{min})$, dispersive clay can be adsorbed by granular soil particles and form a coating on the grain surface. In sand layers used for filtering clay, the amount of clogging depends more on the concentration of fine particles in suspension than on the particle size or the flow rate (Reddi et al., 2000). After stabilization has been reached, the final flow rate through the soil-filter system is controlled by the self-filtration process rather than by fine particle deposition in soil capillary conduits, especially under high flow rate. However, the critical velocity below which fine particles start to deposit in filter material is much higher in sand $\left(10^{-1} \mathrm{~cm} / \mathrm{sec}\right)$ than in geotextile $\left(10^{-3} \mathrm{~cm} / \mathrm{sec}\right)$. This is an indication that clay particles have the more affinity for granular filter particles than for geotextile fiber and seems to validate the concept of sand-geotextile composite filter for clay soils. For analysis purpose, it should be noted that in case of a geotextile filter, the number-based particle size distribution of fine particles suspended in water is a more relevant factor than the mass concentration of fines, while in the case of a granular filter, the opposite is true (Xiao and Reddi, 2000).

\subsection{Clogging Factors Related to Geotextile Properties}

According to Rigo et al (1990) geotextile properties playing an important role in filtration are: fiber diameter, fabric thickness, fabric density (mass per area), fabric porosity and filtration opening size. Among these properties, the opening size has been found in various types of laboratory tests a key parameter in control of geotextile filter performance. However, the size of constrictions between fibers, which is mainly the 
result of the weaving method (sometimes referred to as the manufacturing style) seems to play a more fundamental role than the opening size.

\subsubsection{Filter Opening Size and Constriction Size Distribution}

In a granular filter, a constriction is a narrowed pore space area between particles that allows the smaller particle transference between two pores. Given the random nature of granular media, the constriction size can only be described statistically. Constrictions can control the travel of migrating solid particles within the pore space of a filter. Thus, the constriction size distribution (CSD) is often considered to play a more important role in the filtration process than the pore size distribution (PSD) itself (Kenney and Lau, 1985). A similar concept has been used for describing the porous structure of geotextiles. Here, a constriction is a narrowed pore space area between polymer fibers that control passage from one pore to another. In nonwoven geotextiles in particular, the CSD influences filtration even more importantly than in granular filters (Bhatia and Smith, 1996a). This make difficult the formulation of simple retention criteria, alike those formulated for granular filters, which would be based on a single representative opening size of the geotextile fabric.

Several experimental methods are available for determining opening size distribution of geotextiles (OSD), directly or indirectly, but no method has been yet universally accepted for determining the CSD of nonwoven geotextiles. Sieving techniques (dry or wet) are indirect methods that are commonly used in engineering practice whereas mercury intrusion porometry, bubble point testing and image analysis are direct methods that require more sophisticated equipment (Bhatia and Smith, 1996b). The dry sieving method 
(ASTM D 4751) used for the determination of the apparent opening size (AOS) has been the standardized method of choice in United States engineering practice (a description of the test and definition of AOS are provided in Chapter 1). However, the dry sieving method has several shortcomings. The test results are affected by electrostatic attraction between the test beads and geotextile fibers, which is not considered representative of subsurface conditions (Sharma and Lewis, 1995, Giroud, 1996), and during dry sieving the geotextile fabric yarns can move away from each other, thereby allowing the test beads to pass through an enlarged constriction (Koerner, 1998). Because of cyclic conditions applied during dry sieving, the $\operatorname{AOS}\left(\right.$ or $\mathrm{O}_{\mathrm{f}, 95}$ ) value obtained from the test is overestimated as compared to the operating value for the geotextile subjected in the field to quasi- steady state flow conditions. For these reasons, the dry sieving method has been gradually substituted with a (wet) hydrodynamic test method standardized under ISO/DIS 12956. The resulting index value representative of opening size is filtration opening size (FOS). Among direct methods, the bubble point test (ASTM D 6767) is considered to provide reliable information on the number and size of the smallest effective opening channels (i.e. the constriction size) in a geotextile sample (Bhatia et al, 1996). However, the complexity of the test is a hurdle for its practical implementation.

\subsubsection{Weaving Pattern}

Geotextiles are classified into two broad categories according to their fiber patterns that are the woven and nonwoven types. Sub-categories exist, each one corresponding to a particular manufacturing process. Typically, a woven fabric has a regular structure defined by two orthogonal orientations of fibers and a narrow (in a statistical sense) opening size distribution. In contrast, a nonwoven geotextile is characterized by a random 
structure and a wide range of opening size with a broad statistical distribution (Figure 2.4). These structural differences between the two classes of geotextiles result in different filtration responses. For instance, mono-slit woven geotextiles are more effective as components of leachate control systems in landfills where there is high potential for clogging of drainage layers by organic matter, while the tortuous pore network of thick nonwoven geotextile makes them more prone to retention of well graded non cohesive soils in transportation infrastructures (Giroud, 1996). Another example of different retention responses is the observation, made in coastal applications, that under hydrodynamic flow generated by sea waves (with a period shorter than 10sec) greater amounts of fines seep through woven textiles than through nonwoven (Chew et al, 2000). Other properties of geotextiles are influenced by their manufacturing style and can affect their overall performance as filters. Whereas woven geotextiles are in general much stiffer than nonwovens under planar tensile stress applied along machine direction of weaving, this is not necessarily the case in the transverse-machine direction which is weaker. For a particular geotextile, variation in FOS as a function of applied stress is strongly linked to the fabric thickness (Fourie and Addis, 1999). This, in turn, influences the geotextile cross-flow hydraulic conductivity. The flow rate reduction, consecutive to axial loading, is much more severe with a woven geotextile, and also occurs at smaller tensile stress level, than with a nonwoven geotextile (Fourie and Kuchena, 1995). 

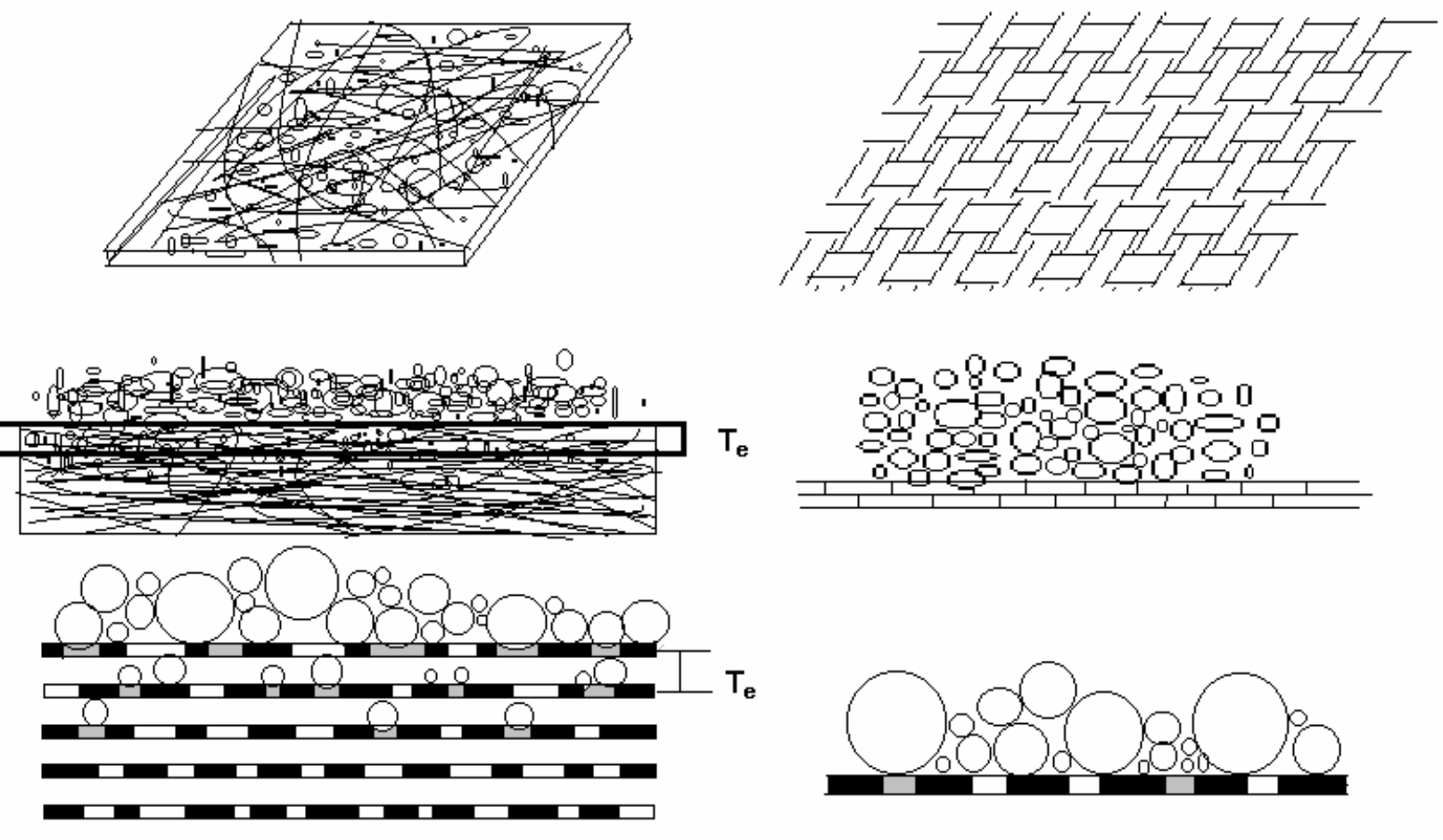

a) Nonwoven geotextile

b) Woven geotextile

Figure 2.4 Different weaving patterns for non woven and woven geotextiles $\left(\mathrm{T}_{\mathrm{e}}\right.$ : elementary thickness) 


\subsubsection{Porosity}

In general, nonwoven geotextiles have very high porosity ( 85 to $95 \%$ ) at atmospheric pressure whereas for woven fabrics it is often lesser than $40 \%$ (for the area porosity POA) according to Giroud (1996). Therefore, the two classes of geotextile differ also by their specific surface of fiber per unit area of geotextile $\left(S_{a}\right)$. For instance a woven textile with $\mathrm{POA}=10 \%$ may have a specific area, $\mathrm{S}_{\mathrm{a}}=4.3 \mathrm{~m}^{2} / \mathrm{m}^{2}$ while a nonwoven with porosity, $\mathrm{n}=0.9$, thickness of $2.8 \mathrm{~mm}$ the specific area would be $\mathrm{S}_{\mathrm{a}}=38 \mathrm{~m}^{2} / \mathrm{m}^{2}$. Porosity is closely related to geotextile density (mass per total volume), and to specific density (volume of fiber per total volume). These parameters altogether are indicative of how tight is the fabric micro-structure. These have been found to be related to the time-rate of the clogging process and its acceleration observed with high specific density geotextiles (Faure and Kehila, 1998). The porosity seems to play an important role in controlling the geotextile ultimate degree clogging by fine particles. If the pore space is large and the specific area small, which is the case of geotextiles, the probability of fine deposition or adsorption on the fibers will be very low because in such a filter the flow velocity is relatively high and thus contact between a fine particle and a fiber is of very short duration. As compared with granular filters which have lower porosity and larger specific area (e.g. $\mathrm{n}=0.3, \mathrm{~S}_{\mathrm{a}}=463 \mathrm{~m}^{2} / \mathrm{m}^{2}$ for a $74 \mathrm{~mm}$ thick layer), the deposition rate of fine particles on geotextile fibers can be considered negligible (Reddi et al, 2000, Xiao and Reddi, 2000)

\subsubsection{Thickness}

The role played fabric thickness in filtration is still a subject of debate, but some trends have been identified through experiments and theoretical analysis. Because for a given 
fabric the FOS decreases linearly with increasing thickness, likelihood for migrating particles being retained inside the fabric, and therefore the fabric being clogged, should theoretically increase linearly with thickness. This, in principle, applies to both woven and nonwoven geotextiles, but in fact, fabric thickness (as well as porosity) has more influence on filtration performance of nonwoven than woven geotextiles (Giroud et al, 1998). For internally unstable soil, filter design is focused on preventing blinding of the small openings at the interface between soil and geotextile, independently of fabric thickness. But thick geotextiles with large apertures have also the advantage of allowing unstable fines to pipe through the filter until bridging can take place. It was found by Qureshi et al. (1990) that the clogging by fine particles is less severe for thicker geotextiles while the opposite was reported by Mannsbart and Christopher (1997). On a theoretical basis, Giroud et al (1998) proposed using two-layer stratified geotextile filters for well graded soils. In this type of design, the up-gradient fabric in contact with the base soil would have large openings and the down-gradient fabric would have smaller openings. This combination would prevent both blinding at the soil-filter interface and internal clogging of the filter. Thickness contributes also to the geotextile tensile stiffness $^{3}$ and therefore makes the pore structure less prone to being altered while it is subjected to tension (Fourie and Kuchena,1995). Under out-of plane compression, the thickness of a woven geotextile remains almost unchanged even in the case of relatively large overburden pressure. On the contrary, nonwoven geotextiles, especially needlepunched fabrics, are compressible and in some cases their thickness can be decreased by as much as $50 \%$ under high confining pressure of the order of $200 \mathrm{kPa}$ (Koerner, 1998).

\footnotetext{
${ }^{3}$ It is noted that nonwoven geotextiles are more ductile than woven geotextiles. Under uniaxial tension, nonwoven fabrics have a tensile strain at failure greater than $50 \%$. For woven fabrics, the failure strain is typically smaller than $30 \%$.
} 
This, of course, can considerably affect their pore space geometry, including the opening size, and reduce their hydraulic conductivity (Giroud, 1996).

\subsubsection{Fiber Material}

Fibers used in manufacturing of geotextiles are made of plastic polymers. Polypropylene and polyester are the most frequently used polymers. In the past decade, these two materials accounted respectively for $85 \%$ and $12 \%$ of the production (Koerner, 1998). The role played by geotextile fiber material in filtration relates mainly to the interaction between fiber and pore fluid. The effect of fiber wettability on geotextile filter performance was well documented by Giroud (1996). This property can contribute to discrepancy between filter performance observed in wet versus dry conditions. Polypropylene and polyester are slightly hydrophilic. In unsaturated conditions, strong surface tension restricts water movement and slows the flow inside the geotextile. Then, when full saturation is reached there is a very steep rise in flow velocity and flow rates can increase by an order of magnitude. If a clay cake is formed at the interface with the geotextile, the jump in flow rate may be even greater though it takes more time for saturation being achieved. If oil is used as permeate instead of water, the wettability of the polymers is somewhat different. Polyester fabrics are more permeable to oil than to water while polypropylene fabrics are more permeable to water than oil (Scott et al,

1991). Another characteristic of polypropylene fibers is that they swell when in contact with oil. This can result in significant reduction of permeability of highway drainage filters in the eventuality of an oil spill.

\subsection{Hydraulic Conditions and External Loading}


Field hydraulic conditions around drains vary from site to site and upon time. The conditions relevant to filter performance can be divided into steady-state flow and transient flow. Laboratory column filtration tests are most often performed in steadystate, constant head, or transient, falling head, conditions. Other hydrodynamic situations of interest include, for instance, cyclic alternate-direction flow experienced by coastal protection revetment systems (Cazzuffi et al, 1999, Chew et al, 2000) and pulsed unidirectional flow due to traffic-induced excess pore pressure at the vicinity of pavement edge drains (Bhatia and Huang, 1995). Depending on particular site conditions to be simulated, testing protocols could involve cyclic transient flow modeled as pulse or sinusoidal input.

Field hydraulic gradients relevant to geotextile filter applications are considered to be of the order of 1 to 10 (Luettich, 1993). However, the hydraulic gradients applied in laboratory filtration tests are usually higher than these values in order to shorten the duration of tests. For internally stable soils, applying hydraulic gradients that are higher than typical field values does not affect significantly the final hydraulic conductivity of the samples in long term flow tests (Kossendey, 1999). On the contrary, with internally unstable soils, the hydraulic gradient magnitude influences the final hydraulic conductivity because the amount of migrated fine particles depends on flow velocity (Wayne and Koerner, 1993, Bhatia and Huang, 1995). In cyclic transient flow condition, the rate of change in hydraulic gradient, $\mathrm{R}_{\mathrm{i}}=2 \mathrm{i} / \Delta \mathrm{T}$, where, $\mathrm{i}$, is the maximum gradient and, $\Delta \mathrm{T}$, the period of sinusoidal variation, is a convenient index parameter. Usually, at high value of $\mathrm{R}_{\mathrm{i}}$ (i.e. rapid gradient variation), the amount of soil internal erosion is high, 
and woven geotextiles allow for a larger mass of piping soil to cross the filter than nonwoven geotextiles (Chew et al, 2000). Experimental evidence suggests that, when gradient variation period is long (e.g. 10sec), the condition can be approximated as steady-state flow.

Compression stress in the base soil induced by externally applied load is not a critical factor in the case of steady-state flow if the soil skeleton is likely to have already reached a stable state prior to the application of the load. However, the mass of piping soil is influenced by load-induced effective stress and hydraulic gradient in the case of transient flow. According to Cazzuffi et al. (1999), if the geotextile surface is not in tight contact with the trench backfill, the interface zone between base soil and geotextile filter can easily become internally unstable under the effect of effective stress decreasing or hydraulic gradient increasing. This notion is represented graphically in Figure 2.5 where $\mathrm{U} 1$ represents a negative increment of effective stress and $\mathrm{U} 2$ a positive increment of hydraulic gradient.

\subsection{Test Methods for Geotextile Clogging Assessments}

Commonly used laboratory testing methods of geotextile clogging potential are classified into three types - long term flow (LTF) test, gradient ratio (GR) test and hydraulic conductivity ratio (HCR) test (Koerner, 1998). The LTF is a simple test designed for detecting the change in flow rate through a soil sample and geotextile filter over time, under constant head condition. This type of test requires a long duration of sustained flow (sometimes over 200hrs) and, during this time, biological clogging can also occur (Figure 2.6 (a)). The GR test (ASTM D5101) was designed to detect local 


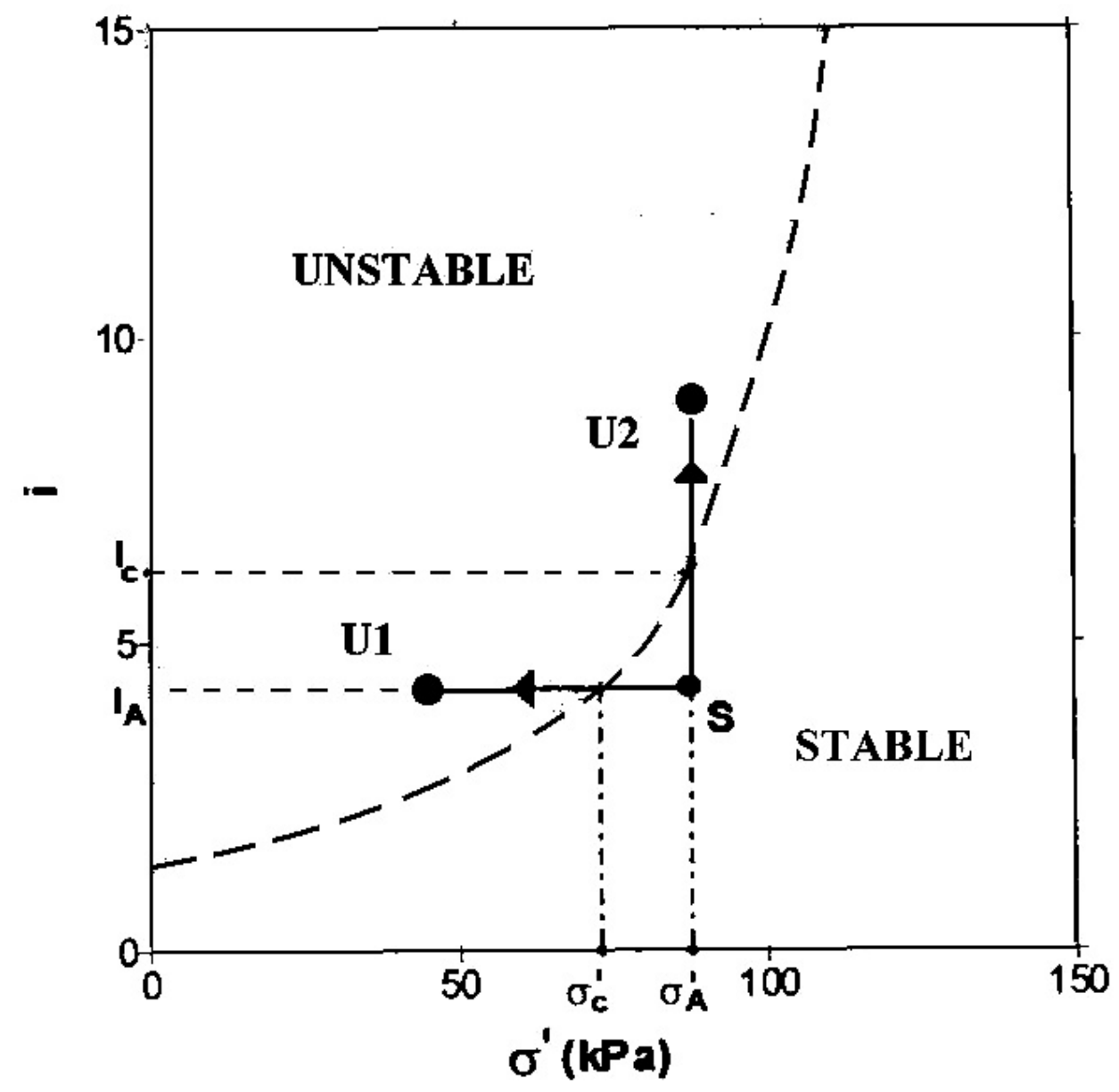

Figure 2.5 Relationship between hydraulic gradient and effective confining stress for soil internal stability in transient flow condition(after Cazzuffi et al, 1999)

variations in hydraulic gradient along the soil column and through the filter sample, as a result of particle migration (Figure 2.6 (b)). Local gradients are determined from pore pressures measured at various port locations along the sample and at the flow boundaries. 
The U.S. Army Corps of Engineers criterion for soil-geotextile compatibility based on this test is that the gradient ratio determined according to the ASTM Standard $\left(\mathrm{GR}_{\mathrm{ASTM}}=\mathrm{i}_{0-25} / \mathrm{i}_{25-50}\right)$ be less than 3 . In the above formula $\left(\mathrm{i}_{0-25}\right)$ and $\left(\mathrm{i}_{25-50}\right)$ are the hydraulic gradients measured between elevations 0 and $25 \mathrm{~mm}$ above the sample lower boundary (including the geotextile) and between elevations 25 and $50 \mathrm{~mm}$, respectively above the sample base. A gradient ratio larger than 1 indicates that more hydraulic energy is lost (due to clogging) through the filter and its interface zone (the bottom $25 \mathrm{~mm}$ zone) than in the base soil (the $25 \mathrm{~mm}$ thick adjacent layer). A modified version was proposed by Fannin et al. (1994) where the gradient ratio $\left(\mathrm{GR}_{\mathrm{Mod}}=\mathrm{i}_{0-8} / \mathrm{i}_{25-50}\right)$ is used for detecting the occurrence of blinding at the geotextile surface. The HCR test was proposed by Williams and Abouzakhm (1989) as a mean to reduce testing time for fine soils and to simulate in-situ conditions in case of external loading. The outcome of the test is the ratio of hydraulic conductivities corresponding to alternate-direction gradients obtained by reversing the flow through the sample (Figure 2.6(c)). Though the HCR test has been standardized under ASTM D 5567, its shortcoming pointed out by Giroud (1996) is its sensitivity to the soil specimen length and to the range of applied flow rates.

\subsection{Filter Design Criteria}

Retention criteria for geotextile filter design are empirical or semi-empirical formulas. Most often, these relate the smallest particle size of the base soil associated with bridge formation, $\mathrm{D}_{\mathrm{i}}$ (represented, for instance by $\mathrm{D}_{50}$ or $\mathrm{D}_{85}$ ) to the geotextile controlling opening size $\mathrm{O}_{\mathrm{f}}{ }^{*}$ (represented, for instance by the filtration opening size, FOS, or the apparent opening size, AOS, as index values of $\mathrm{O}_{\mathrm{f}, 90}$ or $\left.\mathrm{O}_{\mathrm{f}, 95}\right)$. Most design criteria prescribe a range for the ratio $\left(\mathrm{R}_{\mathrm{r}}=\mathrm{O}_{\mathrm{f}} * / \mathrm{D}_{\mathrm{i}}\right)$ either numerically or in function of additional 
parameters related to soil properties such as grading or soil type (Christopher and Fischer, 1992). More specific design methods take into account the hydraulic conditions or additional geotextile and soil properties (Luettich et al, 1992). Extensive reviews of geotextile retention criteria can be found elsewhere (e.g. Palmeira and Fannin, 2002) A summary of these is presented in Appendix A and only a few representative examples are discussed below.

[a]

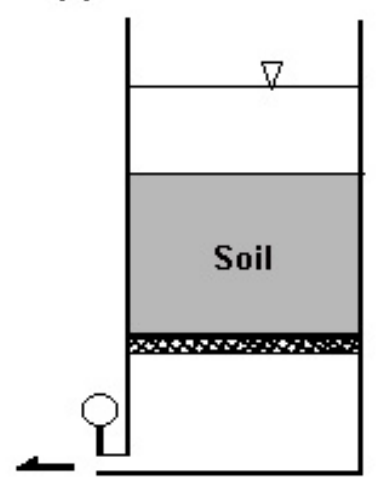

- flow rate measurement

$\equiv$ applied load [b]

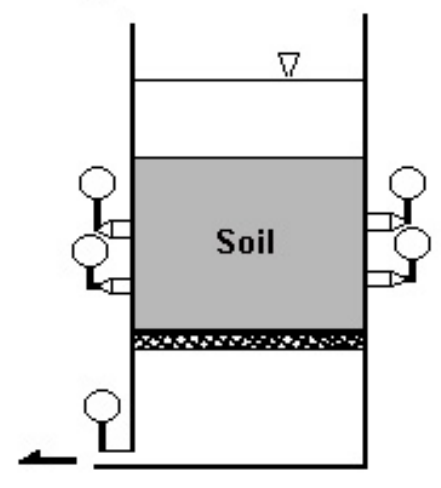

1 pore pressure measurement

porous stone [c]

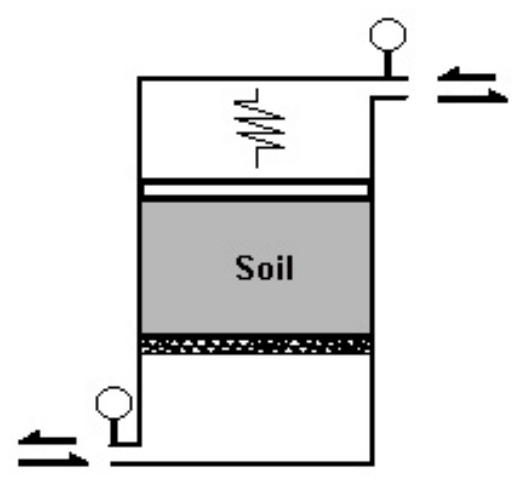

[a] Long Term Flow Test

(b) Gradient Ratio Test

[c] Hydaulic Conductivity Ratio Test

Figure 2.6 Conceptual representation of the main types of geotextile filtration tests 


\subsubsection{FHWA Criteria (Christopher and Holtz, 1985 and Christopher et al, 1995)}

This retention criterion was presented in the 1995 FHWA geosynthetics design and construction guidelines. For internally stable soils with less than $50 \%$ fines $(<0.075 \mathrm{~mm})$, it is expressed as $\mathrm{AOS} / \mathrm{D}_{85}<\mathrm{B}$ where $\mathrm{B}$ is function of the soil uniformity coefficient, $\mathrm{Cu}$. For $\mathrm{Cu}$ lesser than 2 or greater than 8 , coefficient $\mathrm{B}$ is equal to 1 . Within the interval $2<\mathrm{Cu}<8$, coefficient $\mathrm{B}$ varies between 1 and 2 , with the maximum for $\mathrm{Cu}=4$. This, in concept, is similar to the criterion derived by Giroud (1982) for idealized soil made of perfectly packed spherical particles and linearly graded. For soil with more than $50 \%$ fines, Christopher and Holtz recommend $\mathrm{AOS}<0.3 \mathrm{D}_{85}$ when the soil is internally unstable and the flow condition is steady state. When the flow is transient, with alternated directions or pulsing, they recommend $\mathrm{AOS}<\mathrm{D}_{15}$ irrespectively of internal stability. A shortcoming of the method may be the adoption of the dry sieving AOS as the opening size index instead of a wet sieving FOS, which is more representative of field conditions.

\subsubsection{Geosyntec Group Criteria (Luettich et al, 1992)}

Luettich et al (1992) presented their retention criterion as part of a design flow chart applicable to cohesive or non cohesive soils and steady-state or transient flow conditions. In the chart soils are categorized according to their amount of fines and cohesiveness. Unless a soil is non dispersive (DHR $<0.5)$ and plastic $(\mathrm{PI}>5)$, it is categorized as non cohesive. In the case of dispersive $(\mathrm{DHR}>0.5)$ and plastic $(\mathrm{PI}>5)$ soil, the authors recommend installation of an additional fine sand layer up-gradient, in contact with the geotextile filter. In the non cohesive case, they characterize the soil as stable or unstable and determine a pseudo-coefficient of uniformity $\mathrm{Cu}$ ' in the linear section of the GSD, 
tangent to the $\mathrm{D}_{50}$ point. Prescribed values of $\mathrm{O}_{\mathrm{f}, 95} / \mathrm{D}_{50}$ values are function of soil relative density. It is noted that, in this method, a soil can be characterized as cohesive or non cohesive depending on the clay content (30\% being the threshold amount) but also the flow regime. A shortcoming is in the determination of the soil internal stability which is based on a linearized GSD.

\subsubsection{Lafleur’s Criteria (Lafleur, 1999)}

Lafleur (1999) focused on retention of non cohesive soils. For internally stable soils, the ratio $\left(\mathrm{R}_{\mathrm{r}}=\mathrm{FOS} / \mathrm{D}_{\mathrm{i}}\right)$ is recommended to be smaller than 1 , with $\mathrm{D}_{\mathrm{i}}=\mathrm{D}_{85}$ when $\mathrm{Cu}<6, \mathrm{D}_{\mathrm{i}}=\mathrm{D}_{50}$ when $\mathrm{Cu}>6$ and the GSD has a linear shape, $\mathrm{D}_{\mathrm{i}}=\mathrm{D}_{\text {gap,min }}$ when $\mathrm{Cu}>6$ and the GSD is gapped, $\mathrm{D}_{\mathrm{i}}=\mathrm{D}_{30}$ when $\mathrm{Cu}>6$ and the GSD is concave upwards. For internally unstable soils, the ratio $\left(\mathrm{R}_{\mathrm{r}}=\mathrm{FOS} / \mathrm{D}_{\mathrm{i}}\right)$ is to be kept between 1 and 5 , with $\mathrm{D}_{\mathrm{i}}=\mathrm{D}_{30}$ for GSD either gapped of concave upwards. However, Lafleur pointed out that, in order to reflect the broad range of experimental data available, more information related for instance to the opening size distribution or fiber properties would have to be included in filter design.

\subsection{Earlier Experimental Results}

Significant data from filtration tests has been generated by earlier researchers and documented in published literature. As part of the present study, this database was analyzed. The most important aspects of filtration and influence of major factors were identified and discussed in the previous sections of this text.

In addition, synthesis of these data from Williams and Abouzakhm (1989), Siva and Bhatia (1993), Murty et al. (1994), Almeida et al. (1995), Bhatia and Huang (1995) and Nishigata et al. (2000) was performed in order to summarize the test results in function of 
soil GSD and filter opening index parameters. The geotextile filtration opening size (FOS), two specific particle sizes of the soil $\left(\mathrm{D}_{10}\right.$ and $\left.\mathrm{D}_{85}\right)$, its uniformity coefficient $(\mathrm{Cu})$, and the initial and final system hydraulic conductivities $\left(\mathrm{K}_{\mathrm{i}}\right.$ and $\left.\mathrm{K}_{\mathrm{f}}\right)$ were extracted from the database and used for the synthesis. The ratio of $\mathrm{K}_{\mathrm{i}}$ over $\mathrm{K}_{\mathrm{f}}$ indicates change in system (i.e. soil and geotextile) hydraulic conductivity between the start and the end of a test. Ratios significantly larger than 1 indicate a serious reduction of hydraulic conductivity, consecutive to clogging. These data are shown in Figure 2.7 in function of $\mathrm{Cu}$ (Figure 2.7(a)) and FOS/ $\mathrm{D}_{85}$ (Figure 2.7(b)). From these plots, there is no clear evidence of role played by $\mathrm{Cu}$, but there is clear indication of correlation with $\mathrm{FOS} / \mathrm{D}_{85}$. According to Figure 2.7(b), clogging tends to occur for samples tested with ratios, $\mathrm{FOS} / \mathrm{D}_{85}$, in the vicinity of 1 or smaller. This observation seems to be in contradiction with a number of retention criteria where recommended design values of the ratio are close to this region. Further information is presented in Figure 2.8 where the ratio $\mathrm{K}_{\mathrm{i}} / \mathrm{K}_{\mathrm{f}}$ is plotted in function of both FOS/ $\mathrm{D}_{85}$ and $\mathrm{D}_{10}$. Here it appears that cases with strong reduction in hydraulic conductivity, in the range of $F O S / D_{85}$ close to 1 are samples with small values of the smaller particles diameter, $\mathrm{D}_{10}$. This confirms the presence of small particles, not only the larger ones, controls the filter performance in the tests. A possible explanation is that blinding of the filter fabric by fine particles is what occurred in these cases.

This would suggest a most critical circumstance is in the combination of a significant amount of very fine particles with a small filter opening size prone to blinding. 
(a) $\mathrm{K}_{\mathrm{i}} / \mathrm{K}_{\mathrm{f}} \& \mathrm{Cu}$

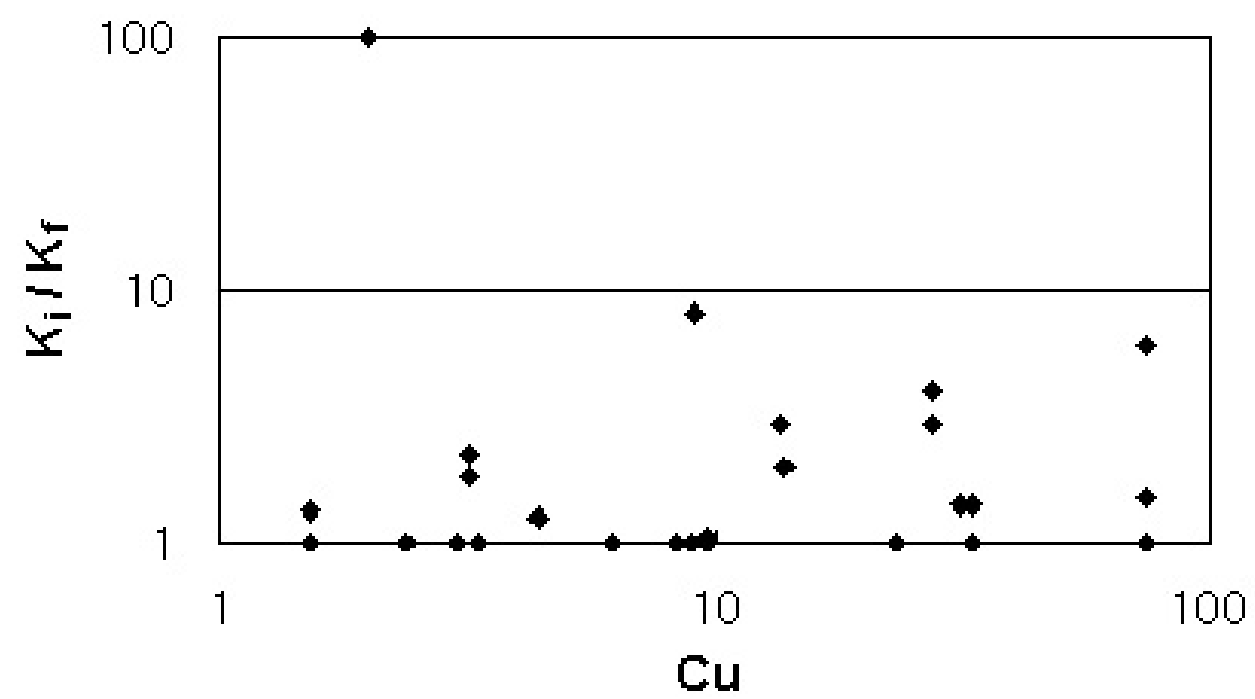

(b) $K_{\mathrm{i}} / \mathrm{K}_{\mathrm{f}}$ \& FOS $/ \mathrm{D}_{85}$

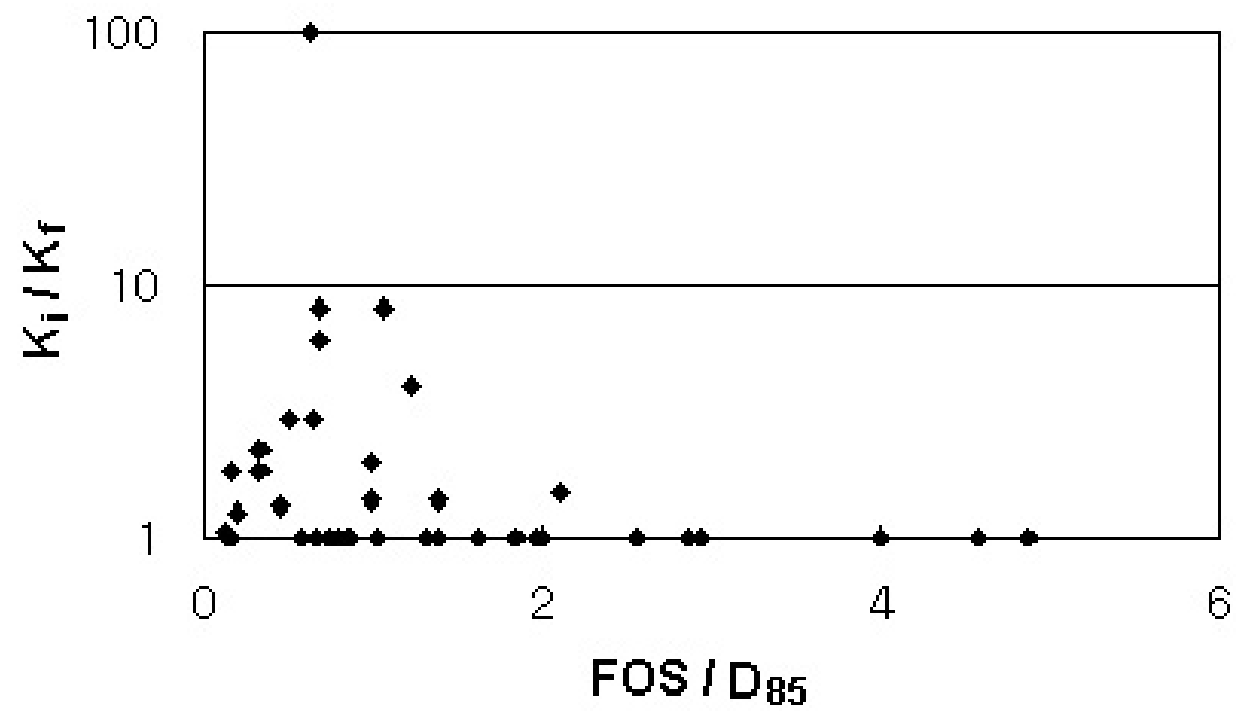

Figure 2.7 Summary of clogging test results in function of material parameters, based on literature review. Large values of $\mathrm{K}_{\mathrm{i}} / \mathrm{K}_{\mathrm{f}}$ ratio indicates clogging of filter system, where $\mathrm{K}_{\mathrm{i}}$ and $\mathrm{K}_{\mathrm{f}}$ are initial and final system hydraulic conductivities respectively 


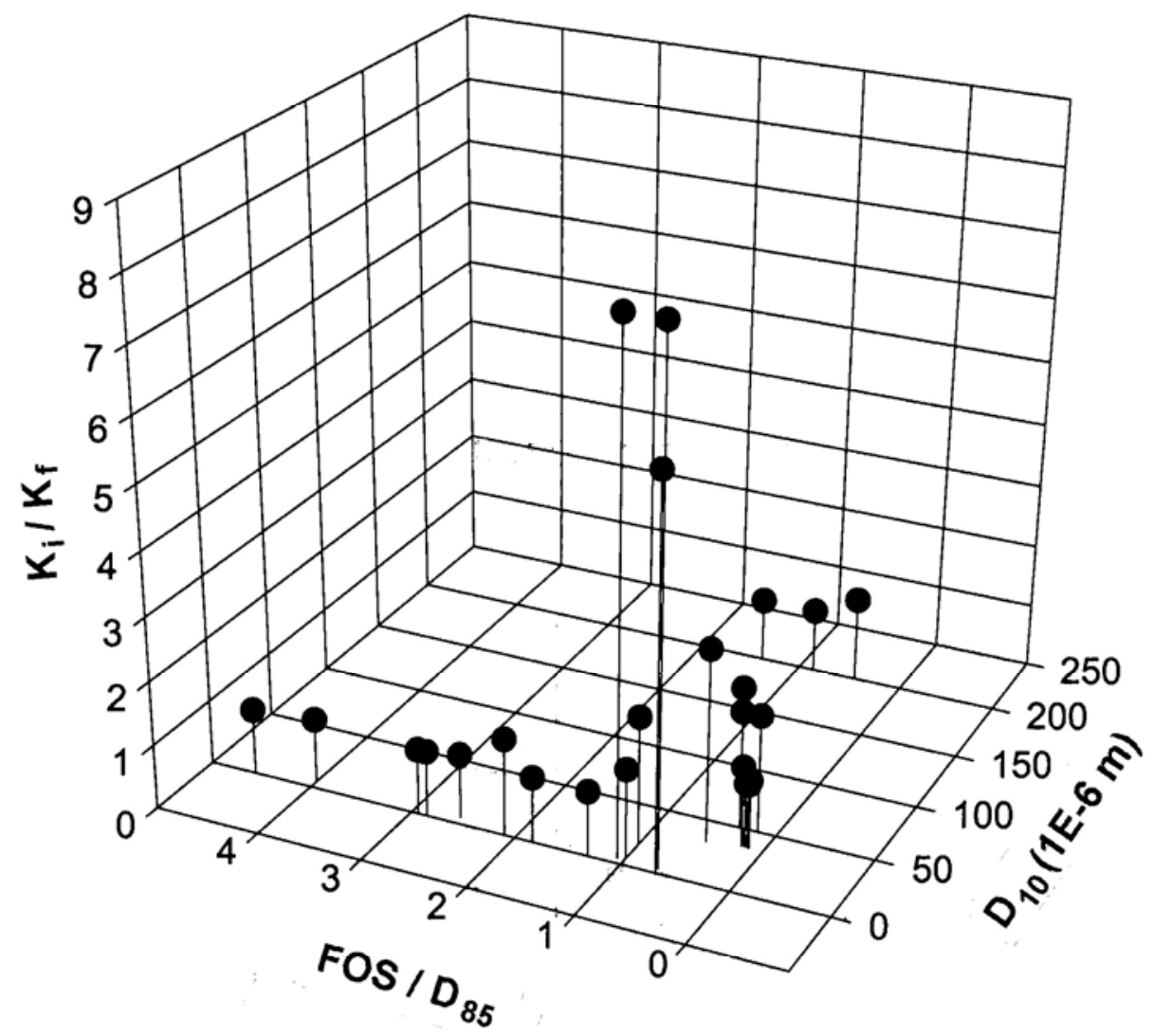

Figure 2.8 Multi -parameter visualization of clogging test results, based on literature review $\left(\mathrm{K}_{\mathrm{i}}\right.$ : initial hydraulic conductivity, $\mathrm{K}_{\mathrm{f}}$ : final hydraulic conductivity, FOS : filtration opening size of geotextile, $\mathrm{D}_{10}, \mathrm{D}_{85}$ : sizes (diameter) of grains at 10 and $85 \%$ in cumulative soil GSD 


\subsection{Earlier Field Performance Study}

An extensive field investigation was performed in the 1990s under the auspices of FHWA and almost all state DOTs (Indiana did not participate) in order to assess the field long-term performance of highway drain geosynthetic filters (Koerner et al,1996, Wilson-Fahmy et al, 1996). The study included exhuming geosynthetic filters from at a number of sites where these had been in service over a period of time and, through examination and testing, find how much clogging and deterioration of their properties had occurred. Filters at 41 edge drain locations were examined for soil retention, permeability and geotextile clogging assessment. Then, these observations were confronted to several current design methods including those proposed by Giroud (1982), the French Committee of Geotextiles and Geomembranes (1986), Fischer et al (1990), Luettich et al (1992) and Christopher and Holtz (1985) for the FWHA. Results of this comparative study are presented in Table 2.1. For each performance criterion and design method, the total numbers of cases where the design method would have been able to predict the observed performance or would have failed to predict it are indicated with symbols $\mathrm{S}$ and F, respectively. It is noted that categories defined by symbols $\mathrm{S}$ or $\mathrm{F}$ do not relate to successful or failing performance of the filters themselves, but to success or failure of the design methods in predicting performance. Inspection of these statistics in Table 2.1 suggests better graded, mixed particle size types of soils (i.e. between $12 \%$ and $50 \%$ in fine content) are the most difficult filter design cases while design methods are more successful in cases of either mainly fine grained (i.e. more than $50 \%$ fines) or coarse grained (i.e. less than $12 \%$ fines) soils. 
Table 2.1 Capability of selected geosynthetic filter design criteria to predict filter field performance, based on observation of exhumed samples at sites investigated by Koerner et al (1996) (after Wilson-Fahmy et al, 1996)

\begin{tabular}{|c|c|c|c|c|}
\hline Criteria & Source & $\begin{array}{l}\text { Coarse Soil } \\
\leq 12 \% \text { fine }\end{array}$ & $\begin{array}{l}\text { Mixed Soil } \\
13-49 \% \text { fine }\end{array}$ & $\begin{array}{c}\text { Fine Soil } \\
\geq 50 \% \text { fine }\end{array}$ \\
\hline \multirow{3}{*}{ Permeability } & Giroud (1982) & $\mathrm{S}^{*}-15 ; \mathrm{F}^{*}-1$ & $\mathrm{~S}-44 ; \mathrm{F}-2$ & $\mathrm{~S}-10 ; \mathrm{F}-1$ \\
\hline & French (1986) & $\mathrm{S}-0 ; \mathrm{F}-7$ & $S-25 ; F-21$ & $\mathrm{~S}-15 ; \mathrm{F}-5$ \\
\hline & FHWA (1985) & $\mathrm{S}-7 ; \mathrm{F}-9$ & $\mathrm{~S}-43 ; \mathrm{F}-3$ & $\mathrm{~S}-19 ; \mathrm{F}-1$ \\
\hline \multirow{3}{*}{ Retention } & French(1986) & $\mathrm{S}-16 ; \mathrm{F}-0$ & $\mathrm{~S}-38 ; \mathrm{F}-2$ & $\mathrm{~S}-19 ; \mathrm{F}-0$ \\
\hline & Fisher (1990) & $\mathrm{S}-16 ; \mathrm{F}-0$ & $S-30 ; F-10$ & $\mathrm{~S}-1 ; \mathrm{F}-8$ \\
\hline & Luettich(1992) & $\mathrm{S}-16 ; \mathrm{F}-0$ & $\mathrm{~S}-35 ; \mathrm{F}-5$ & $\mathrm{~S}-16 ; \mathrm{F}-3$ \\
\hline \multirow{3}{*}{ GT clogging } & French (1986) & $\mathrm{N} / \mathrm{A}$ & $\mathrm{S}-24 ; \mathrm{F}-22$ & $\mathrm{~S}-19 ; \mathrm{F}-1$ \\
\hline & FHWA (1985) & $\mathrm{N} / \mathrm{A}$ & $S-33 ; F-13$ & $\mathrm{~S}-19 ; \mathrm{F}-1$ \\
\hline & Fisher (1990) & $\mathrm{N} / \mathrm{A}$ & $\mathrm{S}-28 ; \mathrm{F}-18$ & $\mathrm{~S}-19 ; \mathrm{F}-1$ \\
\hline
\end{tabular}

* S : success in predicting filter field performance; $\mathrm{F}$ : failure to predict filter field performance; numbers indicate corresponding frequencies of cases. 


\section{Investigation of Field Conditions and Long-Term Performance}

\subsection{Purpose of the investigation}

The purpose of this particular part of the project was two-fold:

(a) Identify and characterize, using samples provided by INDOT, several types of subgrade soils encountered in Indiana highway construction for which geotextile filters would likely be required. These soil types would be later used for filter selection and design examples.

(b) In order to assess long-term field performance of geosynthetic filters already utilized by INDOT, it was necessary to sample material (filter and adjacent soil) from selected site(s) of Indiana highways where geotextile filters had been in service for a significant amount of time. Then, the state of clogging of these samples was to be assessed in the laboratory by performing detailed visual examination for evidence of fine particles blinding or penetrating the fabric, and by performing hydraulic conductivity tests. It was also expected that results of underdrain pipes video inspections would be available in order to detect intrusion of sediment into the pipes.

\subsection{Study of Soil Samples Provided by INDOT}

Four disturbed samples from 4 different locations were delivered to the Purdue geotechnical laboratories. These are listed in Table 3-1 together with their origin and preliminary description. Sample water contents are also indicated but it should be noted that, because of sample disturbance, these are inaccurate representations of field values. 
Tests performed on these samples included grain size analysis (sieve and hydrometer test ASTM D 422) and determination of Atterberg's limits (ASTM D 4318). As can be verified from the grain size distributions (GSD) in Figures 3-1 \& 3-2,

Table 3-1 Soil samples provided by INDOT

\begin{tabular}{cccc}
\hline Sample & Location & Soil description & water content (\%) \\
\hline M1 & Gibson Co. US highway \& CR50S & Silt & 9.5 \\
S1 & SR103 \& CR700S & Sandy loam & 11.8 \\
C1 & SR641 \& US41 RB23 & Silty clay & 40.5 \\
C2 & Bloomington sub-district & Bloomington Clay & 6.9 \\
\hline
\end{tabular}

the samples are from essentially fine-grained soils (even the sandy loam S1 sample has over $40 \%$ in weight passing the No 200 sieve) with broadly distributed size (i.e. silt M1 and sandy loam S1, Fig. 3-1) or clay with high silt content, over 50\% in weight (i.e. silty clay $\mathrm{C} 1$ and Bloomington clay $\mathrm{C} 2$, Fig. 3-2). Plasticity charts are shown in reference to the Unified Soil Classification System (USCS) and the American Association of State Highway and Transportation Officials (AASHTO) systems in Figures 3-3a \& 3-3b respectively. Soil classifications based on this information are summarized in Table 3-2.

Table 3-2 Soil Classifications for samples provided by INDOT

\begin{tabular}{cccc}
\hline Sample & Description & $\begin{array}{c}\text { USCS classification } \\
\text { (ASTM D2487) }\end{array}$ & $\begin{array}{c}\text { AASHTO classification } \\
\text { (ASTM D3282, } \\
\text { AASHTO M145) }\end{array}$ \\
\hline M1 & Silt & CL or ML & A-6 (8) \\
S1 & Sandy loam & CL or ML & A-6 (2) \\
C1 & Silty clay & CL & A-6 (18) \\
C2 & Bloomington clay & $\mathrm{CH}$ & A-7-6 (29) \\
\hline
\end{tabular}


It is interesting to note that, if one follows strictly the current INDOT guidelines (see Chapter 1), only the soil of sample M1 (fine fraction greater than $50 \%$ and clay fraction lesser than 20\%) would require installation of a filter. The other 3 samples do not meet the current INDOT criteria for a filter being required because, for S1 the fine fraction is only $40 \%$, and for C1 \& C2 the clay fraction is greater than $20 \%$ in spite of the fine fraction being much greater than $50 \%$.

\subsection{Field Evaluation of Filter Long-Term Performance}

\subsubsection{Site Selection and Sampling}

Criteria for sampling site selection were of technical and logistical nature:

(a) Presence of geotextile filters in service for at least several years at a site was required for the site be eligible to. The preferred configuration, in line with the project objectives, had to be that of a geotextile lined around edge drain trenches and providing filter protection to a perforated drain pipe. Prefabricated geocomposite edge drains were not to be considered in priority because this type of edge drain is not anymore the technology of choice for INDOT. It is noted, however, that a number of such prefabricated geocomposite edge drains are still in service in Indiana highways.

(b) In order for the collected information be of optimal relevance, it was anticipated that site at which inadequate filter or drain performance had been reported or was suspected by INDOT personnel were much preferable.

(c) In order to minimize the cost the field work, avoid disrupting traffic, and for access to sampling locations be facilitated, candidate sites were likely to be 
highway reconstruction or rehabilitation project sites. At such sites where old underdrains were being removed and replaced by new ones, sampling of the old filters and of the soil would be possible in the best conditions.

Requests were sent to all INDOT Districts in order to identify sites that would meet the above criteria. As a result of this survey only one site, located in the Vincennes District on Sullivan County, along US 41 at its intersection with SR 154, seemed to be a good candidate and was selected. This location is the site of a US 41 widening and reconstruction project. During the Summer of 2004 old underdrains were removed and new ones installed. However the old underdrains installed c. 1990 appeared to be of the prefabricated geocomposite edge drains type (i.e. Monsanto Hydraway) made of a corrugated plastic drainage core encapsulated with needle-punched nonwoven geotextile filter. In spite of this shortcoming and because it was apparent that clogging had occurred to the filters, it was decided to take samples of these edge drains and further examine their geotextile components in the laboratory. During collection and transport of the samples, precautions were taken for preventing disturbance and loss of the fines that were present on the surface or within the geotextile fabric. Soil representative of the subgrade in contact with the edge drains was also taken from a shallow excavation at the site. Two soil samples were collected: one disturbed sample and one low-disturbance sample, the latter being obtained using a Shelby tube. In addition to the geosynthetic and soil samples, recycled concrete aggregates utilized for the reconstruction project were also collected. 


\subsubsection{Analysis of Soil Samples from the Sullivan Co. US 41 Site}

On the basis of its grain size distribution (i.e. $13 \%$ sand, $55 \%$ silt and $27 \%$ clay fractions in weight), its classification and its appearance, the soil sampled at the site is very similar to Sample C2 , Bloomington clay, already provided by INDOT (see Fig. 3-2, Fig. 3-3, and Table 3-2). The saturated hydraulic conductivity was determined, in the laboratory, using a falling head permeability test performed with a flexible wall permeameter. For this test the sample, $37 \mathrm{~mm}$ in diameter and $62 \mathrm{~mm}$ thick, was reconsolidated at an effective confining pressure of $10 \mathrm{kPa}$, full saturation being achieved by application of back pressure. The corresponding void ratio was 0.52 . Permeation was performed under an average gradient of 30 , and the resulting coefficient of permeability was $3.8 \times 10^{-6} \mathrm{~cm} / \mathrm{s}$.

\subsubsection{Analysis of Geotextile Samples from the Sullivan Co. US 41 Site}

Once the geocomposite edge drains samples were in the laboratory, their geotextile filter layers were carefully separated from the drainage cores for further inspection and testing. According to manufacturer's documentation, this geotextile is a needle-punched nonwoven fabric made of polyethylene fibers. It is $2.5 \mathrm{~mm}$ thick, has a mass per unit area of $253 \mathrm{~g} / \mathrm{m}^{2}$ and filter opening size, FOS $=0.06 \mathrm{~mm}$. Visual inspection revealed that most fine soil particles had remained within the filter fabric and no sediment was found in the drain core. The geotextile degree of blinding or clogging after 15 years of service varied from sample to sample, depending probably on local variations in soil and hydraulic conditions at the site. Some samples were practically intact while others were covered with soil lining their surface and significant clogging was suspected. In Fig. 3-4 are shown two pictures of non-clogged (right-hand side) and heavily clogged (left-hand side) specimens. In order to quantify the effect of clogging on the capacity of the filters to 
allow free flow of water to the drainage, the hydraulic conductivity perpendicular to the geotextile plane of clogged samples was compared to that of non-clogged samples. The hydraulic conductivity was determined on disk-shaped specimens placed in a permeameter with no soil sample present. Gradients across the geotextile were kept equal to 20. The non-clogged samples still had a high hydraulic conductivity close to that of an intact sample of $\mathrm{K}=0.15 \mathrm{~cm} / \mathrm{sec}$, but the hydraulic conductivity of the clogged samples was only $1.89 \times 10^{-5} \mathrm{~cm} / \mathrm{sec}$ that is about 10,000 times smaller than the intact value.

\subsubsection{Analysis of Bloomington Clay Filtration with Geotextile Samples from the Sullivan Co. US 41 Site}

In order to verify the ability of the exhumed geotextile to still work as a filter for the soil conditions encountered on the site, a filtration test was performed in the laboratory using a non-clogged geotextile sample and Bloomington clay. The type of test performed is known as the Rapid Retention Test (RRT). It is simple but accurate enough for being routinely performed on geotextile filters and has been used extensively in this study.

Greater detail on the RRT development, technique and equipment is provided in a subsequent chapter (Chapter 6) of this report. For the sake of the present discussion, only the principle is described briefly and results are presented. The test consisted in placing the soil specimen, $25 \mathrm{~mm}$ (1 in) thick and $100 \mathrm{~mm}$ (4 in) in diameter on top of a geotextile disk in a flexible wall permeameter. After specimen saturation and consolidation had been achieved in the cell, downward flow was induced under a fairly high gradient, $i=10$, with the direction of seepage going from the soil to the geotextile, and the overall hydraulic conductivity of the composite system (soil and geotextile) was determined. The test was kept running for 8 hours in order to monitor changes in 
hydraulic conductivity due to soil particle migration. At the start of the test the system hydraulic conductivity was $1.2 \times 10^{-4} \mathrm{~cm} / \mathrm{s}\left(2.3 \times 10^{-4} \mathrm{ft} / \mathrm{min}\right)$ and, after 8 hours, had decreased to $2.6 \times 10^{-6} \mathrm{~cm} / \mathrm{s}\left(5.1 \times 10^{-6} \mathrm{ft} / \mathrm{min}\right) \mathrm{cm} / \mathrm{sec}$. Such a decrease of the soil $/$ geotextile interface zone permeability (by a factor 100) is significant enough as the indication that clogging occurred during the test. However, it is noted that the gradient applied during the test was likely to be higher than typical values occurring in the field. Thus, in the test, seepage forces induced to soil particles and their resulting mobility were probably more severe than in the field.

\subsubsection{Filtration Test of Recycled Concrete Aggregate from the Sullivan Co US 41 Project}

Filtration testing was also attempted on the aggregates used on the site for reconstructing the pavement. These aggregates, produced by rubbleization of the old concrete pavement, have been suspected of being a source of contamination for the underdrains at various INDOT projects. The rubbleized aggregate is occasionally mixed with chemicals asphalt emulsion (AE) or polymer modified prime (PMP) for purpose of base course stabilization. The aggregate sample taken from the site was agglomerated with AE and PMP chemicals. It was necessary to break it down to gravel-size grains in order to perform tests in standard laboratory equipment. Fractioning also had the effect of increasing the specific surface area and enhancing chemical reactions with water. Crushed aggregates encrusted with stabilizer were separated from the clean ones (Fig.35) and placed in a transparent plastic cylinder to form a $5 \mathrm{~cm}$ (2 in) thick layer resting on three geotextile filter disks (Fig.3-6). With this setup shown in Fig. 3-7, a long term filtration test was kept running for 2 weeks. A longer duration would have allowed 
bacteria to grow inside the system and to interfere with the chemical or mechanical clogging processes. Untreated tap water was used as permeating fluid. The test was conducted in unsaturated condition at constant influent flow rate $(100 \mathrm{cc} / \mathrm{min})$ and the effluent rate was monitored once a day. In case of clogging, the effluent rate would be observed to decrease with time. But no significant change in effluent rate was observed during the test and, therefore, no hydraulic evidence of clogging was obtained. However, after the sample was dismantled mottled stains were found on the geotextile layers, with their extent decreasing from the top layer to the bottom one (Fig.3-8). Though no chemical analysis was performed, their color and odor seem to exclude that these stains were made of stabilizer chemicals. More likely suspects are the hardness of tap water and cement chemicals present in recycled concrete aggregates. The latter is consistent with earlier findings by Wukash and Siddiqui (1996).

\subsubsection{Video Inspection of Subdrainage Pipes}

Several VHS tapes of underdrain pipe non-destructive inspections performed using a system similar to the borescope (an optical device that can be inserted in the drain and is connected to a video recorder) at different sites were made available to the investigators by INDOT Vincennes District's engineers. Although these inspections do not relate to the same US 41 project but were performed at other sites, the video tapes contain information

of interest in the present study. All the underdrains were installed in Fall of 2000 and were inspected in 2001 after 8 to 12 months of service. More information on the sections inspected is presented in Table 3-3. 
The tapes were reviewed in detail and important features were noted. However analysis of this information and lessons that can be learnt from it are limited because clear, unambiguous correspondence between the project sections described in Table 3-3 and the video recording sections shown on the tapes is not provided. Also, in a number of instances the inspection instrument is used under water or is moved too fast within the pipes and, as a result, the recorded pictures are blurred.

Table 3-3 General information on video inspections of drainage pipes

\begin{tabular}{|c|c|c|c|c|}
\hline Section & Project/Location & Type of Drain & Geotextile Filter & Rubbleization \\
\hline $1 a$ & $\begin{array}{c}\text { R-24635 / SR } 37 \\
\text { Oolitic-50 West }\end{array}$ & $\begin{array}{c}100 \mathrm{~mm} \\
\text { perforated pipe }\end{array}$ & No & No \\
\hline $1 b$ & same as above & $\begin{array}{l}150 \mathrm{~mm} \\
\text { perforated pipe }\end{array}$ & Yes & No \\
\hline $2 a$ & $\begin{array}{c}\text { R-24844 / SR } 37 \\
\text { Laurence Co. }\end{array}$ & $\begin{array}{l}100 \mathrm{~mm} \\
\text { peforated pipe }\end{array}$ & No & Yes \\
\hline $2 b$ & same as above & $\begin{array}{c}150 \mathrm{~mm} \\
\text { perforated pipe }\end{array}$ & Yes & No \\
\hline 3 & $\begin{array}{l}\text { R-24881 / US } 41 \\
\text { Sullivan \& Knox }\end{array}$ & $\begin{array}{l}100 \mathrm{~mm} \\
\text { perforated pipe }\end{array}$ & Yes & No \\
\hline
\end{tabular}

Following is a summary of observations (dates and times indicated are inspection dates and times that are marked on the tapes):

Sections 1a \& $1 b$ (inspected July 27-31, 2001)

- Water is present in pipe with level varying along section. Light sediment deposit 
is present in most of the section of pipes recorded. This sediment has the appearance of light silty powder lining about $10 \%$ to $20 \%$ of the pipe interior perimeter but it doest form a cake nor create obstruction or significant reduction in cross-section. Structural damage of pipe is observed at several locations.

Sections 2a \& $2 b$ (inspected June 18- July 9, 2001)

- Water is present in pipes with level varying along section.

- June 18 footage: Along most of the segment, beige sediment forming cake lines $50 \%$ to $70 \%$ of pipe perimeter, reducing inflow of water to the pipe. Cross-section of pipe is reduced by about $10 \%$. At several locations, pipe has collapsed and inspection instrument is blocked. At clock mark, 14:24, heavy accumulation of white shining deposit, possibly of chemical origin rather than soil particles. Crosssection of pipe is reduced by approximately $40 \%$.

- June 19 footage: Same as previous segment. At clock mark, 10:56, pipe is completely obstructed by sediment, blocking inspection instrument.

- June 20 footage: Sediment cake present, similar to previous section, but no obstruction of pipe. Several instances of pipe collapse.

- June 27 footage: Sediment forming cake lining 30\% to 50\% of pipe perimeter. Cross-section reduced by approximately $10 \%$ but no obstruction. From clock mark, 17:30 to end of segment, pipe is clean.

- June 28 footage: Along the first 440' of this segment, significant sediment accumulation forming cake over $30 \%$ of perimeter and reducing the cross-section by $10 \%$ to $20 \%$, then clean pipe. At clock mark, 9:17, intrusion of vegetal material and obstruction of pipe combined with structural damage. Starting at clock mark, 9:55, presence of light sediment lining 20\% of perimeter, with no cake formation or obstruction. At clock mark, 11:00, pipe has collapsed. Starting at clock mark, 13:04, light sediment lining approximately $60 \%$ of perimeter.

- June 29 footage: Light sediment lining about 30\% of perimeter. Between clock marks 8:49 and 9:30, pipe is clean, then sediment lining $20 \%$ to $50 \%$ of perimeter.

- July 5 footage: Starting at clock mark, 7:46, heavy sedimentation lining $100 \%$ of perimeter and forming cake. Pipe cross-section is deformed and reduced by $60 \%$. At clock mark , 7:47, pipe is obstructed by sediment and instrument blocked. Next segment, starting at clock mark, 8:05, is 20\% lined by light sediment. At clock mark, 8:08, pipe is obstructed by sediment and instrument is blocked. From clock mark, 8:22, to the end of the segment, sediment deposits covering between $10 \%$ and $60 \%$ of pipe perimeter, with minor cake formation.

- July 9 footage: no data because of bad operation of instrument.

Section 3 (inspected August 8, 2001)

- This section was completely dry on day of inspection. Starting at clock mark, $11: 16$, until 14:30 the pipe is clean or lined with light sediment lining up to $30 \%$ of its perimeter. No cake formation or obstruction. Next, vegetal material is present in pipe with, at 14:34, heavy accumulation of sediment obstructing $50 \%$ of cross-section. Rats are present in pipe. From clock mark, 14:44, to end of segment, pipe is clean or lined with light sediment deposit (up to 30\% of 
perimeter) with no cake formation or obstruction except at 17:07 where vegetal material has accumulated.

\subsection{Summary of Field Studies Findings}

Geotechnical situations that are considered prone to filtration problems with highway underdrains and from which soil samples were analyzed are characterized by high silt content. At the Sullivan Co. US 41 project site where samples of exhumed filters were obtained, the soil is similar to Bloomington clay with its grain size distribution dominated by the silt fraction. The filter samples from this site exhibited variable degree of clogging after 15 years of service. When quasi-intact specimens were tested in the laboratory together with Blooomington clay, their tendency to clogging with this soil was confirmed. Additional, but very limited, testing in the laboratory suggests chemicals from recycled (rubbleized) concrete aggregates might also affect the integrity of geotextile filters.

Video recording of underdrain pipe non-destructive inspections from different INDOT projects show moderate to heavy sedimentation within pipes after one year of service, suggesting adequate filtration was lacking. Heavy sedimentation is characterized by formation of a cake around the pipe interior perimeter. This cake is likely to clog the pipe perforations and prevent drainage water to enter. It also decreases the pipe cross-section and affects its discharge capacity. In several instances, complete obstruction of pipes by sediment is observed as well as structural damage or failure. Sediment accumulation was found to vary significantly along all the sections inspected irrespectively of the presence 
or absence of geotextile filters or of pavement rubbleization. These spatial variations are likely to be related to spatial variations in soil and hydraulic conditions.

(a) Silt GSD ( M1 )

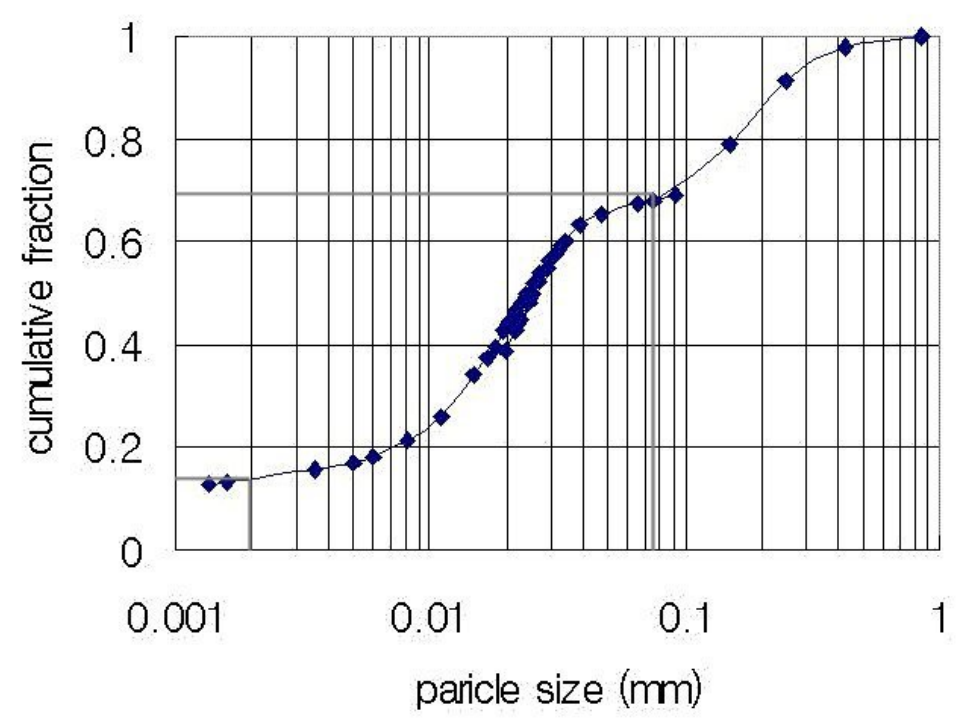

(b) Sandy loam GSD ( S1 )

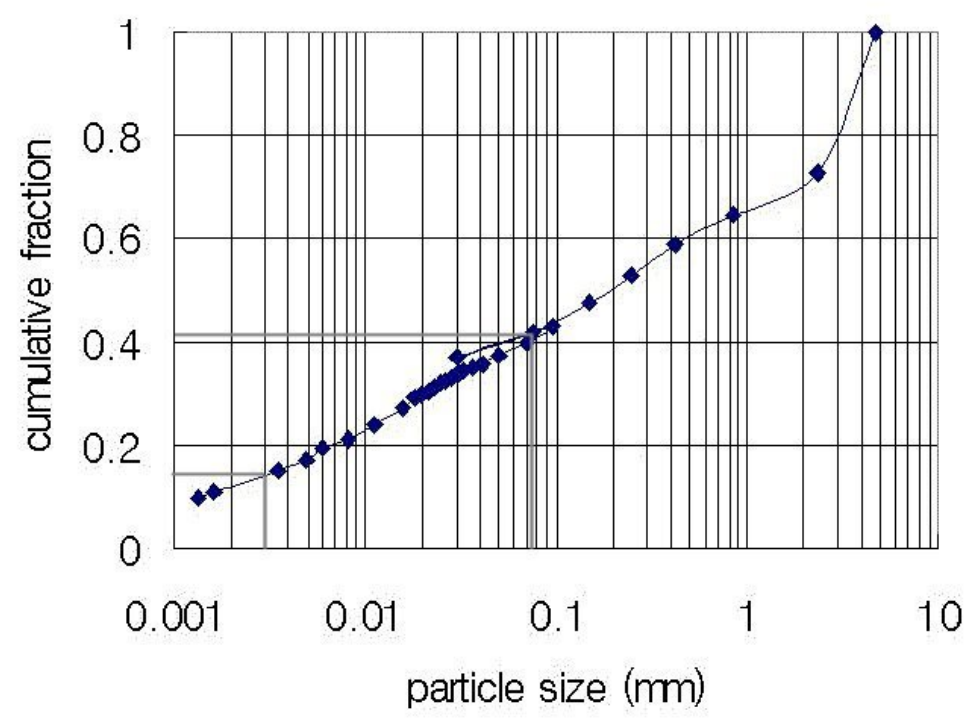

Figure 3-1 Grain size distribution of the silty soil samples provided by INDOT 
(a) Silty clay GSD ( $\mathrm{C} 1$ )

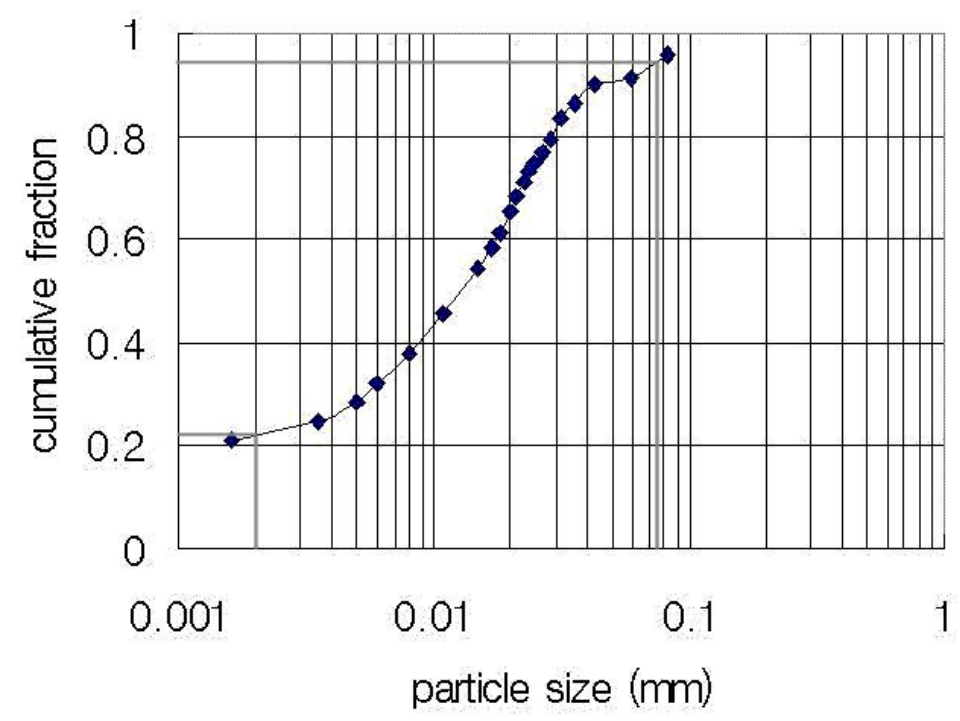

(b) Bloomington clay GSD ( C2 )

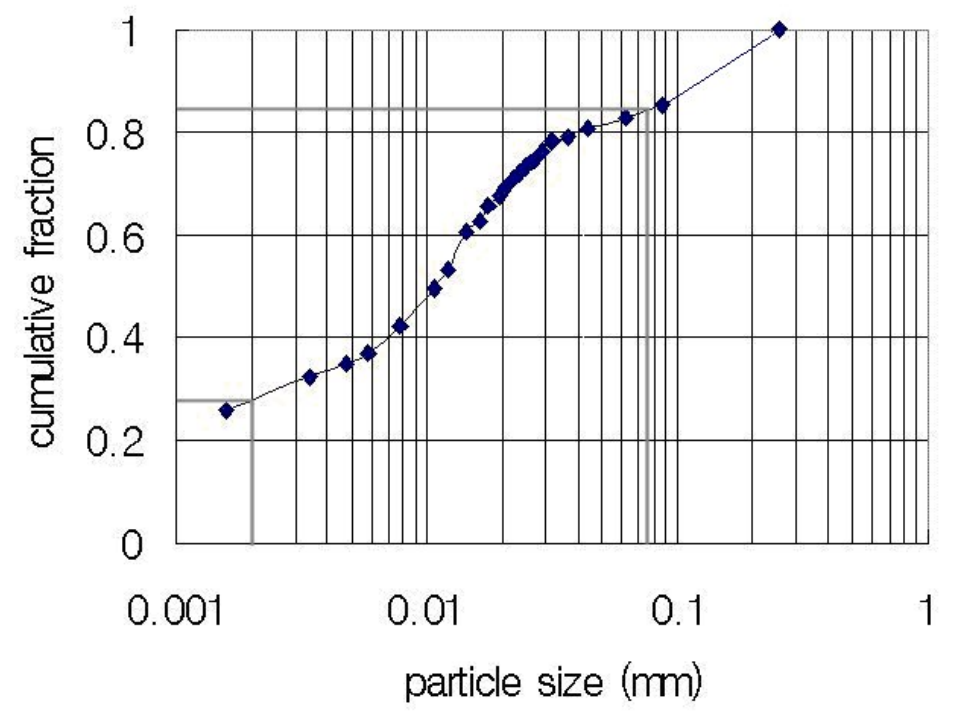

Figure 3-2 Particle size distribution of the clayey soil samples provided by INDOT 
(a) Plasticity Chart (USCS)

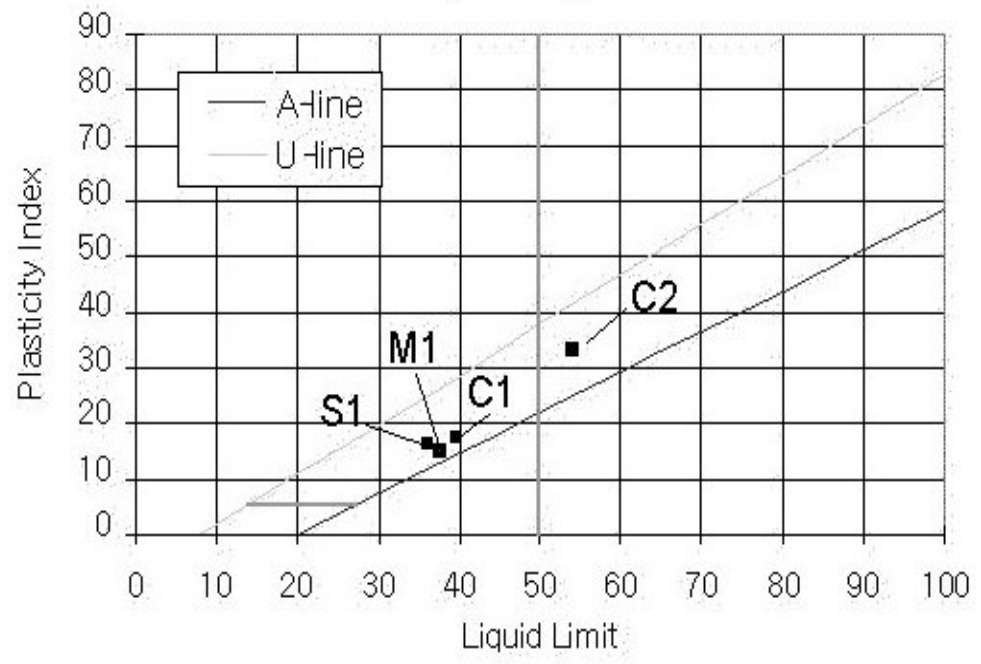

(b) Plasticity Chart

(ASSHTO)

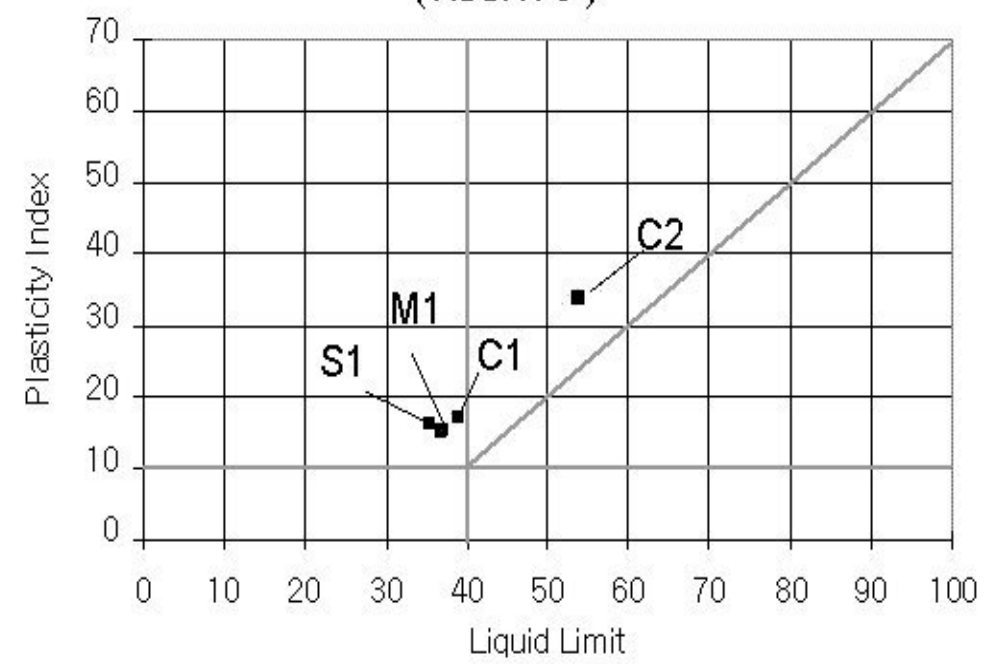

Figure 3-3 Atterberg's limit analysis for soil samples provided by INDOT 


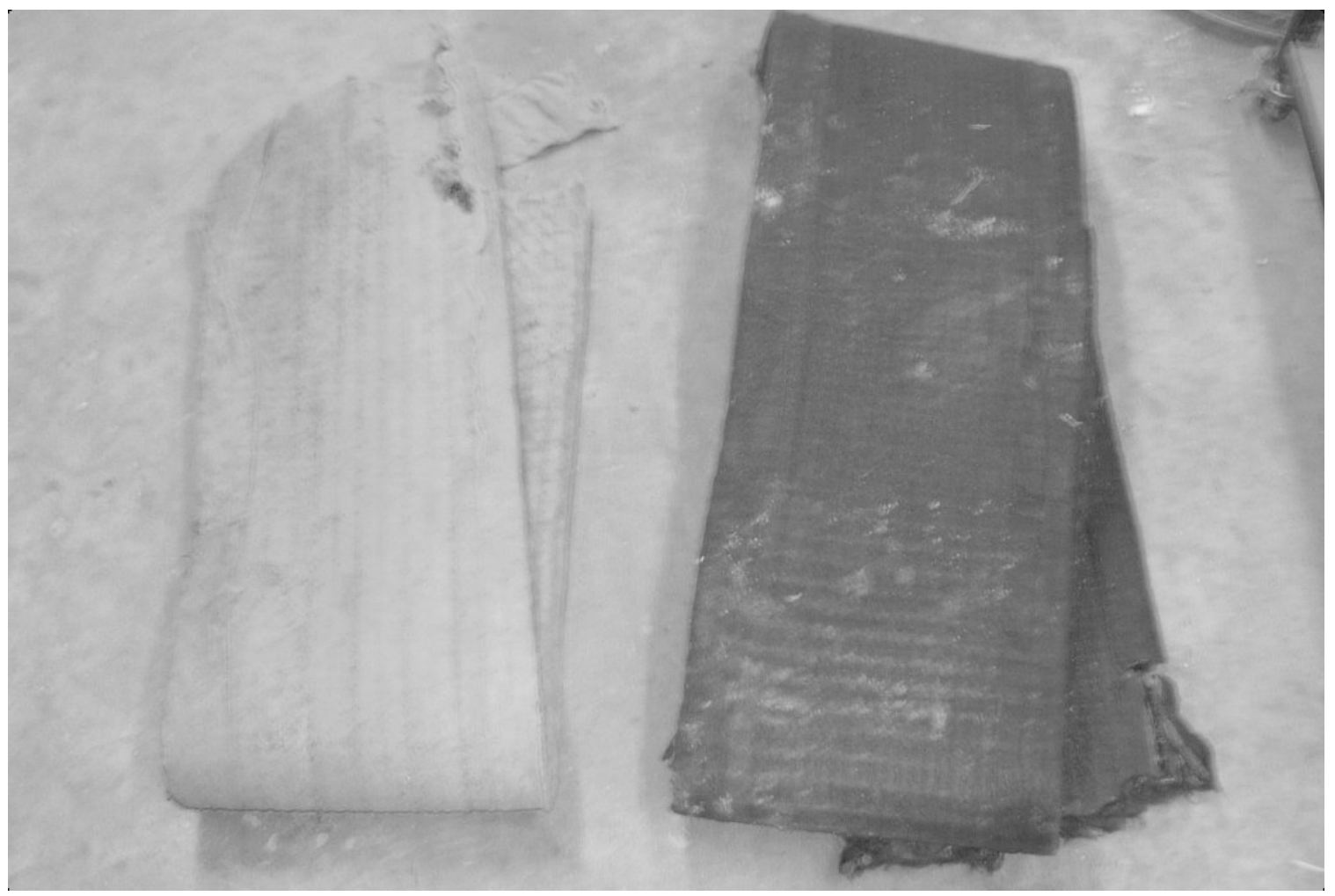

Figure 3-4 Two samples of the same geotextile filter from the Sullivan Co. US 41 site exhumed after 15 years of service: heavily clogged (left-hand side) and almost intact (right-hand side) 


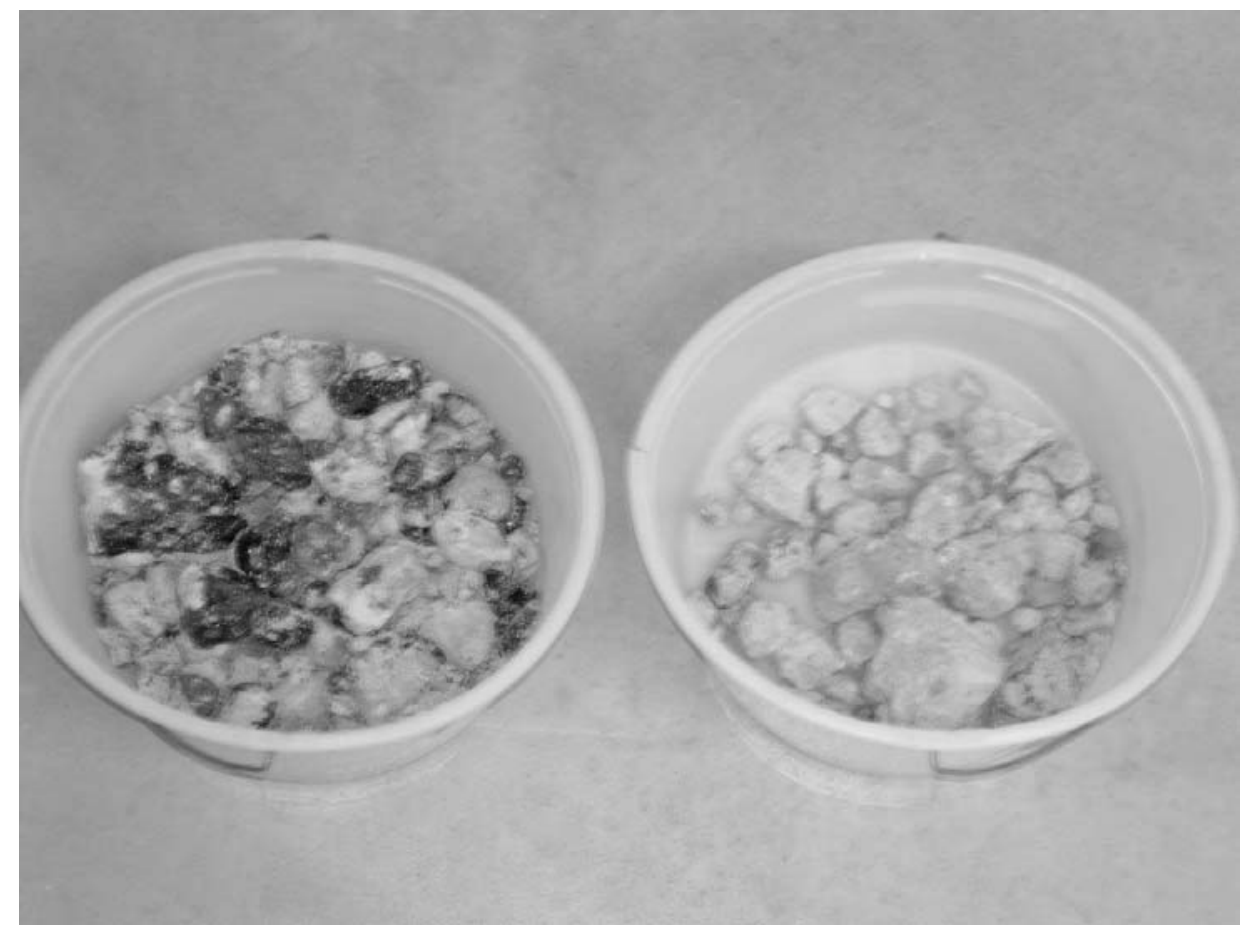

Figure 3-5 Rubbleized concrete aggregates after crushing (LHS : with stabilizer, RHS : after stabilizer is removed) 


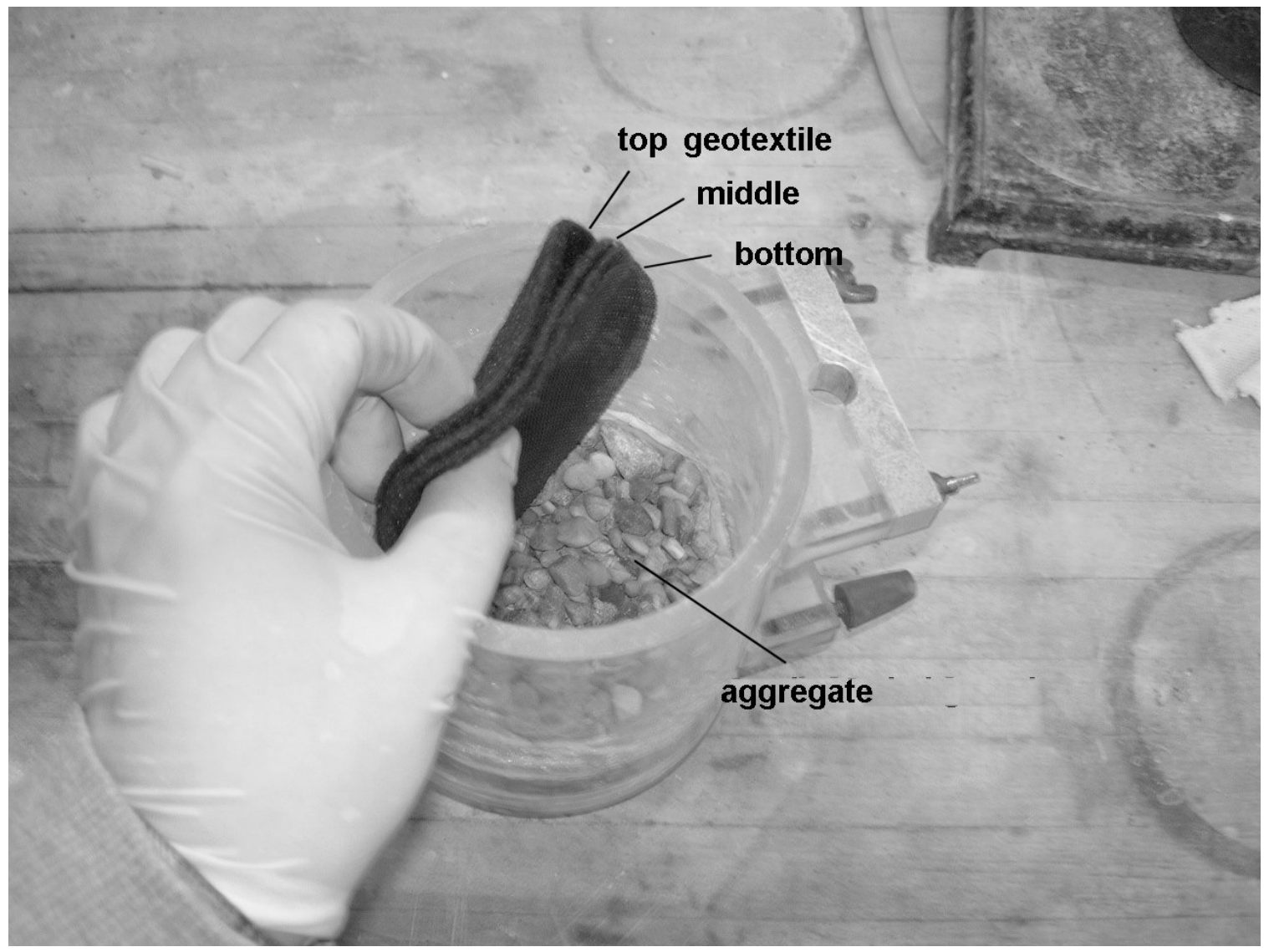

Figure 3-6 Installation of 3-layer non woven geotextile filter prior to testing with rubbleized concrete aggreagate 


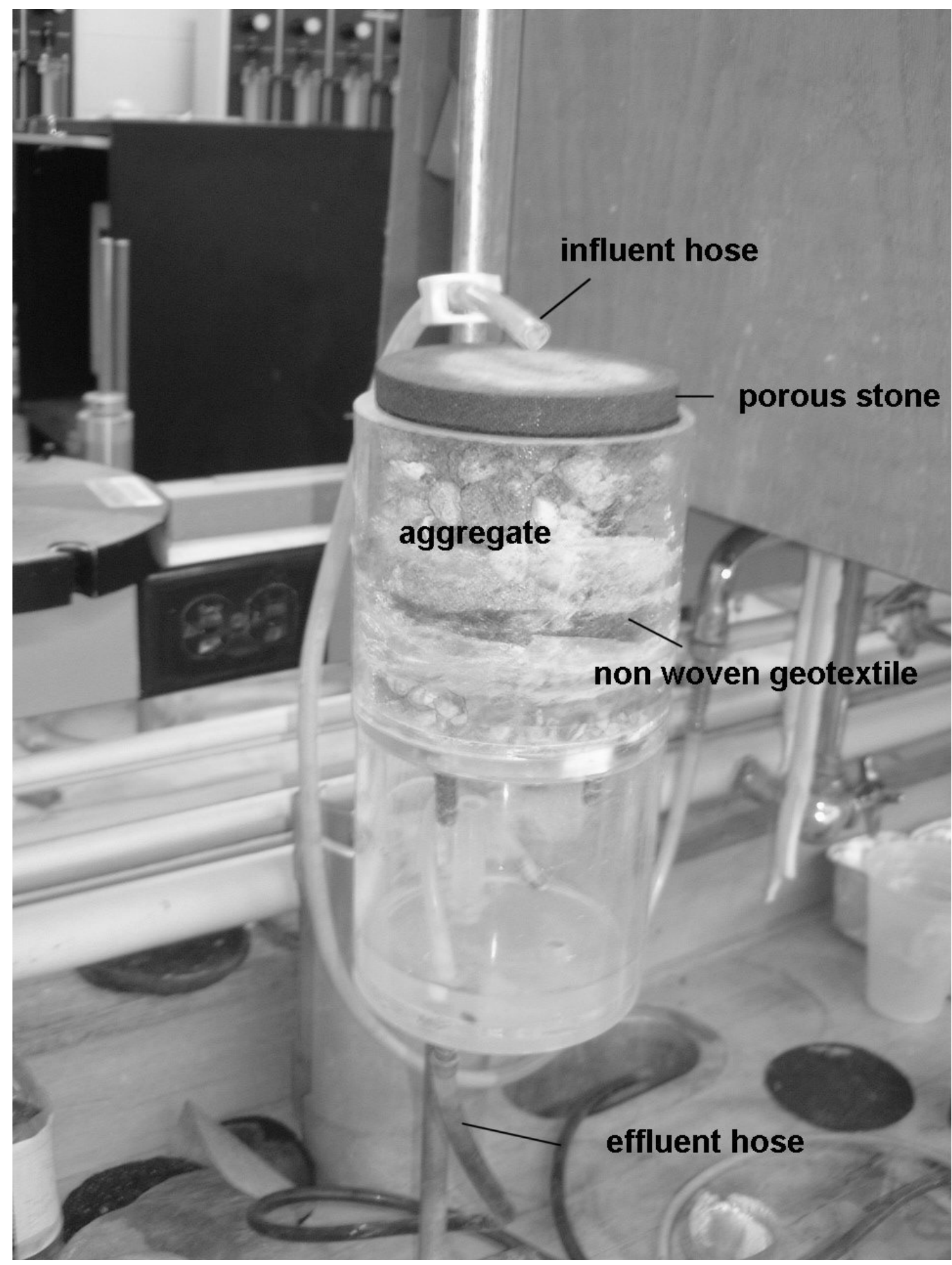

Figure 3-7 Testing device for chemical clogging of geotextile filters with rubbleized concrete aggregate 


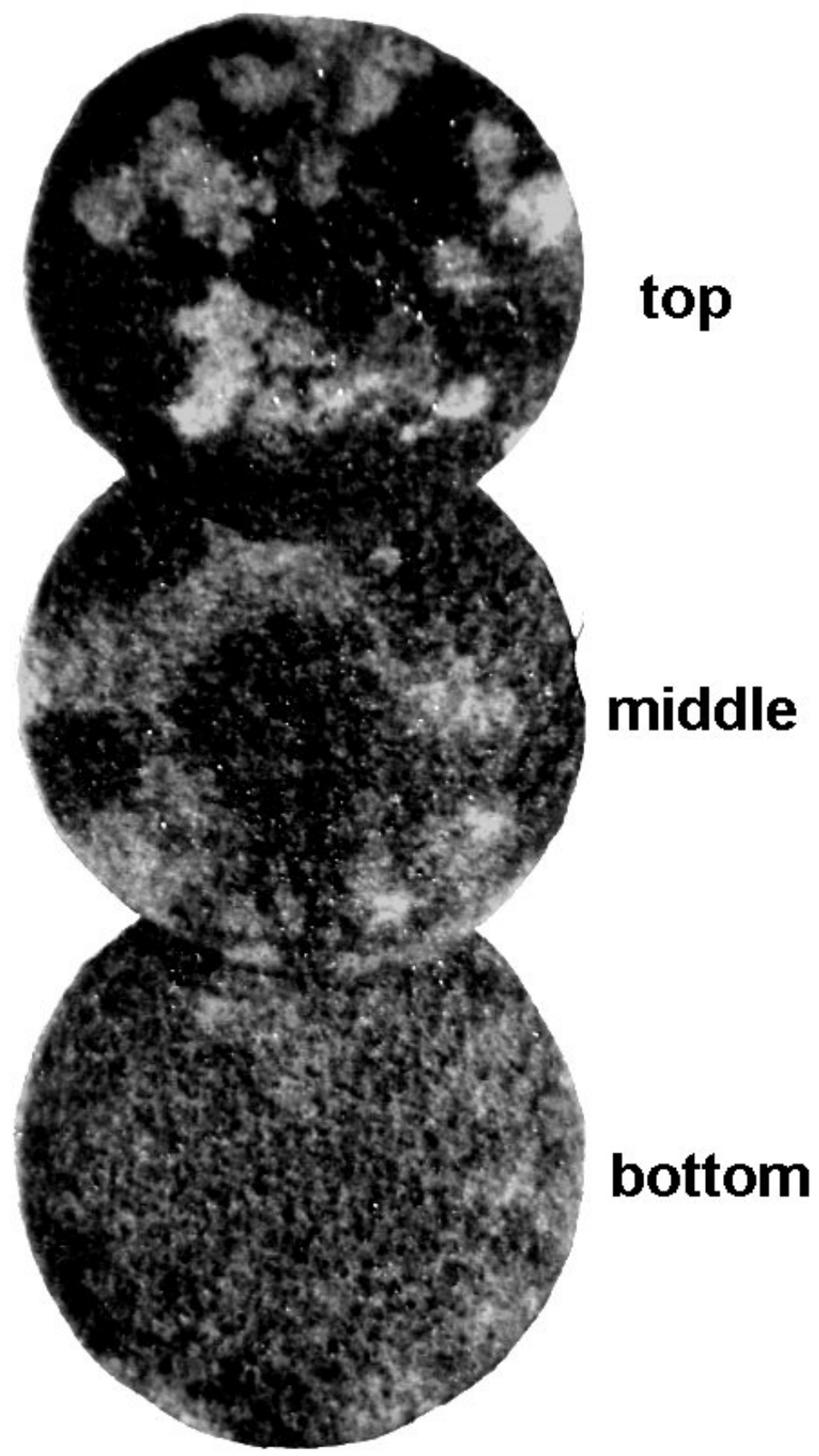

Figure 3-8 Chemical stains or deposits on geotextile filters after 2 weeks of testing with rubbleized concrete aggregates 


\section{Numerical Simulation of Hydraulic Conditions in Pavement}

\subsection{Introduction}

Moisture and flow conditions within pavement structures and their drainage systems are highly variable with time and space. Like in other physical systems exposed to the environment and in contact with atmosphere, the amount of moisture present in the layers of a pavement and its movement are subject to seasonal, daily and even shorter term variations in function of precipitation and weather patterns. Pavement structures are stratified systems made of material layers that are relatively thin (as compared to natural soil deposits in general) and have contrasted hydraulic properties. For instance, in a particular roadway cross-section the hydraulic conductivity of concrete pavement course, aggregate base or subbase layers, and subgrade soil often differ by orders of magnitude. Furthermore, the nature of subgrade soil or the groundwater table elevation is not often uniform along a highway section and these variations, in turn, affect the hydraulic situation in the pavement and drainage system. As a result of such complexity, intuition is often deceptive and simple models misleading as to predicting the distribution of moisture and its flow patterns in pavement and underdrain systems. In Fig. 4-1a is shown a simple model of rainfall water infiltrating through a permeable material overlaying an open drainage layer. If the rainfall is of intensity and duration sufficient to produce saturation of the upper layer and steady-state vertical flow, the gradient becomes uniform and equal to one, which is the typical value suggested by Giroud (1996) for pavement edge drains. But when the flow toward a pipe drain is considered (Fig. 4-1b) the simple one-dimensional flow model is irrelevant because with this geometry, under saturated, 
steady-state flow regime, the velocity must increase with decreasing distance to the pipe and therefore the gradient is neither uniform nor equal to one.

In the present study, one is particularly interested in the magnitude of hydraulic gradients in the vicinity of and across geosynthetic filters. The gradient magnitude is an important parameter in the filtration process because it controls flow velocity and seepage forces that cause fine solid particles to migrate. When planning for the performance of filtration tests in the laboratory, which will be presented in the subsequent chapters of this report, it is desirable that the gradient applied in the test be at least as strong (or even stronger) than the operating field gradient, so that conclusions drawn from test results be on the safe side for engineering purpose. Thus a quantitative assessment, or at least a reasonable approximation, of flow patterns and resulting gradient distributions are required. The practical mean of obtaining this information is through numerical modeling and simulation of hydraulic events in a pavement system. The software, PURDRAIN, originally developed as part of a JTRP Research Study (Espinoza et al., 1993) was utilized for performing this task. Using PURDRAIN it is possible to model the twodimensional geometry of a pavement cross-section and its materials hydraulic properties. Rainfall events can be simulated and resulting subsurface moisture and flow patterns in the system analyzed. The program takes into account changes in degree of saturation, as a function of time, and corresponding changes in hydraulic conductivity. The numerical solution technique used in PURDRAIN is the finite difference method. It is computerintensive but provides reasonably accurate solutions for the governing system of non- 
linear differential equations. Details on the related theory, material constitutive models and solution algorithms can be found elsewhere (Espinoza et al., 1993, Espinoza, 1993).

\subsection{Analysis of Subsurface Flow Patterns Using PURDRAIN}

A two-dimensional example case was devised, defined by its geometry, cross-section and material hydraulic properties. Then, three hydraulic scenarios were simulated and the resulting subsurface flow analyzed. The example characteristics that were considered are believed to be, in simplified form, representative of a range of possible situations in Indiana highways. Some of the characteristics, such as the boundary conditions or the rainfall intensity, may seem restrictive or extreme, but these were selected for the purpose of maximizing flow toward the edge drain and generating severe gradients across the filter.

\subsubsection{Geometry}

A cross-section drawing, obtained from INDOT, of pavement-shoulder joint and edge drain area configuration is shown in Fig. 4-2. The cross-section used for numerical simulations (Fig. 4-3) is a simplified version of this original.

\subsubsection{Boundary conditions}

Also indicated in Fig. 4-3 are impervious boundary conditions at the bottom and sides of the model. In fact, the lateral conditions are not physically true impervious boundaries but are assumed to be symmetry axis and, because of symmetry, behave hydraulically as if they were impervious. At the surface, the concrete pavement layer is assumed impervious while the shoulder is assumed open to infiltration from rainfall. In the edge drain, the boundary condition for the perforated of slotted pipe is that of a "sink" (Espinoza et al. 1993). 


\subsubsection{Material hydraulic properties}

When they are partially saturated porous materials exhibit complex behavior with respect to their interactions with pore water. Of particular interest for the present analysis are the relationship between matric suction (i.e. the capillary pressure head) and degree of saturation, and the relationship between hydraulic conductivity and degree of saturation. When the degree of saturation increases the matric suction decreases while the hydraulic conductivity increases. These two relationships control the material constitutive response to boundary-induced moisture movement. A number of constitutive models have been proposed to mathematically represent this behavior and several of these are available to PURDRAIN users. Detailed discussions on the relative merits of these constitutive models can be found elsewhere (e.g. El-Kadi, 1985, Espinoza, 1993a). In the present study, the Brooks and Corey (1964) model was selected for its accuracy and still relative simplicity. Analytical expressions of the suction-vs-saturation and the permeability-vssaturation functions in the Brooks and Corey model are given in Eq. 4-1 and 4-2, respectively, and example plots are shown in Fig. 4-4.

$$
\begin{aligned}
& \mathrm{S}_{\mathrm{e}}=\left(\frac{\psi}{\mathrm{PB}}\right)^{-\frac{1}{v}} \text { for } \psi \geq \mathrm{PB} \\
& \mathrm{S}_{\mathrm{e}}=1 \quad \text { for } \psi<\mathrm{PB} \\
& \mathrm{K}=\mathrm{K}_{\mathrm{S}} \cdot \mathrm{S}_{\mathrm{e}}^{\eta}
\end{aligned}
$$

In this formulation, $\mathrm{S}_{\mathrm{e}}$ is the effective degree of saturation, $\Psi$, the matric suction, $\mathrm{PB}$, the bubbling pressure and, $v$, the pore size distribution index parameter. $\mathrm{K}$ is the hydraulic conductivity at partial saturation, $K_{s}$ the hydraulic conductivity at full saturation and $\eta$ the 
hydraulic conductivity factor. The effective degree of saturation is related to the volumetric moisture content, $\theta$, or to the degree of saturation, $\mathrm{S}$, as

$\mathrm{S}_{\mathrm{e}}=\left(\theta-\theta_{\mathrm{r}}\right) /\left(\theta_{\mathrm{s}}-\theta_{\mathrm{r}}\right)=\left(\mathrm{S}-\mathrm{S}_{\mathrm{r}}\right) /\left(1-\mathrm{S}_{\mathrm{r}}\right)$

where $\theta_{\mathrm{s}}$ and $\theta_{\mathrm{r}}$ represent the volumetric moisture content at full saturation (equal to the porosity) and its irreducible value (i.e. the residual moisture under high suction), respectively. The residual degree of saturation, $\mathrm{S}_{\mathrm{r}}$, corresponds to the residual moisture content. The difference between the two limiting values of the moisture content ( $\Delta \theta=\theta_{\mathrm{s}^{-}}$ $\theta_{\mathrm{r}}$ ) is called volumetric water capacity and is equal to the effective porosity. Data for the model parameters used in the analysis are summarized in Table 4-1. These were derived from the experimental study performed by Ahmed (Ahmed et al., 1993) on the hydraulic properties of Indiana pavement materials. Two cases were considered for the subgrade properties, in order to test the influence of its permeability on the flow patterns while the properties of the aggregate layers are kept unchanged. The subgrade hydraulic conductivity at saturation in Case 2 is one order of magnitude lower than in Case 1. Still, in both cases the characteristics are compatible with sandy silt or silt subgrades that make filtration such an important issue.

Table 4-1 Input parameters for the Brooks \& Corey partially saturated materials model

\begin{tabular}{cccc}
\hline & Aggregate layers & Subgrade Case 1 & Subgrade Case 2 \\
\hline Saturated permeability (cm/sec) & $3.00 \mathrm{E}-2$ & $6.00 \mathrm{E}-3$ & $6.00 \mathrm{E}-4$ \\
(ft/min) & $(5.9 \mathrm{E}-2)$ & $(1.2 \mathrm{E}-2)$ & $(1.2 \mathrm{E}-3)$ \\
Irreducible moisture content & 0.005 & 0.01 & 0.05 \\
Volumetric water capacity & 0.4 & 0.38 & 0.38 \\
Maximal matric suction* $(\mathrm{cm})$ & 15000 & 15000 & 15000 \\
(ft) & $(492)$ & $(492)$ & $(492)$ \\
Bubbling pressure (cm) & 12 & 20 & 30 \\
(in) & $(4.7)$ & $(7.9)$ & $(11.8)$ \\
Pore size index parameter & 2.5 & 2.8 & 3.2 \\
Hydraulic conductivity parameter & 6.5 & 7.5 & 9 \\
\hline
\end{tabular}

* A maximal value is assigned to the matric suction for computational purpose only 


\subsubsection{Simulated scenarios}

Three events, each almost 3 hours long, were simulated. These are defined with different initial hydraulic conditions (i.e. initial degrees of saturation) and rainfall history sketched in Fig. 4-5. With Scenario A, computation starts immediately after the end of a rainfall of such intensity and duration that the whole system has been completely saturated. The computation simulates the drainage phase which follows. At the opposite, Scenario B starts with very dry initial conditions at the time a heavy rainfall occurs. The consecutive infiltration and wetting phase is then simulated. Scenario $C$ is an intermediate case in terms of initial conditions, with high water table in the subgrade and relatively dry aggregate layers. Then, a heavy rainfall occurs and the infiltration and subsequent flow are simulated. In simulation $\mathrm{B}$ and $\mathrm{C}$, the modeled rainfall characteristics were based on statistical records available from the Indiana Department of Natural Resource in reference a centennial event of intensity, $72 \mathrm{~mm} / \mathrm{hr}(3 \mathrm{in} / \mathrm{hr})$. This intensity was kept constant throughout the whole simulated event duration.

\subsection{Simulation results}

Accounting for three hydraulic scenarios (A, B and C), each combined with two hypotheses of subgrade permeability (Cases 1 and 2 in Table 4-1), a total of six simulations were performed using PURDRAIN. For each of the six simulation cases, A1, A2, B1, B2, C1 and C2, outputs were obtained at programmed computation time steps. A selection of the most interesting results is presented in Figures 4-6 to 4-10 where equal value contours of total hydraulic head (i.e. the equipotentials) and saturation degree are

plotted. In each case plots for only the two stages, most representative of gradients 
observed in the vicinity of the edge drain, are shown herein. Plots labeled (a) show the distribution of total hydraulic head and allow determination of both flow direction and gradient magnitude. At each point in the figure the flow trajectory is normal to the equipotential line and goes from high to low hydraulic head location. Plots labeled (b) allow visualizing the spatial redistribution of moisture from the initial state and the progression of drying or wetting fronts.

With Scenario A (Figures 4-6 \& 4-7), drainage from the initially fully saturated state is evidenced by flow patterns converging toward the drain and the downward progression of a wetting front from the shoulder surface to the subbase-subgrade interface. The drainage action is more concentrated in the case of a lesser permeable subgrade A2 (Fig. 4-7) than in case A1 (Fig. 4-6), but in both cases the largest gradients take place at the early stage of the process. At time, 10 minutes, the largest gradient occurs at the left side boundary of the drainage trench, crossing the filter obliquely. The maximal gradient magnitude is approximately 0.5 in case A1, but reaches 2.5 in case A2. Thus, for this scenario, larger contrast in permeability between subbase and subgrade results in stronger gradient across the filter.

With Scenario B (Figures 4-8 \& 4-9), rainfall water infiltrates into an initially very dry system and a wetting front moves rapidly downwards from the shoulder surface. Comparison of cases B1 and B2 shows significant differences in moisture movement and gradients. In case B1 (Fig. 4-8) where the ratio between saturated hydraulic conductivities of aggregate layers to subgrade is only 5, moisture is able to reach the 
subgrade below the shoulder infiltration and then migrates laterally toward the drain trench. zone. Maximal gradients cross the filter with magnitude, up to 4, after 40 minutes, then decrease to approximately 1 after 160 minutes. In contrast, when the subgrade is 50 times less permeable than the aggregate layers (case B2), moisture must first re-saturate the aggregate base/subbase layers in order to buildup enough energy for infiltrating the subgrade. This translates (Fig. 4-9) in moisture distributions and flow patterns quasisymmetrical with respect to the drainage trench and in gradients that are oriented almost vertically downwards. With the assumed design configuration, in this case (B2) water would enter the drainage trench directly from above, without crossing the filter lining only the sides and bottom of the trench. Maximal values for these vertical gradients are in the range, 1 (at 40 minutes) to 1.5 (at 160 minutes).

With Scenario C (Figures 4-9 \& 4-11) rainfall infiltrates in a system where the subgrade is already saturated. The process of moisture migration is, qualitatively, similar to scenario B2 but limited to the region located above the phreatic level in the subgrade. Maximal gradients enter the drainage trench vertically through its top boundary. In this case their magnitude, practically independent of the subgrade permeability, varies from approximately 1 at time, 10 minutes, to 2 at time, 40 minutes.

\subsection{Summary}

The series of numerical simulations performed using PURDRAIN for a range of hydraulic scenarios indicate maximal gradients can reach values up to 4 across the geotextile filter region during a heavy rainfall event following a period of drought. Other scenarios result in maximal gradients slightly lesser but generally greater than 1 (Table 4- 
2). However, it should be noted that the peak gradient condition occurs in a state of partially saturated soil where the mobility of individual fine particles is restrained by surface tensions making the soil apparently cohesive. This somewhat mitigates the severe gradient condition with respect to the filter performance. On the other hand, the numerical simulations performed using PURDRAIN do not account for dynamic gradient pulsing and consecutive fine pumping that could be generated by traffic load in fully saturated conditions such as scenario A. Thus, when using these results as guidance for selecting the range of gradients to be applied in laboratory tests, significant margins of safety should be applied. Another interesting information provided by the numerical simulations is related to flow trajectories toward the edge drain. In general, the maximal gradients are associated to stream lines entering the drainage trench laterally and crossing the filter. But in case of rainfall infiltration with low permeability subgrade or in case of fully saturated subgrade the maximal gradient stream lines come directly from the aggregate subbase and would lead to the drain without crossing the filter unless the geotextile was wrapped over the trench.

Table 4-2 Maximal gradient values from numerical simulations

\begin{tabular}{ccc}
\hline & $\begin{array}{c}\text { Subgrade case 1 } \\
\mathrm{Ks}_{\text {aggregate }} / \mathrm{Ks}_{\text {subgrade }}=5\end{array}$ & $\begin{array}{c}\text { Subgrade case 2 } \\
\mathrm{Ks}_{\text {aggregate }} / \mathrm{Ks}_{\text {subgrade }}=50\end{array}$ \\
\hline $\begin{array}{c}\text { Scenario A } \\
\text { (drainage after saturation) }\end{array}$ & 0.5 & 2.5 \\
$\begin{array}{c}\text { Scenario B } \\
\text { (infiltration after dry state) } \\
\begin{array}{c}\text { Scenario C } \\
\text { (infiltration after wet state) }\end{array}\end{array}$ & 4 & 1.5 \\
\hline
\end{tabular}


(a)

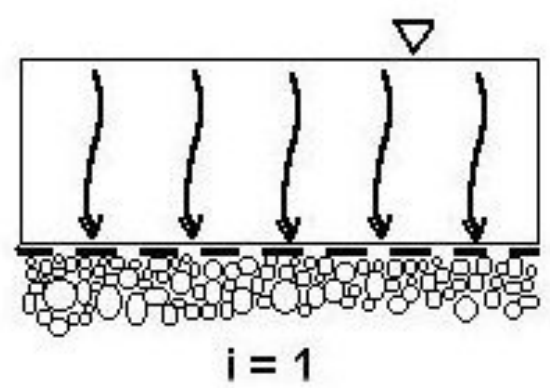

(b)

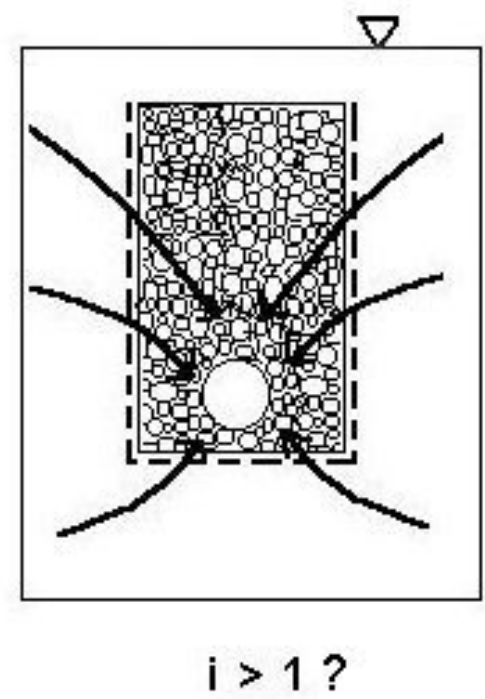

Figure 4-1 Simple flow models in subdrainage: (a) uniform vertical flow toward drainage layer and (b) radial flow toward drainage pipe 


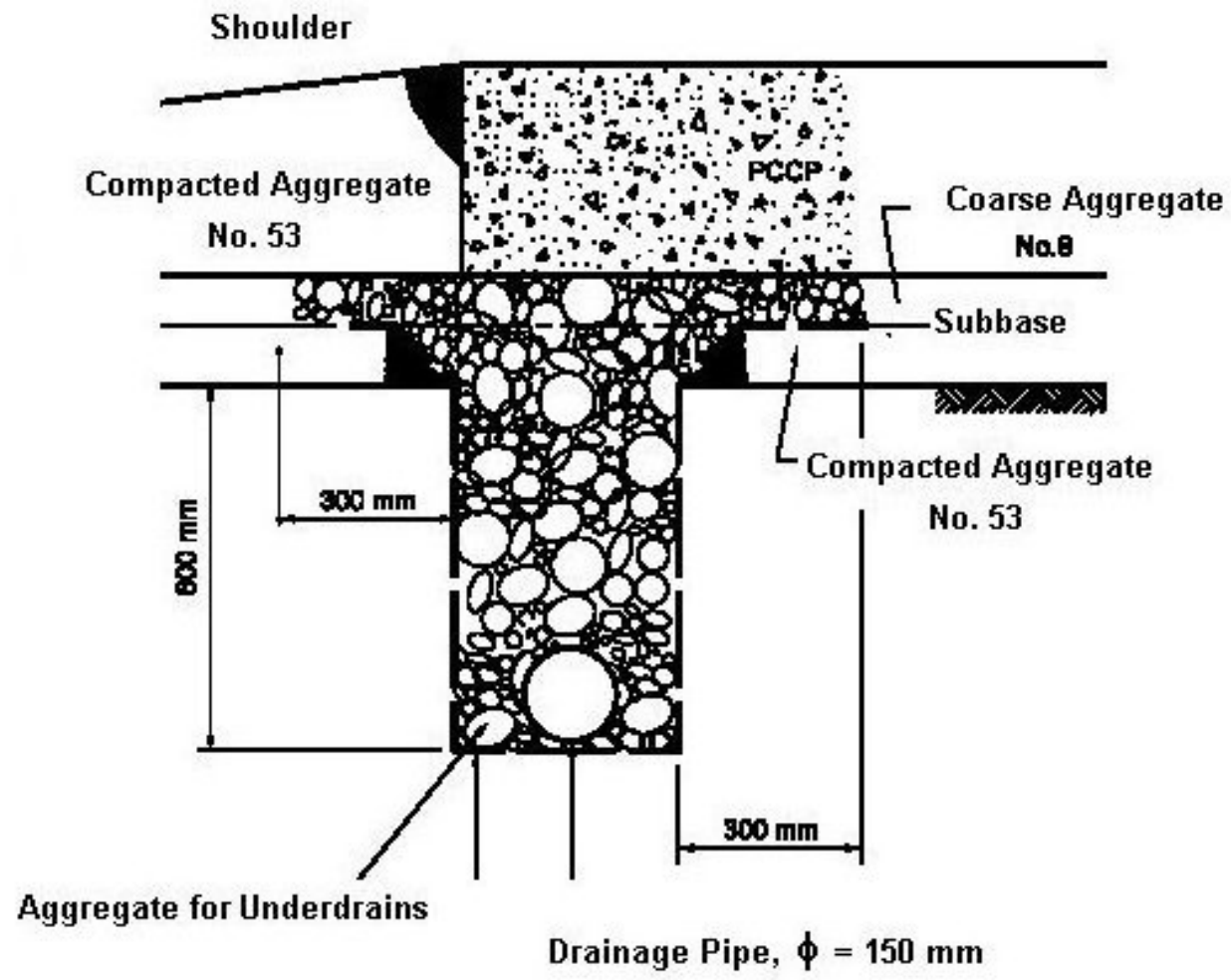

Figure 4-2 Design example cross-section for pavement-shoulder joint area and edge drain in Indiana roadways 


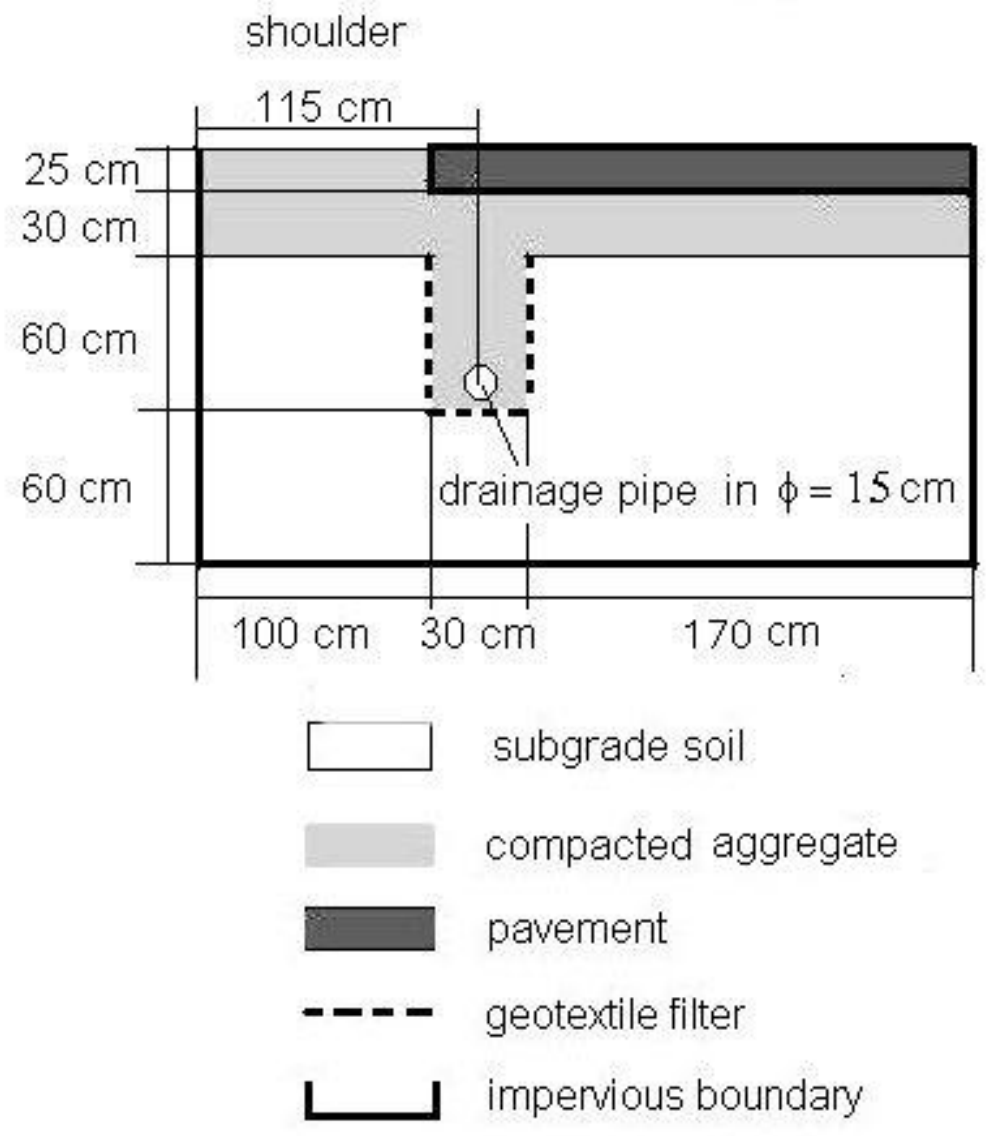

Figure 4-3 Simplified cross-section and boundary conditions used in numerical simulations using PURDRAIN 


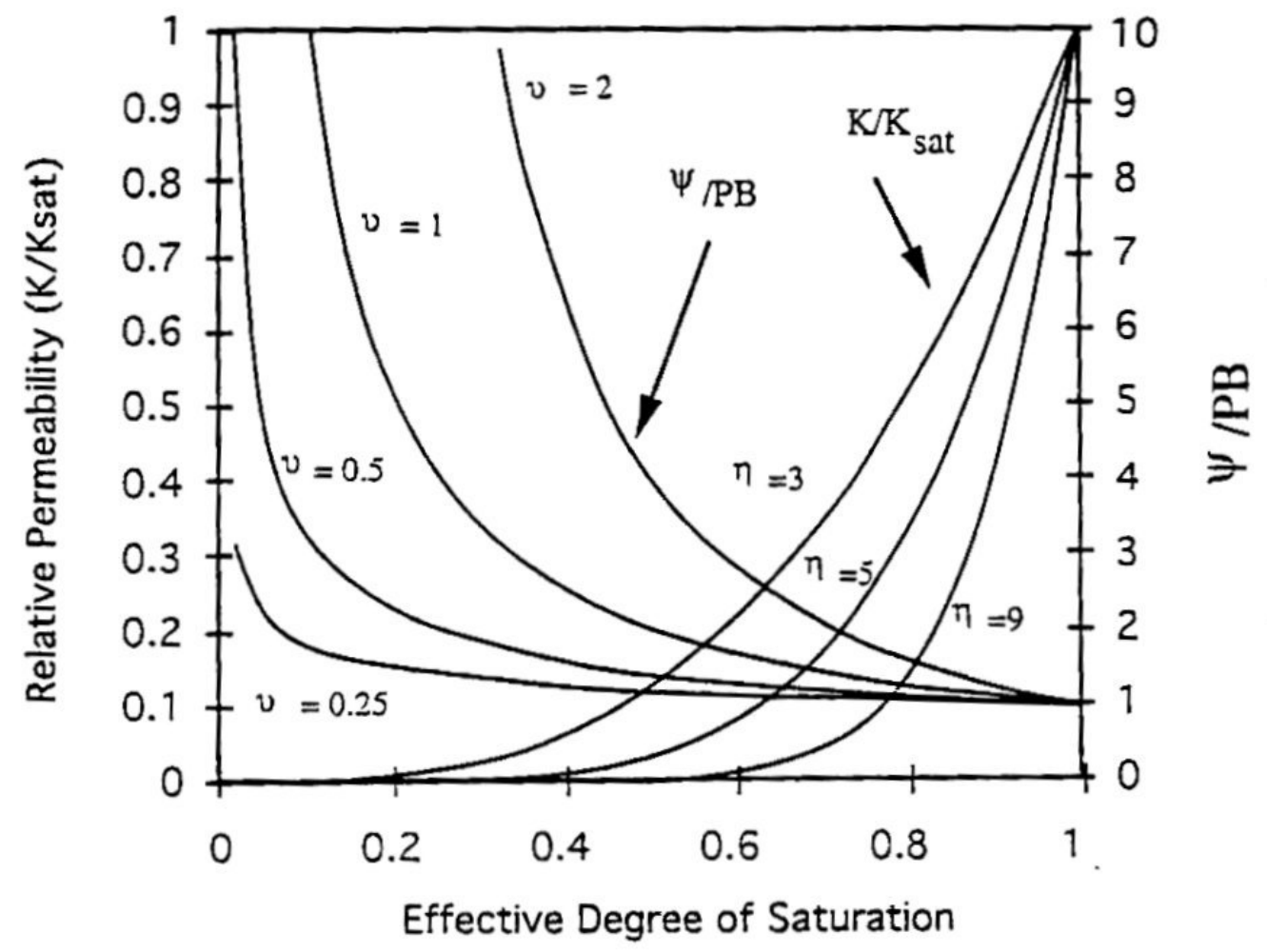

Figure 4-4 Brooks and Corey (1964) model for water retention and hydraulic conductivity functions 


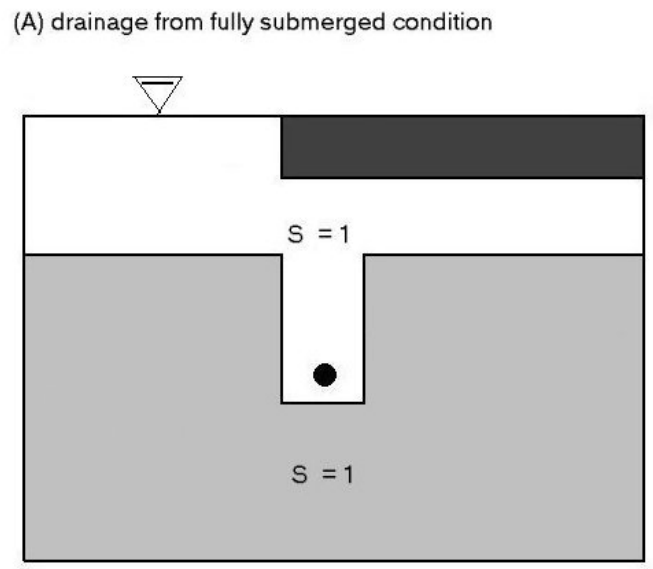

(B) rainfall following dry period

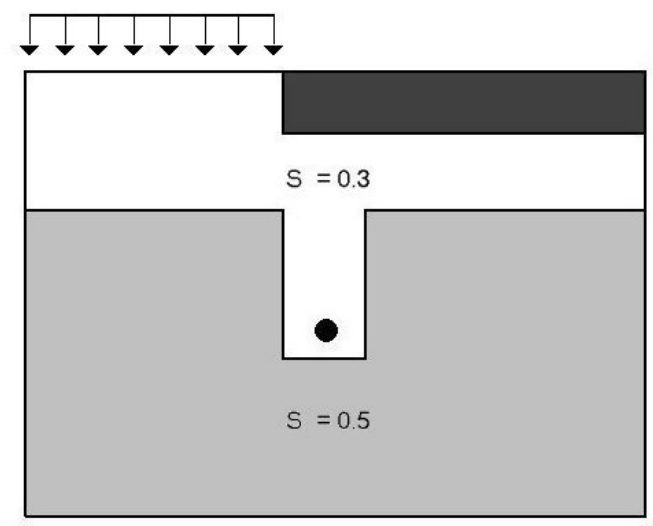

(C) rainfall following wet period

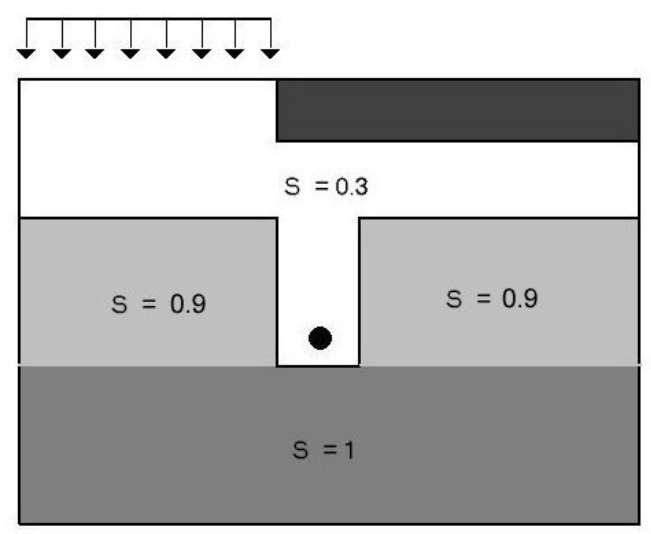

Figure 4-5 Simulated initial conditions and rainfall scenarios: (A) Drainage from fully submerged condition, (B) Rainfall infiltration following very dry period and (C) Rainfall infiltration following wet period with high water table in subgrade 
( a )

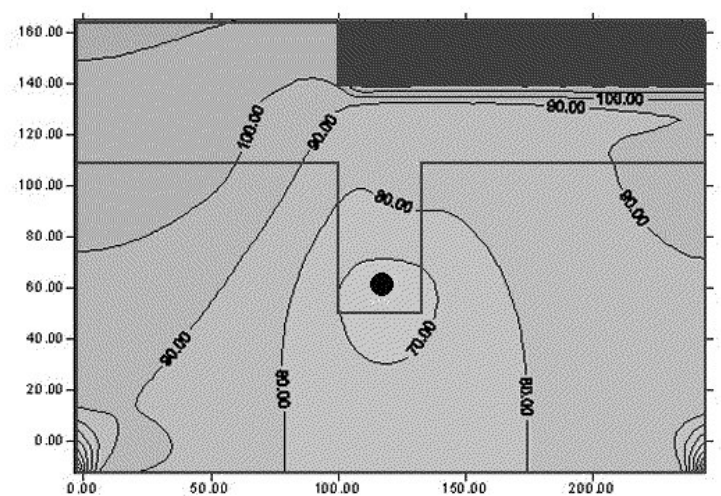

(b)

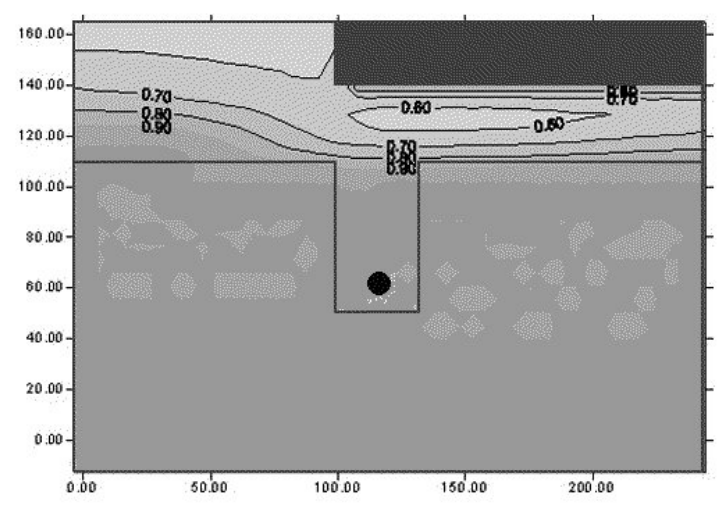

(1) after 10 minutes (a)

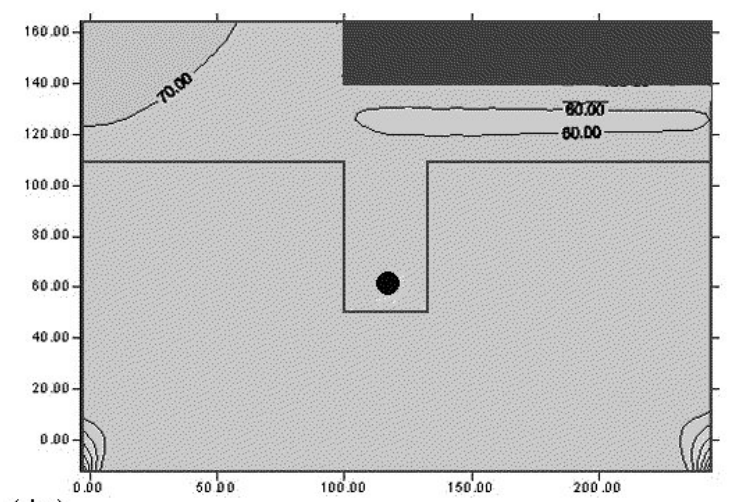

(b)

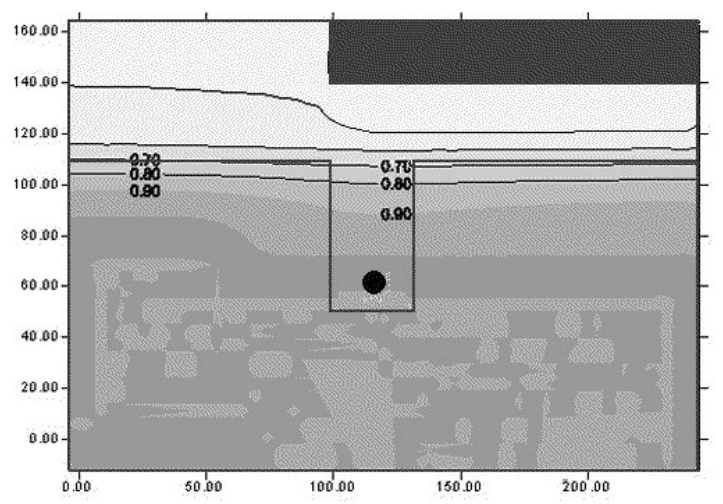

(II) after 160 minutes

Figure 4-6 Simulation results for Scenario A1: drainage from fully submerged condition with low permeability contrast between subgrade and aggregate layers

(a) hydraulic head distribution in $\mathrm{cm}$ (the elevation datum plane is at bottom boundary);

(b) saturation degree distribution 
( a )

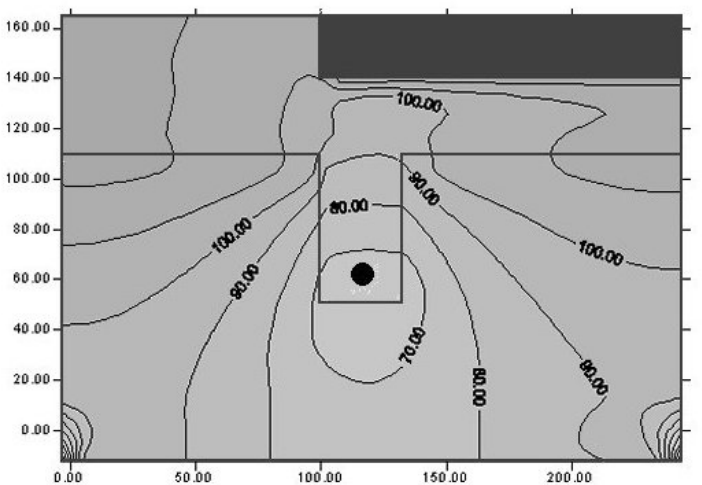

(b)

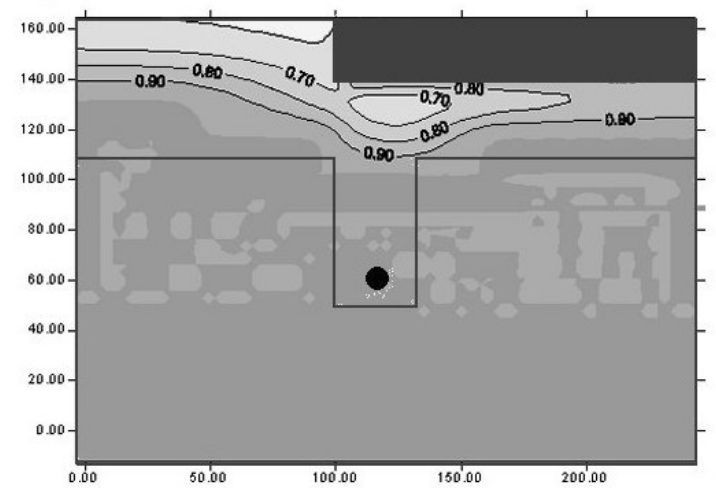

(1) after 10 minutes

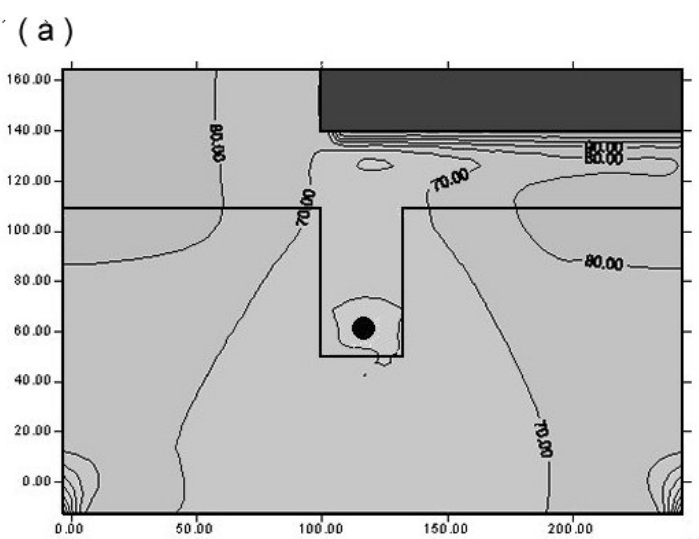

(b)

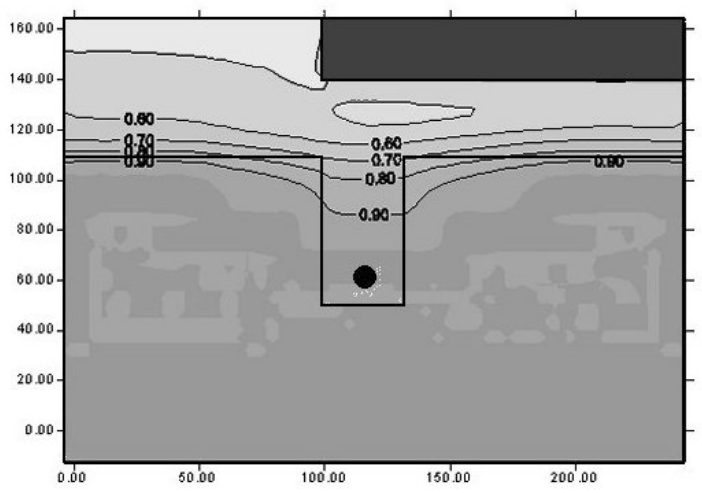

(II) after 160 minutes

Figure 4-7 Simulation results for Scenario A2: drainage from fully submerged condition with high permeability contrast between subgrade and aggregate layers

(a) hydraulic head distribution in $\mathrm{cm}$ (the elevation datum plane is at bottom boundary);

(b) saturation degree distribution 
( a )

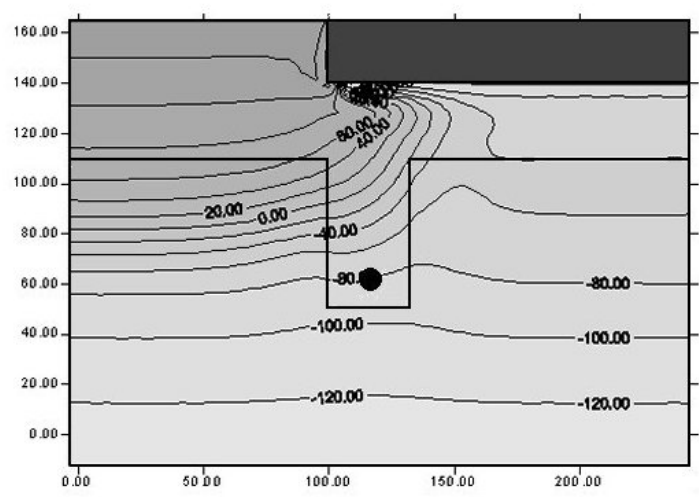

(b)

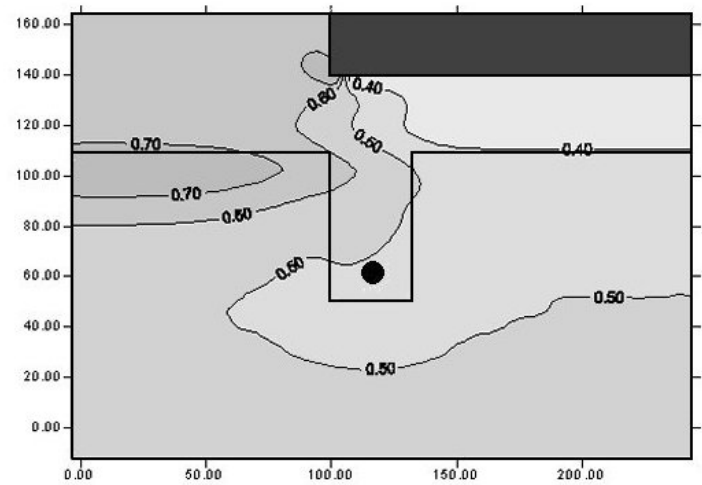

( I ) after 40 minutes
( a )

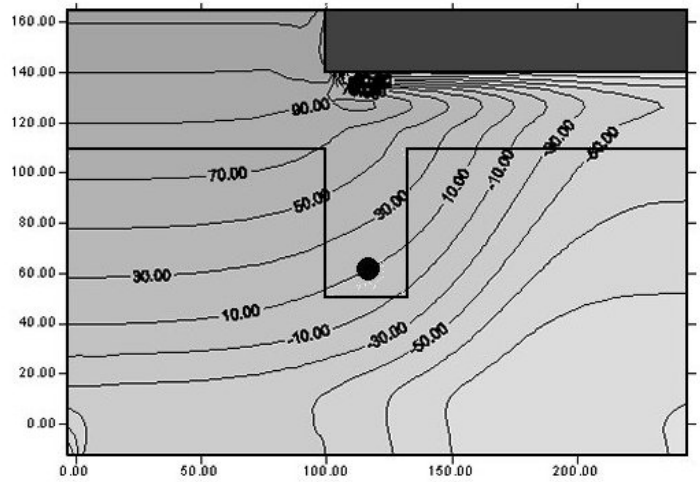

(b)

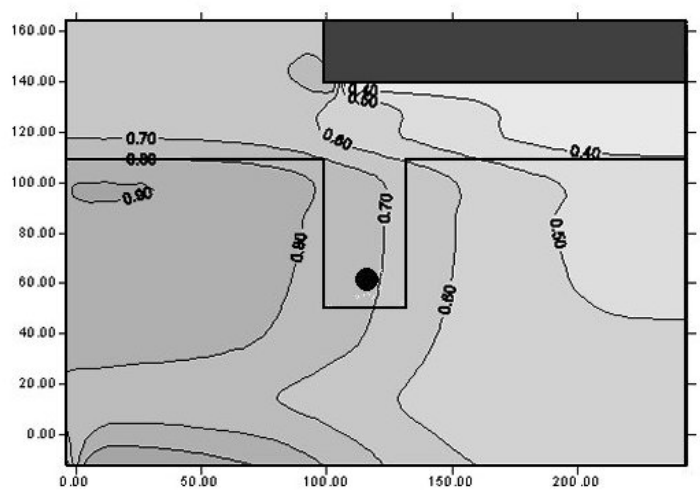

( II ) after 160 minutes

Figure 4-8 Simulation results for Scenario B1: rainfall infiltration following very dry period with low permeability contrast between subgrade and aggregate layers (a) hydraulic head distribution in $\mathrm{cm}$ (the elevation datum plane is at bottom boundary); (b) saturation degree distribution 
( a )

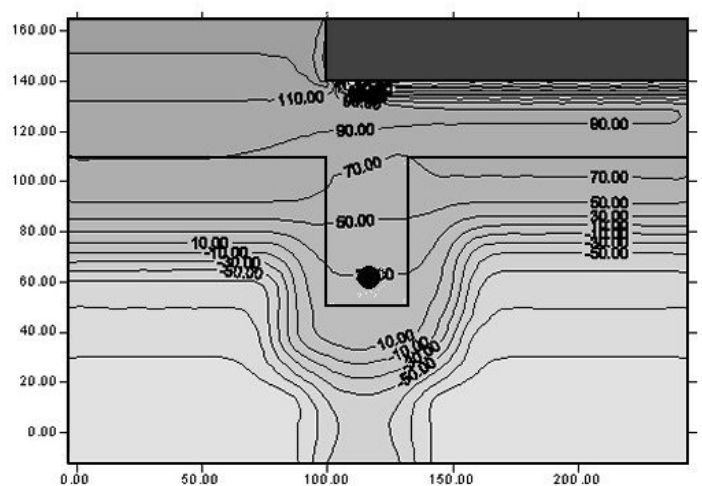

(b)

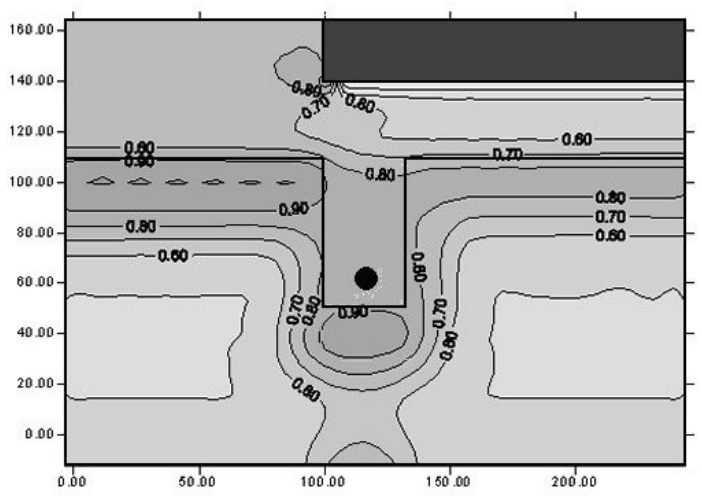

( 1 ) after 40 minutes
( a )

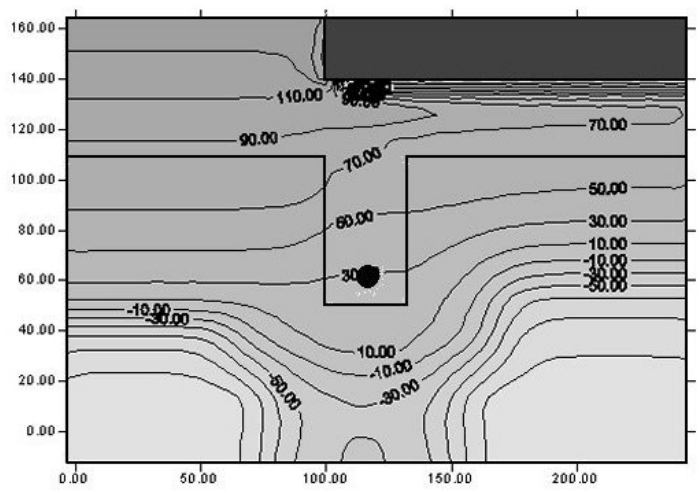

(b)

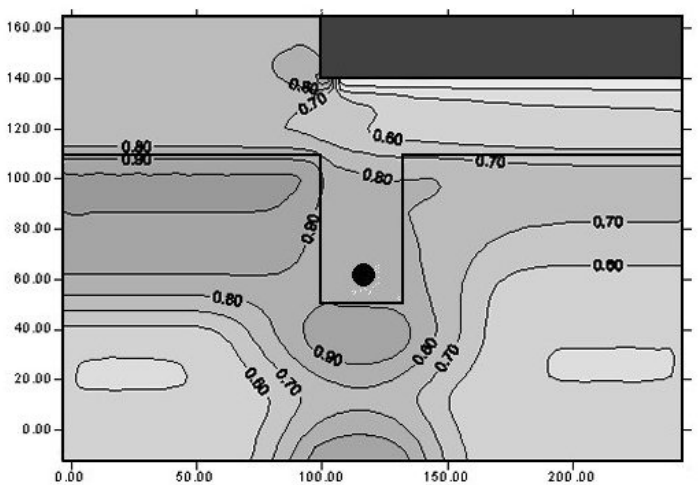

( II ) after 160 minutes

Figure 4-9 Simulation results for Scenario B2: rainfall infiltration following very dry period with high permeability contrast between subgrade and aggregate layers (a) hydraulic head distribution in $\mathrm{cm}$ (the elevation datum plane is at bottom boundary);

(b) saturation degree distribution 
( a )

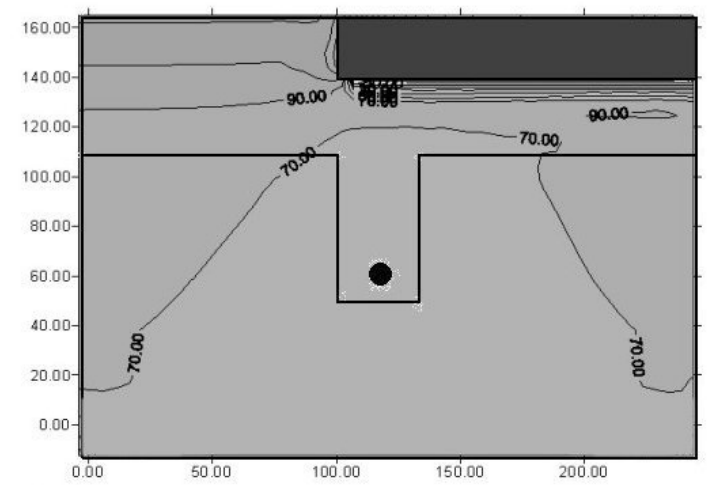

(b)

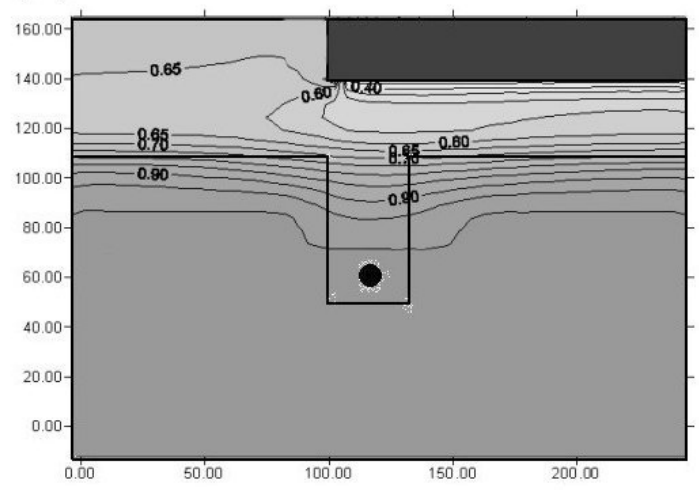

( 1 ) after 10 minutes
( a )

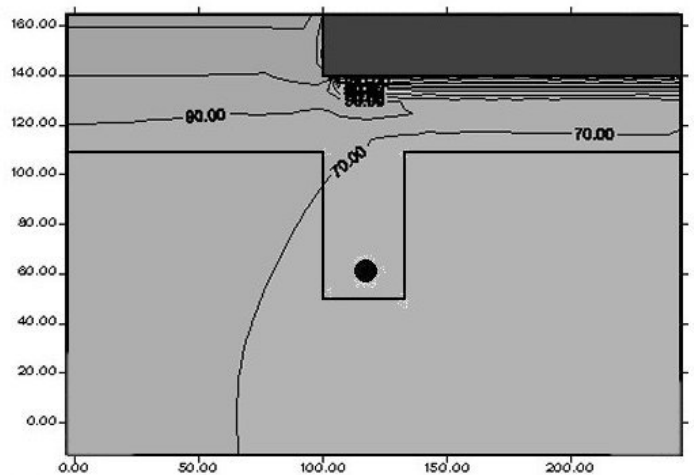

(b)

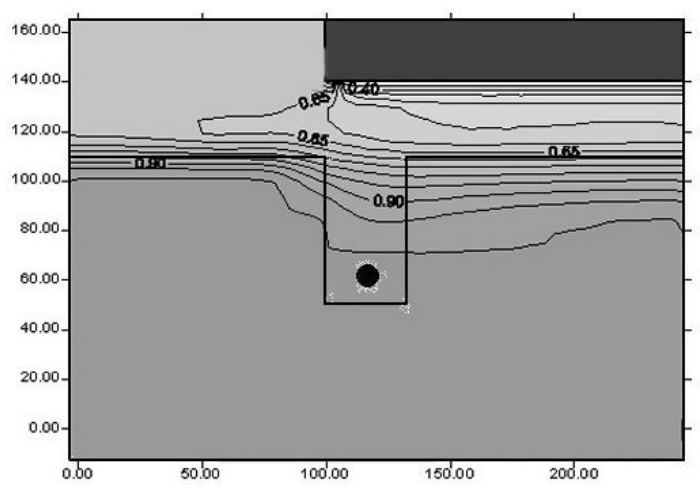

( II ) after 40 minutes

Figure 4-10 Simulation results for Scenario C1: rainfall infiltration following wet period with low permeability contrast between subgrade and aggregate layers

(a) hydraulic head distribution in $\mathrm{cm}$ (the elevation datum plane is at bottom boundary);

(b) saturation degree distribution 
( a )

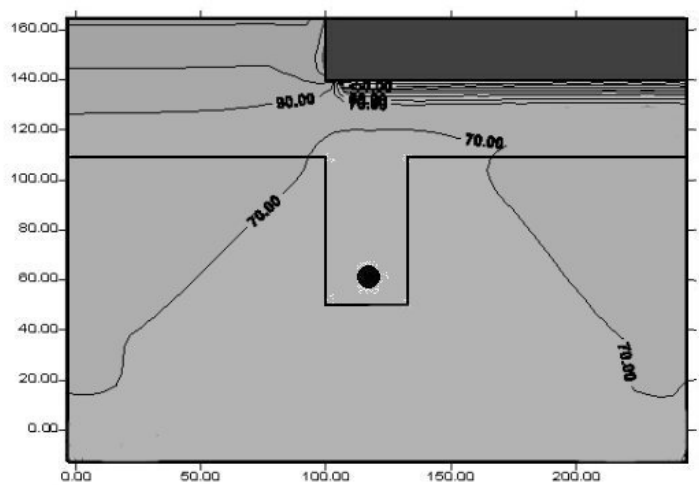

(b)

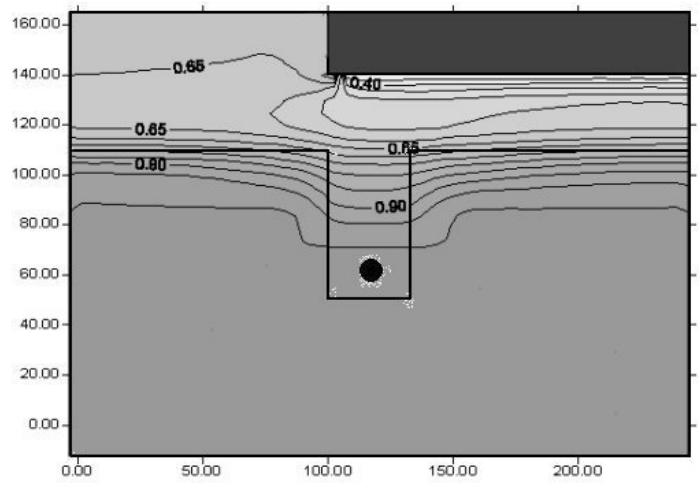

( I) after 10 minutes
( a )

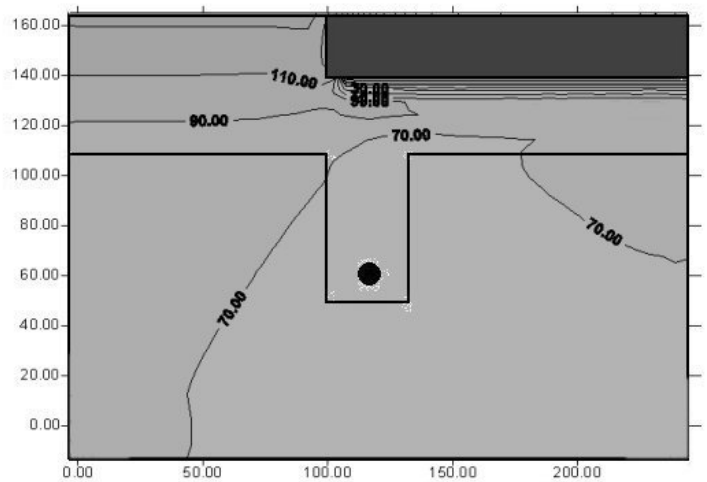

(b)

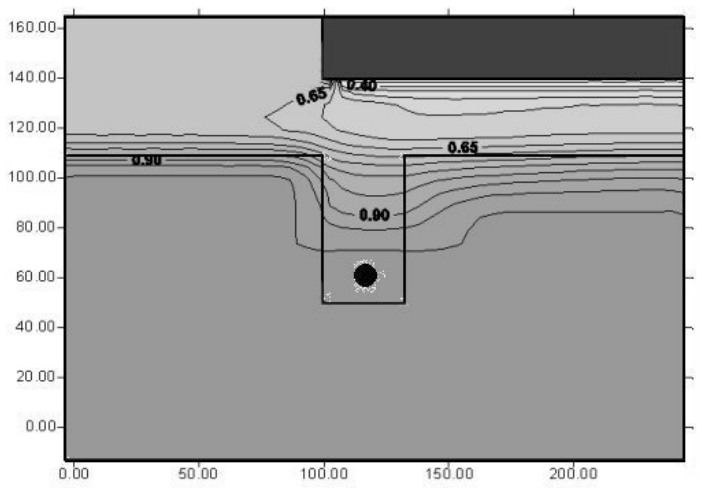

( II ) after 40 minutes

Figure 4-11 Simulation results for Scenario C2: rainfall infiltration following wet period with high permeability contrast between subgrade and aggregate layers

(a) hydraulic head distribution in $\mathrm{cm}$ (the elevation datum plane is at bottom boundary);

(b) saturation degree distribution 


\section{Laboratory Investigation of Geotextile Filtration by Flexible Gradient Ratio Test - Effect of Soil Property}

\subsection{Introduction}

The objective of this chapter is to present the results of the flexible wall gradient ratio (FWGR) tests performed to investigate the effects of soil properties (fines content and degree of compaction) on the internal stability of a soil medium. Section 5.2 presents a description of the FWGR test. Then, the material properties of soil and geotextile and test hydraulic conditions are described in Section 5.3. Test results are presented and discussed in Sections 5.4 and 5.5. Section 5.6 summarizes the key findings presented in the chapter

\subsection{Description of FWGR Test}

The flexible wall gradient ratio (FWGR) test was proposed by Harney and Holtz (2001) in order to combine the advantages of the gradient ratio test (GR [ASTM D5101]) and the hydraulic conductivity ratio test (HCR [ASTM D5567]). The advantages of the GR and HCR tests are described in Section 2.6.

The FWGR test device allows application of an effective overburden stress thus more closely simulating actual field conditions. Fully saturated soil conditions can be achieved with the application of a back-pressure. Side leaking in a conventional GR test is fully prevented by using a flexible membrane and a confining cell pressure. Pore pressure 
changes in the vicinity of the geotextile (GT) filter are monitored so that the fine particle migration at the soil-GT interface can be traced in real time.

The FWGR testing apparatus used in this research is comprised of the following major components: the cell; the pressure panel for application and control of the cell and pore pressures; the sensors for measuring cell and pore pressures as well as axial and volumetric changes; the data acquisition system interfaced with a PC.

The cell, shown in Figure B.2 in appendix, is similar to that employed for triaxial testing. It houses a specimen that is $10.2 \mathrm{~cm}$ in diameter and 15 to $17 \mathrm{~cm}$ in height (Figure 5.1). The test soil is seated on top of a geotextile specimen. Wire mesh underlying the geotextile supports the weight of the test specimen. A bowl type container is installed below the wire mesh to collect the fine particles that migrate through the geotextile. The capture capacity of this hollow container is $86 \mathrm{cc}$.

A pressure panel manufactured by GEOTEST (1994) is used for application of the cell pressure and of the back pressure. The panel is equipped with three air pressure regulators which control the cell pressure and the pressure heads at the top and bottom of the test specimen. Actual back pressure is evaluated from averaging the two pressure heads applied to the test column. Four scaled burettes, each with $60 \mathrm{cc}$ capacity, connected to each other in parallel, continuously measure the flow rate through system Therefore, large flow rates, which are anticipated at the beginning of a test, can be 
promptly monitored even for soil specimens having high hydraulic conductivity. A reservoir tank with a capacity of $20 \mathrm{~L}$ provides deionized water.

While the panel is instrumented with a gage for monitoring the pressures applied, sensors are mounted on the cell for direct measurement of the pressures. Specifically, the cell is instrumented with a $100 \mathrm{psi}(689 \mathrm{kPa})$ capacity diaphragm pressure gauge for measuring the cell pressure. Six similar additional transducers are used for monitoring the pore pressure at different heights within the soil specimen. As shown in Figure B.2 in appendix, all sensors are mounted on the base of the cell. The pore pressure transducers are connected to the specimen through internal ports specially fabricated on the latex membrane.

Figure 5.1 shows the locations in the specimen where the pore pressure is measured. Pore pressure measurements are made at the bottom of the soil specimen and $12.5 \mathrm{~mm}$ above the specimen base (Figure 5.1). Two independent measurements are performed at each of these two elevations to verify repeatability in the data. They provide the means to measure the hydraulic head difference across the filtration zone. The data presented in the following are obtained by averaging these two independent measurements. Additional ports are located at $25 \mathrm{~mm}(1 \mathrm{in})$ and $75 \mathrm{~mm}$ ( $3 \mathrm{in})$ from the bottom. From these the head difference in the portion of the soil that is considered to be free of fine particle migration can be determined. The specimen height varies during the various stages of the test because of the change in effective stresses and the fine particle migration through the 
filter material. This change is monitored by an external LVDT mounted on the cell piston.

Acquisition of the signals from the pressure transducers and the LVDT is achieved through a 8 channel data acquisition system manufactured by Geotac of Houston, TX. The system relies on a 22 bit A/D converter and is interfaced with a PC. A general purpose data acquisition program provided by the manufacturer is used to record the voltage signals from all the transducers. These are then converted to engineering units based on calibration curves determined for each of the sensors.

The FWGR tests conducted in this research involved the application of a constant head difference across the test specimen (soil + GT), while measuring the resulting flow rate, and the pore pressures generated in time throughout the soil specimen. In the setup used for this research a pressure panel equipped with precision regulators was employed to apply constant values of the back pressure at the bottom and top of the soil specimen to create downward flow through the specimen. The values of the pressure were selected to yield an initial gradient of 5 (see Section 5.2.5 for details). The resulting flow rate was measured through the burettes mounted on the pressure panel. As the water flowed through the specimen, readings of the pore pressure were taken at the various pore pressure transducers. Based on these readings the gradients existing across different portions of the specimen were determined. From these values the gradient ratio (GR), one of the key parameters used to interpret the test data, was calculated. Note that in this research the GR is defined as GR $=\mathrm{i}_{0-12} / \mathrm{i}_{25-75}$, where $\mathrm{i}_{0-12}$ is the value of the hydraulic 
gradient across the bottom $12.7 \mathrm{~mm}$ of the soil specimen, and $i_{25-75}$ is the gradient in the portion of the specimen between 25 and $75 \mathrm{~mm}$ elevation. Note that this definition of the GR differs from those previously employed by other researchers (e.g. $\mathrm{GR}_{\mathrm{ASTM}}=\mathrm{i}_{0-25} / \mathrm{i}_{25-75}$ [ASTM D 5101] or $\mathrm{GR}_{\mathrm{MOD}} \mathrm{i}_{0-8} / \mathrm{i}_{25-75}$ [modified by Fannin et al, 1994]). Note also that the $\mathrm{i}_{0-12}$ gradient is restricted to the bottom portion of the soil specimen and excludes the head loss across the GT filter. Differences in hydraulic head between the lowest port and the base container can be used to determine the head loss across the geotextile (GHL), which is expected to be close to zero at the beginning of any test and may increase as a result of internal clogging.

At the end of the test the base hollow container, in which all the fine particles that penetrated the GT filter were captured, was inspected and the amount of passing soil was weighed and compared with the soil mass retained inside the geotextile. At the same time the GT specimens were oven-dried and their mass compared to the initial one to determine the amount of soil clogged in the GT. 
Flow Direction

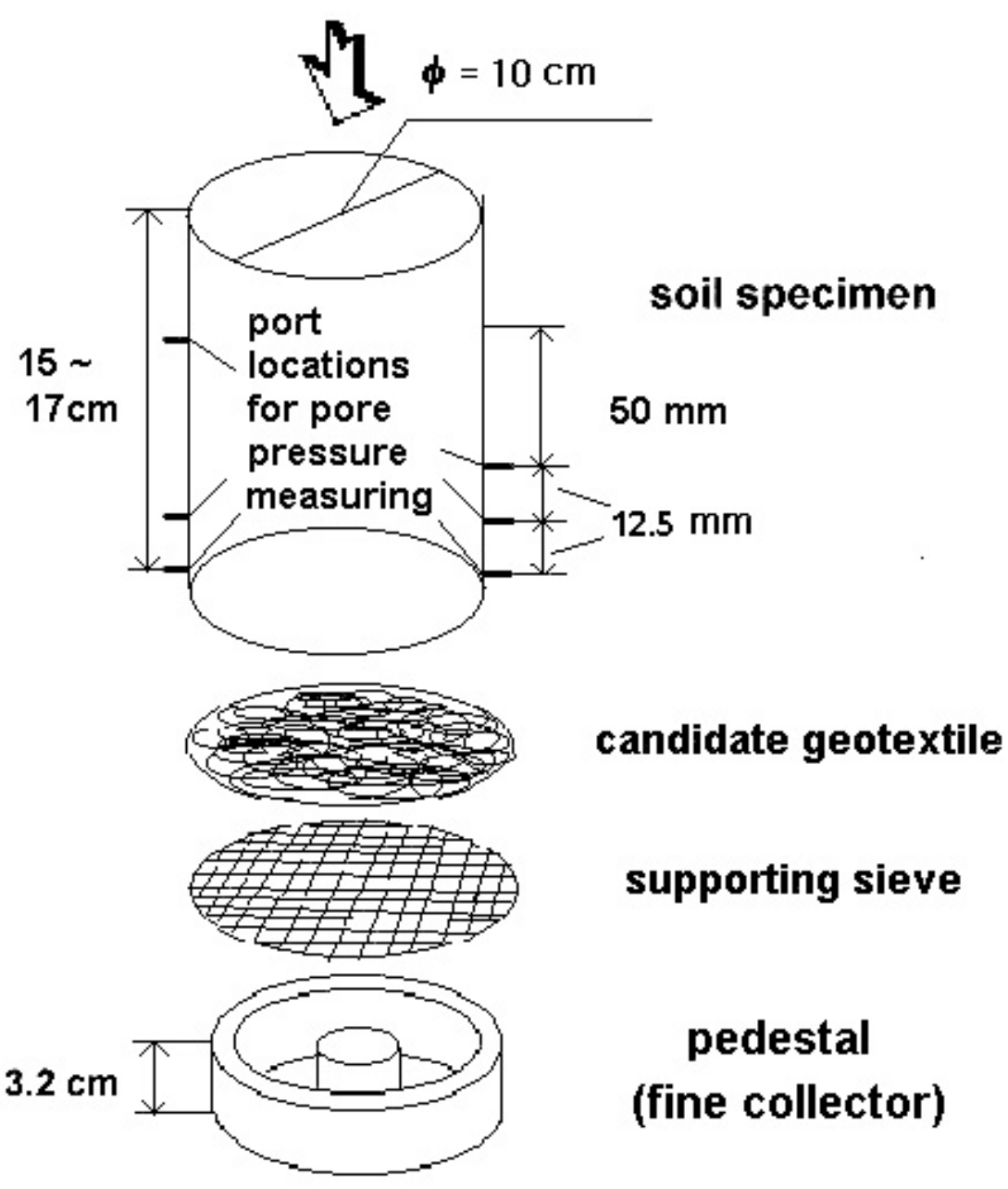

Figure 5.1 Port locations and soil column specs in FWGR test 


\subsection{Material Properties and Testing Conditions}

\subsubsection{Overview}

FWGR tests were conducted employing three different soils and two different geotextiles. The soil specimens were prepared with different silt contents $(10 \%, 20 \%$ and $50 \%$ by weight) at two compaction states. Two geotextile specimens different in thickness $(3.2 \mathrm{~mm}$ and $1.1 \mathrm{~mm})$ and opening size $(0.15$ and $0.21 \mathrm{~mm})$ were selected for testing the filter performance. The following sections cover in detail the preparation of the soil specimens (5.3.2), the relationship between limiting void ratios ( $\mathrm{e}_{\max }$ and $\left.\mathrm{e}_{\min }\right)$ and silt content (5.3.3), the properties of the geotextiles (opening size in 5.3.4 and thickness in 5.3.5) and the selection criteria for the hydraulic conditions (5.3.6).

\subsubsection{Soil Specimen Preparation}

The basic material used for all the tests was concrete sand. Silt was added to the sand at percentages by dry mass of 10,20 and 50\%. Figure 5.2(a) shows the grain size distribution (GSD) curves of the resulting soil mixtures. Note that as a result of the different percentage of silt used the curves display very distinct shapes: upward concave (10\%), gap graded (20\%) and upward convex (50\%). As shown by Kenney and Lau (1985), the shape of the GSD determines the soil's internal stability which controls the fine particle migration during the filtration process. In Figure 5.2(a) the GSD curves are plotted in terms of $\mathrm{F}$ and $\mathrm{H}$ where $\mathrm{F}$ and $\mathrm{H}$ are defined in Section 2.3.1. It is shown that only the 50 silt GSD satisfies the criterion for soil internal stability (Kenney and Lau, 
1985) of $\mathrm{H}>1.3 \mathrm{~F}$ up to $\mathrm{F}=0.2$ (Figure $5.2(\mathrm{~b})$ ). Note that internal stability analysis charts are based on densely compacted soil states. Therefore even a soil that met this criterion could be internally unstable under loose conditions.

Soil specimens were prepared using the slurry deposition method (Siva and Bhatia, 1994) to guarantee uniform particle distribution. The water content of the slurry varied between 13 and $15 \%$ to limit fine particle segregation. A mold with dimensions of 10.2 $\mathrm{cm}$ (inner diameter) $\times 18 \mathrm{~cm}$ (height) was specially designed to protect the extruding ports of the membrane during specimen preparation.

Once poured into the mold the slurry was left to consolidate for a period that varied between 12 and 24 hours, depending on the percentage of fines. During this stage dead weights (from $0.5 \mathrm{~kg}$ to $4.5 \mathrm{~kg}$ ) were placed on the slurry to reach the target void ratio. The following loading increment schedule was applied to the $10 \%$ silt specimens: no load - $2 \mathrm{hr}, 0.5 \mathrm{~kg}-2 \mathrm{hr}, 1 \mathrm{~kg}-1 \mathrm{hr}, 2 \mathrm{~kg}-1 \mathrm{hr}$, and $4.5 \mathrm{~kg}-30 \mathrm{~min} .$. Identical loading schedules were employed to the $20 \%$ silt and $50 \%$ silt specimens but with double and quadruple durations, respectively. This type of schedule was selected to limit seepage forces associated with excess pore pressure generation. If a denser soil specimen was desired, after this phase the mold was tapped following a standard procedure (75 taps evenly around the mold side), and an additional mass $(15 \mathrm{~kg})$ was placed on top of the specimen. Table 5.1 summarizes the test conditions (silt percentage and degree of compaction) examined in the investigation program. In this table and thereafter in this chapter, the terms "loose" and "dense" are used to refer to compaction states achieved without and 


\section{(A)}

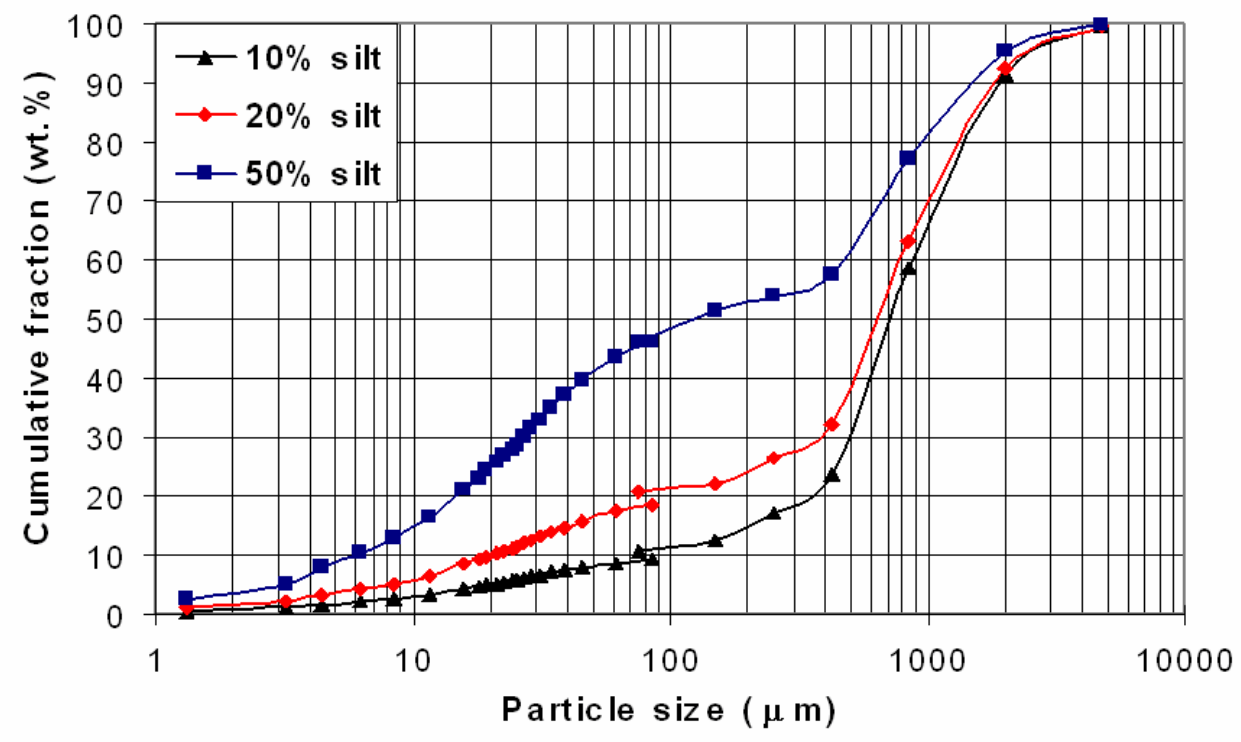

( B )

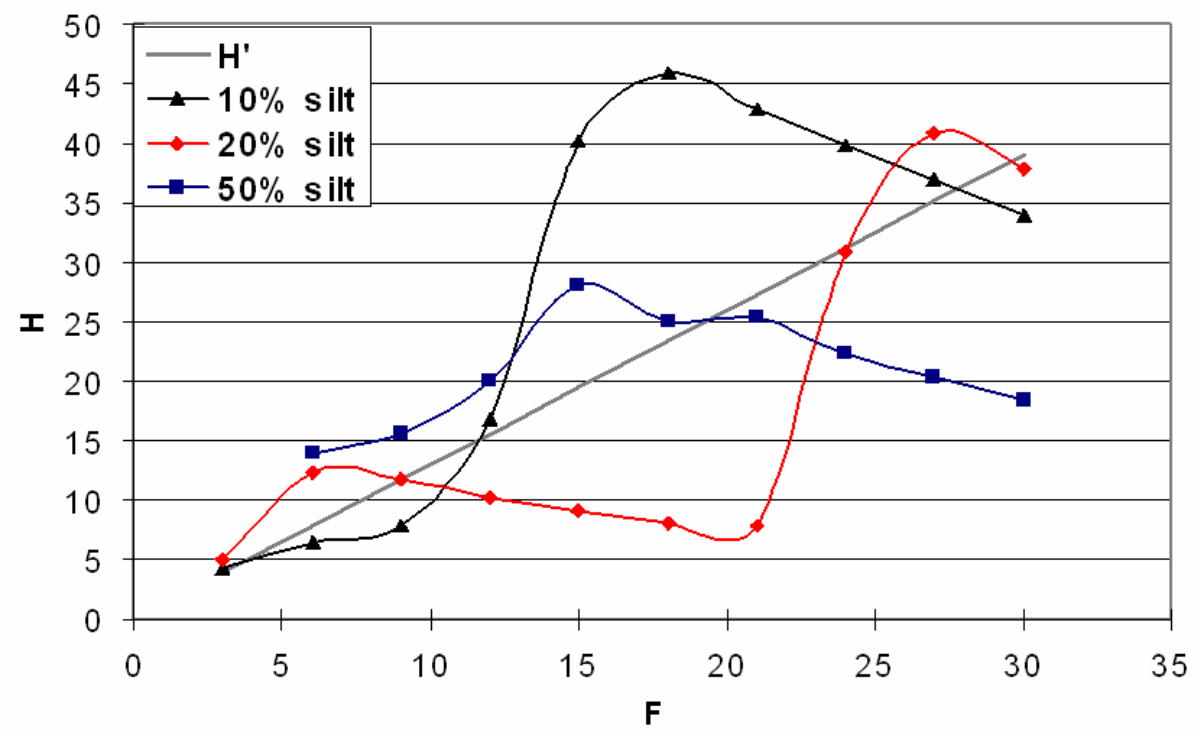

Figure 5.2 (a)Grain size distribution (GSD) of soil specimens and (b) internal stability evaluation $\left(\mathrm{H}^{\prime}=1.3 \mathrm{~F}\right.$ where $\mathrm{F}$ is cumulative fraction of GSD in percentage after Kenney and Lau, 1985) 
Table 5.1 Void ratio and relative density values of test soil specimens

\begin{tabular}{rllccc}
\hline silt \% & d.o.c. & $\mathrm{e}^{2)}$ & rel. density (\%) & $\mathrm{e}_{\min }{ }^{3)}$ & $\mathrm{e}_{\max }{ }^{4)}$ \\
\hline 10 & loose & 0.42 & 62.5 & 0.33 & 0.57 \\
10 & dense & 0.33 & 100.0 & 0.33 & 0.57 \\
20 & loose & 0.35 & 82.8 & 0.30 & 0.59 \\
20 & dense & 0.29 & 103.4 & 0.30 & 0.59 \\
50 & loose & 0.36 & 86.1 & 0.39 & 0.73 \\
50 & dense & 0.3 & 126.5 & 0.39 & 0.73 \\
1) degree of compaction for soil specimen & & & \\
2) void ratio of soil specimen \\
3) estimation from standard proctor test (ASTM D698) \\
4) estimation from funnel method (ASTM D4253)
\end{tabular}

with tapping, respectively. . Table 5.1 also includes the values of the void ratio measured at the end of the FWGR tests, as well as the values of the minimum and maximum void ratio for the three sand-silt mixes considered obtained from the standard Proctor test, and the funnel method, respectively (see more details in section 5.3.3).

Following the consolidation process, the porous stone and head cap were positioned on top of the soil specimen, and the membrane sealed using $\mathrm{O}$ rings. A suction pressure of $5 \mathrm{kPa}$ was then applied to allow removal of the mold and assembly of the triaxial chamber.

Back pressure saturation was conducted in 40 steps raising the back pressure up to a maximum value of $400 \mathrm{kPa}$. All the increase steps were controlled with effective confining stress less than $5 \mathrm{kPa}$. At the final pore pressure B values greater than 0.95 were measured in all the specimens. 
Air bubbles can be trapped inside the tube connecting the membrane port to the external pressure transducer during the specimen preparation stage. The air bubbles need to be removed at the beginning of the back pressuring stage since the high compressibility of the air interferes with the accurate assessment of pore pressure changes inside the soil sample. The trapped air bubbles could be successfully removed during the initial back pressure stage (when the cell pressure had been increased to $10 \mathrm{kPa}$ ) by temporarily releasing the pore pressure built within the soil specimen through the external ports.

Following back pressure saturation the soil specimens were consolidated in hydrostatic conditions to an effective confining stress of $10 \mathrm{kPa}$. This value was selected to reflect the typical effective stress level at the depth of a sub surface drainage system (e.g. @ $1.2 \mathrm{~m})$. The volume change associated with reaching this effective stress was generally very small and was the greatest $(0.14 \%)$ in the case of the $50 \%$ silt soil.

\subsubsection{Silt Content and Compaction States}

The funnel method and the tapping method were used to evaluate the limiting void ratios of the soil specimens in the fully dried state (ASTM D 4253). Both the vibration method and the standard proctor test (ASTM D 4254 and 698) were employed to assess the minimum reference values in the wet state for $10 \%, 20 \%, 35 \%$ and $50 \%$ silt. Figure 5.3 summarizes the data obtained. It is shown that there is a significant difference between the values of $e_{\min }$ obtained for each silt content with the three methods: both the tapping method and the vibration method yield values of $\mathrm{e}_{\min }$ that are consistently higher than the value obtained from the proctor test. The difference appears to increase with silt 
content (above $30-35 \%$ silt the figure reports data for only the proctor test). Comparison with the void ratio data in Table 5.1 shows that the tapping procedure employed to densify the specimens (in wet conditions) in the FWGR test as well as the seepage force associated with permeation of the specimen during the test itself, yielded final values of the void ratio equal or lower than the $\mathrm{e}_{\min }$ values from the proctor test. The difference is especially significant for the $50 \%$ silt soil. It appears that for such a high fines percentage the concept of limiting densities loses significance.

Despite this, the curves of void ratio versus silt percentage are consistent with those reported in the literature for other silt sand mixtures (e.g. Thevanayagam et al, $2002-$ Figure 5.3 (b)). The maximum void ratio shows a small decrease with silt percentage up to $10 \%$ silt, and then increases steadily. In the case of the minimum void ratio the decrease is very significant up to a silt content between 20 and 35\% (e.g. for $20 \%$ silt $\mathrm{e}_{\min }$ is approximately $60 \%$ of the value measured on the pure sand). Again after reaching this minimum, $e_{\min }$ goes back to increase with further silt addition. These trends in $\mathrm{e}_{\min }$ and $\mathrm{e}_{\max }$ have been extensively discussed in the literature (e.g., Lade et al, 1998 and Thevanayagam, 2002). These researchers concluded that the content of fines is important in determining the sand structure and the consequent limiting void ratios. Test results also support the hypothesis that as the (relative) density of the soil increases, an increasing number of fine particles participate in playing the role of the soil skeleton. In other words, with increased degree of compaction, the fraction of the fine particles that remains free to migrate across the soil pores decreases while the particle structure resisting wash-out increases. 


\subsubsection{Geotextile Apparent Opening Size (AOS)}

There are several filter design methods (or criteria) available in the literature for selecting the opening size range (AOS) of a geotextile based on the soil GSD. Table 5.2 summarizes the results of applying these criteria to the soils investigated in this research. It is shown that both GT used in this research ( $\mathrm{AOS}=0.15$ and $0.21 \mathrm{~mm})$ meet the first two criteria for all three soils. Thus piping (severe soil erosion) is not expected to occur in any of the three soil specimens (10\%wt, 20\%wt and 50\%wt silt). The last criterion by Lafleur (1999) recommends AOS values larger than 0.4-0.5 $\mathrm{mm}$ to reduce the potential of blinding in the case of the $10 \%$ and $20 \%$ silt soils (this opening size is hardly found in commercial products of needle punched GT). Therefore, poor hydraulic performance (e.g. blinding or clogging) should be expected for the $10 \%$ and $20 \%$ silt soils with the GTs used in this research. The choice of AOS in the $0.15-0.21 \mathrm{~mm}$ range would instead be expected to yield satisfactory result for the $50 \%$ silt soil.

Table 5.2 Opening size values recommended from GT retention criteria

\begin{tabular}{cccc}
\hline GT filter criteria & $10 \%$ silt & $20 \%$ silt & $50 \%$ silt \\
\hline FWHA $^{1)}(1985)$ & $<2.2 \mathrm{~mm}$ & $<2.7 \mathrm{~mm}$ & $<0.25 \mathrm{~mm}$ \\
Luettich et al (1992) & $<1.8 \mathrm{~mm}$ (loose) & $<1.7 \mathrm{~mm}$ (loose) & $<0.08 \mathrm{~mm}$ (loose) \\
Lafleur (1999) & $<3.6 \mathrm{~mm}$ (dense) & $<3.4 \mathrm{~mm}$ (dense) & $<0.17 \mathrm{~mm}$ (dense)
\end{tabular}

1) authored by Christopher and Holtz 


\subsubsection{Geotextile Constrained Compressibility and Thickness}

If geotextiles are stretched by tensile forces along a planar direction, the FOS (see

Chapter 2 for definition of FOS) is generally reduced by the opening elongation along the direction of force (Fourie and Kuchena, 1995). Besides the FOS reduction due to lateral load, another type of reduction in opening size can be expected from the vertical compression of the thickness due to the overburden pressure. The compressibility of GT is also of significant concern in that it will affect the area of contact between the fiber and coarse soil particles. In light of the above, the constrained compressibility of the two GT specimens employed for the FWGR test as well as of an additional GT with an intermediate thickness was measured. This measurement was performed uni-axially loading the GT specimens in a displacement controlled load frame using a strain rate of $0.85 \% / \mathrm{sec}$. A stainless steel ring was used to prevent lateral extension of the GT during the loading. The axial load and displacement of the loading cap, designed to fit inside the remaining ring, were continuously monitored.

Table 5.3 summarizes the specifications under atmospheric pressure of the three GT used while Figure 5.4 presents the results of the uni-axial loading test. It is observed that at the stress level employed in this testing program $(10 \mathrm{kPa})$ for the FWGR tests, the strain of the GT ranges between 4\% and 15\%, for the thick GT (G1202) and thin GT (G402) respectively. The results presented in Figure 5.4 also indicate a lower compressibility of the thick GT compared to the thin one. Furthermore, there appears to be no relationship 


\section{( A)}

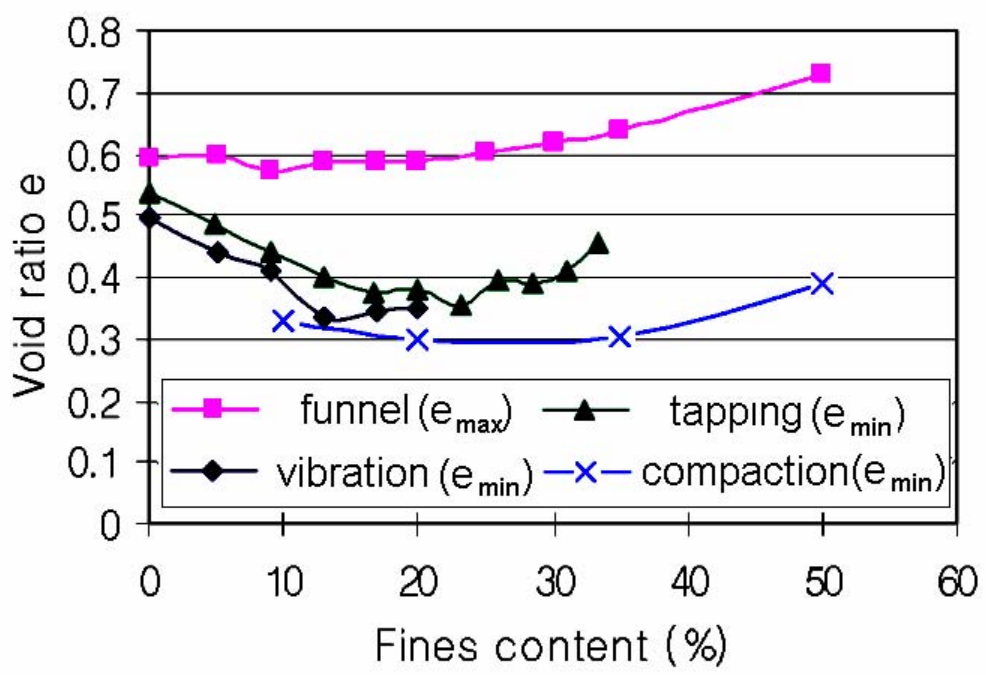

( B )

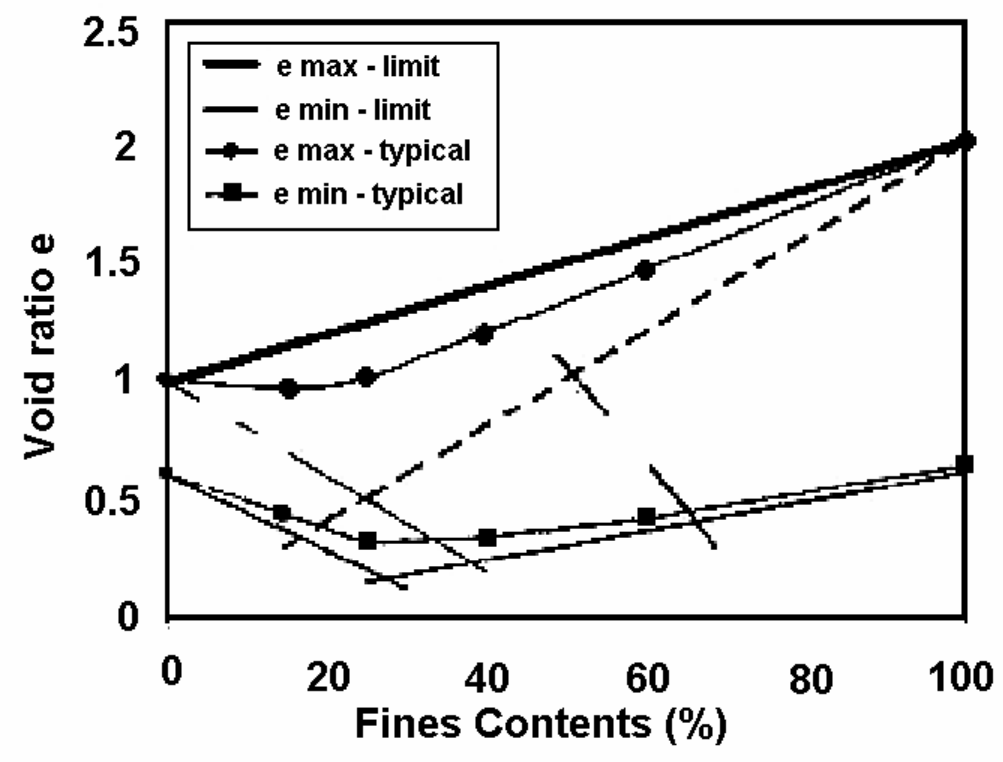

Figure 5.3 (a) Compaction test results for different fine contents by various method types and (b) the comparable reference data (Thevanayagam et al, 2002) 


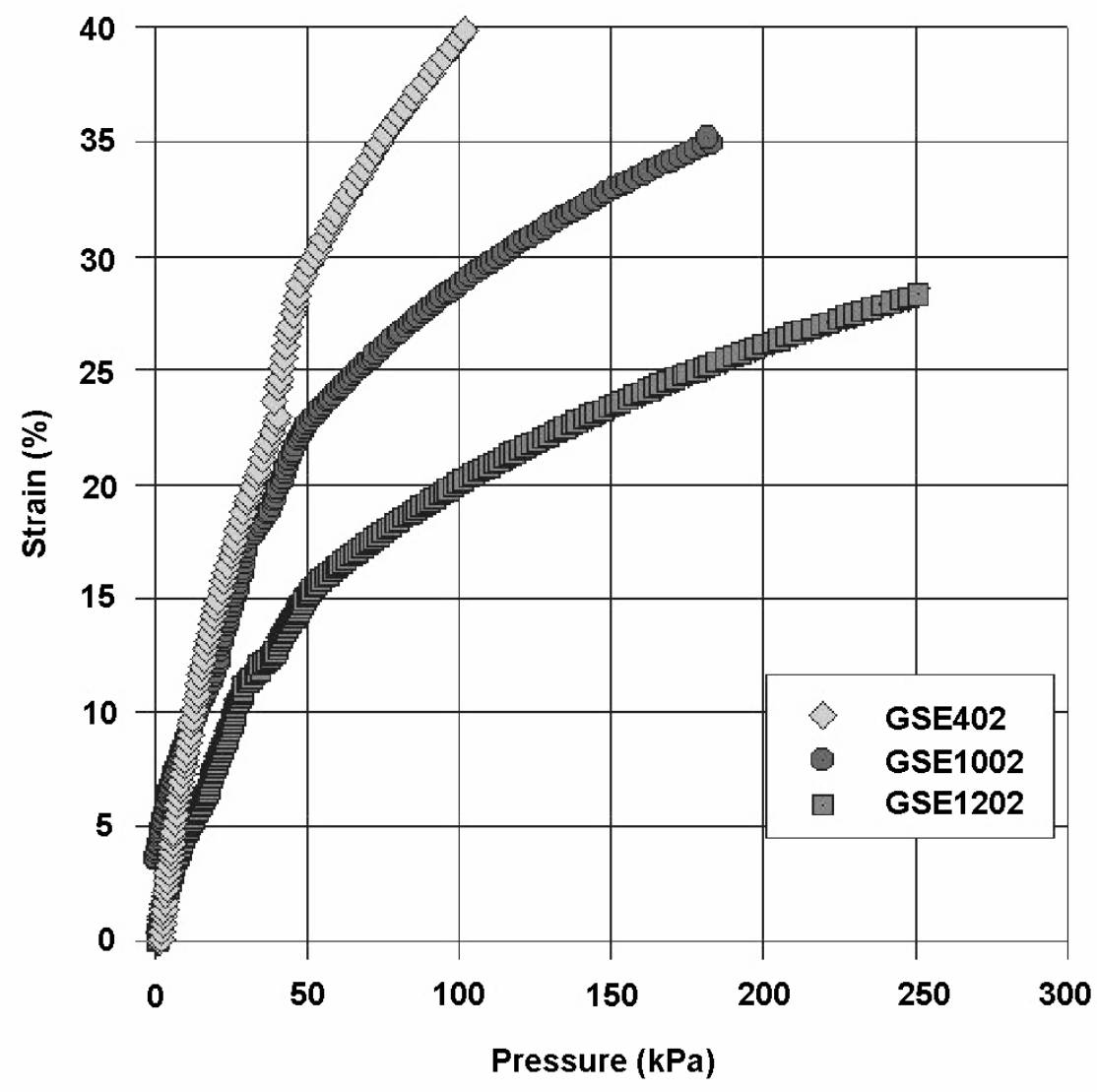

Figure 5.4 Constrained Compressibility of GT with Different Thickness (higher product number indicates larger GT thickness) 
Table 5.3 Specs of non woven geotextiles in the constraint compression test (GSE, 2003)

\begin{tabular}{cccccc}
\hline Brand/Product & $\begin{array}{c}\text { Mass/area } \\
\left(\mathrm{g} / \mathrm{m}^{2}\right)\end{array}$ & $\begin{array}{c}\text { Initial } \\
\text { thickness } \\
(\mathrm{mm})\end{array}$ & $\begin{array}{c}\text { Specific } \\
\text { density }) \\
(\mathrm{kg} / \mathrm{m} 3)\end{array}$ & $\begin{array}{c}\text { Permeability } \\
(\mathrm{cm} / \mathrm{sec})\end{array}$ & $\begin{array}{c}\text { A.O.S. }{ }^{2)} \\
(\mathrm{mm})\end{array}$ \\
\hline GSE 402 & 135 & 1.1 & 123 & 0.17 & 0.21 \\
GSE 1002 & 333 & 2.5 & 134 & 0.21 & 0.15 \\
GSE 1202 & 405 & 3.2 & 127 & 0.25 & 0.15
\end{tabular}

1) Specific density $=$ mass / area / initial thickness

2) A.O.S is apparent opening size (estimated by ASTM D4751)

3) Fiber bonding type is needle punched

between GT specific density (i.e. mass per area divided by thickness) and GT compressibility.

\subsubsection{Hydraulic Conditions}

Field hydraulic conditions can not be exactly simulated in a laboratory environment, and thus the concomitant simplifications must be accepted. While most column tests used to examine GT clogging have adopted a constant head condition, the values of the system hydraulic gradient employed vary over a wide range. For example for the GR test (ASTM D5101) it is recommended that the gradient be between 0.5 and 10. In the HCR test (ASTM D5567) the maximum system gradient is set at 5 for soil specimens with $\mathrm{K}$ between 1.E-3 and 1.E-5 cm/sec. Giroud (1996) suggested that the appropriate hydraulic gradient value for the underdrain near the surface is one. 
The highest gradient value expected at a site can be applied as the system hydraulic gradient in a test to simulate the worst case scenario. Whereas site hydraulic gradient values are dependent on initial degree of soil saturation, the ambient hydraulic gradient value of a road drainage layer can increase to 17.5 because of the flow convergence pattern onto a sink point or a drainage pipe (Mlynarek et al, 1993). From the analysis of the hydraulic head distribution around an underdrain pipe presented in Chapter 4, the hydraulic gradient levels at the geotextile filter were expected to be 0.25 to 0.5 for subgrade soils with $\mathrm{K}$ between $6 \mathrm{E}-4 \mathrm{~cm} / \mathrm{sec}$ and $6 \mathrm{E}-3 \mathrm{~cm} / \mathrm{sec}$ under fully saturated conditions (Table 4.2). These hydraulic gradient values would be expected to increase under more realistic site conditions, for example if partial leakage through the pavement boundary was allowed. The presence of less pervious subgrade soil (e.g. silty soil with K ranging from $1 . \mathrm{E}-6 \mathrm{~cm} / \mathrm{sec}$ to $1 . \mathrm{E}-4 \mathrm{~cm} / \mathrm{sec}$ ) would also lead to higher gradients. These considerations justify the selection of a system hydraulic gradient of 5 for all the tests presented in this chapter.

\subsection{Test Results}

\subsubsection{Normalized Parameters}

The soils tested in this research exhibit a significant range in hydraulic conductivity $(6.8 \mathrm{E}-6 \mathrm{~cm} / \mathrm{sec}$ to $1.1 \mathrm{E}-4 \mathrm{~cm} / \mathrm{sec}$ - see Table 5.4). As a result of this range in $\mathrm{K}$, it is 
expected that under the same hydraulic gradient, the process of fine particle migration will occur over different time scales depending on the fine contents in soil.

To effectively compare the data from experiments conducted on different soils characterized by different initial compaction state and often markedly different in initial hydraulic conductivity, the following normalized parameters are introduced: relative pore volume (r.p.v.) and relative hydraulic conductivity $\left(\mathrm{K}_{\text {rel }}\right)$.

The relative pore volume (r.p.v.) is defined as the flow volume divided by the initial soil pore volume, i.e.

$$
r . p . v .=\int q d t / n \cdot V
$$

where $\mathrm{q}$ is the system flow rate $(\mathrm{cc} / \mathrm{sec}), \mathrm{n}$ the initial soil porosity and $\mathrm{V}$ is the initial soil volume (cc).

The relative hydraulic conductivity, $\mathrm{K}_{\text {rel }}$ is defined as $\mathrm{K} / \mathrm{K}_{\mathrm{ini}}$ where $\mathrm{K}$ is the absolute system (i.e., soil + GT) hydraulic conductivity at any given time during the test and $\mathrm{K}_{\mathrm{ini}}$ is the initial system hydraulic conductivity.

The results from any of the FWGR tests can then be presented either in terms of K versus testing time or using the normalized parameters. An example of how the data from a single experiment appear in these two representations is presented in Figures 5.5 (a) and 5.5 (b). Plotting the data in absolute terms has some advantages. For example, Figure 5.5 (a) highlights the difference in the initial values of $\mathrm{K}$ and the marked decrease 
in $\mathrm{K}$ over time of the $10 \%$ silt system. It is also shown that at the end of the test the measured hydraulic conductivity falls within a very narrow range regardless of silt content. The evaluation and comparison of the hydraulic performance of a GT filter used in combination with different soils is, however more effectively performed using the normalized scales of Figure 5.5 (b). This is the representation selected in section 5.4.2 to present and discuss the experimental data.

\subsubsection{Filter Hydraulic Performance during Soil Filtration}

FWGR tests were performed on three soils (with 10\%, 20\% and 50\% silt), at two different compaction states ("loosely" deposited and "densely" compacted), using two types of needle punched GT with different AOS and thickness (i.e. G402 [termed 'thin”] and G1202 [termed "thick"], see Table 5.3). Tests proceeded either until the system flow reached a steady state (i.e. the measured flow rates remained constant with time), or when the system $\mathrm{K}$ fell below $1.0 \mathrm{E}-6 \mathrm{~cm} / \mathrm{sec}$ (below this value of $\mathrm{k}$ physicochemical clogging by fine particles impedes accurate measurement of the system flow rate).

Figure 5.6 presents the data, in terms of $\mathrm{K}_{\text {rel }}$ versus relative pore volume (r.p.v.), for all the FWGR tests conducted, while Table 5.4 summarizes key results obtained from each test. Specifically, for each test the table includes: the test duration; the total flow volume permeated through the soil column; the average flow rate (i.e. flow volume divided by test duration); the initial and final values of the hydraulic conductivity; the void ratio of the soil measured at the end of the test; the relative hydraulic conductivities at r.p.v. $=1$ 
and at the end of test; the amount of soil trapped inside the geotextile; the amount of soil that piped through the geotextile (given by the soil present in the base hollow container).

The last row of the table summarizes the "filtration result" for each of the tests. In this research the distinction between bridging, blinding, clogging is based on the following criteria (for descriptions of these phenomena see Chapter 2):

- bridging is said to occur when a relatively high system $\mathrm{K}$ is measured throughout the test period (i.e., $\mathrm{K}_{\text {rel }} \geq 0.1$ at r.p.v.=10);

- blinding is said to occur when the test results show a sharp reduction of the system $\mathrm{K}$ early in the test $\left(\mathrm{K}_{\mathrm{rel}}<0.1\right.$ or $\mathrm{K}<1 . \mathrm{E}-6 \mathrm{~cm} / \mathrm{sec}$ at r.p.v. $\left.=1\right)$;

- clogging is said to occur when the test results show a retarded blinding process $\left(\mathrm{K}_{\mathrm{rel}} \geq\right.$ 0.1 at r.p.v. $=1$ but $\mathrm{K}_{\mathrm{rel}}<0.1$ at r.p.v.=10).

The discussion that follows relies on the data shown in Table 5.4 and Figure 5.6 to present the observations drawn from the tests conducted. First, the test parameters shown in Table 5.4 are discussed. Then, the filtration results (i.e. bridging, blinding, clogging) are discussed and their occurrence related to the conditions of the test specimens.

As shown in Table 5.4, test periods ranged from 13 hours to 107 hours. For blinding and clogging the test duration cited in Table 5.4 refers to the time required for this process to occur. In the case of bridging the test period refers to the time required to reach the steady value of the hydraulic conductivity (or of $K_{\text {rel }}$ ) (see Figures 5.6(a) and (b)). For the three cases in which bridging occurred (Table 5.4) the test duration varied in 
a fairly narrow range, between 62 and 72 hours. The time associated with blinding showed, instead, greater variability. While in six out of the eight tests it occurred under 24 hours, in the other tests, the test duration was extended to 47 and 92 hours, respectively. As discussed in more detail in the following, clogging was found to occur only in one test (loose 50\% silt soil with thick GT), which, not surprisingly, given that clogging is essentially a form of delayed blinding, presented the longest test duration of 107 hours.

The values of the total flow volume and, more importantly, of the average flow rate, are useful indicators of the hydraulic performance of filter system. The greater these values, the more effective the filter system. As indicated in Table 5.4 the measured values of the total flow volume and of the average flow rate varied greatly from test to test. The dense $10 \%$ silt with thick GT exhibited the best drainage performance (12580 cc in flow volume), while the dense $50 \%$ silt with thin GT exhibited the worst drainage performance (136 cc in flow volume) (Table 5.4). Accordingly, the same two test specimens showed the best and worst hydraulic performances respectively (i.e. $203 \mathrm{cc} / \mathrm{hr}$ and $7.6 \mathrm{cc} / \mathrm{hr}$ in average flow rate).

Another significant observation that can be made from the data shown in Table 5.4 is that the final $K_{\text {rel }}$ value correlates well with the value of $K_{\text {rel }}$ at r.p.v. =1 (c.f. a correlation coefficient equal to 0.87 excluding the case of $10 \%$ silt with thin GT). This indicates that under constant head conditions the degree of $\mathrm{K}$ reduction at the beginning of the test can be used to predict the ultimate clogging state. 
The data on the amount of soil clogged in the GT and collected below it can also provide insight into the mechanisms responsible for the observed filtration outcomes. It is worthwhile pointing out that in comparing these data, one must consider the amount of flow that occurred during the test, i.e. it is necessary to consider the soil clogged (or soil penetrated) per cc of water flowed through the specimen. For example, in the cases where bridging is observed to happen it is expected that the amount of soil collected in the GT as well as the amount flushed through it would be small. Comparison of the data shown in the third to last and second to last rows of Table 5.4 does not necessarily reflect this observation. However, the amount of soil normalized by the total flow volume is found, in fact, to be the smallest in the case of bridging.

Concluding the remarks on the data reported in Table 5.4, it must be noted that the initial hydraulic conductivity data present a discrepancy, which cannot at this time be explained. Table 5.4 shows in fact that in four out of the six cases examined (and always in presence of a thin GT) the $\mathrm{K}_{\mathrm{init}}$ for the dense specimen exceeds the value measured on the loose specimen.

Moving on to discuss the occurrence of the different filtration outcomes in the tests performed, Table 5.4 shows that successful filtration, i.e. bridging occurred in only three out of the twelve cases considered: when the dense $10 \%$ silt and $20 \%$ silt soils were filtered by the thick GT (G1202), and when the loose 20\% silt soil was combined with the thin GT (G402). Successful filtration, i.e. bridging is associated with both a good hydraulic performance of the filter system as well as with success in retaining the fine 
particles present in the soil (retention criterion). In fact, all three cases listed above were characterized by large values of the final $\mathrm{K}_{\mathrm{rel}}$ (the three largest measured in all the tests) and by average flow rates over $40 \mathrm{cc} / \mathrm{hr}$ (Table 5.4). Additionally, after normalization by the total flow volume the amounts of soil clogged in the GT or penetrated through it GT were the three lowest recorded.

Blinding was the most common filtration result observed in the tests conducted, occurring irrespective of the fines content, the degree of compaction and the GT thickness (Table 5.4). As shown in Figure 5.6, for low fine content (10\% and 20\% silt) the curve of $\mathrm{K}_{\text {rel }}$ versus r.p.v. is characterized by an upward convex shape, which indicates that the rate of reduction of K steadily increases with time. This would arise if blinding occurred as a result of blockage of the GT openings by the coarse particles. Any further migration of the fines on the GT surface would, in fact, be expected to cause the $\mathrm{K}$ to rapidly decrease.

This trend is not apparent in the case of high fines content (50\% silt), suggesting that in addition to coarse particle blockage some other mechanism may also be responsible for the accumulation of particles on top of the GT surface .The analysis of the test results in terms of gradient ratio (GR) and geotextile head loss (GHL) presented in Section 5.4.3 provides additional insight into the mechanisms responsible for the occurrence of blinding. 
Clogging was observed only in the case of the loose $50 \%$ silt specimen filtered by the thick GT. Compared to all other tests conducted on the 50\% silt soils, this test showed distinctive features: a long test duration $(107 \mathrm{hr})$, a large amount of clogged soil in the GT (13.2 g), and a relatively high value of $\mathrm{K}_{\text {rel }}$ at r.p.v.=1 (0.3) (Table 5.4). Additional discussion of this test and hypotheses for the occurrence of clogging under these test conditions are presented in Section 5.4.3.

The next section further expands on the discussion of the different clogging processes and their relationship with the testing parameters considered. This is done employing the concepts of gradient ratio (GR) and gradient head loss (GHL) which permit to distinguish between what is happening in the base soil and what is happening in the immediate proximity of the geotextile. 


\section{(A) Real Test Outputs}

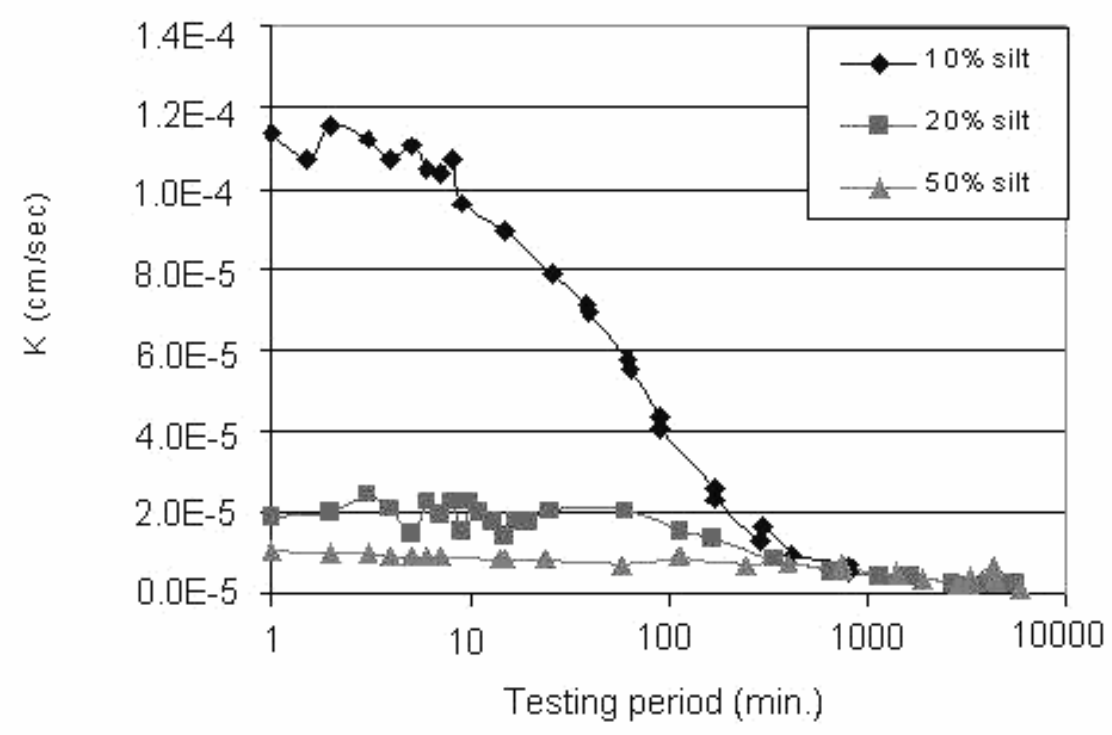

(B) Normalized Parameters

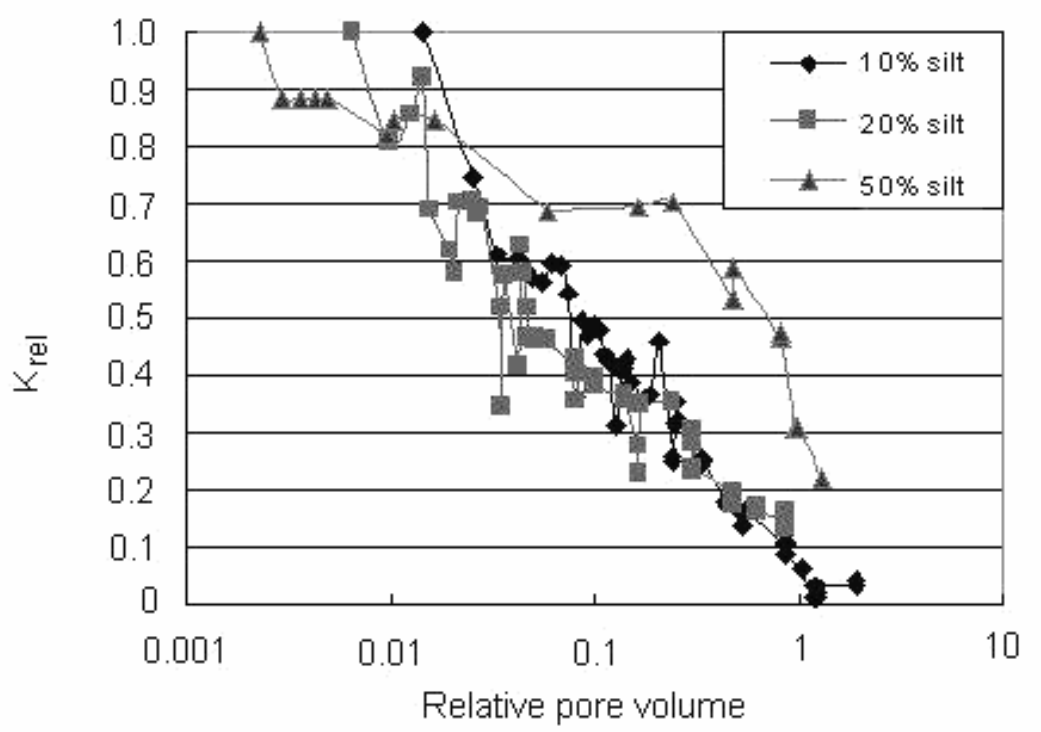

Figure 5.5 Conversion of real test outputs into normalized parameters (for the loosely deposited soils filtered by a thick GT (GSE1202)) 
Table 5.4 Operational data and test results of Flexible Wall Gradient Ratio method

\begin{tabular}{|c|c|c|c|c|c|c|c|c|c|c|c|c|}
\hline \multirow{3}{*}{$\begin{array}{c}\text { Silt \% } \\
\text { GT type } \\
\text { Compaction } \\
\text { degree }\end{array}$} & \multicolumn{4}{|c|}{10} & \multicolumn{4}{|c|}{20} & \multicolumn{4}{|c|}{50} \\
\hline & \multicolumn{2}{|c|}{ thin GT } & \multicolumn{2}{|c|}{ thick GT } & \multicolumn{2}{|c|}{ thin GT } & \multicolumn{2}{|c|}{ thick GT } & \multicolumn{2}{|c|}{ thin GT } & \multicolumn{2}{|c|}{ thick GT } \\
\hline & dense & loose & dense & loose & dense & loose & dense & loose & dense & loose & dense & Loose \\
\hline Test period $^{1)}(\mathrm{hr})$ & 24 & 23 & 62 & 13 & 24 & 62 & 72 & 92 & 18 & 13 & 47 & 107 \\
\hline $\begin{array}{l}\text { Total flow volume } \\
\text { (cc) }\end{array}$ & 2278 & 680 & 12580 & 306 & 340 & 2550 & 4420 & 646 & 136 & 340 & 374 & 986 \\
\hline $\begin{array}{l}\text { Ave. flow rate } \\
\text { (cc/hr) }\end{array}$ & 94.9 & 29.6 & 202.9 & 23.5 & 14.2 & 41.1 & 61.4 & 7.0 & 7.6 & 26.2 & 8.0 & 9.2 \\
\hline $\begin{array}{l}\text { Final soil void } \\
\text { ratio }\end{array}$ & 0.30 & 0.38 & 0.36 & 0.46 & 0.27 & 0.38 & 0.31 & 0.32 & 0.28 & 0.35 & 0.32 & 0.36 \\
\hline $\mathrm{K}_{\text {rel. }}$ at r.p.v. $=1$ & 0.74 & 0.15 & 0.70 & 0.04 & 0.30 & 0.46 & 0.35 & 0.13 & N/A & 0.04 & 0.18 & 0.31 \\
\hline $\mathrm{K}_{\text {init. }}(\mathrm{cm} / \mathrm{sec})$ & $3.0 \mathrm{E}-4$ & $9.5 \mathrm{E}-5$ & $6.2 \mathrm{E}-4$ & $1.6 \mathrm{E}-4$ & $2.8 \mathrm{E}-5$ & $1.1 \mathrm{E}-4$ & $1.6 \mathrm{E}-4$ & $2.8 \mathrm{E}-5$ & $6.8 \mathrm{E}-6$ & $7.5 \mathrm{E}-5$ & $1.3 \mathrm{E}-5$ & $1.0 \mathrm{E}-5$ \\
\hline $\mathrm{K}_{\text {final }}{ }^{2)}(\mathrm{cm} / \mathrm{sec})$ & $7.7 \mathrm{E}-6^{*}$ & 4.7E-6* & $1.4 \mathrm{E}-4$ & $5.0 \mathrm{E}-6$ & $2.3 \mathrm{E}-6^{*}$ & $1.1 \mathrm{E}-5$ & $2.8 \mathrm{E}-5$ & $2.2 \mathrm{E}-6^{*}$ & $1.6 \mathrm{E}-6^{*}$ & $2.8 \mathrm{E}-6$ & $2.3 \mathrm{E}-6^{*}$ & 7.1E-7* \\
\hline $\begin{array}{l}\text { Soil clogged in GT } \\
(\mathrm{g})\end{array}$ & 1.9 & 2.1 & 4.8 & 3.3 & 2.0 & 3.3 & 6.2 & 8.2 & 3.4 & 2.4 & 9.2 & 13.2 \\
\hline $\begin{array}{l}\text { Soil penetrating } \\
\qquad \text { GT }(\mathrm{g})\end{array}$ & 1.3 & 3.2 & 3.0 & 3.0 & 2.6 & 3.9 & 4.6 & 5.4 & 4.6 & 4.1 & 6.8 & 8.0 \\
\hline Final $\mathrm{K}_{\text {rel. }}$ & 0.03 & 0.05 & 0.23 & 0.03 & 0.08 & 0.10 & 0.18 & 0.08 & 0.23 & 0.04 & 0.18 & 0.07 \\
\hline Filtration result & blinding & blinding & bridging & blinding & blinding & bridging & bridging & blinding & blinding & blinding & blinding & clogging \\
\hline
\end{tabular}

All the test specimens are under confining stress of $10 \mathrm{kPa}$

1) Test period under the constant head condition of $i=5$

2) Value corresponding to the last measurement made before terminating the test

* in this test values of K below $1 . \mathrm{E}-6 \mathrm{~cm} / \mathrm{sec}$ were measured in the final stages of the test, leading to terminate the test 


\section{(A) $10 \%$ wt silt}

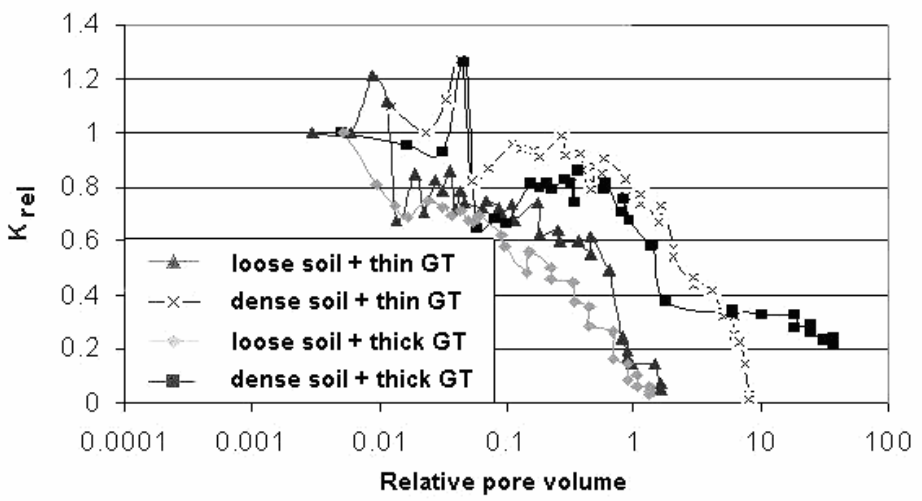

(B ) $20 \%$ wt silt

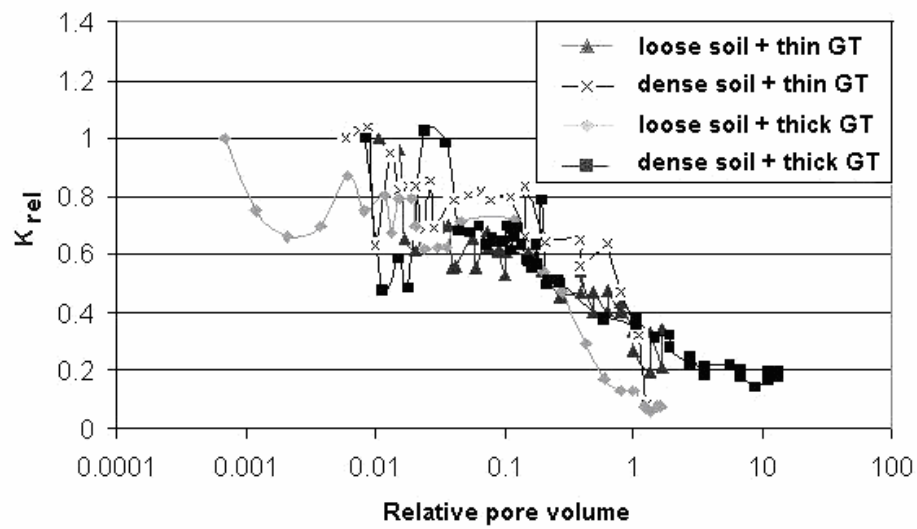

(C) $50 \% w t$ silt

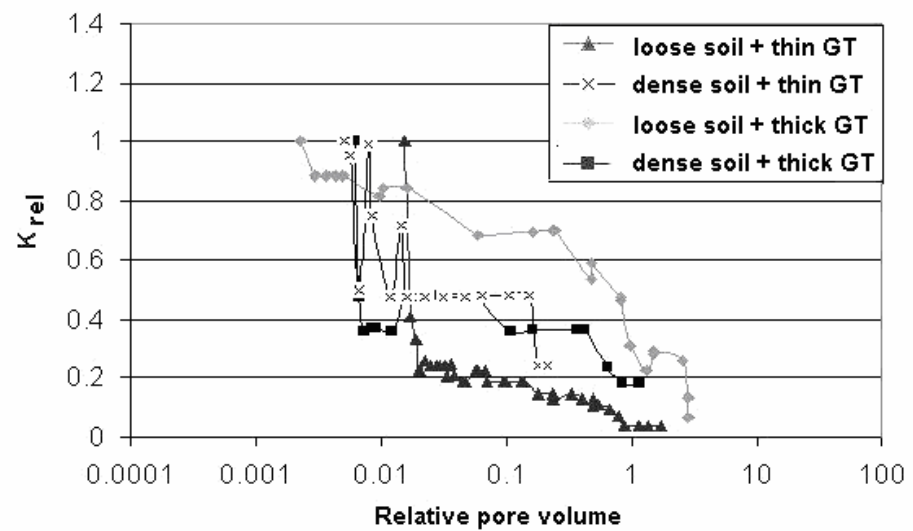

Figure 5.6 System Hydraulic Conductivity Variations of the Different Silt Content 


\subsubsection{Gradient Ratio and Geotextile Head Loss}

The filtration processes described in the previous section can be reexamined making use of the concepts of gradient ratio (GR) and geotextile head loss (GHL), the definitions of which are presented in Section 5.1. Figures 5.7 through 5.12 plot the data of GR and GHL versus relative pore volume obtained from the same tests described in the previous section.

The GR represents an indicator of the erodibility of the fines in the soil matrix: the higher the GR, the more significant the migration of the fine particles. The GHL is, instead, a measure of the clogging state of the GT openings: the greater the GHL, the greater the amount of fines that have been transported from the soil into the GT.

Ideally, if the preparation of the soil specimen did not cause any particle segregation, the GR and the GHL should have initial values of one and zero, respectively. As shown in Figure 5.7 through 5.10, the initial value of GR was generally found to be close to one for most specimens prepared with $10 \%$ and $20 \%$ silt. This was not the case for the $50 \%$ silt soil (Figures 5.11 and 5.12): for this soil the initial GR was found to be greater than one when a thick GT was employed, and smaller than one when a thin GT was used. These results suggest that during the specimen preparation stage fine particles at the soil base penetrated through the thin GT or accumulated on the surface of the thick GT (in this case the smaller opening size would have limited penetration of the fines). In the first case the initial GR would be expected to fall below one, while in the second case it would be greater than one. 
Figures 5.7 through 5.12 also show that for most of the systems examined the initial values of the GHL were close to zero. The exception is represented by the tests conducted on specimens with $10 \%$ silt (Figures 5.7 and 5.8). In these tests, while the initial GHL was observed to be consistently greater than zero, it quickly decreased during the early stage of the test to a value close to zero before increasing once again with continued permeation. It can be hypothesized that the initial GHL values greater than zero are caused by the formation of a thin layer of fines on the GT surface. As soon as flow is initiated, the layer breaks apart leaving the openings of the GT unblocked. The fact that this phenomenon is limited to the $10 \%$ silt specimens is most likely a result of the weak internal stability of this soil which promotes particle segregation near the GT.

As shown in Figure 5.7 through 5.12, for all tests conducted on the dense specimens the GR was found to remain basically constant during most part of the test, indicating that migration of the fines was suppressed. Fine particle migration appears instead to have occurred in the loosely deposited specimens, in particular those with $20 \%$ and $50 \%$ silt. For both these soil types, in particular when used in combination with the thick GT, a significant increase in GR, evidence of fine particle migration, is observed over the duration of the test.

The following paragraphs discuss the filter clogging behavior observed in each of the soil-GT specimens tested based on the GR and GHL profiles. 
Figure 5.7 compares the GR and GHL profiles for the 10\% silt, used in combination with the thick GT, both in the loose and dense states. The data indicate that the improved internal stability of the soil following densification leads to a significant improvement in the GT filter performance. For the loose specimen (Figure 5.7 (a)) a significant increase in GHL is observed throughout the test as a result of the accumulation of fines on the GT surface (the small opening size of the thick GT is expected to limit the penetration of fines). As a result, as summarized in Table 5.4, blinding occurs. For the dense specimen, instead, the GHL is observed to remain constant during the test (Figure 5.7 (b)). This is indeed one of the successful occurrences of bridging observed in the tests conducted (Table 5.4). What seems to be the controlling factor here is the increased stability of the soil fines as a result of densification.

Figure 5.8 reports a similar comparison to that shown in Figure 5.7, this time pertaining to the $10 \%$ silt specimens filtered by the thin GT. As summarized in Table 5.4, both the loose and dense specimens showed blinding results. The differences in the GR and GHL profiles presented in Figures 5.8(a) and 5.8(b) suggest, however, that blinding resulted from different causes.

In the case of the dense $10 \%$ silt specimen, no change in GR is observed until the very end of the test. This is evidence that densification produced a more stable soil structure, limiting the migration of fines. The GHL is instead found to increase. It is hypothesized that the increase in GHL is a result of blockage by the coarse particles (which due to the low fines content play a dominating role in this soil) of the GT openings (this effect is 
enhanced by the densification operation and is likely to be more significant in the case of the more deformable thin GT, which will tend to conform around the particles). Given the small amount of migrating fines, the growth of the GHL is observed to be slow. Note that ultimately, at the end of the test, the increase in GHL drives an increase also of the GR, i.e. as no penetration of fines is allowed through the GT, the fines start to "backup" in the base soil

In the case of the loose $10 \%$ silt soil specimen, there is a sharp increase in GR around 1 r.p.v., without any significant change in GHL (Figure 5.8 (a)). While the increase in GR is the reflection of the migration of fines through the base soil, it remains unclear why this does not translate also in an increase in the GHL. Differences in the filter performance depending on the soil density and the GT employed are observed also in the case of the $20 \%$ silt specimens.

As seen in the case of the $10 \%$ silt soil, the filter performs effectively (i.e. bridging occurs) when the $20 \%$ silt is compacted to a dense state and associated with the thick GT. As shown in Figure 5.9 (b), under these conditions both the GR and GHL remain fairly stable throughout the test. Also consistent with the observations reported for the $10 \%$ silt soil specimen (Figure 5.8(b)) are the GR and GHL trends for the dense 20\% silt soil filtered by the thin GT (Figure 5.10(b)): while the GR remains constant and essentially equal to one throughout the test, the GHL shows a clear growth. This is again thought to result from the fact that the large coarse particles block the access to the GT openings. 
While, as discussed above, the thick GT proved to perform effectively under the dense $20 \%$ silt soil (leading to bridging), the same is not true if the soil is in a looser state. This is shown by the results presented in Figure 5.9(a). In this case, as already seen for 10\% silt, a sharp increase in the GHL is observed from very early in the test (r.p.v. 0.1). As discussed above for Figure 5.7(a), this increase in GHL is attributed to the small opening size of the GT, and blinding can be considered driven by limited available openings. Note that, as already described above for another test, ultimately the increase in GHL drives an increase in the GR and results in blinding.

As shown in Figure 5.10(a), the loose 20\% silt exhibited instead a very different behavior when combined with a thin GT as no change in GR or GHL was measured until the very end of the test (and even then quite small). This is the last of three cases of bridging observed in this testing program.

Finally Figures 5.12 and 5.13 compare the results for the $50 \%$ silt specimens. The presence of such a high percentage of fines has a significant impact on the filter performance and leads to some differences with respect to the observations made for the $10 \%$ and $20 \%$ silt soils. As summarized in Table 5.4 with this soil neither of the GT performed effectively, independently of the compaction state (three cases of blinding and one of clogging). Note that bridging formation was not expected from the $50 \%$ silt soil since the tested GT products have larger openings (i.e. AOS $>0.15 \mathrm{~mm}$ ) compared to the fine size $(0.075 \mathrm{~mm})$. Under these conditions, internal GT clogging is considered to be 
the best filtration performance that can be expected, as the clogging process takes place throughout the base soil rather than being limited to the surface openings.

For $10 \%$ and $20 \%$ silt it was shown that bridging occurred when the soil was placed dense on top of the thick GT, i.e. the hydraulic performance of this GT was improved through densification of the soil above it. As shown in Figure 5.11(b) this is not the case for $50 \%$ silt (for high silt contents there is little difference in internal stability between loose and dense state). In this test, the GHL (which, as discussed above shows an initial value greater than zero due to accumulation of fines on the GT during the specimen setup phase) shows a very rapid growth which leads to blinding. This is likely a result of the greater percentage of fines available in the soil specimen.

Blinding was also observed in the other test conducted on the dense $50 \%$ silt specimen but with the thin GT (Figure 5.12(b)). While in this case the initial GHL value is equal to zero, there is a early (at 0.1 r.p.v.) and rapid increase in GHL, which also in this case leads to blinding. This result is consistent with the data obtained under similar conditions for 10\% (Figure 5.8(b)) and 20\% silt (Figure 5.10(b)). In both these cases it was hypothesized that the coarse particles blocked the surface openings leading to fine particle accumulation on the thin GT. Given the similarities in the GR and GHL trends, the same is expected to be true here, with the greater availability of fines being responsible for the more rapid GHL growth. 
The third case of blinding for 50\% silt is shown in Figure 5.12(a) which pertains to the soil tested loose with the thin GT. In this case the increase in GHL is delayed to r.p.v. of approximately one, but the subsequent growth is very rapid. Also significant is the fact that, unlike what was observed in all other cases of blinding, the GR starts to increase at the same time and also very rapidly. This suggests that a mechanism different from the one so far discussed (blockage of the GT openings by the coarse particles) is responsible for the blinding. Additional discussion on this test is presented in Section 5.5.1.

Finally the single example of clogging occurs in the case of the $50 \%$ silt soil tested under loose condition with the thick GT (Figure 5.11(b)). In this case the increase in GHL is delayed compared to what was observed above for the same soil with the thin GT. It is suggested that it is the smaller AOS of the thick GT ( $0.15 \mathrm{~mm}$ compared to 0.21 $\mathrm{mm}$ for the thin GT) which reduces the migration of fines. 


\section{( A ) loose state}

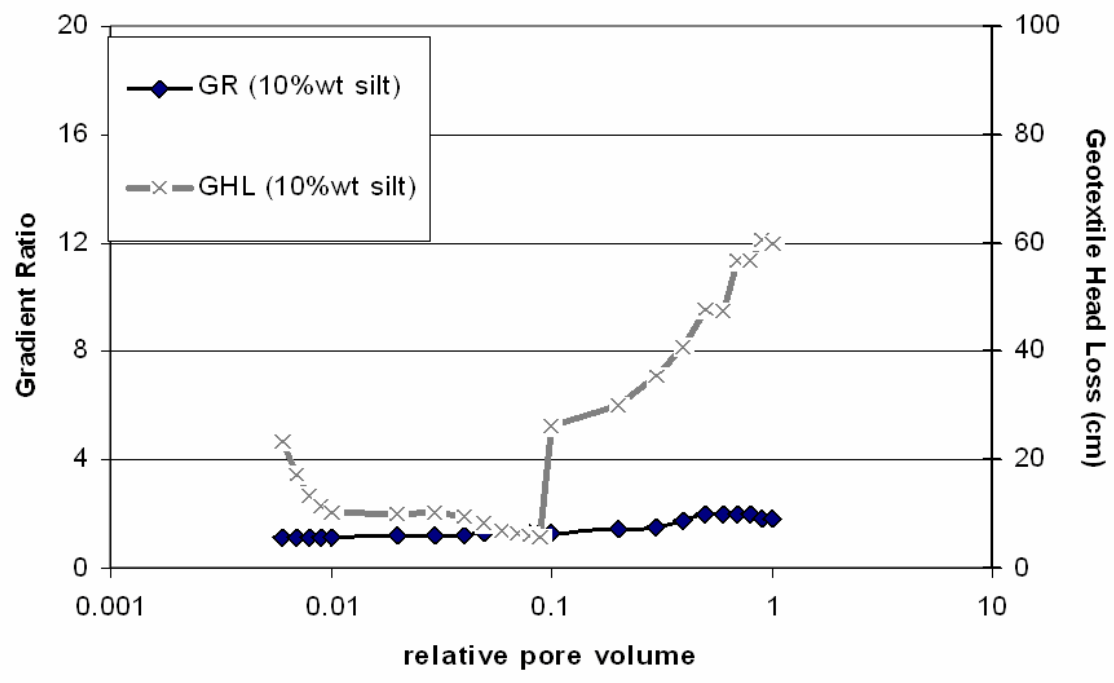

( B ) dense state

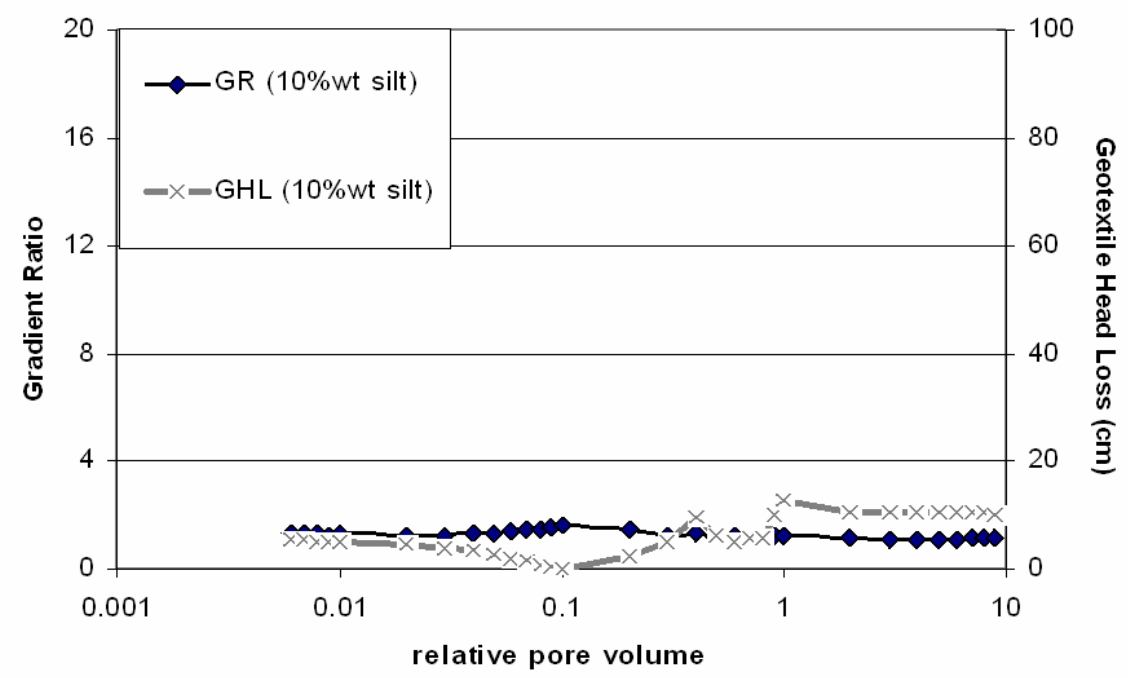

Figure 5.7 Gradient ratio and GT head loss responses for 10\% silt with thick geotextile (GSE1202) 


\section{( A ) loose state}

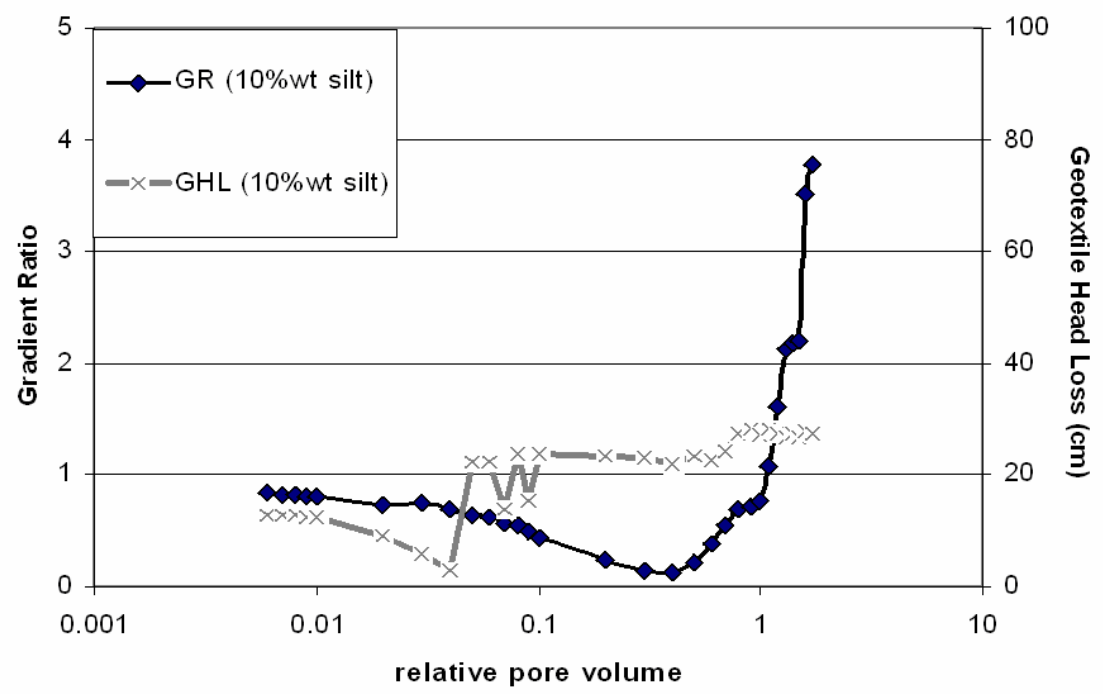

(B ) dense state

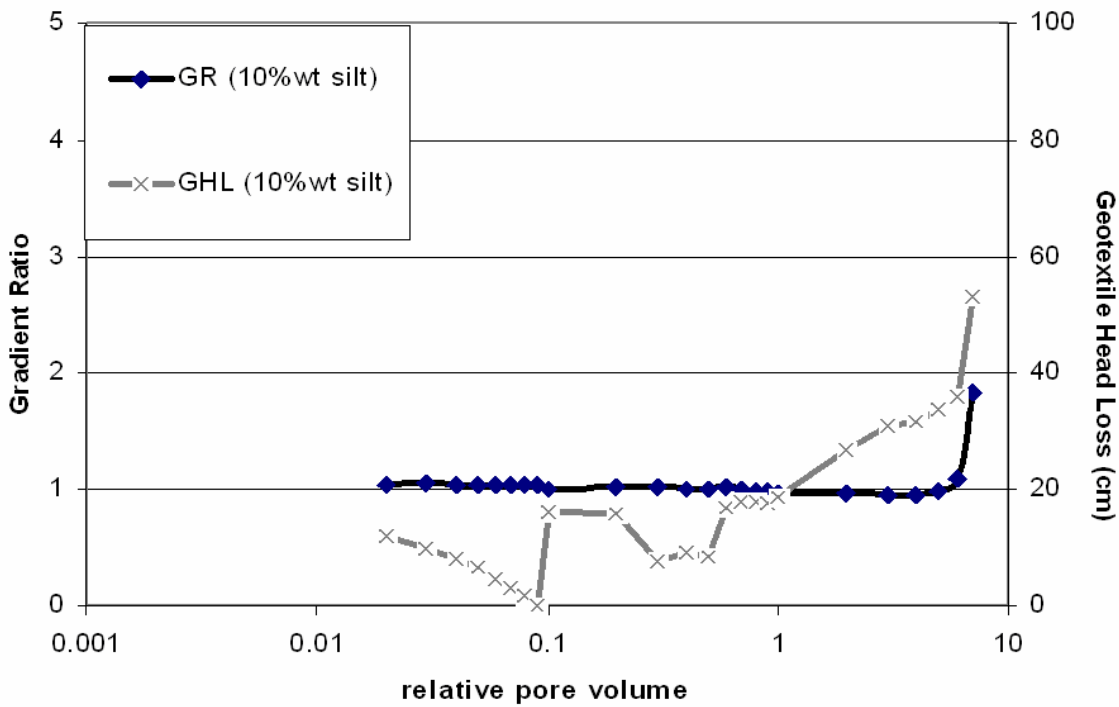

Figure 5.8 Gradient ratio and GT head loss responses for $10 \%$ silt with thin geotextile (GSE 402) 


\section{( A ) loose state}

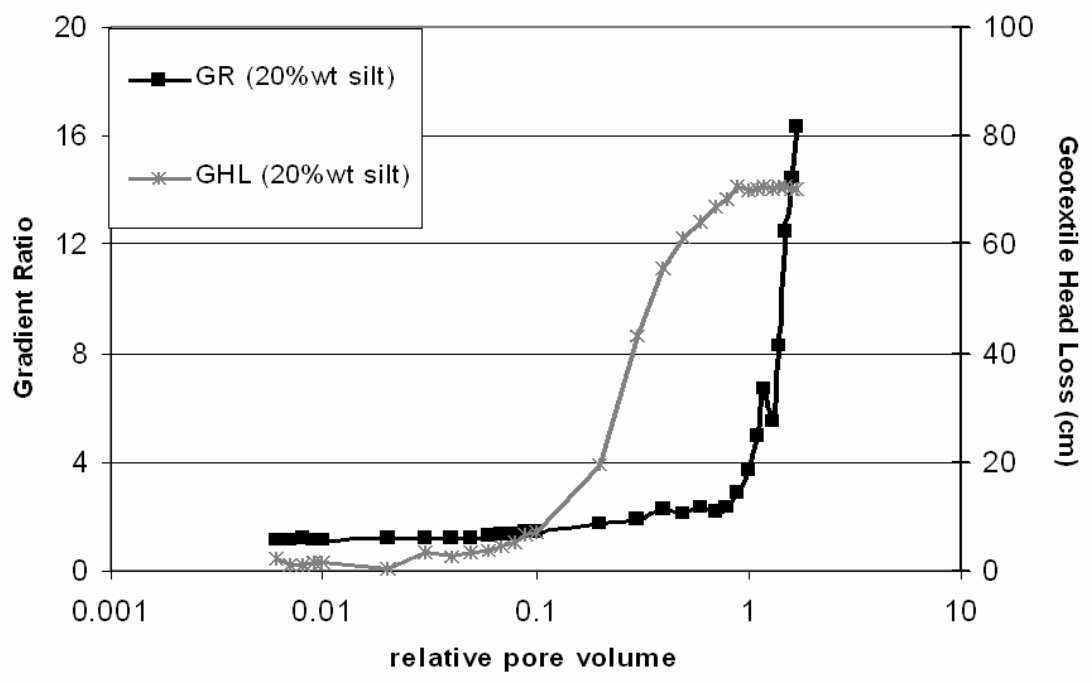

(B ) dense state

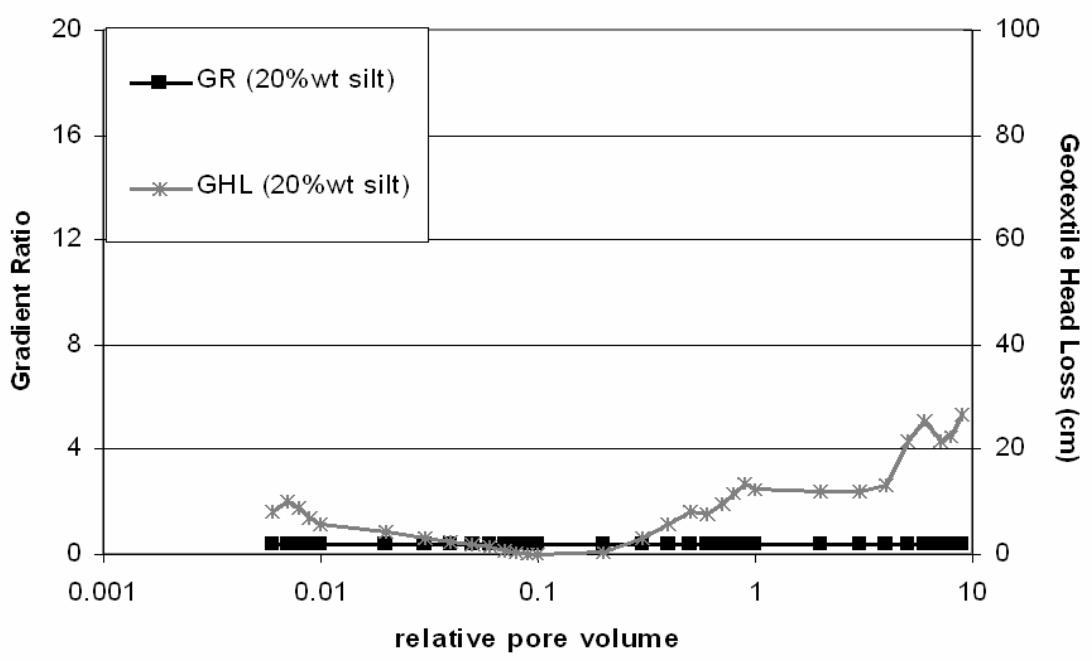

Figure 5.9 Gradient ratio and GT head loss responses for $20 \%$ silt with thick geotextile (GSE 1202) 


\section{(A) loose state}

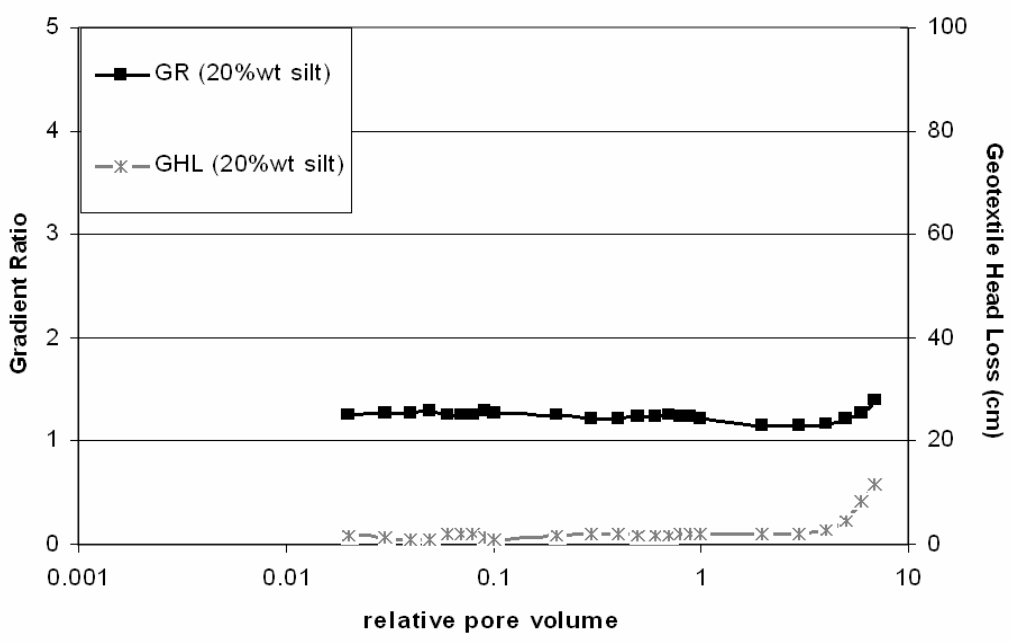

(B ) dense state

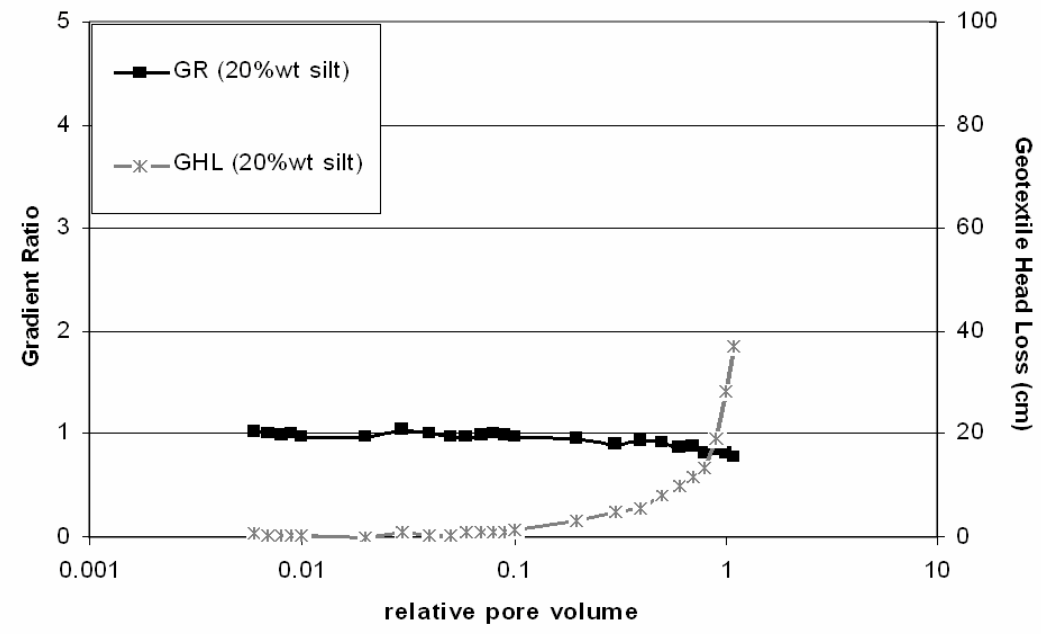

Figure 5.10 Gradient ratio and GT head loss responses for $20 \%$ silt with thin geotextile (GSE 402) 


\section{( A ) loose state}

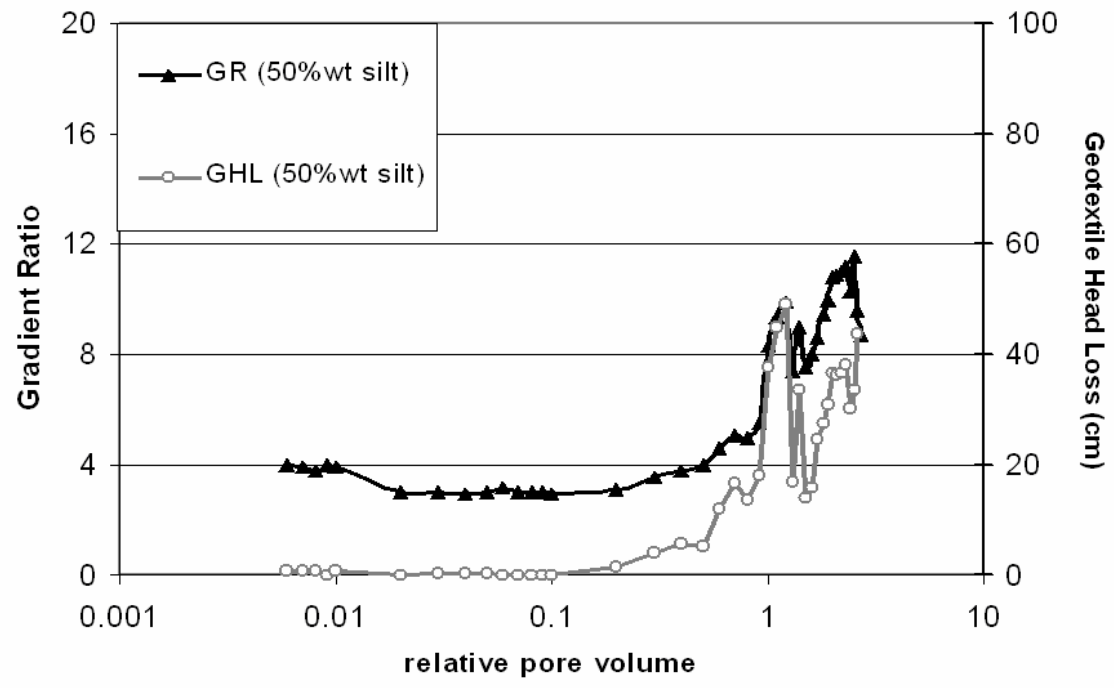

( B ) dense state

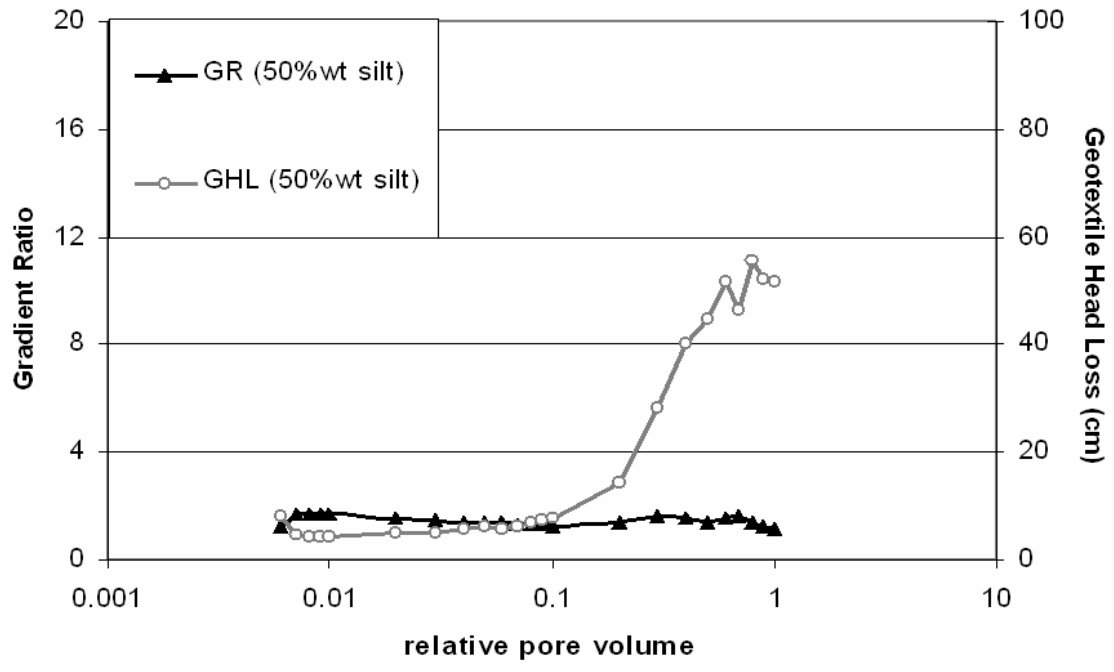

Figure 5.11 Gradient ratio and GT head loss responses for 50\%silt with thick geotextile (GSE 1202) 


\section{( A ) loose state}

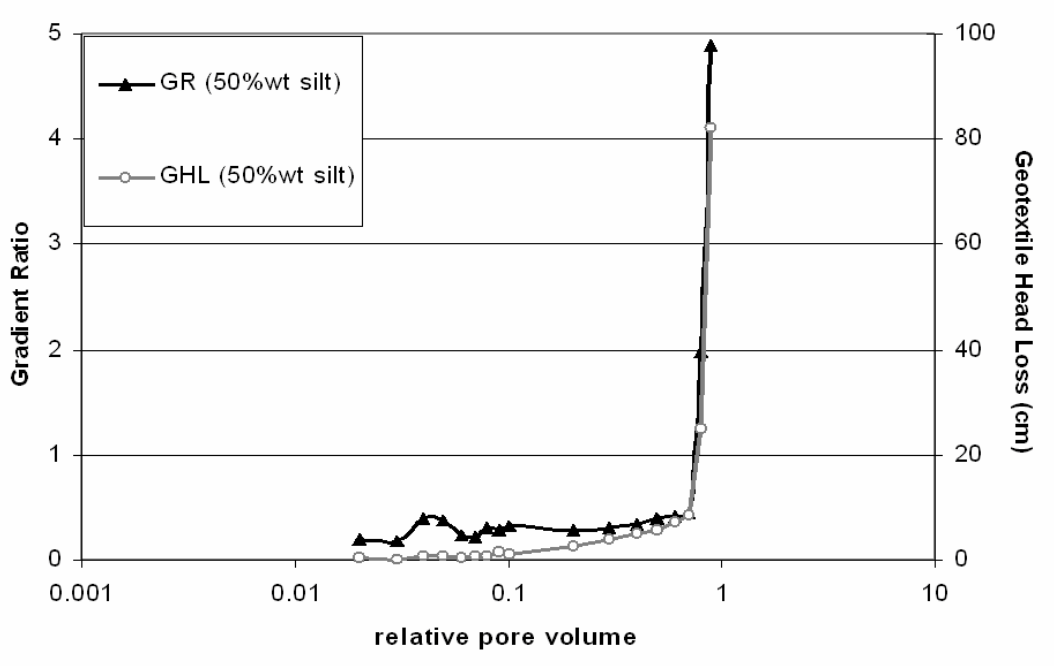

(B ) dense state

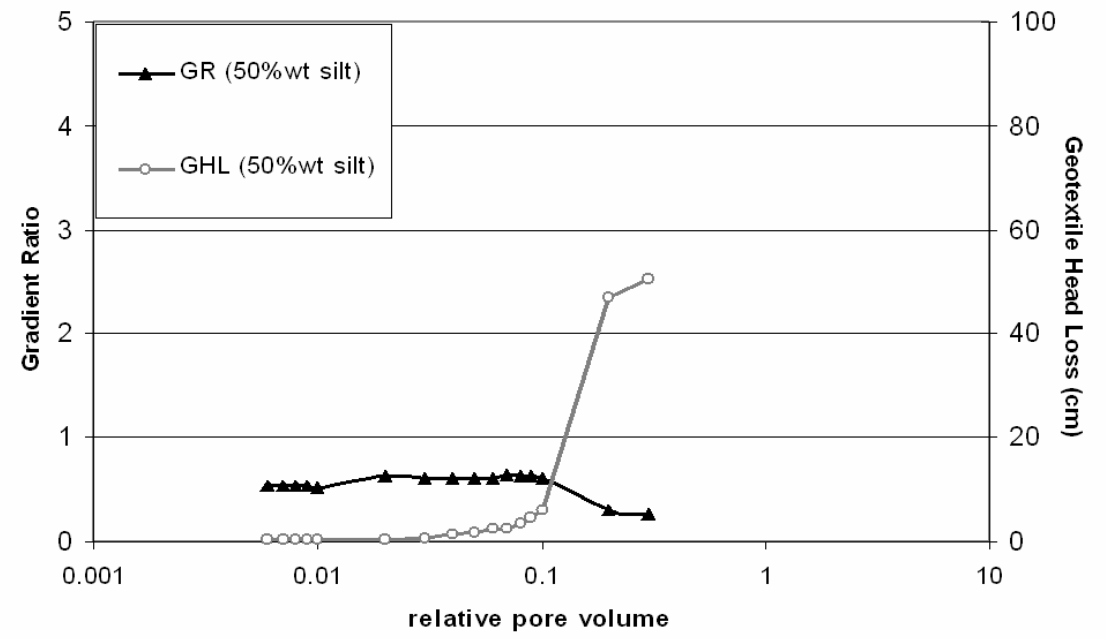

Figure 5.12 Gradient ratio and GT head loss responses for $50 \%$ silt with thin geotextile (GSE 402) 


\subsection{Discussion}

\subsubsection{Analysis of GR and GHL Profiles}

The objective of this section is to relate the GR and GHL profiles shown in Figures 5.7 through 5.12, to the filtration results presented in Table 5.4.

Successful filtration results (i.e. bridging) were observed for the dense $10 \%$ and $20 \%$ silt soils with the thick GT and for the loose $20 \%$ silt soil with the thin GT (see Table 5.4). For these tests (Figures 5.7 (b), 5.9 (b) and 5.10 (a)) the GR values remained clearly below 5, corresponding to values less than 3 using the GR definition contained in ASTM D 5101, and thus satisfying the clogging criterion specified in the standard. For these same tests the GHL showed only a marginal increase in the GHL, slightly more significant in the case of the dense $10 \%$ and $20 \%$ silt soils (Figure 5.7 (b) and 5.9 (b)). The curves shown in Figure 5.13 (a) summarize the GR and GHL trends associated with the occurrence of bridging.

Two different patterns in the GHL and GR variation were observed to ultimately lead to the occurrence of blinding.

In most of the cases (dense $10 \%$ and $20 \%$ silt soils with thin GT, loose $10 \%$ and $20 \%$ silt soils with thick GT., dense 50\% silts with thin and thick GT) a sharp initial growth of the GHL was observed ahead of a relatively retarded GR growth (Figure 5.13(b)). As discussed earlier, it is hypothesized that in these cases the coarse particles are blocking 
the GT openings, while the remaining gap openings are being filled up by the loose fines migrated from the base soil. Ultimately the fines "backup" in the base soil and drive an increase in the GR.

For the case of the loose 50\% silt soil combined with the thin GT (Figure 5.12(a)) the GR and GHL trends resemble those shown in Figure 5.13(c). The distinctive feature in this case is the sharp increase of both GR and GHL before the r.p.v reaches a value of one. The speculation is that in this case blinding is a result of the mass migration of fine particles through the base soil which end up "crowding" on top of the GT surface. Given the high percentage of fines present and the loose state of the soil, this process is initiated as soon as the test starts.

Internal clogging was observed for the loose $50 \%$ silt with the thick GT (see Table 5.4 and Figure 5.11(a)). In this test the growth of the GHL and GR was not only delayed (GHL and GR build-up did not initiate until the flow volume reached r.p.v. $=1$ ) but also showed slower growth compared to the blinding processes. Figure 5.13 (d) show the trends in GR and GHL associated with the occurrence of clogging.

The test conducted on the loose $10 \%$ silt soil with the thin GT does not fall in any of the categories shown in Figure 5.13, and the mechanism responsible for the increase in GR and the stationary value of GHL shown in Figure 5.8(a) remains unclear. 
(A)

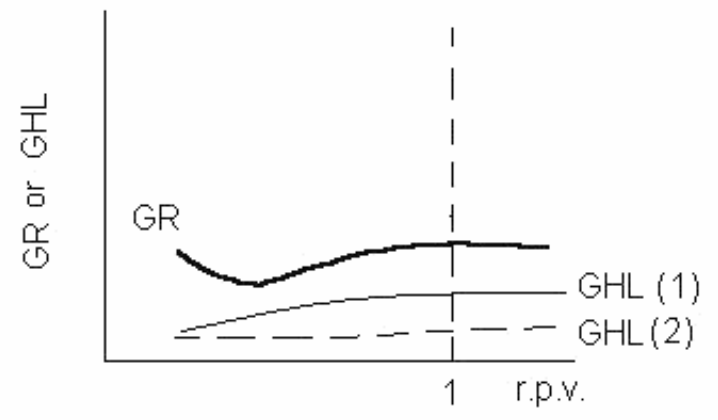

Bridging

for compacted soil (1)

for non compacted soil (2)

(C)

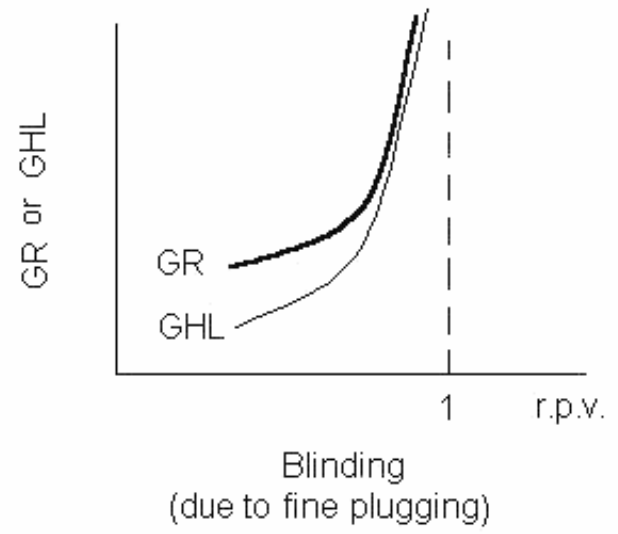

(B)

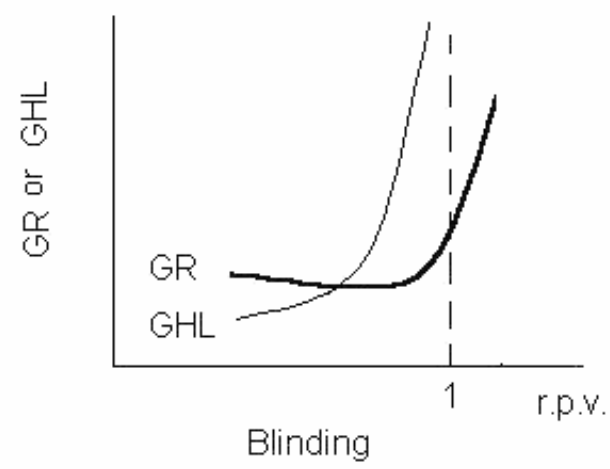

(due to coarse blocking)

(D)

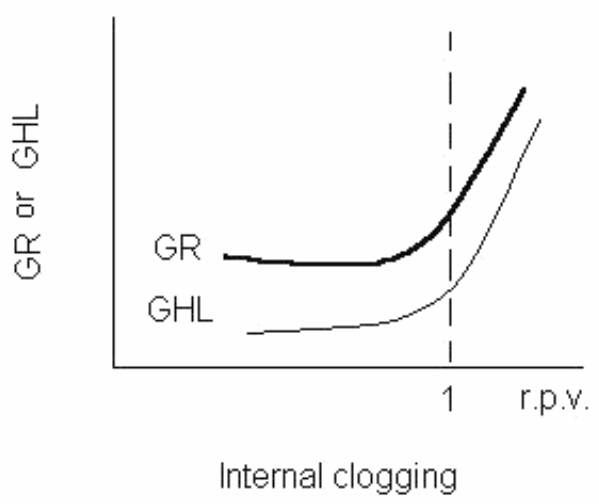

Figure 5.13 Summary of GR and GHL variations for each different clogging mechanism the filtration results are classified in Table 5.4)

\subsection{Summary}

Nonwoven geotextiles (GT) have been installed in underdrain systems at many construction sites as the filter material. During densification of the drainage layer, compaction energy applied to the drainage material (e.g. aggregate) can be delivered to 
the GT filter. Where geotextiles are employed as a separation layer under railroad ballast or a pavement base, the bad hydraulic performance of geotextiles causes subgrade deformations because the moisture desiccation of the subgrade soil occurs mainly through the upper pervious aggregate. More severe subgrade deformation is expected in high fine content soils, the hydraulic conductivity of which is relatively small. Therefore, hydraulic performance of the separation layer is important with regards to long term maintenance.

GT have been used as filtration and separation materials for several decades, but there has been no specific research to investigate the impact of compaction work on the hydraulic performance of the GT. Compaction usually improves the internal stability of soil, but can also generate some initial soil accumulation inside the GT openings, which promotes clogging of the GT. This adverse effect can be alleviated through proper selection of the GT properties (opening size and thickness) for the specific soil type.

The Flexible Wall Gradient Ratio (FWGR) test (Harney and Holtz, 2001) was employed to investigate the migration features of fines at the interface of soil and geotextile, associated with soil compaction and geotextile properties (AOS and thickness). Soil specimens $(10 \%, 20 \%$, and $50 \%$ silt $)$ were used to represent the different levels of internal stability (i.e. piping resistance) expected from site soils.

In the FWGR test, the profiles of gradient ratio (GR) and geotextile head loss (GHL) can be used to establish the effectiveness of the soil-GT systems employed as well as to 
explain the different clogging mechanisms, and in particular distinguish between surface opening blockage by coarse particles and internal GT clogging by fine particles.

The main conclusions drawn from the tests performed can be summarized as follows:

- The internally unstable soil (10\% silt), vulnerable to opening blockage by coarse particles, was filtered successfully by using a thick GT $(\mathrm{AOS}=0.15 \mathrm{~mm})$ after the soil was properly compacted.

- The gap graded soil (20\% silt) was successfully filtered by using a thin GT with large opening size $(\mathrm{AOS}=0.21 \mathrm{~mm})$ in non-compacted state, and by using a thick GT, characterized by a stiffer surface, in the compacted state.

- The high fine content soils (50\% silt), vulnerable to internal clogging, was successfully filtered using a thick GT provided that it was in a loosely deposited state.

- There are potential issues in the use of a thin, compressible GT such as the one employed in this study as a filter or separator material at construction sites where compaction is employed to improve the internal stability of subgrades.

- The process of internal GT clogging by fine particles is associated with a much longer filtration process compared to opening blockage by coarse particles. 


\section{Laboratory Investigation of Geotextile Filtration by Rapid Retention Test - Effect of Geotextile Property}

\subsection{Introduction}

The objective of this chapter is to present the results of rapid retention test (RRT) performed to investigate the effects of geotextile properties (opening size, fiber bonding type and thickness) on filtration of the soils with different silt and clay contents. Noncohesive and cohesive soils are separately prepared for soil specimens. Geotextile specimens are selected by fiber boding type and thickness which are related to the filter performance. In this part of the study, the rapid retention test (RRT) was employed as an efficient method to promptly estimate the compatibility of geotextile with a given soil. The forthcoming sections describe the principle of RRT (Section 6.2), preparation of soil specimens (Section 6.3), geotextile properties (Section 6.4), and the filtration experiment results (Section 6.5). In Section 6.5, analysis of the test results is organized according to the following observations: compatibility of the different types of geotextiles with noncohesive soils (6.5.1), effectiveness of geotextiles over a range of applied hydraulic gradients (6.5.2), sensitivity of the tested geotextiles to soil compaction (6.5.3), influence

of geotextile thickness on the filtration of soils with high content in fine particles (6.5.4), and the performance of double layer filters with cohesive soils (6.5.5). 


\subsection{Description of RRT}

Common fitration testing methods such as the Gradient Ratio (GR) test (ASTM D5101) and Hydraulic Conductivity Ratio (HCR) test (ASTM D 5567) require the soil specimen height to be greater than its diameter in order to prevent preferential flow paths. This typically results in tests of long duration (e.g. 100-1000 hours) because, with such volume of soil specimen, observed variables (i.e. gradient ratio in GR test and hydraulic conductivity ratio in HCR test) are slow to reach stable values. In order to accelerate the tests, the flow rate needs to be increased by raising the hydraulic gradient through the soil/geotextile system or by using a shorter specimen. Observations during FWGR tests suggest most of the particle migration and clogging mechanisms involve only a thin interface zone of thickness lesser than $1 \mathrm{~cm}$, especially when non-woven geotextile (GT) filters are used. This means filtration tests could be performed much faster by using short soil specimens if these can be prepared with high degree of homogeneity so that preferential flow paths do not occur.

The Rapid Retention Test (RRT) was proposed by Siva and Bhatia (1994) as a timeeffective method of testing GT filter compatibility with soil. It relies on the application of high hydraulic gradients through short specimens of soil. The test consists in placing the soil specimen, $10 \mathrm{~mm}$ in thickness and $100 \mathrm{~mm}$ in diameter on top of a geotextile disk in a rigid wall or a flexible wall permeameter. After specimen saturation and consolidation had been achieved in the cell, downward flow is induced under a fairly high gradient (e.g., $\mathrm{i}=10$ to $\mathrm{i}=40$ ) with the direction of seepage going from the soil to the geotextile, and the overall hydraulic conductivity of the composite system (soil and geotextile) is 
determined. The test is kept running in order to monitor changes in hydraulic conductivity due to soil particle migration. Significant decrease of soil/geotextile system permeability during the test is indication that filter clogging has occurred. A schematic of the rigid wall permeameter used in the present study for performing RRT is shown in Figure 6.1.

The earlier utilizations of the RRT by Siva and Bhatia (1994) was with soil slurries, in connection with hydraulic fill problems, cracks in earth dam clay cores, and edge drain systems that are in poor contact with surrounding soils. In order to meet slurry condition for the tested specimens, these earlier investigators had to maintain the soil particles continuously suspended in a turbulent flow. However, in the present study laminar flow is considered better representative of hydraulic conditions prevailing in highway subdrainage systems. Thus we need at first to examine flow rate applied in the present testing program in order to verify the high gradients are compatible with laminar flow and Darcy's law is still applicable. Using the equation from Rose (1945), Reynold's number expressed in Equation 6.1 must be smaller than 1 in order for the flow to remain laminar.

$$
\begin{aligned}
& \operatorname{Re}=\frac{\mathrm{v} \cdot D_{5}}{n \cdot v}<1 \\
& \mathrm{v}: \text { discharge velocity } \\
& \mathrm{D}_{5}: \text { diameter of } 5 \% \text { particle size } \\
& \mathrm{n}: \text { porosity } \\
& \mathrm{v}: \text { fluid kinematic viscosity }
\end{aligned}
$$

Application of the above criterion to the present study RRT and material conditions ( $v=1 . \mathrm{E}-5 \mathrm{~m} / \mathrm{sec}$ for silty sand, $\mathrm{D}_{5}=1$.E- 5 to 1 .E- $4 \mathrm{~m}$ for silty sand, $\mathrm{n}=0.2$ to $0.5, v=$ 
$1.12 \mathrm{E}-6 \mathrm{~m}^{2} / \mathrm{sec}$ ) indicates the gradient of 40 used in the present study is acceptable. This value of $\mathrm{i}=40$ was used in all the RRT presented in this chapter, except those discussed in Section 6.5.2 where results obtained using $\mathrm{i}=40$ and $\mathrm{i}=10$ are compared.

Another preliminary consideration is on the selection of soil specimen thickness and how it affects contrasts between systems with different soil initial properties. In the FWGR tests presented in Chapter 5 , the system hydraulic conductivity $\left(\mathrm{K}_{\mathrm{sys}}\right)$ is mainly governed by the soil specimen hydraulic conductivity because the soil thickness is over 100 times greater than that of the GT and the soil is less permeable than the GT. For instance, in the FWGR test results shown in Figure 5.5 (a), the initial system $\mathrm{K}_{\text {sys }}$ with $10 \%$ wt silt is 10 times greater than with $50 \%$ wt silt. With the most permeable specimen, decrease in system conductivity is clearly observed during the test, but with the less permeable soil the trend is not so clear in comparison (unless parameters are normalized, Figure 5.5 (b)) because when the initial $\mathrm{K}$ is already small and the clogging process is slow, $\mathrm{K}_{\mathrm{sys}}$ decreases slowly too. In contrast, when the soil specimen thickness is reduced to $1 \mathrm{~cm}$ for the series of RRT performed herein, the influence of GT clogging on the variation of $\mathrm{K}_{\mathrm{sys}}$ is emphasized. In Figure 6.2, such an example is shown. Here, the $\mathrm{K}_{\text {sys }}$ profiles are clearly differentiated for the soils with different silt contents (i.e. $20 \% \mathrm{wt}$ silt, $50 \% \mathrm{wt}$ silt and $100 \%$ wt silt). With the RRT, quick comparison can be made even without parameter normalization. 


\subsection{Soil Specimen Preparation}

Soils used to performed the Rapid Retention Tests (RRT) in this part of the study include dune sand, silt (at different content mixed with sand), sandy silt, and clayey silt. The main particle size fractions are summarized in Table 6.1 and the particle size distributions of the silt specimens are shown in Figure 6.3. For these silt specimens, silt contents of $20 \% \mathrm{wt}, 50 \% \mathrm{wt}$ and $100 \% \mathrm{wt}$ were chosen to generate gap graded soil, well graded soil and pure fine soil, respectively. The test specimens were reconstituted using the same silt and fine sand than those previously used for the FWGR test series described in Chapter 5. The largest of the silt particles $\left(\mathrm{D}_{90}=0.08 \mathrm{~mm}\right)$ were smaller than the AOS of the GT specimens $\left(\mathrm{O}_{\mathrm{f}}=0.15 \sim 0.21 \mathrm{~mm}\right)$ whereas the fine sand particles $(0.25$ to 0.43 $\mathrm{mm}$ in diameter) mixed with would be retained above the GT during filtration. The retained sand particles were also expected to block the GT openings to a degree varying with GT surface conditions (i.e. hard or flexible, depending on the GT type).

Experience shows that laboratory soil preparation in wet condition produces better regularity in sample quality and better reproducibility in test results than other preparation methods (Bhatia et al, 1990, Siva and Bhatia, 1994). For loose condition, the specimens were prepared in slurry state with $50 \%$ water content. For dense condition, the $20 \% \mathrm{wt}, 50 \% \mathrm{wt}$ and $100 \% \mathrm{wt}$ silts specimens were trampled 25 times using a wood pestle at successively $10 \%, 15 \%$ and $30 \%$ water contents. Clayey soil specimens were prepared in the same way with addition of commercially available kaolinite in proportions as indicated in Table 6.1 
For mounting of the specimens, an acrylic ring (10 cm in diameter; $2.5 \mathrm{~cm}$ in height) was pre-installed on of the GT specimen supported by the metal screen above the fine collector (Figure 6.1). After the soil specimen was successfully seated, the head cap was placed on the acrylic ring and all the cell components were sealed together within a latex membrane and installed in a confining chamber. After all the effluent valves were closed, the test cell was subjected to a back pressure of $140 \mathrm{kPa}$ through the influent ports.

Pressure increment of $35 \mathrm{kPa}$ were applied at intervals of 30 minutes in order to minimize soil particle migration during back-pressuring. A confining pressure corresponding to 70 $\mathrm{kPa}$ in effective stress was found to be adequate for preventing leakage along the vertical boundary between the acrylic ring and the specimens.

Table 6.1 Compositions of soil specimens used in RRT

$\begin{array}{ccccc}\text { Soil type } & \begin{array}{c}\text { Sand } \\ (0.25-0.43 \mathrm{~mm})\end{array} & \begin{array}{c}\text { Silt } \\ (\text { manufacture })\end{array} & \begin{array}{c}\text { Clay } \\ \text { (kaolinite) }\end{array} & \begin{array}{c}\text { Specimen state } \\ \text { Dune sand }\end{array} \\ \begin{array}{c}100 \% \\ (\text { from dune) }\end{array} & & & \text { Loose } \\ 20 \% \text { silt } & 80 \% & 20 \% & & \text { Loose/Dense } \\ 50 \% \text { silt } & 50 \% & 50 \% & & \text { Loose/Dense } \\ 100 \% \text { silt } & & 100 \% & & \text { Loose } / \text { Dense } \\ \text { Sandy silt (10\% clay) } & 40 \% & 50 \% & 10 \% & \text { Dense } \\ \text { Sandy silt (20\% clay) } & 30 \% & 50 \% & 20 \% & \text { Dense } \\ \text { Clayey silt (10\% clay) } & & 90 \% & 10 \% & \text { Dense } \\ \text { Clayey silt (20\% clay) } & & 80 \% & 20 \% & \text { Dense }\end{array}$




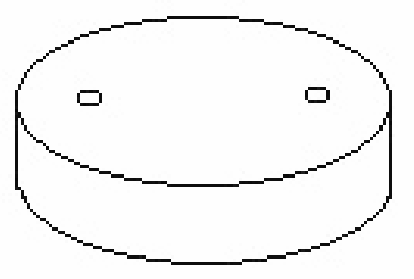

\title{
head cap
}

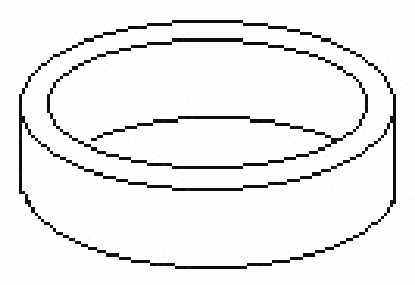

\author{
shield \\ ring
}

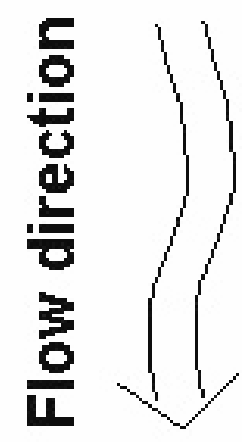

$$
\begin{aligned}
& 000010=0 \\
& 0000000 \\
& 0000000
\end{aligned}
$$

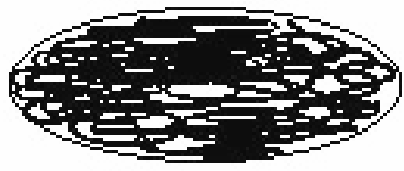

candidate geotextile

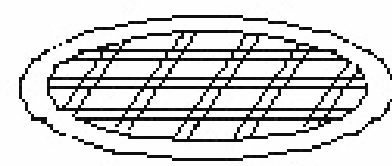

wire sieve

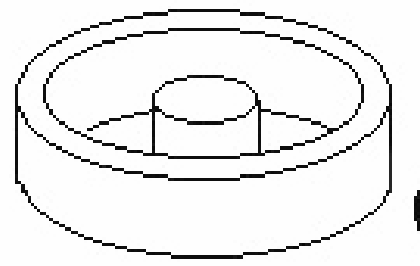

pedestal (fine collector)

Figure 6.1 Schematic of RRT cell components 


\subsection{Geotextiles Selected for Testing}

Eight different geotextiles, all belonging to the non-woven category, were selected for performing the Rapid Retention Tests (RRT). This selection spans a wide range of properties such as thickness, density, AOS, hydraulic conductivity and fiber bonding type that are relevant to filtration behavior. These characteristics are summarized in Table 6.2. Three different manufacturing processes and resulting fiber bond types are represented in this selection of GT specimens: the heat bonded non-woven, needle punched non-woven and heat set non-woven types.

Heat bonding geotextile (HB) produces a firm GT surface, not easily deformed or indented by coarse soil particle. The typical porosity range of $\mathrm{HB}$ is relatively low, between 0.5 and 0.6 , because as part of the manufacturing process the fabric is precompressed normally to its plane during by thermal calendering. Thus the hydraulic conductivity of $\mathrm{HB}$ is about 10 times smaller than that of other non-woven GT due to the reduced porosity (Table 6.1). In addition, the thermal treatment reduces surface wettability as illustrated in Figure 6.4. In consequence the minimum hydraulic head necessary for initiating flow through $\mathrm{HB}$ is about 10 times larger than for needle punched geotextiles.

Needle punched geotextiles (NP) are obtained by mechanically interweaving their fibers using high frequency alternated needle movement normal to the fabric plane. The resulting GT surface can be deformed or indented easily by coarse particles. 
Heat set non-woven geotextiles (HS) have attributes of both HB and NP. The fabric is initially needle punched and then thermal treatment is applied to only one side of the GT. This thermal treatment improves the fabric tensile strength without reducing significantly the hydraulic conductivity.

The thickness of the GT specimens ranges from $0.2 \mathrm{~mm}$ (BBA3201) to $4.2 \mathrm{~mm}$ (CM160). The NP and HS were further separated by thickness $\left(t_{G}\right)$ ranges that are, thin GT $\left(\mathrm{t}_{\mathrm{G}}<1 \mathrm{~mm}\right)$, medium thickness $\mathrm{GT}\left(1<\mathrm{t}_{\mathrm{G}}<3 \mathrm{~mm}\right)$ and thick $\mathrm{GT}\left(\mathrm{t}_{\mathrm{G}}>3 \mathrm{~mm}\right)$. Note that both HB specimens in Table 6.2 are thin. In general, the thickness and AOS are inversely proportional (e.g. $A O S=0.21 \mathrm{~mm}$ for $\mathrm{t}_{\mathrm{G}}=1 \mathrm{~mm}, \mathrm{AOS}=0.15 \mathrm{~mm}$ for $\mathrm{t}_{\mathrm{G}}=4 \mathrm{~mm}$ ) for $\mathrm{HS}$ and NP specimens. Thick GT have smaller AOS than thin GT because they have a higher fiber density per fabric area. 
Table 6.2 Specifications of geotextile specimens used in RRT

\begin{tabular}{ccccccc}
\hline $\begin{array}{c}\text { Property } \\
\text { weight } \\
\left(\mathrm{g} / \mathrm{m}^{2}\right)\end{array}$ & $\begin{array}{c}\text { thickness } \\
(\mathrm{mm})\end{array}$ & $\begin{array}{c}\text { density } \\
\left(\mathrm{kg} / \mathrm{m}^{3}\right)\end{array}$ & $\begin{array}{c}\left.\mathrm{AOS}^{2}\right) \\
(\mathrm{mm})\end{array}$ & $\begin{array}{c}\mathrm{K}_{\mathrm{GT}} \\
(\mathrm{cm} / \mathrm{sec})\end{array}$ & $\begin{array}{c}\text { fiber } \\
\text { bonding } \\
\text { type }^{3)}\end{array}$ \\
\hline B3201 & 71 & 0.2 & 355 & 0.59 & 0.02 & $\mathrm{HB}$ \\
B3501 & 180 & 0.5 & 400 & 0.2 & 0.02 & $\mathrm{HB}$ \\
C-M60 & 203 & 1.8 & 113 & 0.21 & 0.24 & $\mathrm{HS}$ \\
G1202 & 405 & 3.2 & 127 & 0.15 & 0.29 & $\mathrm{NP}$ \\
L125 & 130 & 1.3 & 100 & 0.21 & 0.2 & $\mathrm{NP}$ \\
L140 & 157 & 1.5 & 105 & 0.21 & 0.2 & $\mathrm{NP}$ \\
L250 & 364 & 2.5 & 146 & 0.15 & 0.25 & $\mathrm{NP}$ \\
L350 & 543 & 3.8 & 143 & 0.15 & 0.25 & $\mathrm{NP}$
\end{tabular}

1) Specific density $=$ mass / area / thickness

2) Apparent opening size

3) HB : heat bonded; HS : heat set; NP : needle punched 
(A) Thin heat bonded geotextile

(B3501)

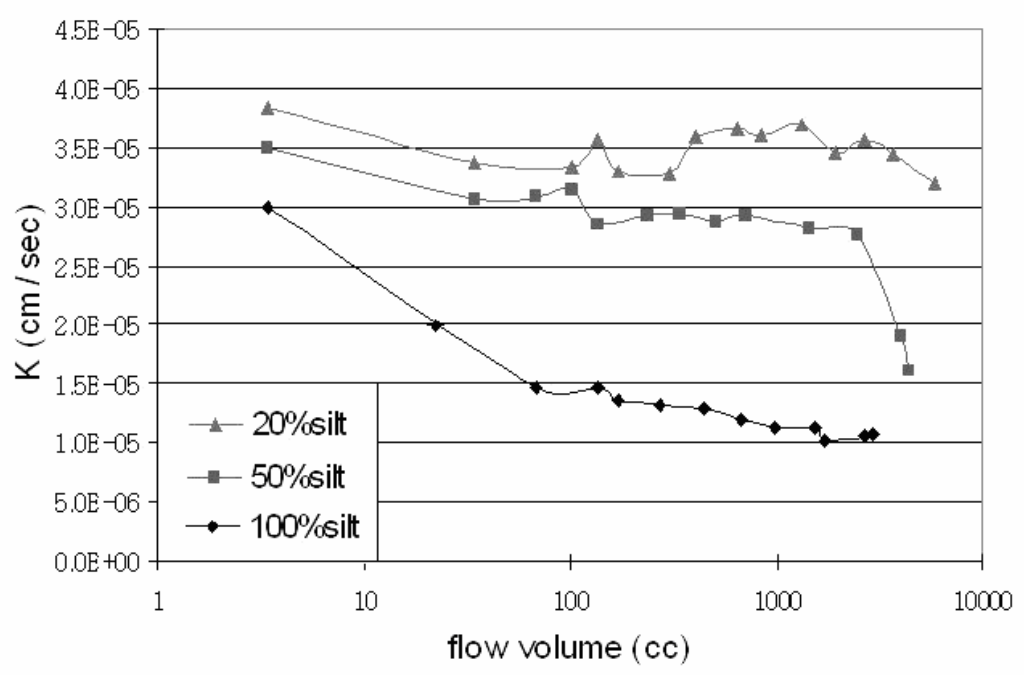

(B) Thick needle punched geotextile

(G1202)

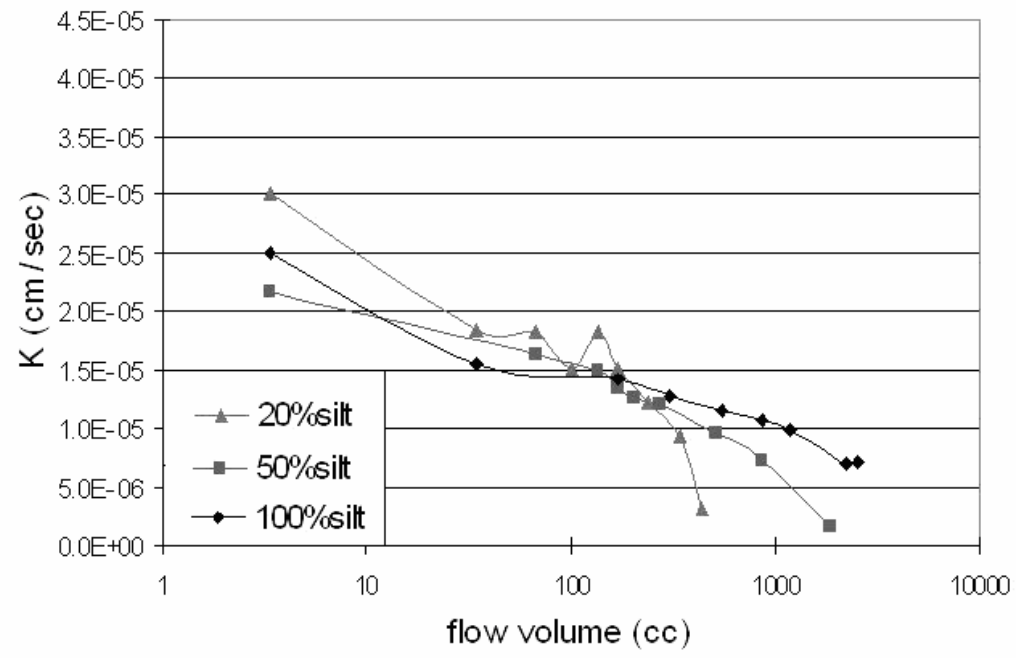

Figure 6.2 Example of system hydraulic conductivity variations during RRT for loose soils with different silt contents under gradient, $i=40$ 


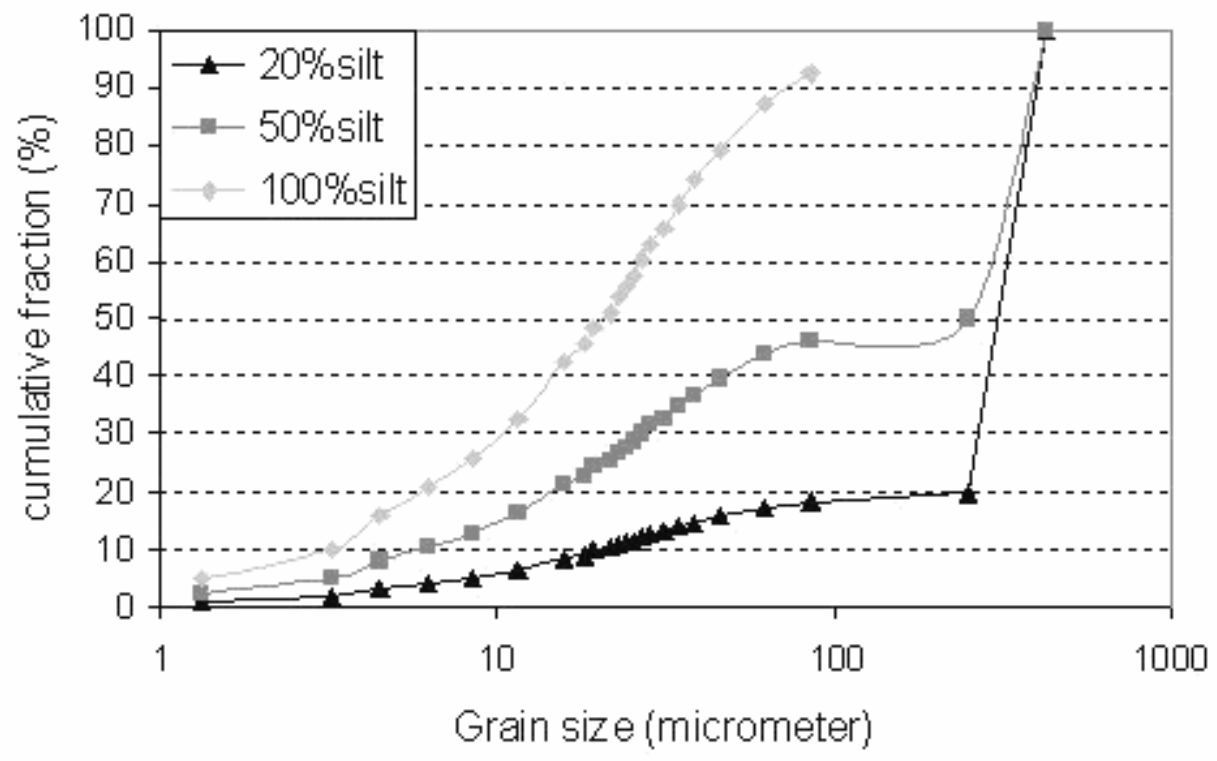

Figure 6.3 Grain size distributions of soil specimens 
(A)

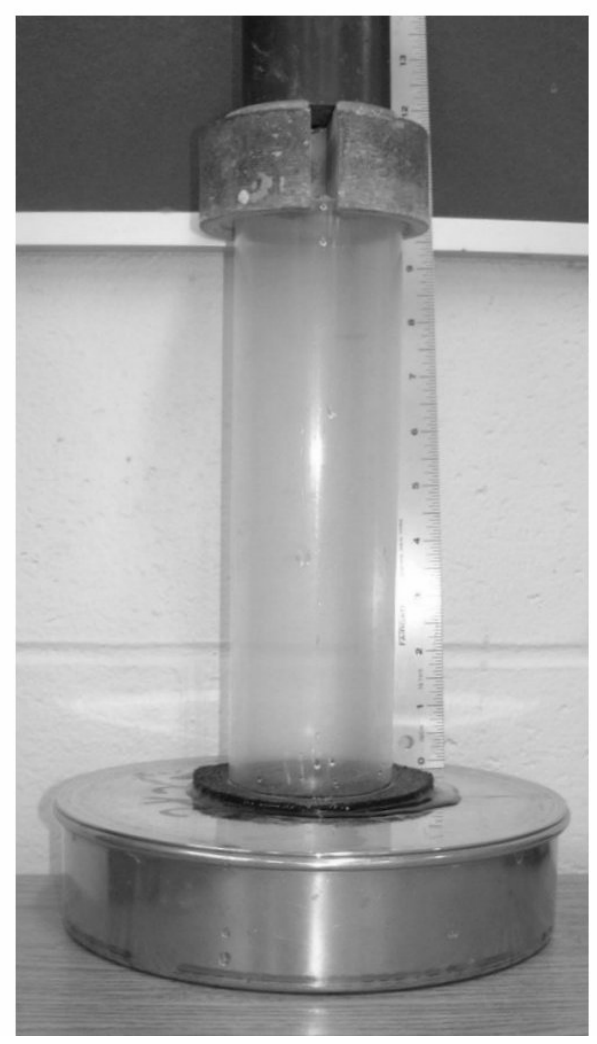

(B)

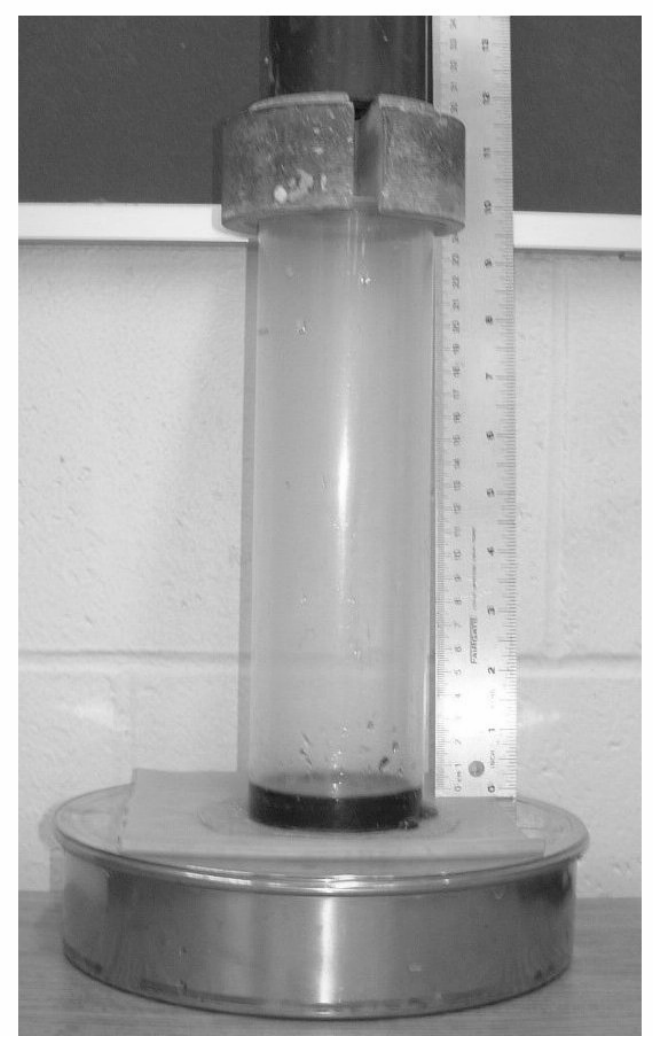

Figure 6.4 Illustration of difference in wettability between needle punched (A) and heat bonded (B) geotextiles. A water column of $1 \mathrm{~cm}$ stands above the heat bonded GT while none remains above the needle punched specimen. 


\subsection{Testing Results}

The program performed using the RRT method is summarized in Table 6.3 where tested combinations of soils and geotextile types are indicated. For each test, Table 6.3 refers to the text section in which it is discussed. All the tests were conducted under a hydraulic gradient of 40 except for the tests discussed in Section 6.5.2 where gradients of 10 and 40 were used for comparison. Observed trends in these results are presented herein.

\subsubsection{Compatibility of Tested Geotextiles and Soils}

It has been shown (Watson and John, 1999) that the uniformly sized beads used as filter test material have the ability to bridging or arching above a hole of diameter up to 4.21 times their size. If this also true for real soils, uniformly graded soils $(\mathrm{Cu}<3)$ can be successfully filtered by GT with AOS greater than their maximum grain size. This was verified with $\mathrm{RRT}$ on uniformly graded Indiana dune sand $\left(\mathrm{Cu}=1.3, \mathrm{D}_{90}=0.3 \mathrm{~mm}\right)$ used in the present study in association with GT of different fiber bonding types (BBA3201, 3501, C-M60 and Linq125). Of these geotextiles, one (BBA3201) has a AOS of 0.59mm which is approximately twice larger than the sand $\mathrm{D}_{90}$ while the other three GT have AOS smaller than $\mathrm{D}_{90}$. No piping of sand grains through the GT specimens was observed and, as shown in Figure 6.5, good filter performance (i.e. only a small reduction in system hydraulic conductivity) was obtained with the HB having the largest AOS $(0.59 \mathrm{~mm})$ as well as with two other GT having AOS smaller than the grain size. Among the GT tested, the largest reduction in hydraulic conductivity is observed for an AOS 
smaller than the grain size. We see here that a uniformly graded soil can be successfully filtered by a GT with AOS twice the size of its coarse particles.

The other types of soil (gap graded, well graded and pure fines) were also tested in association with the GT of different fiber bonding types (B3501 as a HB; L125 and G1202 as NP; and C-M60 as HS). The results are presented in Figures 6.6(a,b,c). As seen in Figure 6.6(a), gap graded soils (20\%wt silt) exhibited the best filtration performance with HB (B3501) or HS (C-M60) and the worst performance with thick NP (G1202). But the thin NP (L125) was also inadequate with this type of soil. The pure fine soil (100\%wt silt) was best filtered by a thin NP (L125) though an abrupt loss of permeability is observed at the end of the curve following a long period of sustained values, as is shown in Figure 6.6(c). With this soil, the worst performance is observed when it is associated with HS (C-M60) while HB (B3501) and thick NP (G1202) show practically the same loss of more than $60 \%$ in system permeability. For the well graded soil in Figure 6.6(b), (50\%wt silt), the best performance was obtained using HS (C-M60) relatively poor results were obtained using $\mathrm{HB}$ and NP.

Different compressive stiffness between HB and NP is perhaps a reason for their different filtration performances with gap-graded soil (20\%wt silt) and pure fines (100\%wt silt). The mechanism is illustrated with the schematic plots in Figure 6.7 where HB is characterized by the firm GT surface that is not easily deformed by coarse particle indentation, while having a relatively small porosity (i.e. $n=50$ to $60 \%$ ). In contrast thin NP is easily indented by coarse particle contacts, while having a relatively large porosity 
(i.e. $\mathrm{n} \geq 80 \%$ ). A filter for gap-graded soil should allow passing of fines after coarse particles have partially blocked openings. A rigid surface HB is able to satisfy this need because it can resist closing of its channels under coarse particle compressive contact

pressure. A thin NP would be considered acceptable for filtering pure fines $(100 \% \mathrm{wt}$ silt) since its many openings can prevent fines to accumulate when the flow initiates. The small filter opening size (i.e. $\mathrm{AOS}=0.15 \mathrm{~mm})$ of thick $\mathrm{NP}(\mathrm{G} 1202)$ is believed responsible for the poor filter performance with loose $20 \%$ wt silt soil. With this type of GT, similarly rapid clogging induced by coarse particle blockage was also observed with gap graded soil (20\%wt silt) during FWGR testing.

\subsubsection{Effect of Hydraulic Gradient Magnitude on RRT Outcomes}

In filtration tests of soils with high silt contents (50\%wt to $100 \% \mathrm{wt}$ silt), if clogging occurs it typically takes a longer time to develop than with smaller silt fraction soils (e.g. 20\%wt silt). During a FWGR test reported in Chapter 5 clogging of the GT by soil with $50 \%$ wt silt took over a week whereas the same GT clogging by soil with $10 \%$ wt silt, under the same gradient $i=5$, was took only a day. In RRT the process is accelerated by using a gradient as high as 40 , still compatible with laminar condition and the application of Darcy's law as discussed in Section 6.2. However, the impact of gradients of such magnitude on the RRT geotextile overall response is unclear. In order to assess this effect, a limited number of RRT were performed under a gradient of $\mathrm{i}=10$ and changes in system hydraulic conductivity $\mathrm{K}_{\text {sys }}$ were compared to those observed under $\mathrm{i}=40$. It is noted that a gradient of 10 is still at least twice greater than field gradients predicted by 
numerical models of seepage toward roadway edge drains (see Chapter 4). For the tests performed under each gradient level, dense soil specimens prepared with $50 \% \mathrm{wt}$ silt and $100 \%$ wt silt were combined with NP geotextiles of three different in thicknesses, Linq125 (1.5mm), Linq250 (2.5mm) and Linq350 $(3.8 \mathrm{~mm})$. Results are presented in Figures $6.8_{(\mathrm{a}, \mathrm{b}, \mathrm{c})}$ for the soil with $50 \% \mathrm{wt}$ silt and Figures $6.9(\mathrm{a}, \mathrm{b}, \mathrm{c})$ for the soil with 100\%wt silt.

A first observation is that the general shapes of the curves in Figures 6.8(a,b,c) obtained with 50\%wt silt are different from those in Figures $6.9(\mathrm{a}, \mathrm{b}, \mathrm{c})$ obtained with $100 \%$ wt silt though, in each of these two groups, there is no very clear difference between the filter performances of thin GT (a), medium thick GT (b) and thick GT (c). Furthermore, for both families of results, the flow volume required for clogging of the filter (i.e. at the end of the curve) is always larger under the smaller gradient $\mathrm{i}=10$ than under the large gradient $\mathrm{i}=40$. For instance the relative hydraulic conductivity is consistently reduced by $90 \%$ after a flow volume of approximately $1000 \mathrm{cc}$ under $\mathrm{i}=10$ and $100 \mathrm{cc}$ under $\mathrm{i}=40$. 
Table 6.3 Summary table for test program used in RRT

\begin{tabular}{|c|c|c|c|c|c|c|c|c|}
\hline Soil type & B3201 & B3501 & C-M60 & G1202 & L125 & L140 & L250 & L350 \\
\hline Dune sand & $6.5 .1^{*}$ & $6.5 .1^{*}$ & $6.5 .1^{*}$ & & $6.5 .1^{*}$ & & & \\
\hline $20 \%$ silt & & $6.5 .1^{*}$ & $\begin{array}{l}6.5 .1^{*} \\
(6.5 .3)\end{array}$ & 6.5.1* & $\begin{array}{l}6.5 .1^{*} \\
(6.5 .3)\end{array}$ & & & \\
\hline $50 \%$ silt & & $6.5 .1^{*}$ & $\begin{array}{l}6.5 .1^{*} \\
(6.5 .3)\end{array}$ & $6.5 .1 *$ & $\begin{array}{l}6.5 .1^{2} \\
\{6.5 .2\} \\
(6.5 .3) \\
\{6.5 .4\}\end{array}$ & $\{6.5 .4\}$ & $\begin{array}{l}\{6.5 .2\} \\
\{6.5 .4\}\end{array}$ & $\begin{array}{l}\{6.5 .2\} \\
\{6.5 .4\}\end{array}$ \\
\hline $100 \%$ silt & & $6.5 .1 *$ & $\begin{array}{l}6.5 .1 * \\
(6.5 .3)\end{array}$ & 6.5.1* & $\begin{array}{l}6.5 .1^{*} \\
\{6.5 .2\} \\
(6.5 .3) \\
\{6.5 .4\}\end{array}$ & $\{6.5 .4\}$ & $\begin{array}{l}\{6.5 .2\} \\
\{6.5 .4\}\end{array}$ & $\begin{array}{l}\{6.5 .2\} \\
\{6.5 .4\}\end{array}$ \\
\hline $\begin{array}{l}\text { Sandy silt } \\
\text { (10\% clay) }\end{array}$ & & & & & & & & $\{6.5 .5\}$ \\
\hline $\begin{array}{l}\text { Sandy silt } \\
\text { ( } 20 \% \text { clay) }\end{array}$ & & & & & & & & $\{6.5 .5\}$ \\
\hline $\begin{array}{l}\text { Clayey silt } \\
\text { (10\% clay) }\end{array}$ & & & & & & & & $\{6.5 .5\}$ \\
\hline $\begin{array}{l}\text { Clayey silt } \\
\text { ( } 20 \% \text { clay) }\end{array}$ & & & & & & & & $\{6.5 .5\}$ \\
\hline
\end{tabular}

- Figures in table present the section numbers with relation to the soil and GT specimens

- *: loose soil specimen only; \{\} : dense soil specimen only; ( ): loose/dense specimens

- All the tests were implemented under the system hydraulic gradient of 40 .

- Supplementary hydraulic gradient of 10 was employed at Section 6.5.2 


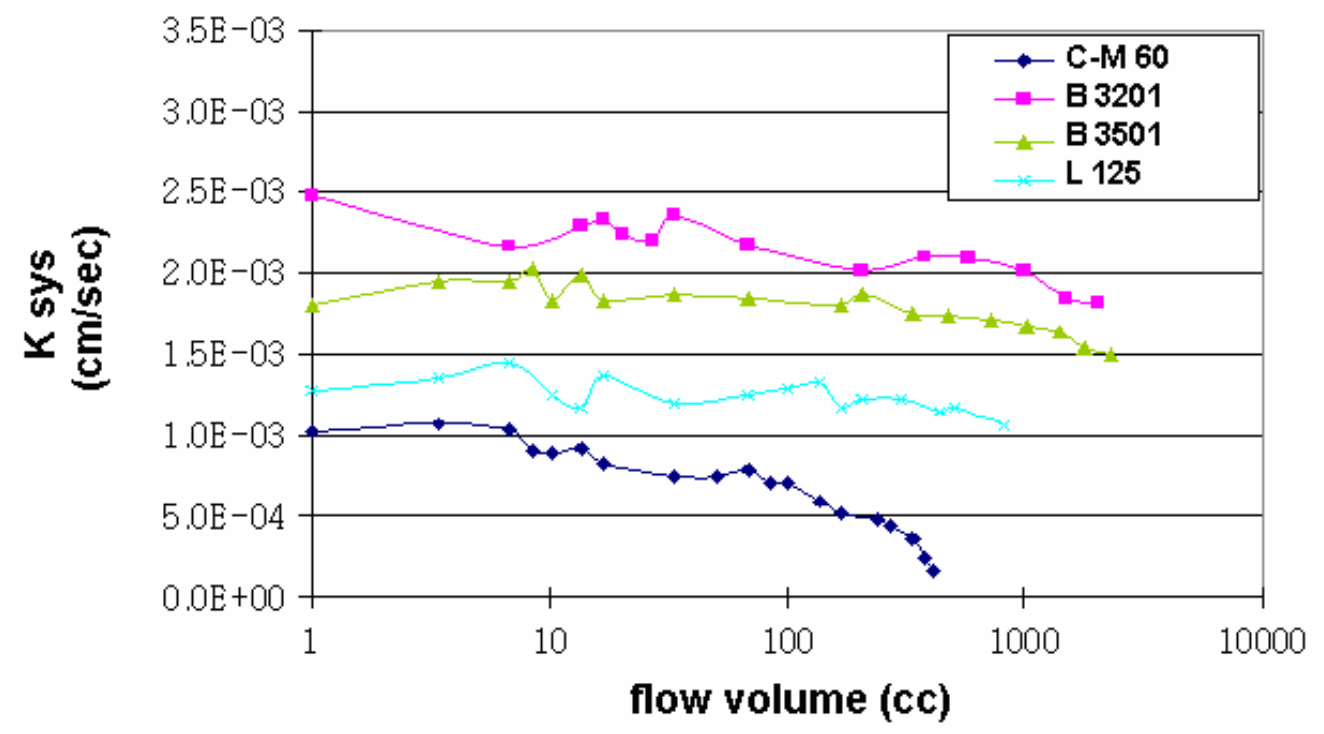

Figure 6.5 RRT results obtained in filtration ( $\mathrm{i}=40$ ) of uniformly graded dune sand in loose state with GT of different types 
(A) $20 \%$ wt silt

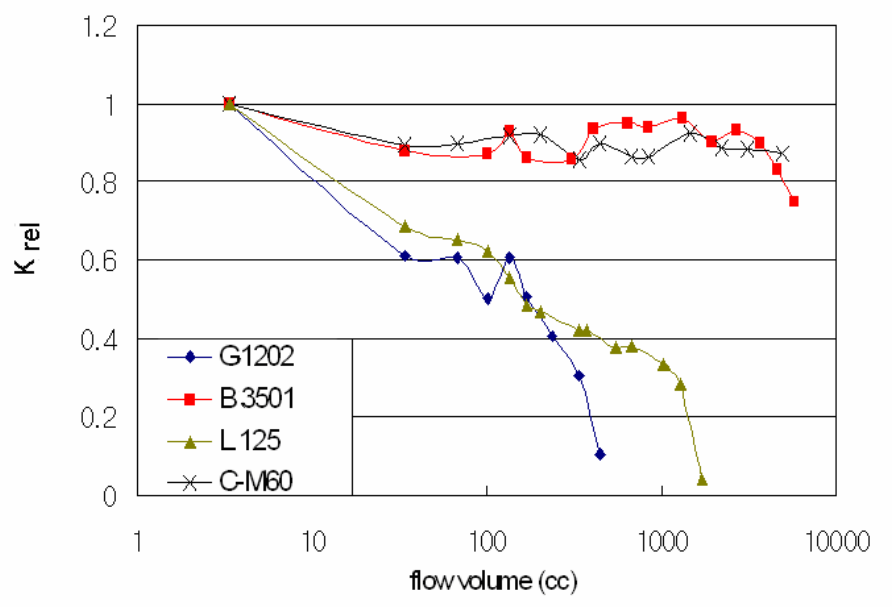

(B) $50 \%$ wt silt

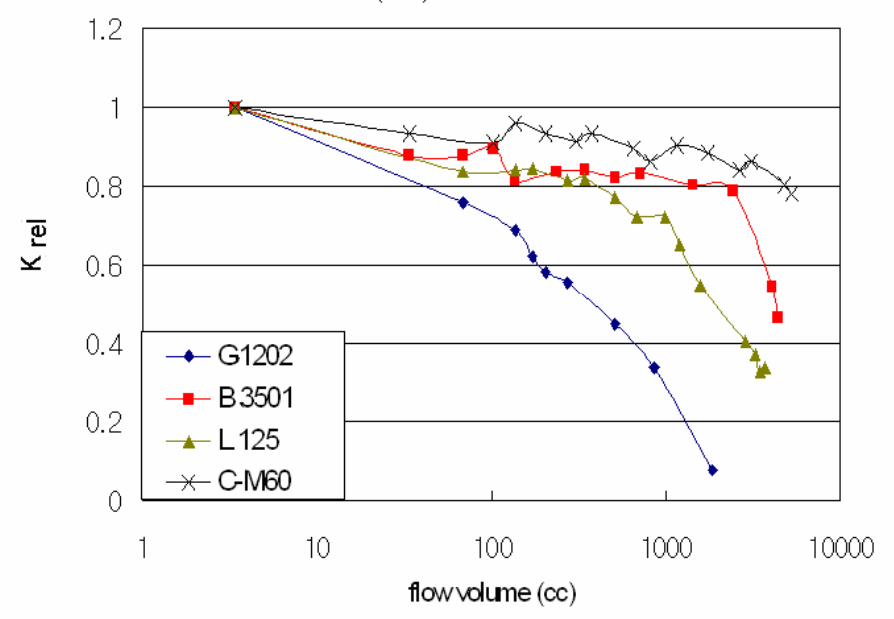

(C) $100 \%$ wt silt

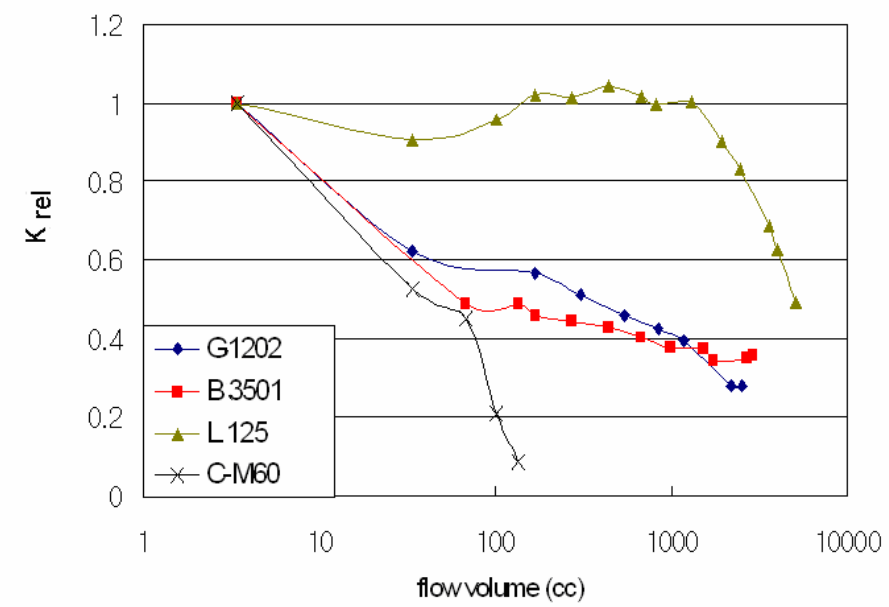

Figure 6.6 RRT $(\mathrm{i}=40)$ results for various $\mathrm{GT}$ types with loose soils of different silt contents $(20 \% \mathrm{wt}$ gap graded, $50 \% \mathrm{wt}$ well graded and $100 \% \mathrm{wt}$ silt pure fine) 

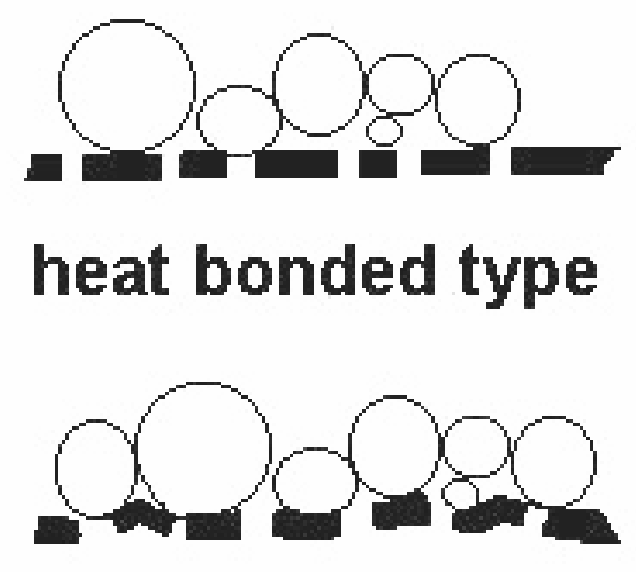

needle punched type

Figure 6.7 Schematic plots of different surface properties between heat bonded (HB) and needle punched GT (NP). 
(A) small thickness

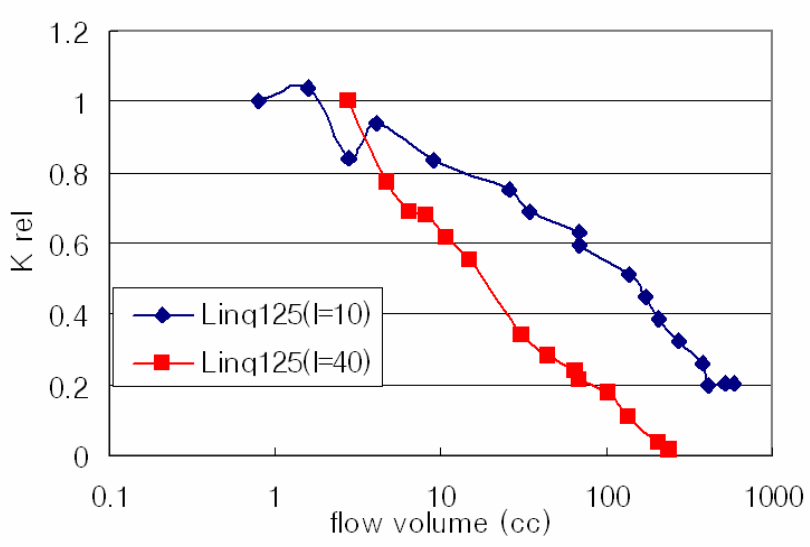

(B) medium thickness

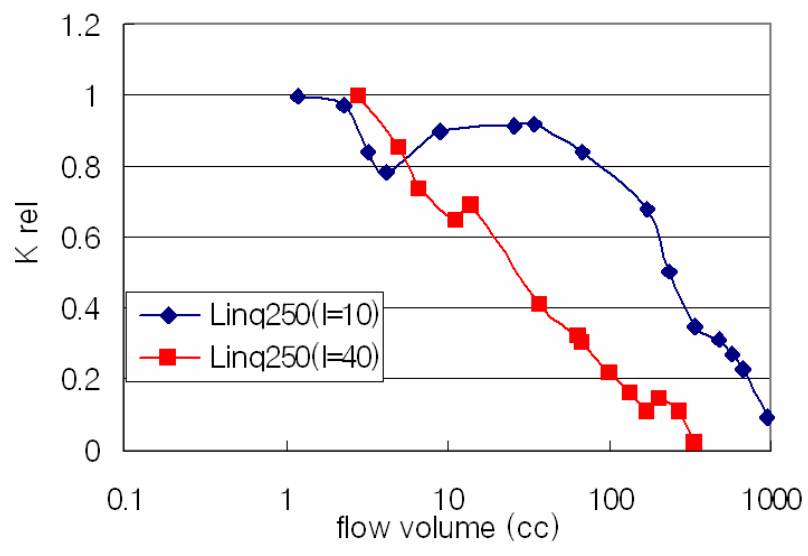

(C) large thickness

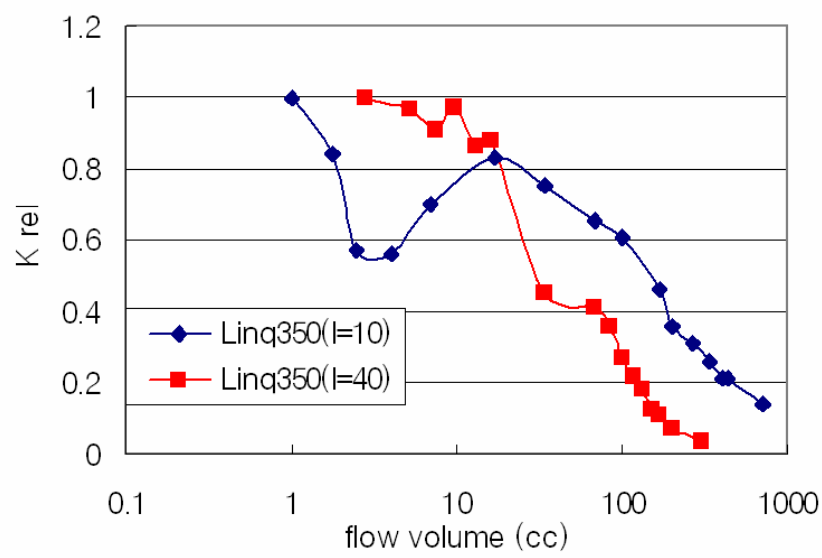

Figure 6.8 RRT results for NP of thicknesses, $1.5 \mathrm{~mm}, 2.5 \mathrm{~mm}$ and $3.8 \mathrm{~mm}$ with dense $50 \%$ wt silt soil filtered under hydraulic gradients of 10 and 40 


\section{(A) small thickness}

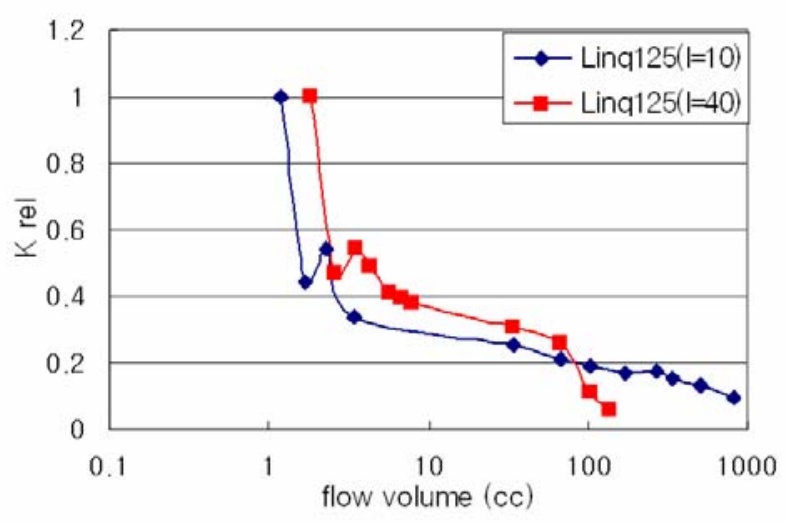

(B) medium thickness

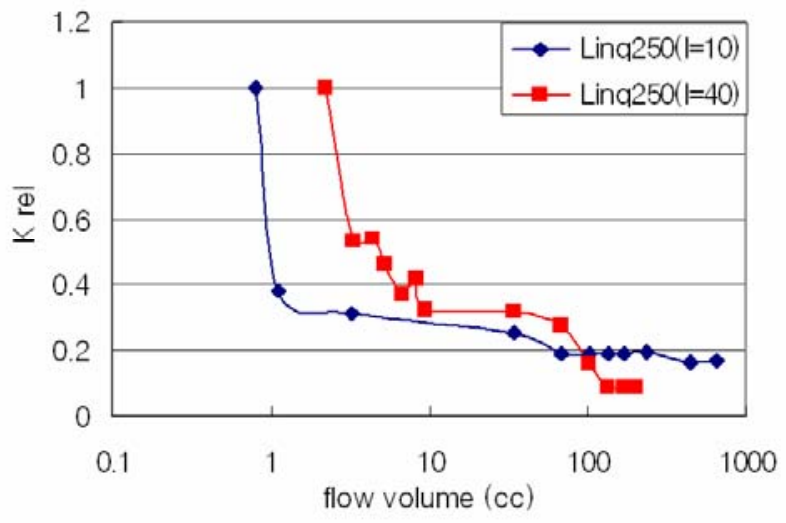

(C) large thickness

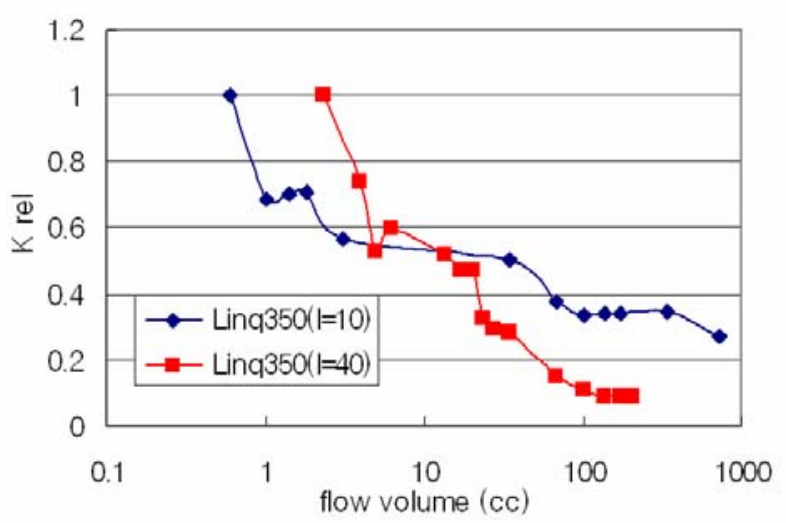

Figure 6.9 RRT results for NP of thicknesses, $1.5 \mathrm{~mm}, 2.5 \mathrm{~mm}$ and $3.8 \mathrm{~mm}$ with dense $100 \%$ wt silt soil filtered under hydraulic gradients of 10 and 40 
The significant difference between the two families of results is in the rate at which clogging progresses as evidenced by the shapes and slopes of the curves. In Figures 6.8(a,b,c) obtained using $50 \%$ wt silt, the decrease in $\mathrm{K}_{\text {rel }}$ is, after some fluctuations at the start of the curves, almost linear in function of the log of volume flow. In contrast, with $100 \% \mathrm{wt}$ silt the slope of the curves is very steep at the start and it takes only a small flow volume (i.e. less than 1 or $2 \mathrm{cc}$ ) for $\mathrm{K}_{\text {rel }}$ to decrease by about $50 \%$, then the process continues much slower. This particular behavior might be related to large amount of fines accumulating rapidly close to the filter openings.

\subsubsection{Influence of Soil Compaction on RRT Outcomes}

RRT were performed on dense vs. loose specimens of soils with $20 \% \mathrm{wt}$ (gap-graded), $50 \%$ wt (well graded) and $100 \%$ wt (pure fine) combined to two types of GT of different fiber bonding styles but having similar AOS and thicknesses. These GT were the C-M60 (HS with AOS $=0.21 \mathrm{~mm}, \mathrm{~T}_{\mathrm{G}}=1.8 \mathrm{~mm}$ ) and the $\mathrm{L} 125(\mathrm{NP}$ with $\mathrm{AOS}=0.21 \mathrm{~mm}$, $\mathrm{T}_{\mathrm{G}}=1.3 \mathrm{~mm}$ ); both are considered "thin".

With the HS filter, contrasted results were obtained both the loose (Figure 6.10a) and dense soils (Figure 6.10b). In loose state, both the well graded and gap-graded soils were filtered successfully by the HS with only $10 \%$ to $20 \%$ decrease in system permeability, while the pure fine soil could not be filtered and the system permeability was lost at fast rate. In dense state, the best result was obtained with the gap-graded soil but was not as good as in loose state. The well graded and pure fine soils were not well filtered in this case, the system permeability decreasing by $80 \%$ over $1000 \mathrm{cc}$ of flow. The most 
important effect of soil compaction with the thin HS is certainly the dramatic deterioration of performance with the well graded soil when switching from loose to dense specimen.

Performance of NP filter (Figure 6.11a,b) shows progressive deterioration in system permeability in all cases except in the case of loose pure fine soil where $\mathrm{K}_{\text {rel }}$ is sustained close to 1 over $1000 \mathrm{cc}$ of flow before falling. In dense state, the pure fine soil shows also the slowest deterioration of performance but still faster than with the HS filter. Here the most interesting observation is that the thin NP fails consistently to filter the gap-graded specimen, whether loose or compacted. The more rapid deterioration of the system permeability in the dense case than in the loose one confirms the susceptibility of thin NP to blinding by coarse particles of gap-graded soils. 


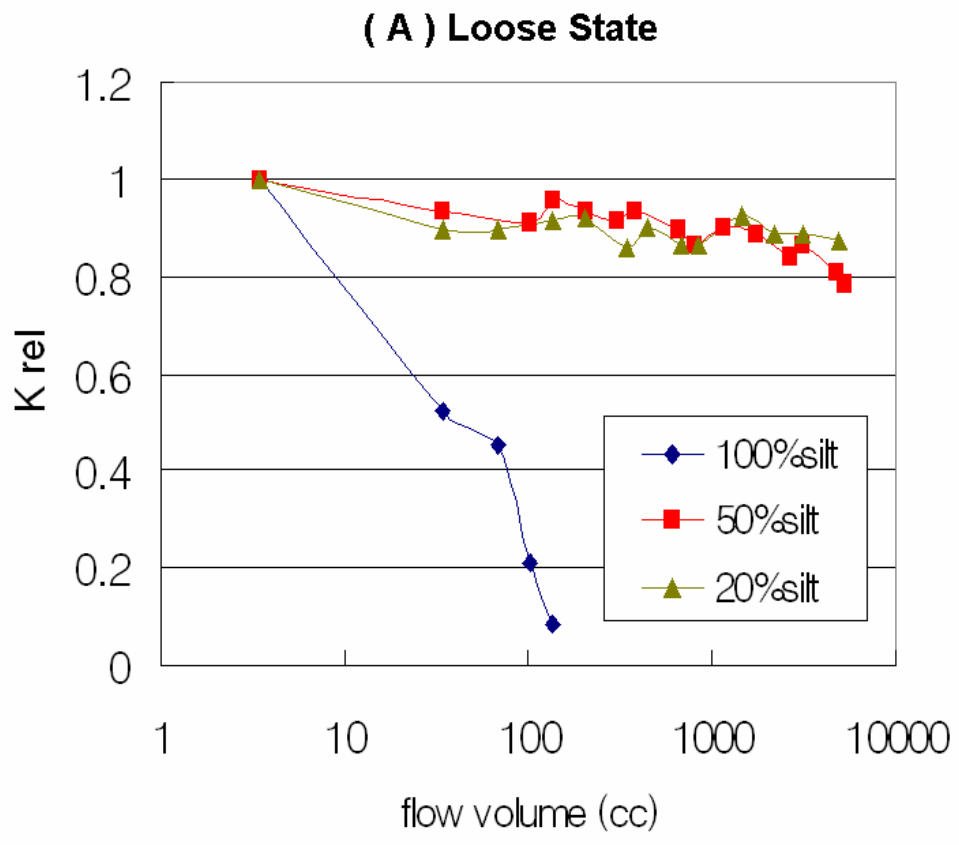

(B) Dense State

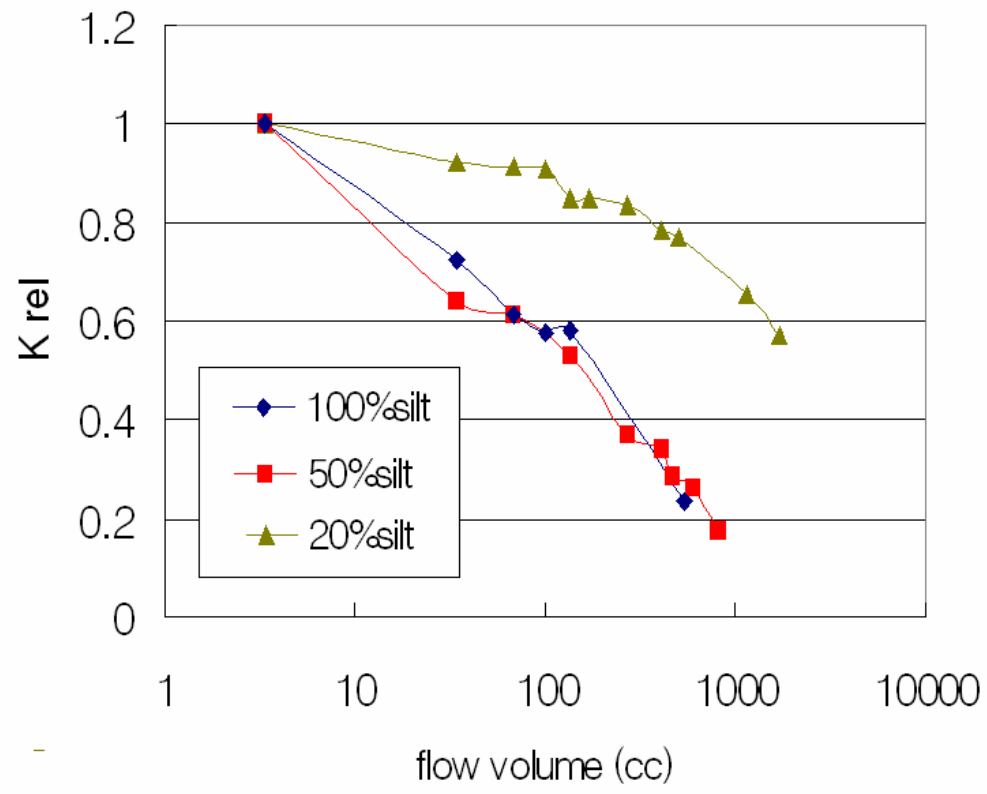

Figure 6.10 Compaction influence on RRT performance of a thin HS filter (C-M60) with soils of different silt contents 


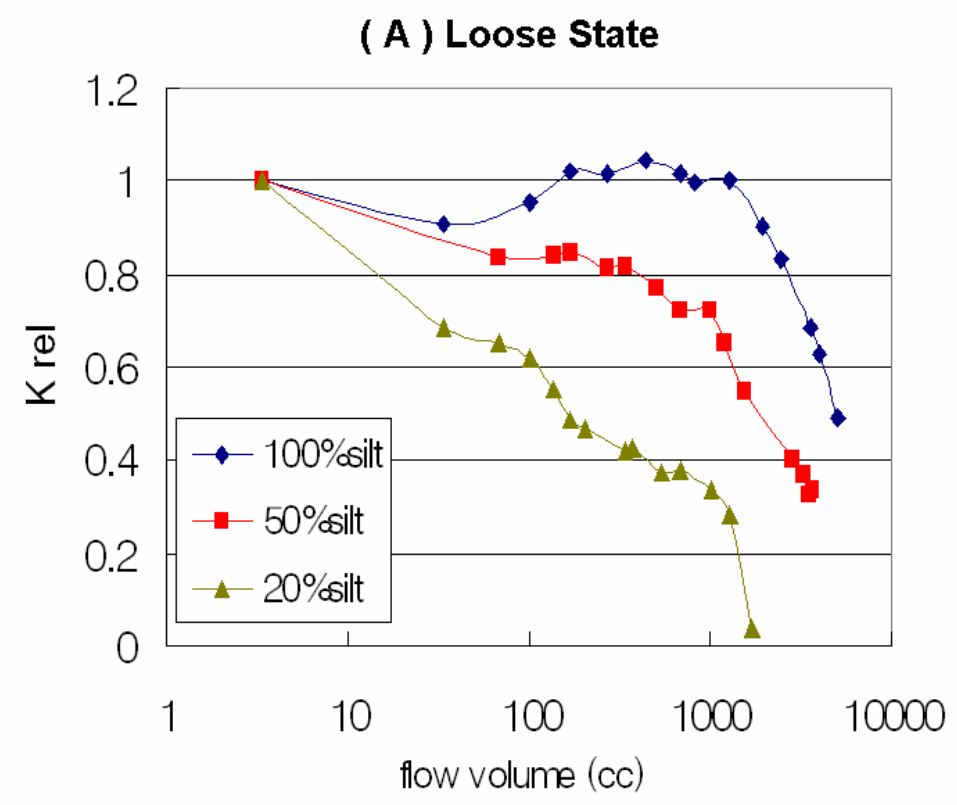

(B) Dense State

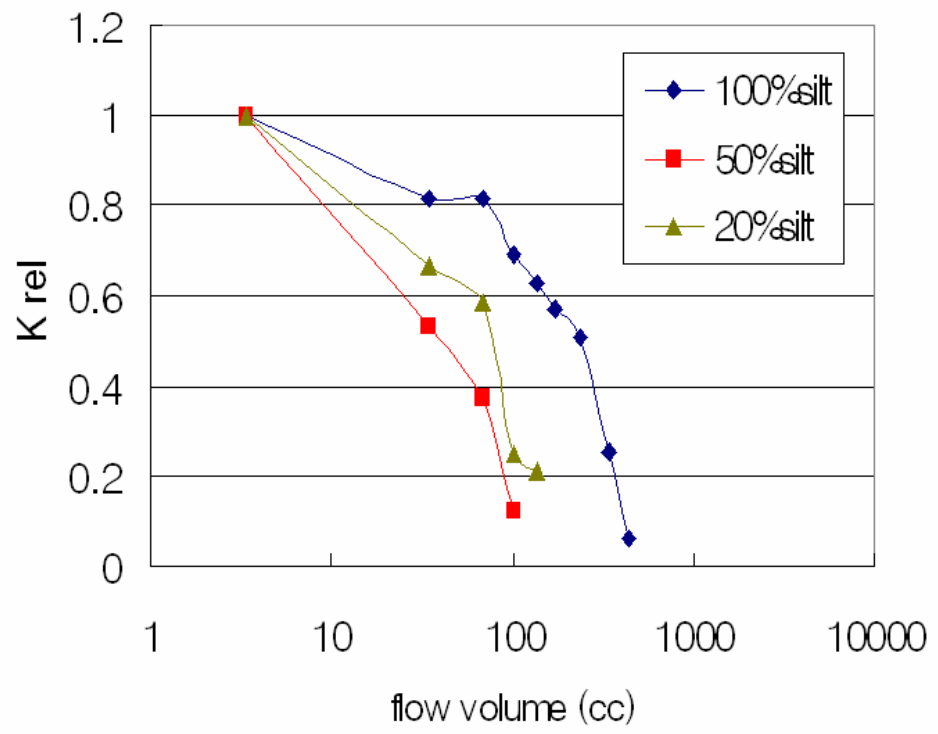

Figure 6.11 Compaction influence on RRT performances of a thin NP filter (Linq125) with soils of different silt content 


\subsubsection{Effect of GT Thickness on the Clogging Process in RRT}

As the GT thickness increases, the number of constrictions a particle migrating through the filter would possibly encounter also increases, and thus the likelihood of this particle being captured within the GT increases too. This suggests the GT thickness should influence its filtration function. However, RRT reported in Section 6.5.2 with three different GT thicknesses did not show clearly a difference in hydraulic behavior related to this parameter. This somewhat counterintuitive observation motivates further examination on how the filter thickness influences the filtration process. To this purpose, dense specimens of soil with $50 \%$ wt and $100 \%$ wt silt were filtered in RRT, under gradient $\mathrm{i}=40$, using NP with different thicknesses ranging from $1.3 \mathrm{~mm}$ (L125) to $3.8 \mathrm{~mm}$ (L350). At the end of each test, the mass of piping particles and clogging particles were determined by weighting. Results are summarized in Figures 6.12 and 6.13. Overall, the mass of clogging particles is greater (i.e. between 2 and 4 times greater) than the mass of piping particles, but these vary in function of the GT thickness. The clogging mass increases with increasing GT thickness while the piping mass decreases as the GT thickness increases. This was anticipated on the basis of the constriction encountering concept discussed above. Similar trends are observed in Figures 6.12, 6.13 for both silt contents of well graded or pure fine soils, with respective masses of particles clogging or piping being practically independent of the silt fraction size. Note that this particular study was not performed using gap-graded soil.

From the same RRT series, the evolution of system hydraulic conductivity (in relative values) vs. $\log$ of filtration time is shown in Figures 6.14 and 6.15 for the $50 \% \mathrm{wt}$ and 
$100 \%$ wt silt soils, respectively. Note that, because semi-log scales are used to plot these data, apparent shapes of the curves can be misleading. But even with this in mind, it can be seen that in the early stages of the tests, the $\mathrm{K}_{\text {rel }}$ reduction patterns are different, depending on the silt contents of the tested soils (Figures 6.14 and 6.15). With 50\%wt silt (well graded soil) $\mathrm{K}_{\text {rel }}$ decreases initially at a slower rate than with $100 \%$ wt silt. Then, for all the cases except the pure fine soil under $\mathrm{i}=10$ (Figure 6.15a) all the curves converge to similar values independently of the GT thickness. For the $50 \%$ wt silt, the $\mathrm{K}_{\text {rel }}$ profiles are possibly the result of a transition from internal clogging to surface opening blockage. This transition would occur faster under higher gradient (Figure 6.14 (a)) than under a smaller one (Figure 6.14 (b)). blocking was also accelerated by increase of system flow rate.

For the $100 \%$ wt silt soil, the initially rapid reductions in $\mathrm{K}_{\text {rel }}$ could be due to concentrations of fines around the GT openings, especially with high gradients used in RRT. In Figure 6.15a, it appears the clogging process is delayed when thick GT is used as compared to the faster rate with thinner GT. This effect might be more sensitive here because with $\mathrm{i}=10$ and $100 \% \mathrm{wt}$ silt content, the flow rate is smaller than in the other cases. One might conclude that thick NP filter might last longer before being clogged in contact with high silt content soils (over 50\%wt silt content) especially under lower hydraulic gradient level expected in field conditions $(i \leq 5)$. Except for this particular case, the quasi independence of the results from the GT thickness might be due to the dominant role of clogging and blocking over piping, as attested by the relatively small masses of piping particles observed in these tests. 
(A) $50 \%$ wt silt

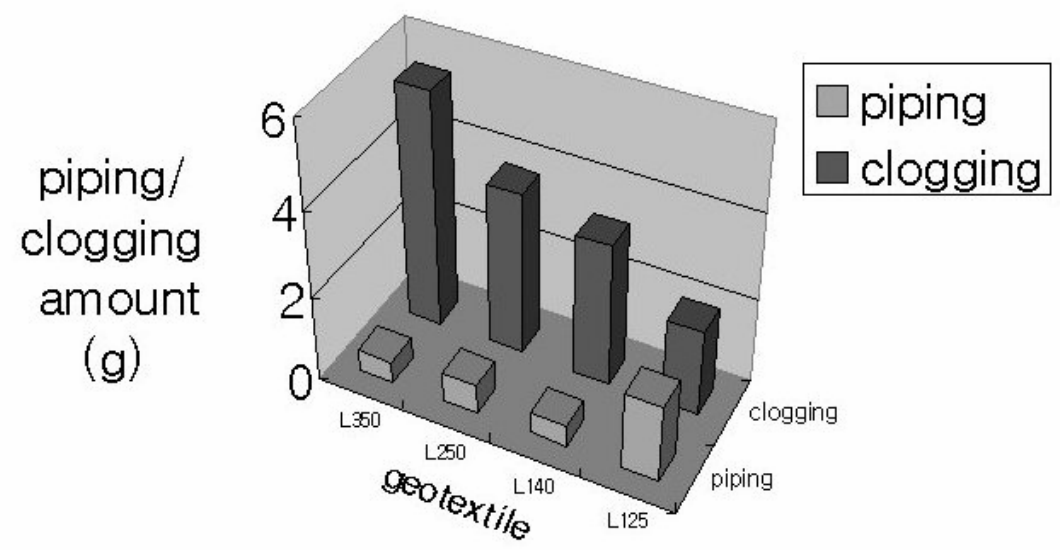

(B) $100 \%$ wt silt

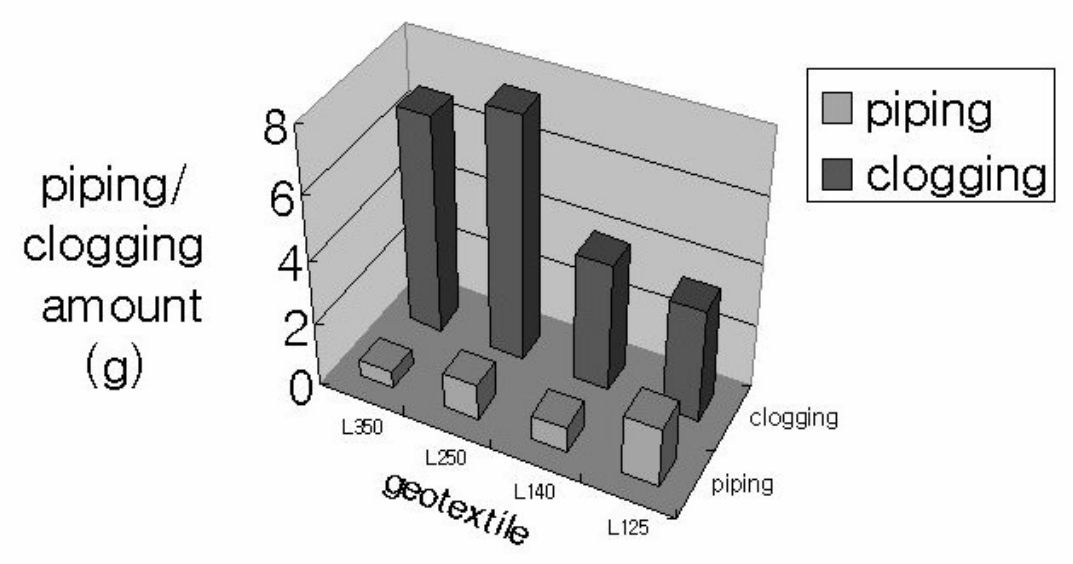

Figure 6.12 Distributions of piping and clogging particle masses in RRT of NP filters, different in AOS and thickness with 50\%wt and 100\%wt silts (Thickness and AOS increase from L125 to L350 GT, see Table 6.2) 


\section{(A) Clogging Soil Amount}

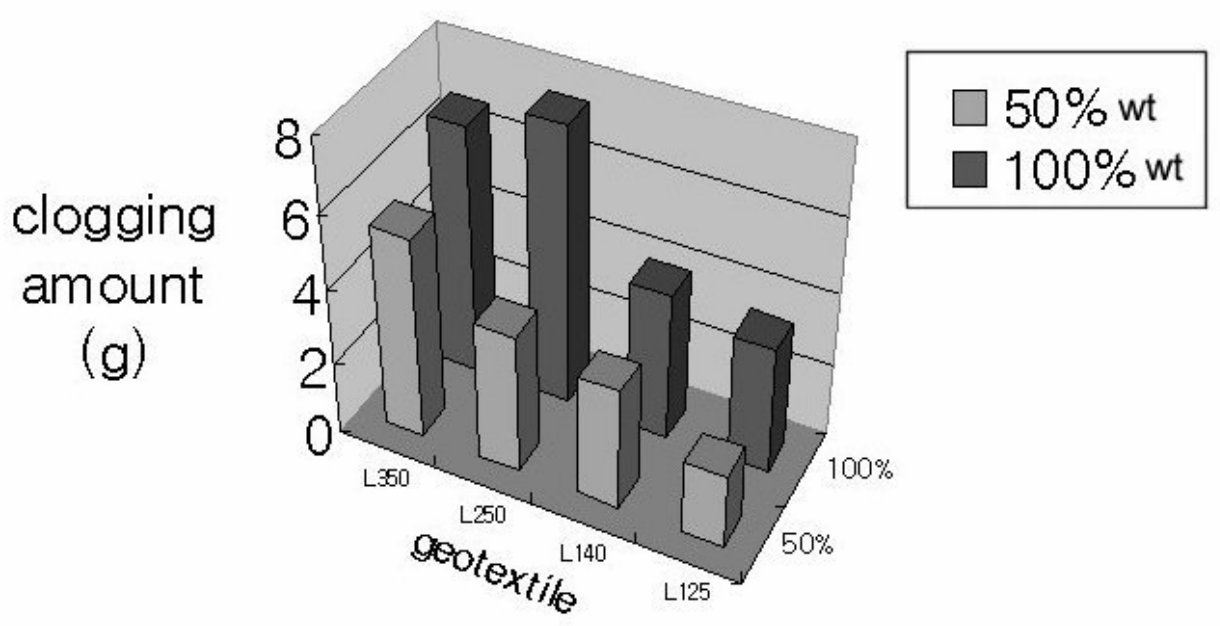

(B) Piping Soil Amount

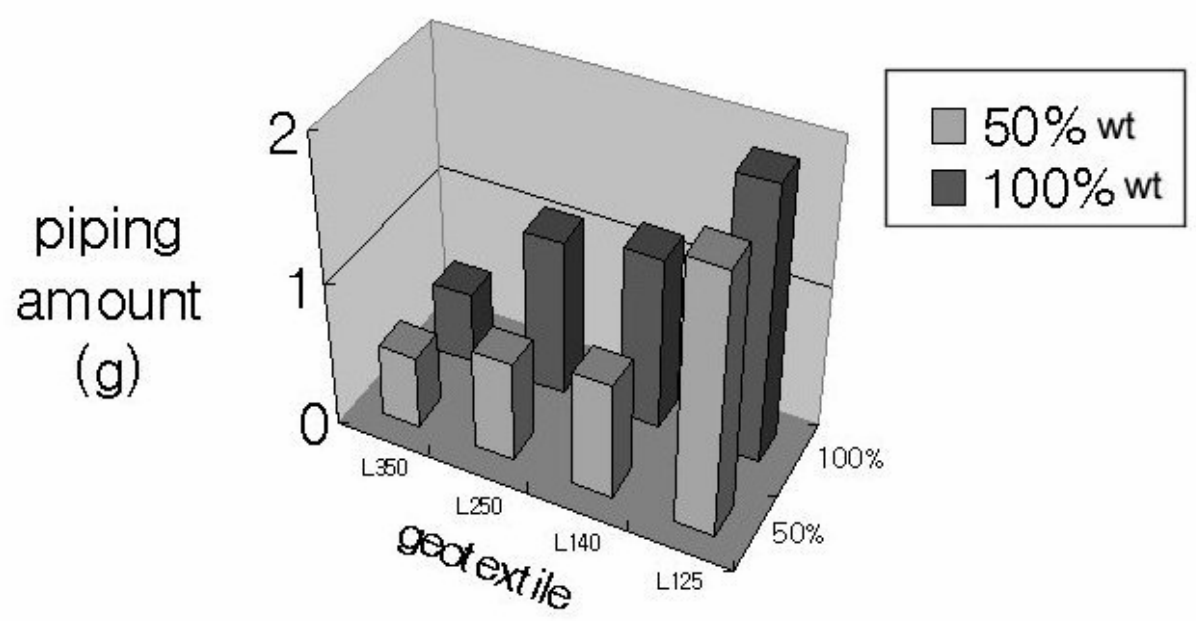

Figure 6.13 Distributions of piping and clogging particle masses in RRT of NP filters, different in AOS and thickness (Thickness and AOS increase from L125 to L350 GT, see Table 6.2) 
(A) $50 \%$ silt $w / i=10$

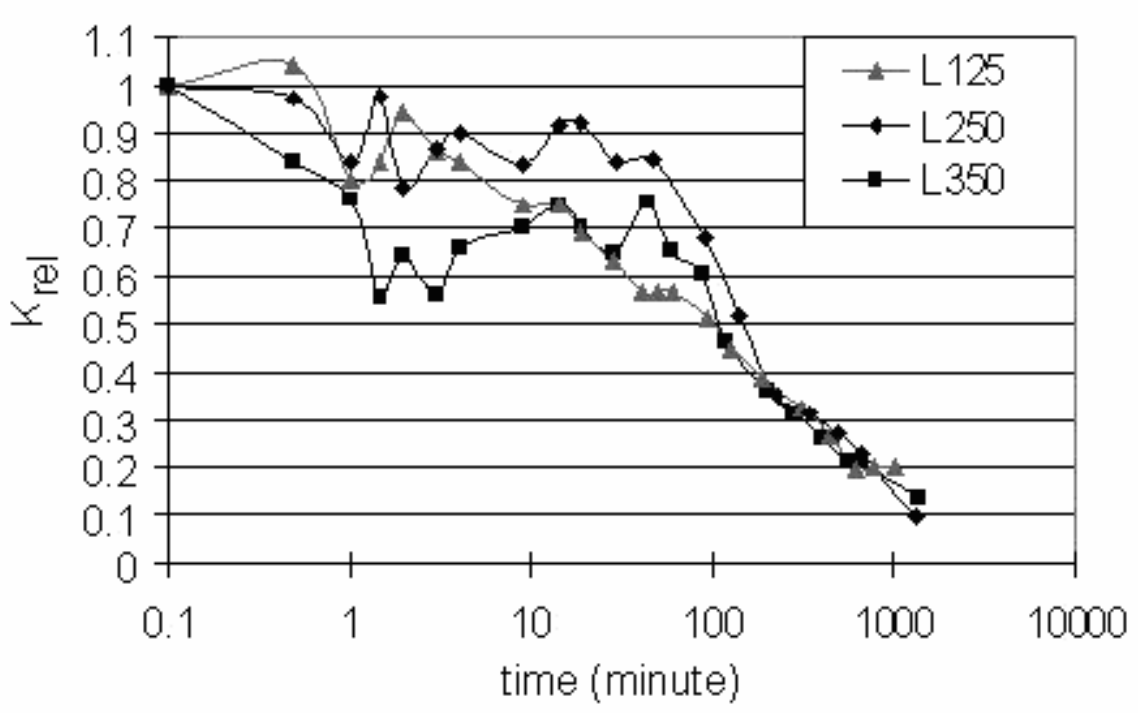

(B) $50 \%$ silt $w / i=40$

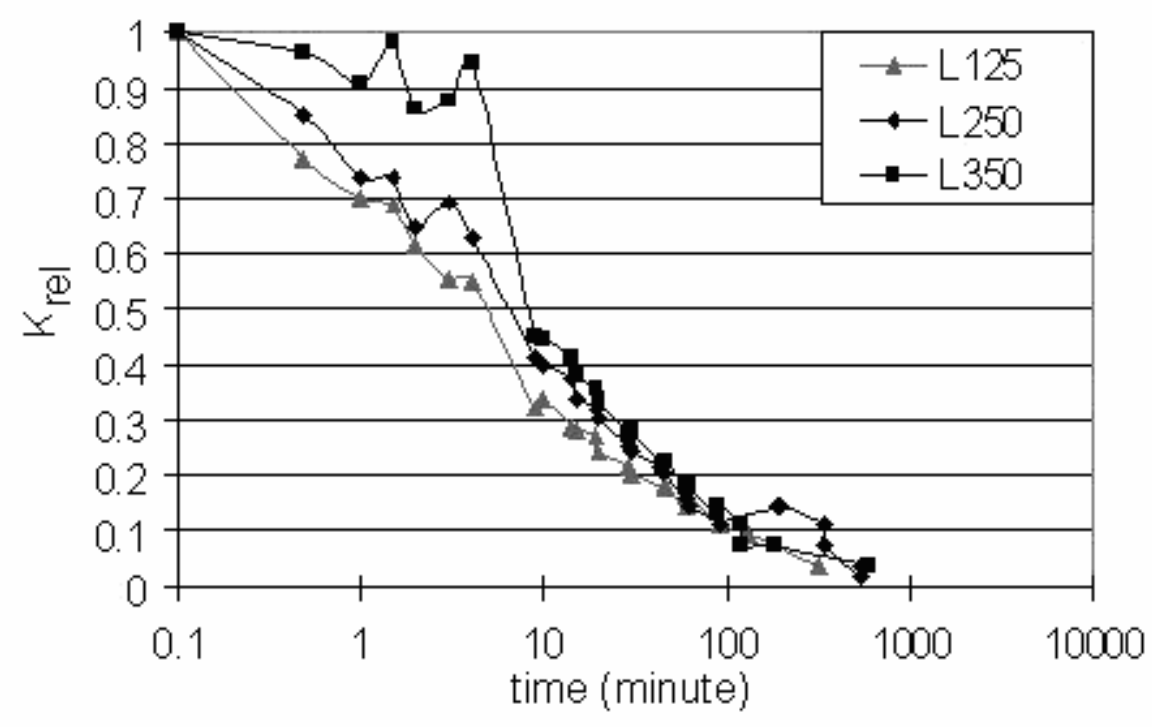

Figure 6.14 GT thickness effect on rate of $\mathrm{K}_{\text {rel }}$ change in RRT for $50 \%$ wt silt soil under different system hydraulic gradients 
(A) $100 \%$ silt $w / i=10$

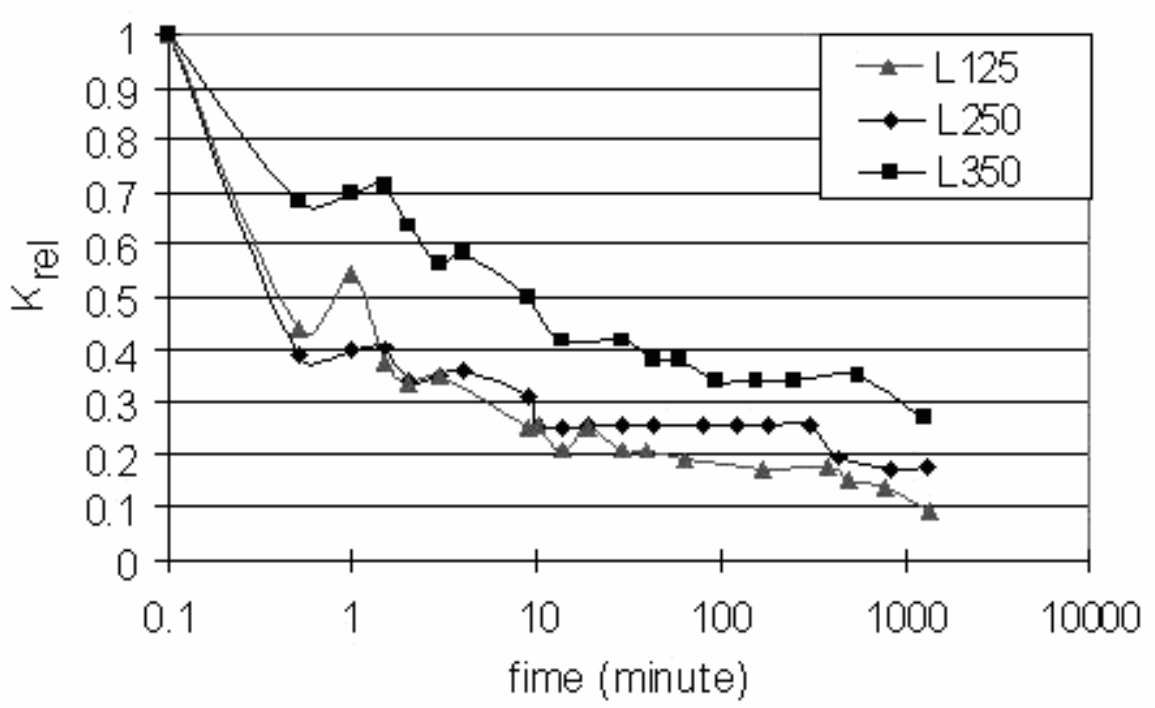

(B) $100 \%$ silt $w / i=40$

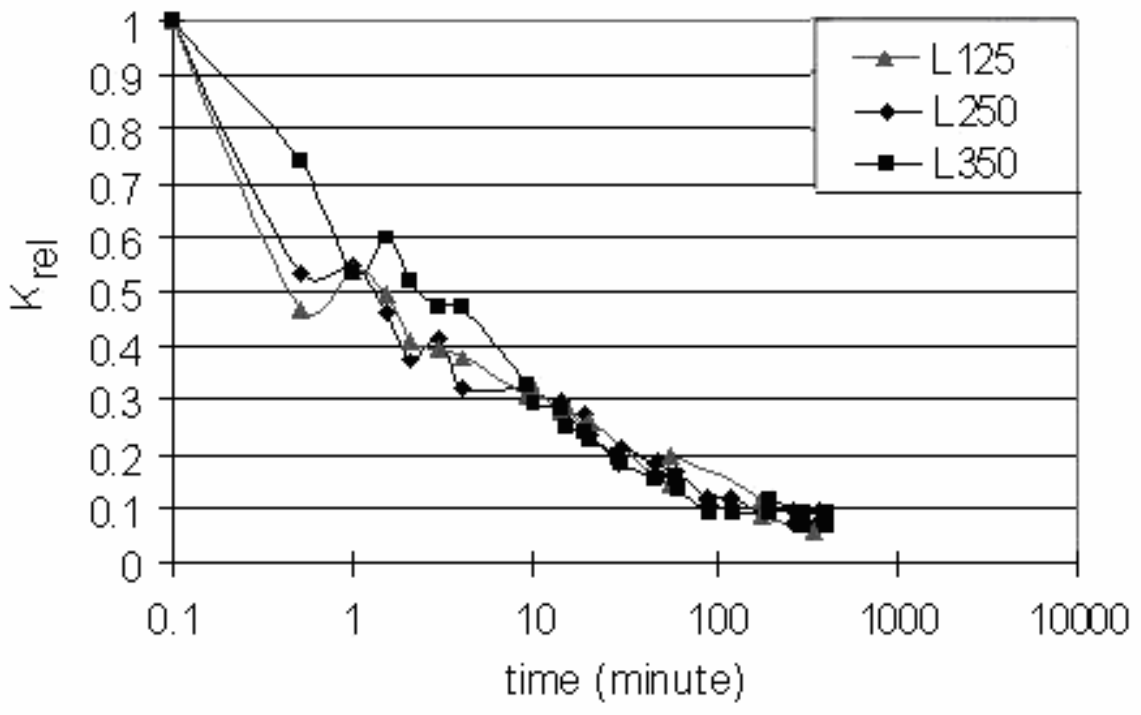

Figure $6.15 \mathrm{GT}$ thickness effect on rate of $\mathrm{K}_{\text {rel }}$ change for pure fine soil under different system hydraulic gradients 


\subsubsection{Influence of Clay Content on GT Clogging}

Whereas INDOT current technical guidelines (Technical Specifications, Sec. 913) for highway subdrainage systems do not require installation of a filter for soils with clay fraction over $20 \% \mathrm{wt}$, there is experimental evidence that clayey soil can induce drainage clogging (see Section 2.3.2). It is also noted that filters are required in earth dams at the contact between clay core and granular fill.

In order to investigate this specific point, dense soil specimens with variable silt and (kaolinite) clay contents were tested in RRT, under gradient $\mathrm{i}=40$, with a thick NP geotextile (L350) which had been found adequate for high silt content soils. As can be seen in Figure 6.16, variations in $\mathrm{K}_{\text {rel }}$ indicate a rapid reduction due to clogging, similarly to what was observed with non-clayey soils, though kaolinite is a non dispersive clay. The soil specimens with high clay contents (20\%wt clay) showed fast clogging regardless of the silt contents $(50 \% \mathrm{wt}$ and $80 \% \mathrm{wt}$ silt). In particular, a faster reduction was observed for the well graded soil specimens including a fine sand fraction (between \#60 and \#40 ASTM sieves). Again, this abrupt $\mathrm{K}_{\text {rel }}$ decrease is considered to result from surface opening blockage by concentrations of fines, as was noted for non-clayey ( $50 \%$ wt silt) soil in the previous section.

According to Kellner and Matei (1991), filtration of clayey soils can be improved by installation of a thin granular layer between the GT and the filtered soil. To examine this proposition, an intermediate layer, $1 \mathrm{~cm}$ thin, of fine sand between \#60 and \#40 in ASTM sieve size was placed above the GT specimen. The RRT result shown in Figure 6.16 


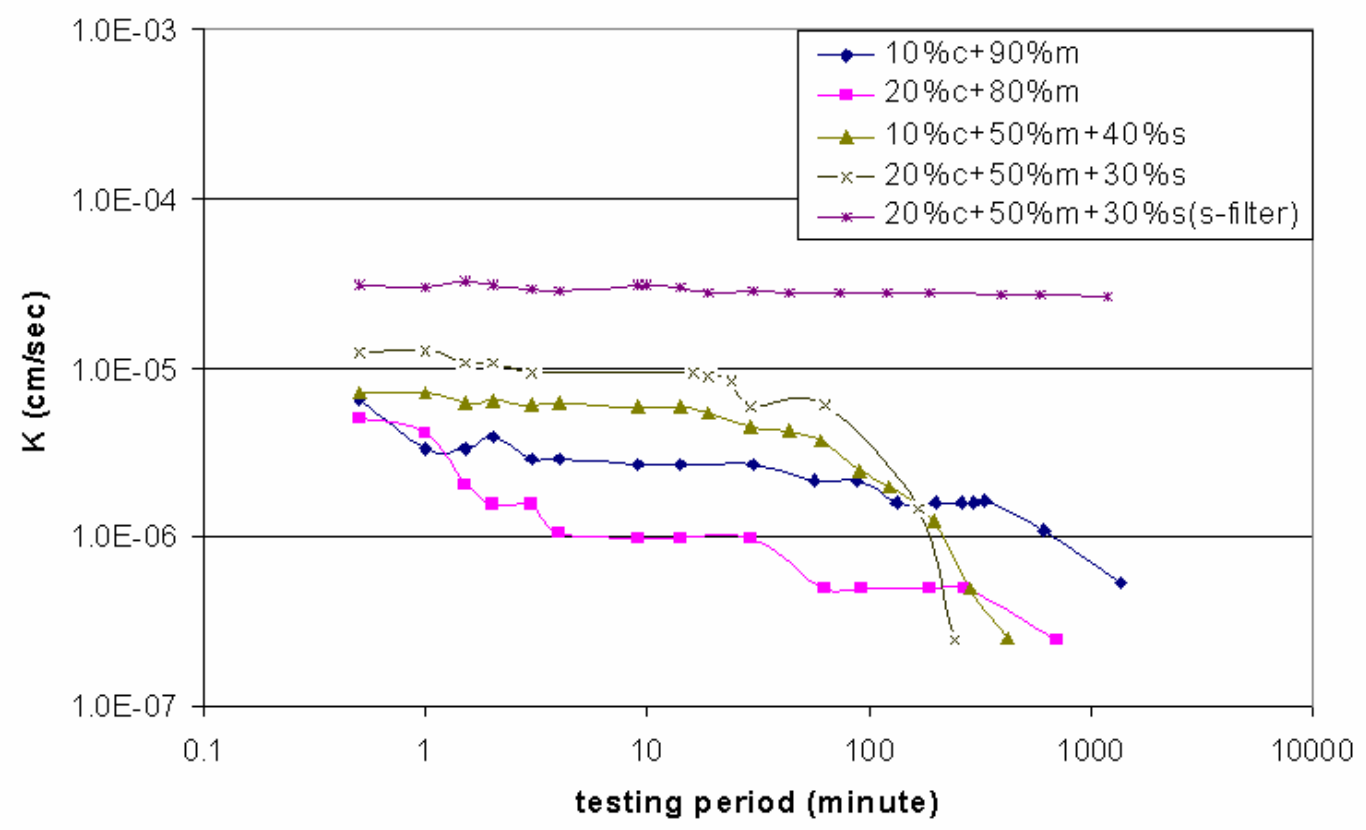

Figure 6.16 Hydraulic performances in RRT under $\mathrm{i}=40$ of thick NP, alone and in association with a fine sand layer, for filtration of dense soils with $10 \%$ wt or $20 \%$ wt clay (c: clay, m: silt and s: fine sand)

indicates this design was very successful in fltrating the clayey soil (i.e. 20\%wt clay, $50 \%$ wt silt and 30\%wt sand).

\subsection{Summary}

Uniformly graded soil $(\mathrm{Cu}<3)$ can be successfully filtered by geotextiles with AOS greater than their largest grain size since the self-filtration zone can be promptly built 
upon the GT filter. Well graded and gap graded soils should be filtered by geotextiles with AOS less than their particle sizes, $\mathrm{D}_{50}$ and $\mathrm{D}_{\text {gap }}$ respectively. This should allow for larger amounts of coarse particles being retained upstream of the geotextile in order to prevent continuing fine migration in unstable base soil. Since the size of soil fines $(0.075$ $\mathrm{mm}$ ) is smaller than the AOS of commercially available geotextiles, most silt particles will penetrate the GT filter rather than being retained on the surface, thus the formation of self-filtration zone is unlikely for high fine content soils.

Hydraulic gradient level plays an important role in controlling the rate of the clogging process. However, the level of system hydraulic gradient does not influence strongly the filter performances as compared to soil and GT properties. The governing soil and GT properties are soil gradation type and compaction degree, GT thickness, opening size and fiber bonding type. Compatibility between site soil and candidate geotextile can be effectively assessed using the RRT as long as the flow rate satisfies laminar conditions. The site conditions would likely result in slower clogging than the RRT conditions.

Depending on base soil type (e.g. gap graded, well graded and pure fines), GT fiber bonding type and porosity need to be considered in selection of a filter. Heat bonded GT is recommended to filter internally unstable soil (e.g. 20\%wt silt) since the GT rigid surface will help minimizing blockage by coarse particles and allowing passage of fines. Otherwise, needle punched GT is recommended to filter pure fines (e.g. 100\%wt silt) since the large geotextile porosity can reduce the possibility of opening blockage by fines under a severe hydraulic condition. For problematic soils (i.e., between $20 \%$ wt silt and 
$50 \% \mathrm{wt}$ silt), the grain size distribution and compaction degree should be considered in the GT filter design because these parameters control the soil internal stability.

Thick GT is recommended to filter high silt content soils (over $50 \% \mathrm{wt}$ silt) rather than thin GT since the fine migration is suppressed by internal geotextile clogging, not by the soil self-filtration process. Thus, the longer the infiltration path extends, the more fine particles can be captured by GT constrictions. Therefore, a thick GT is preferable for the purpose of fine particle retention. At sites where the geotextile is subjected to compaction pressure, a thick GT must be selected.

Soils with relatively small clay content soils (10 to $20 \% \mathrm{wt}$ clay) can contribute to GT filter clogging. The rate of GT clogging is accelerated by the presence of clay as the system flow rate decreases. In presence of silty soil with small clay contents (below $20 \%$ wt clay) it is recommended to use a composite filter consisting of fine sand and thick GT. The affinity of clay minerals for sand grains will minimize clay accumulation over the opening channels of the GT. 


\section{Conclusions and Recommendations of Geotextile Filter Selection Guidelines}

\subsection{Summary of Findings from this Study}

Soil filtration by geotextiles is a complex, multifaceted process. Its successful application depends on physical compatibility between the geotextile filter and the soil to be retained. Therefore, no successful design can be achieved without considering, first the nature and characteristics of the soil present at the site, and then the range of geotextile products eligible. There is no universal solution where a unique geotextile filter would be compatible with all types of soils or even a broad range of soils. But design solutions can be devised where geotextiles would be compatible with soil types defined by simple parameters such as their particle size and state of compaction.

Geotechnical situations that are considered prone to filtration problems with highway underdrains and from which soil samples were analyzed are characterized by high silt content, but the presence of clay together with silt, plays also a role in filter clogging. At a project site from which samples of exhumed filters were obtained, the soil was, typically, silty clay. The filter samples from this site exhibited variable degree of clogging after 15 years of service and, when quasi-intact specimens were tested in the laboratory, they were found incompatible with the soil. Video recording of underdrain pipe non-destructive inspections from different INDOT projects show moderate to heavy sedimentation within pipes after one year of service, suggesting adequate filtration was

lacking at this sites, though other factors such as incorrect installation or damage to the fabrics, may also have played a role. 
The present study was focused on physical clogging of non-woven geotextile filters by migrating solid particles from the surrounding soil. Biological or chemical clogging was not within the scope of this study and could not be investigated in detail. In particular, the problem of chemical clogging in presence of chemically modified soil would require special testing equipment being developed for a future study. Although, in present practice, INDOT does not use filter fabrics for underdrains in rubblized subgrade, a very limited and simplifeied test performed on only one sample suggests cement chemicals from recycled (rubbleized) concrete aggregates would likely affect the integrity of geotextile filters, a conclusion already reached by Wukash and Siddiqui (1996) in an earlier JTRP study. Because of the similarity in chemistry, this information can be considered also as an indication of what could occur with cement modified subgrade.

The two basic requirements for a filter that are, retain solid particles while still allowing water to flow to the drain, depend on the same set of properties for a geotextile. These are its opening size, porosity and internal fabric structure. For nonwoven geotextiles these, in turn, result from the manufacturing style, amount of fibers per unit volume and thickness of the fabric. During filtration, migration and spatial relocation of soil particles take place in the close vicinity of the geotextile. Some particles penetrate the fabric pores and constriction network and may remain trapped inside the geotextile while others cross over and can eventually reach the drain. Even in the case of a successful design and compatibility of the geotextile with the soil, it should not be expected that all the solid particles will be retained. What is expected is that particle migration will reach a steady 
state after a period of time depending on the volume of flow, and internal stability of the soil microstructure will be achieved in an interface zone at the boundary of the geotextile and a thin layer of immediately adjacent soil. As a result of particle migration, permeability in the adjacent soil, and across the filter and interface zone (i.e. the filter system as it was defined in chapters $5 \& 6$ ), varies during the early stage of the filtration process. At steady state, the filter system hydraulic conductivity may have increased as compared to that of the base soil (in case of bridging) or may have increased (in cases of partial blinding of partial clogging). Thus it is legitimate to use the system hydraulic conductivity and its internal variations for monitoring, in laboratory experiments, the filtration mechanism. But, because geotextiles are always more permeable, by orders of magnitude, than fine-grained soils in which filters are needed, and if the filter design is successful, local changes in permeability in the interface zone remain limited, permeability is not the critical factor for a geotextile filter selection. In other words, if a geotextile filter has been selected adequately for its retention function being fulfilled, then automatically its permeability remains sufficient for allowing cross-flow and, therefore, should not be of concern. This is why, in the geotextile filter selection method proposed in the next section, there is no need for an explicit permeability criterion.

Laboratory testing results obtained using the best available experimentation methods, the FWGR and the RRT, for a number of material combinations and testing parameters are believed to be realistic enough for serving as the basis of practical design guidelines. The testing conditions can be considered more severe than most field conditions with respect to particle mobility (because of the high gradients and full saturation imposed in the 
tests). However, adverse dynamic effects induced by traffic close to the roadway edge and the resulting excess pore pressure pulsing in the subgrade near the filter could not be simulated in the laboratory. During flexible wall gradient ratio tests, fine migration within the filter system could be traced indirectly by monitoring the precise pore pressure variation at different elevations along the soil column. Resulting data, gradient ratios and hydraulic head losses through the geotextiles, were consistent altogether to identify the different clogging mechanisms. In particular, they allowed differentiation between surface blocking by coarse particles and internal clogging by fines.

Among the most interesting findings from the testing program, in order to better understand the fundamentals of filtration, is the influence of the soil state of compaction on the filter response. In general, compaction increases interlocking between soil particles, reduces the pore space and, consequently, the internal stability of the soil is improved. This is contributing to good filter performance for soils made of a small to medium amount of silt mixed with coarser particles. But a positive effect was not observed with soils made essentially of silt. However, the effect of compaction is more complex if the soil surrounding the filter is compacted after the getextile has been installed. In this case compaction-induced pressure is applied to geotextile and can modify the fabric pore structure or force soil particles into its openings. In the field, this can be the case during compaction or re-compaction of subgrade but also during compaction of aggregate in the drainage trench and above. If fine particles are forced into the filter fabric by this mechanism, this will contribute to clogging. Thus compaction can affect filtration positively or negatively, depending on the soil composition and 
construction sequence. This can be mitigated by selecting geotextiles with adequate type, opening size and thickness.

Another important factor is the geotextile thickness in connection with its opening size. The thicker is the geotextile, the more likely is a particle to encounter a constriction smaller than its size. High silt content soils can be effectively filtered by thick geotextiles with small opening size rather than by thin ones with large opening size. As described before, most commercially available non woven geotextiles have a opening size larger than silt particle size. Therefore, the fines need be filtered within the geotextile fabric instead of be retained outside To achieve this, a longer infiltration path, characteristic of a thick non-woven geotextile, will offer to a traveling particle more opportunities for small constriction encounter than a thin fabric would. If the soil is to be compacted, a thick geotextile is also less likely to have its porosity decreased and fabric structure disturbed by the compaction process than a thin geotextile.

Filtration tests were performed with different types of soils, including low silt content soil, gap-graded soil and high silt content soil. With low silt content soil (10\%wt silt) it is generally agreed that the filter should be a geotextile with large AOS (>1 mm), but it was observed in this study that, if the soil has been compacted, a thick geotextile with much smaller AOS $(0.15 \mathrm{~mm})$ can also be adequate. Gap-graded soil with $20 \%$ wt silt was successfully filtered using a geotextile with large opening size $(0.21 \mathrm{~mm})$ without need for compaction. However, thin geotextiles should not be used as filters at sites where compaction work is expected to reduce significantly the porosity of subgrades with silt 
content between $10 \%$ wt and $50 \%$ wt. Loose soil with high fine content (50\%wt silt) was filtered successfully by thick geotextile. The internal clogging of a geotextile by fine particles is a relatively slow process as compared to blockage of openings at the surface by coarse particles. But when a geotextile with high permittivity is used as filter, a more rapid penetration of fines can occur at point-wise locations (instead of distributed clogging) where high concentrations of fines can plug the fabric openings and conduits. In such cases with high fine contents (>50\%wt silt) use of a thick geotextile would reduce potential for plugging. The role of constraint compressibility, combined with geotextile thickness, was also observed. Needle punched non woven geotextiles are known to be more compressible than other manufacturing styles. In the tests, it was observed that thinner geotextiles underwent more deformation by localized external load from soil grains than thicker ones.

Of paramount importance is the relationship between filter opening size and soil grain size distribution. Uniformly graded soils $(\mathrm{Cu}<3)$ can be filtered by the geotextiles with large FOS because a self-filtration zone of soil builds itself at the filter interface and forms bridges over filter openings that may be larger than individual particles. On the other hand, well graded or gap-graded soils need to be filtered by geotextiles with opening size smaller than the representative particle size, $\mathrm{D}_{50}$ or the lower limit of the GSD gap $\mathrm{D}_{\mathrm{G}}$, respectively. The reason for this requirement is that a larger quantity of coarse particles needs to be retained at the interface in order to form the self-filtration bridging structure and prevent piping from occurring within the internal unstable soil. But, with these types of GSD, if most of the particles are smaller than the geotextile 
opening size, silt can penetrate easily the filter and the self-filtration zone is unlikely to form.

Another important relationship is between the geotextile manufacturing style (producing different modes of fiber bonding and fabric porosities) and the soil type of GSD (e.g. gap graded, well graded or pure fine). If the soil is internally unstable and has small silt content $(<20 \% \mathrm{wt}$ silt), an even pattern at the surface of the filter faciltates penetration of the loose fines through the openings that still left free from coarse particle blockage. In case of high silt content soil (>50\%wt silt) where particles assemblies are more likely to be in a in loose state, the geotextile porosity should be large in order to limit the risk of plugging by localized fine intrusion. For soils that are the most problematic with respect to geotextile filter design $(20 \%<$ silt $\mathrm{wt}<50 \%)$, selection of a geotextile style will depend on both grain size distribution and state of compaction since these factors control the soil internal stability.

Presence of small amounts of clay in silty soils contributes to filter clogging. It was observed from the experiments that the cohesiveness of clay mineral plays a role in accelerating the filter internal clogging especially at low flow rate (below $1.0 \mathrm{E}-6 \mathrm{~cm} / \mathrm{sec}$ ). A solution for filtering silty soils with small clay content $(<20 \% \mathrm{wt})$ is to associate a thick geotextile and a layer of fine sand placed upstream of the filter. Affinity of clay mineral to sand grains and the increased tortuosity of the pore structure would help preventing clay accumulation on geotextile openings already partially clogged by silt particles. 
The magnitude of the hydraulic gradient across the filter zone influences the time rate of the clogging process but not its result. Application of high gradients in filtration tests had the effect of accelerating the process, as compared to tests performed under smaller gradients, but the ultimate state of the system, in terms of gradient ratios and hydraulic conductivity at steady state, was not significantly different. In addition to being relevant to field conditions, this observation is also useful for setting up laboratory experiments by allowing performance of faster tests at high gradients provided the flow remains laminar.

\subsection{Recommendations for Filter Selection and Design}

Findings of this study and information found in published literature lead to the conclusion that current INDOT specifications, sec. 913 (see Chapter 1 of this report) need to be modified mainly in two areas:

- Filter criteria should account more broadly and accurately for the soil characteristics than the current criterion specifying only a filter with AOS smaller than $0.3 \mathrm{~mm}$ (sieve \#50 or smaller) when the soil is mainly composed of silt;

- Current mechanical properties requirements should be revised for the filter fabric to survive installation and construction operations without being damaged.

Detailed recommendations follow in the next sections .

\subsubsection{Geotextile filter selection guidelines}

In an attempt to formulate criteria that would be simple enough for practical implementation, only the most important factors were considered and their possible ranges of variation were divided in a small number of cases. Unavoidably, these divisions carry some degree of arbitrariness and engineering judgment should be exercised in borderline cases. These recommendations should be understood as tentative. They will 
likely be subject to amendment after some experience with their application has been gained.

The guidelines for selecting geotextile filter in function of soil characteristics that are the grain size composition of the soil, its Atterberg's limits and for clay soils, the hydraulic conductivity, are summarized in Table 7-1 which also includes a number of explanatory notes. Only non-woven geotextiles are recommended. The output consists for each situation, in a recommendation of opening size range that would be adequate (defined in function of soil grain size), bonding type and fabric thickness. The recommended opening size is expressed in terms of the Apparent Opening Size (AOS) instead of the Filtration Opening Size (FOS) because the AOS is the filtration index property commonly reported by geotextile manufacturers in the United States (IFAI, 2005) and its determination is standardized under ASTM D 4751. The FOS determination is standardized under ISO/DIS 12956. An indication of the effect of soil compaction is also provided for information. However, it is noted that INDOT's construction practice is to install edge drains in trenches that are excavated in compacted subgrade. It should therefore be assumed that the compacted soil condition will apply in general. The indication obtained from this study that, in some cases, good soil compaction is beneficial to the filter performance emphasizes the importance of soil compaction and its quality control. 

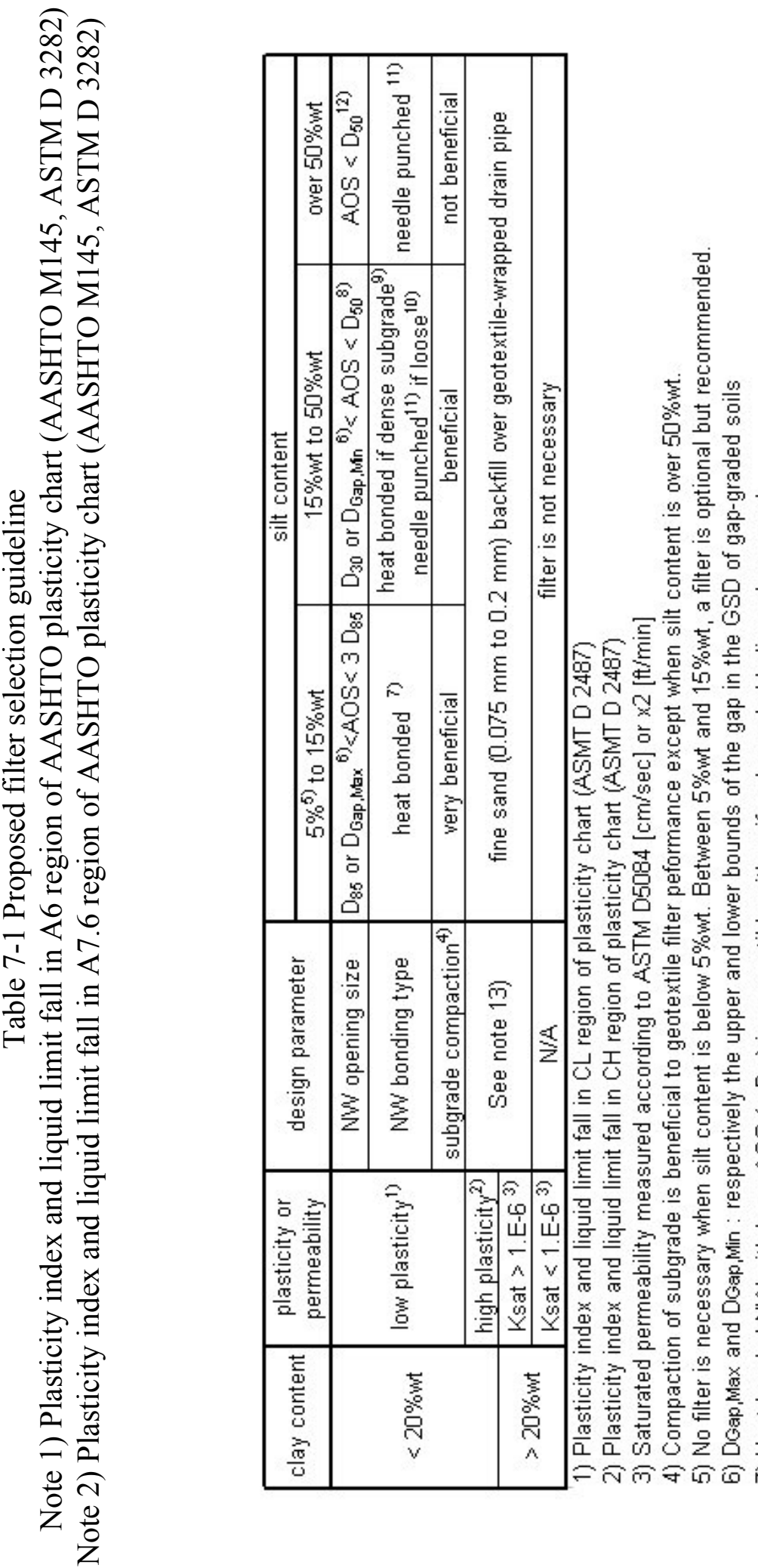

兴言帝

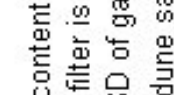

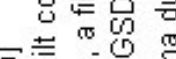

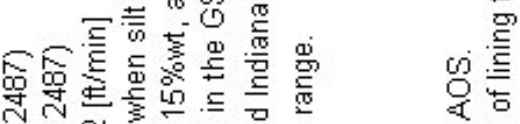

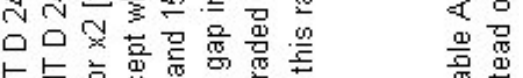
$\sum \sum_{0} \frac{0}{0}$

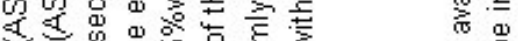

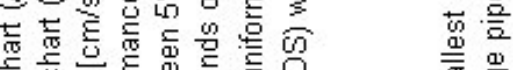

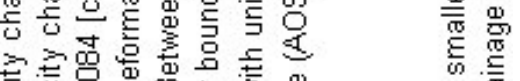

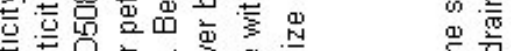

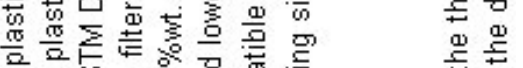

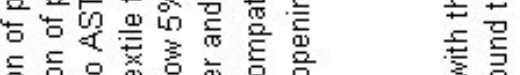

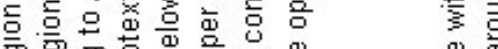

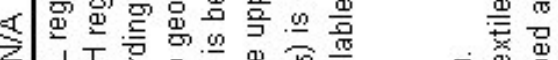

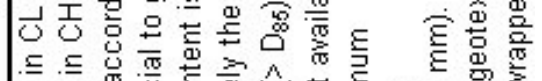
$==\pi$

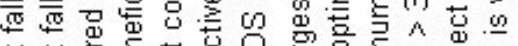

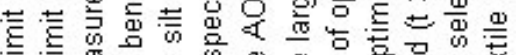
要.

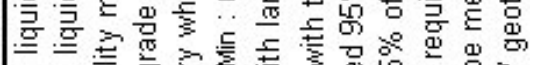

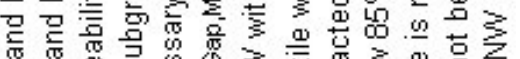

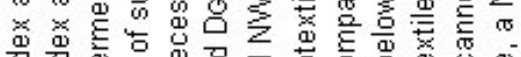

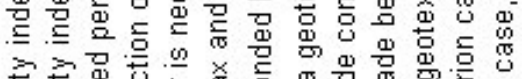

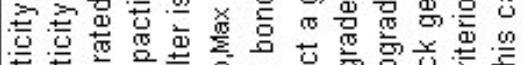

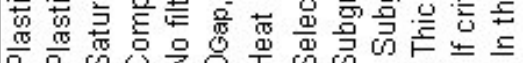

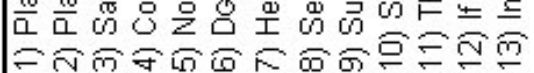


(a)

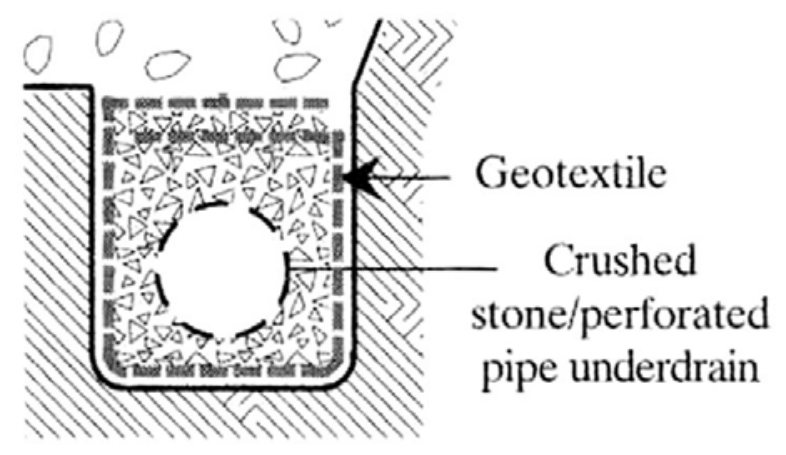

(b)

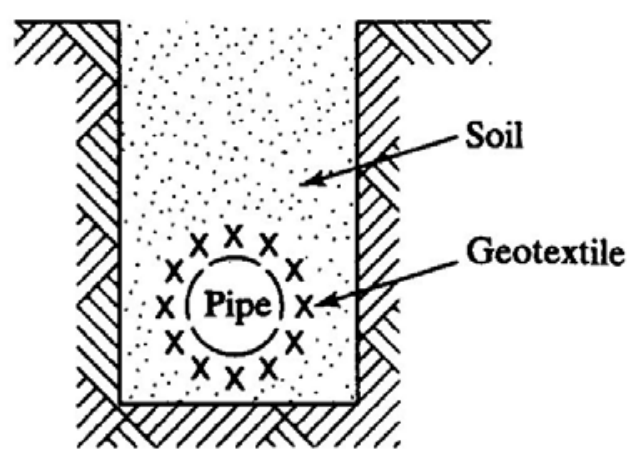

Figure 7-1 Schematic design cross sections for drainage and filter systems (A) General design, (B) special case of clay soil (see Table 7-1) 
(A) Sandy loam GSD

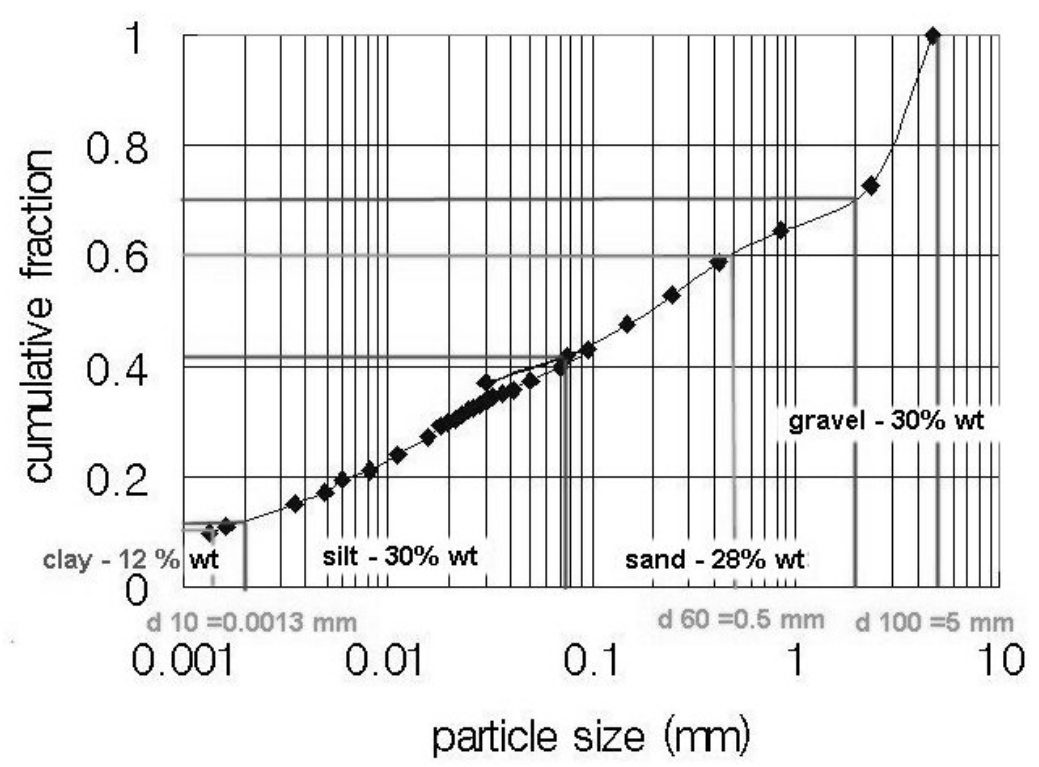

(B) Silty clay GSD

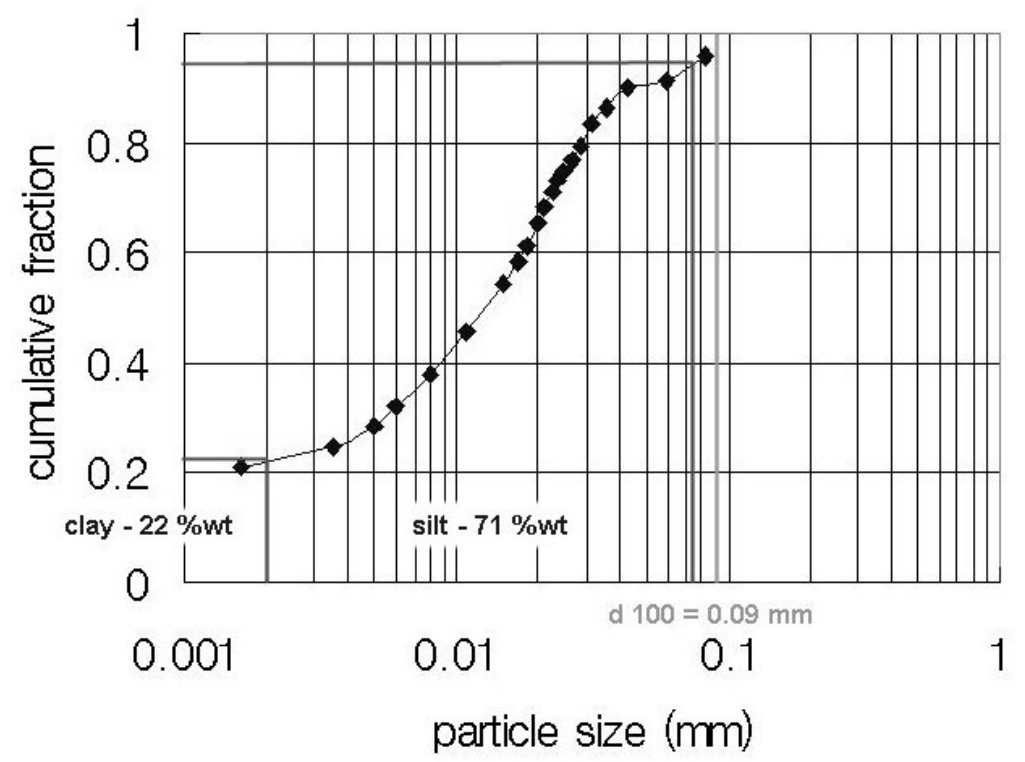

Figure 7-2 Example particle size distributions. (A) example 1, (B) example 2 

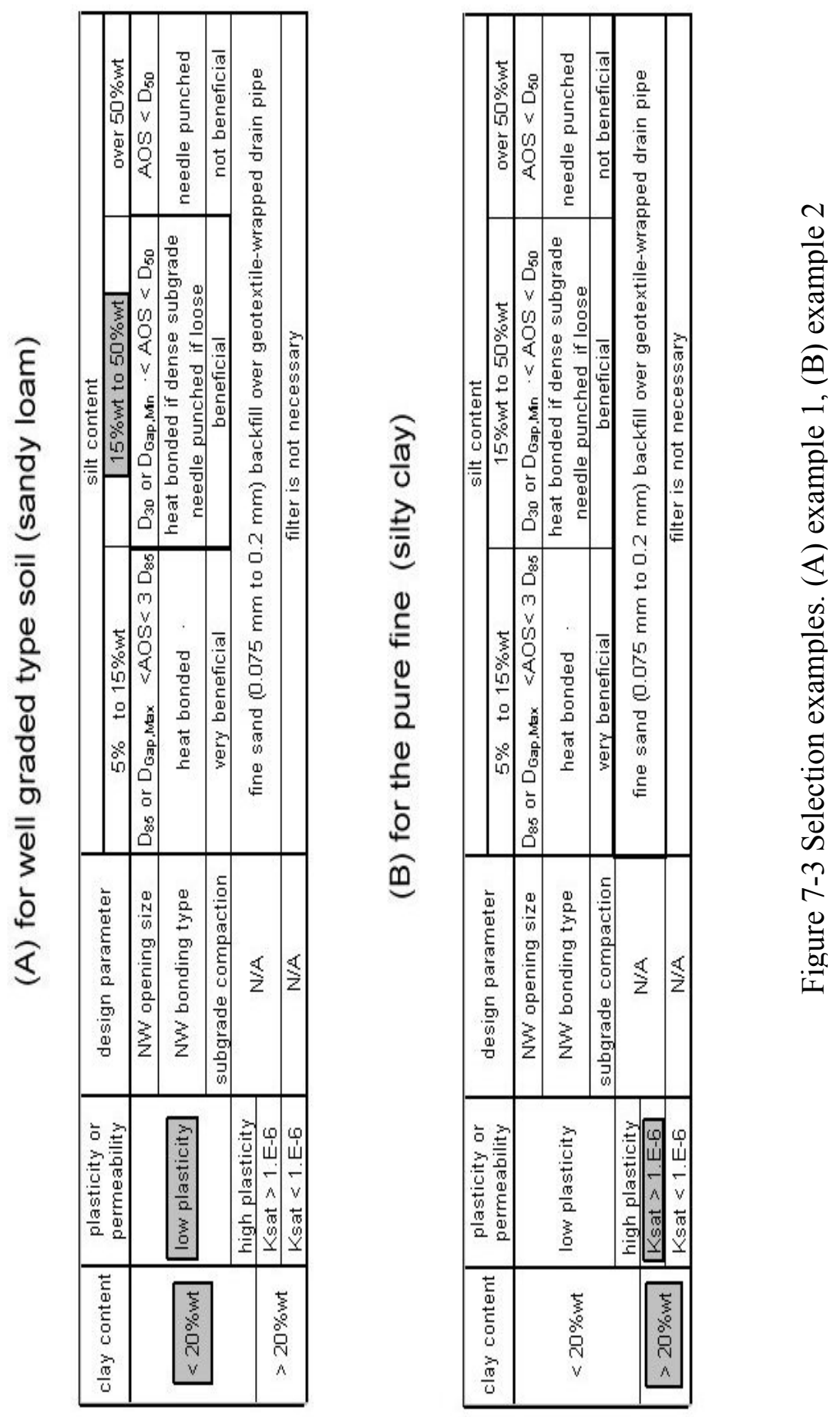
For the solutions recommended in Table 7-1 it is generally assumed, when a filter is required, that the geotextile will be installed as a liner on the bottom, sides and top boundaries of the drainage trench as shown in Fig. 7-1a. A difference between this design and current INDOT practice is that, in the present recommendation, the geotextile is wrapped over the drainage trench top after backfilling. It is believed this configuration is better than current practice in which the trench top is left without filter and allows infiltration of fines or recycled concrete chemicals driven by vertical downwards gradients. There is one exception shown in Fig. 7-1b, when a combination of geotextile and sand filters are recommended. In this case, because the sand component of the filter has to be located upstream of the geotextile, the practical solution is to install the geotextile as a wrapping around the drainage pipe, and then backfill the lower part of the trench with sand, at least up to 4 " above the pipe (the remaining part can be backfilled with coarser aggregate if this is more economical).

\subsubsection{Examples of filter selection}

In order to illustrate the application of the proposed guidelines, two examples are presented. The two soils used as examples have already been described in Chapter 3 .

\section{Example 1}

The soil is a well-graded sandy loam represented by Sample S1 in Tables 3-1 \& 3-2, where it is classified as a A6(2) according to AASHTO. Its grain size distribution is also shown in Figure 7-2a. indicates the largest particle size is greater than $2 \mathrm{~mm}$ and the coefficient of uniformity is less than 3 . The silt fraction is $30 \% \mathrm{wt}$ and the clay content is less than $20 \%$ wt. Entering the silt and clay amounts information in Table $7-1$ leads to the recommended selection. For more convenience, this is shown in Fig. 7-3a. The filter 
opening size (AOS) should be between $0.02 \mathrm{~mm}$ (i.e. the soil $\mathrm{D}_{30}$ ) and $0.25 \mathrm{~mm}$ (i.e. the soil $\mathrm{D}_{50}$ ), and either a heat bonded or a needle punched geotextile type would be selected, depending on subgrade compaction. A number of products are available that would satisfy these requirements. If one considers, for instance, the samples already used in this study (Table 5-1), both the BBA3501 (spun bonded type with AOS=0.21 mm) and Linq 350 (needle punched type with $\mathrm{AOS}=0.15 \mathrm{~mm}$ ) would be adequate.

\section{Example 2}

The soil corresponds to Sample C1 in 3-1 \& 3-2, where it is classified as a silty clay, A6(18) according to AASHTO. The clay content is over 20\%wt (Fig. 7-2b). Thus the criterion, according to Table 7-1, to decide whether or not a filter is required, is based on hydraulic conductivity. The permeability test performed on this sample resulted in Ksat $=2.7 \times 10^{-6} \mathrm{~cm} / \mathrm{sec}$, a value larger than the $10^{-6} \mathrm{~cm} / \mathrm{sec}$ limit of the table. If the guideline is strictly followed, a geotextile filter wrapped around the pipe and combined with fine sand backfill is required. However, considering typical uncertainty due to sample disturbance in hydraulic conductivity assessment, this can be considered a borderline case (a difference of an order of magnitude in Ksat would be considered meaningfull rather than a factor 2) and engineering judgment suggests the use of a filter here is only optional.

\subsubsection{Additional physical requirements for geotextiles: Survivability criteria}

Selection of geotextile filter based on Table 7-1 addresses the primary function of the geotextile where retention and permeability requirements are met. Another important criterion for the selection of a particular geotextile is based on its ability to survive the mechanical constraints imposed during installation, construction of the roadway and later 
in service. It has been observed that a number of failures of geotextiles occur during installation and construction rather than in service. This problem was addressed by AASHTO and FHWA in the 1980s through the Task Force 25 Committee. The empirical criteria and methodology are at the origin of guidelines found in AASHTO-AGCARTBA, Task Force 25 and AASHTO M288. These are based on the severity of pressure load expected to be applied over the geotextile during construction and the quality of preparation of surfaces (i.e. the subgrade) on which the geotextile is installed. Combination of these two factors leads, for the candidate geotextile, to a required degree of survivability and corresponding minimal performance in standardized index tests such as the grab test, puncture test, burst test, puncture test. It is noted that, for meeting the criterion, a geotextile must pass all the tests, not just one of them.

These guidelines are summarized in Appendix B. For edge drain filter fabrics, it is expected that installation is done on well prepared subgrade and low to moderate construction equipment pressure is applied to the fabric. Based on these assumptions, the Class 3 or Class 2 survivability level is required by AASHTO M288-96 (see also Koerner, 1998, sec. 2.1.2). Even when considering the least severe condition, that of Class 3, it is noted that the physical properties required by AASHTO M288 (see Table 2.2a in Appendix B of this report) are higher than the requirements of current INDOT specifications, Sec. 913.19, applicable to geotextiles used with underdrains. In order to ensure compliance with the AASHTO M288 minimal requirements, it is recommended to modify INDOT's Sec. 913.19 physical requirements as follows: 
TEST

Grab Strength
Seam Strength
Puncture Strength
Burst Strength
Trapezoidal Tear
Apparent Opening
Size (AOS)

Permeability

U.V. Degrad. (150h)
METHOD

ASTM D 4632

ASTM D 4632

ASTM D 4833

ASTM D 3786

ASTM D 4533

ASTM D 4751

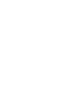

A

ASTM D 4491

$0.1 \mathrm{~mm} / \mathrm{sec}$

same

Sieve No 50 or Sieve No 50 or smaller opening smaller opening

From Table 7.1

\subsection{Implementation: Step-by-Step Procedure}

In order to facilitate implementation of the above recommendations, the following stepby-step procedure can be applied:

\section{STEP 1}

Determine the following properties of the subgrade soil at the drainage trench location.

- From the particle size distribution:

o Silt content (in \% passing weight)

o Clay content (in \% passing weight)

o $\mathrm{D}_{30}, \mathrm{D}_{50}$ and $\mathrm{D}_{85}$ characteristic particle sizes

o If the particle size distribution shows a gap, determine $\mathrm{D}_{\mathrm{Gap}, \text { Min }}$ and $\mathrm{D}_{\mathrm{Gap}, \mathrm{Max}}$, respectively the lower and upper limit of the gap. 
- IF the clay content is less than 20\%, determine Atterberg's consistency limits and plasticity index (ASTM D 2487)

- IF the clay content is greater than $20 \%$, determine the hydraulic conductivity (at saturation).

\section{STEP 2}

IF the silt content is

(a) Over 50\%, then GO TO STEP 3

(b) Between $15 \%$ and $50 \%$, then GO TO STEP 4

(c) Between 5\% and 15\%, then a filter fabric is optional but recommended. GO TO STEP 5 for selection criteria.

(d) Less than 5\%, then NO FILTER FABRIC IS REQUIRED

STEP 3 (filter selection for case a, silt content $>50 \%$ )

(case a.1) IF the clay content is less than $20 \%$, then SELECT a filter fabric with the following characteristics and design recommendation (WHEN DONE, GO TO STEP 6):

Style: Needle Punched Non-woven

Opening size: $\mathrm{AOS}<\mathrm{D}_{50}$

Thickness: $3 \mathrm{~mm}$ (or greater)

- (a.1.a) If the soil plasticity is low (i.e. the point representative of liquid limit and plasticity index in the AASHTO soil plasticity chart, ASTM 2487, is in the A.6 region), use standard design with filter fabric lining the trench (see Fig. 7-1a)

- (a.1.b) If the soil plasticity is high (i.e. the point representative of liquid limit and 
plasticity index in the AASHTO soil plasticity chart, ASTM 2487, is in the A.7.6 region), the filter fabric should be wrapped around the drainage pipe and the trench backfilled with fine sand (see Fig. 7-1b).

(case a.2) IF the clay content is greater than $20 \%$ AND the soil hydraulic conductivity is greater than $10^{-6} \mathrm{~cm} / \mathrm{sec}$ (or $210^{-6} \mathrm{ft} / \mathrm{min}$ ), THEN SELECT a filter fabric with the following characteristics and design recommendation (WHEN DONE, GO TO STEP 6):

Type: Needle Punched Non-Woven

Opening size: $\mathrm{AOS}<\mathrm{D}_{50}$

Thickness: $3 \mathrm{~mm}$ (or greater)

The filter fabric should be wrapped around the drainage pipe and the trench backfilled with fine sand (see Fig. 7-1b).

(case a.3) IF the clay content is greater than 20\% AND the soil hydraulic conductivity is less than $10^{-6} \mathrm{~cm} / \mathrm{sec}$ (or $210^{-6} \mathrm{ft} / \mathrm{min}$ ), THEN NO FILTER FABRIC IS REQUIRED.

STEP 4 (filter selection for case $\boldsymbol{b}, 15 \%<$ silt content $<50 \%$ )

(case b.1) IF the clay content is less than 20\% THEN SELECT a filter fabric with the following characteristics and design recommendation (WHEN DONE, GO TO STEP 6):

Style: Heat Bonded Non-Woven

Opening size: $\mathrm{D}_{30}\left(\right.$ or $\left.\mathrm{D}_{\text {Gap,Min }}\right)<\mathrm{AOS}<\mathrm{D}_{50}$

Thickness: Sufficient for meeting mechanical property requirements of INDOT Specifications, Sec. 913.19.

- (b.1.a) If the soil plasticity is low (i.e. the point representative of liquid limit and plasticity index in the AASHTO soil plasticity chart, ASTM 2487, is in the A.6 
region), use standard design with filter fabric lining the trench (see Fig. 7-1a)

- (b.1.b) If the soil plasticity is high (i.e. the point representative of liquid limit and plasticity index in the AASHTO soil plasticity chart, ASTM 2487, is in the A.7.6 region), the filter fabric should be wrapped around the drainage pipe and the trench backfilled with fine sand (see Fig. 7-1b).

(case b.2) IF the clay content is greater than $20 \%$ AND the soil hydraulic conductivity is greater than $10^{-6} \mathrm{~cm} / \mathrm{sec}$ (or $210^{-6} \mathrm{ft} / \mathrm{min}$ ), THEN SELECT a filter fabric with the following characteristics and design recommendation (WHEN DONE, GO TO STEP 6):

Style: Heat Bonded Non-Woven

Opening size: $\mathrm{D}_{30}\left(\right.$ or $\left.\mathrm{D}_{\text {Gap,Min }}\right)<\mathrm{AOS}<\mathrm{D}_{50}$

Thickness: Sufficient for meeting mechanical property requirements of INDOT Specifications, Sec. 913.19.

The filter fabric should be wrapped around the drainage pipe and the trench backfilled with fine sand (see Fig. 7-1b).

(case b.3) IF the clay content is greater than $20 \%$ AND the soil hydraulic conductivity is less than $10^{-6} \mathrm{~cm} / \mathrm{sec}$ (or $210^{-6} \mathrm{ft} / \mathrm{min}$ ), THEN NO FILTER FABRIC IS REQUIRED.

STEP 5 ( filter selection for case c, $5 \%<$ silt content $<50 \%$ )

(case c.1) IF the clay content is less than 20\% THEN SELECT a filter fabric with the following characteristics and design recommendation (WHEN DONE, GO TO STEP 6):

Style: Heat Bonded Non-Woven

Opening size: $\mathrm{D}_{85}\left(\right.$ or $\left.\mathrm{D}_{\text {Gap,Max }}\right)<\mathrm{AOS}<3 \mathrm{D}_{85}$

Thickness: Sufficient for meeting mechanical property requirements of INDOT 
Specifications, Sec. 913.19.

- (c.1.a) If the soil plasticity is low (i.e. the point representative of liquid limit and plasticity index in the AASHTO soil plasticity chart, ASTM 2487, is in the A.6 region), use standard design with filter fabric lining the trench (see Fig. 7-1a)

- (c.1.b) If the soil plasticity is high (i.e. the point representative of liquid limit and plasticity index in the AASHTO soil plasticity chart, ASTM 2487, is in the A.7.6 region), the filter fabric should be wrapped around the drainage pipe and the trench backfilled with fine sand (see Fig. 7-1b).

(case c.2) IF the clay content is greater than $20 \%$ AND the soil hydraulic conductivity is greater than $10^{-6} \mathrm{~cm} / \mathrm{sec}$ (or $210^{-6} \mathrm{ft} / \mathrm{min}$ ), THEN SELECT a filter fabric with the following characteristics and design recommendation (WHEN DONE, GO TO STEP 6):

Style: Heat Bonded Non-Woven

Opening size: $\mathrm{D}_{85}\left(\right.$ or $\left.\mathrm{D}_{\text {Gap,Max }}\right)<\mathrm{AOS}<3 \mathrm{D}_{85}$

Thickness: Sufficient for meeting mechanical property requirements of INDOT Specifications, Sec. 913.19.

The filter fabric should be wrapped around the drainage pipe and the trench backfilled with fine sand (see Fig. 7-1b).

(case c.3) IF the clay content is greater than $20 \%$ AND the soil hydraulic conductivity is less than $10^{-6} \mathrm{~cm} / \mathrm{sec}$ (or $210^{-6} \mathrm{ft} / \mathrm{min}$ ), THEN NO FILTER FABRIC IS REQUIRED.

STEP 6 (verification of mechanical and other physical properties)

For the geotextile selected on the basis of the above filtration criteria, check that the mechanical and other physical requirements of INDOT's Specification, Sec. 913.19 
Geotextiles for Underdrains (including the modifications recommended in this report), are met. If these requirements are not met, select a geotextile of similar type and AOS, but with greater thickness or better mechanical properties so that it will meet the requirements.

\subsection{Recommendations for Future Study}

Future studies on the subject of filters for highway drainage systems in Indiana should address two types of questions:

(1) How effective are the above recommendations in actual field conditions: this can only be assessed after implementation has been done in actual or pilot projects and performance is observed, by monitoring/inspecting the drains and exhuming fabric filter samples, over a period of several years.

(2) Particular aspects of the filtration problem that could not be addressed in the present study would require further research. Such topics are:

- The effect of chemicals from chemically modified subgrades;

- The effect of dynamic pulsing of pore pressure due to traffic;

- Development of innovative technologies that would facilitate monitoring, maintenance and retrofitting of filters.

It should be kept in mind also that geosynthetic fabric manufacturing is a very dynamic and innovative industry. New geosynthetic products will likely be developed in the near future that will have potential for improved filter performance as compared to currently available fabrics. Evaluation of these new filter geosynthetics will be necessary as they become available. 


\section{References}

AASHTO (1986) Geotextile specifications prepared by joint committee of AASHTOARTBA Task Force 25, Washington, DC, USA

AASHTO (1991) Report on Task Force 25, Joint Committee Report of AASHTO-AGCARTBA, American Association of State, Highway, and Transportation Officials, Washington, D.C., Dec.

Abboud, N. M. and Corapcioglu, M. Y. (1993) Numerical solution and sensitivity analysis of filter cake permeability and resistance, Transport in Porous Media, Kluwer Academic Publishers, Netherlands, 10, 235-255

Aberg, B. (1992) Void ratio of non-cohesive soils and similar materials, Journal of Geotechnical Engineering, ASCE, Vol. 11, No. 9, 1315-1334

Ahmed, Z., White, T.D. and Bourdeau, P.L. (1993) " Pavement Drainage and Pavementshoulder Joint Evaluation \& Rehabilitation”, Draft Final Report, FHWA/IN/JTRP-93/2, Purdue University

Akram, M.H. (1995) Long-term filtration behavior of non-woven geotextiles with fly ash, Proceedings, Geosynthetics' 95 Conference, NAGS, Nashville, TN, Vol.3, 1195-1206

Almeida, M.S.S., Spada, J. and Ehrlich, M. (1995) Geotextile filtration tests on two brazilian soils and current filter criteria, Geosynthetics International, Vol.2, No.1, 357377

Alobaidi, I. and Hoare, D.J. (1996) The development of pore water pressure at the subgrade-subbase interface of a highway pavement and its effects on pumping of fines, Geotextiles and Geomembranes, Vol.14, 111-135

Alobaidi, I. and Hoare, D.J. (1999) Mechanisms of pumping at the subgrade-subbase interface of highway pavements, Geosynthetics International, Vol.6, No.4, 241 - 259

Arulanandan, K. and Pery, E. B. (1983) Erosion in relation to filter design criteria in earth dams, Journal of Geotechnical Engineering, Vol. 109, No. 5, May, ASCE, 682-697

ASTM (2000). ASTM Standards on Geosynthetics, 5th Edition, Committee D-35, American Society for Testing and Materials, Philiadelphia

Babic, M., Bjedov, G. and Shen, H. T. (1992) Sediment-laden oscillatory flow in an idealized porous media, Transport in Porous Media, Kluwer Academic Publishers, Netherlands, 7, 187-204 
Barrington, S. F., Moueddeb, K. E., Jazestani, J. and Dussault, M. (1998) The clogging of nonwoven geotextiles with cattle manure slurries, Geosynthetics International, Vol. 5, No.3, 309 - 325

Barroso, M. C., Lopes, P. and Maria, D. A. (1998) Geotextile characteristic opening size: the Influence of some test parameters, 6th International Conference on Geosynthetics, 1005-1008

Beikae, M. (1999) Monte carlo simulation for filter design, Filtration and Drainage in Geotechnical/Geoenvironmental Engineering, ASCE, 107-122

Bergado, D.T. and Manivannan, R. and Balasubramaniam, A.S. (1996) Filtration criteria for prefabricated vertical drain geotextile filter jacket In soft Bankok clay, Geosynthetics International, Vol.3, No.1, $63-83$

Bhatia, S. K. and Huang, Q. (1995) Geotextile filters for internally stable/ unstable soils, Geosynthetics International, Vol. 2, No.3, 537-565

Bhatia, S. K., Moraille, J. and Smith, J. L. (1998) Performance of granular vs. geotextile filters in protecting cohesionless soils, Filtration and Drainage in Geotechnical/Geoenvironmental Engineering, STP 78, ASCE, 1-29

Bhatia, S.K., Qureshi, S. and Kogler, R.M. (1990) Long-Term Clogging Behavior of Non-woven Geotextiles with Silty and Gap-graded Sands, Geosynthetic Testing for Waste Containment Application, ASTM STP 1081, Edited by Koerner, R.M. , ASTM, Philadelphia, 285-298

Bhatia S. K. and Smith, J. L. (1994) Comparative study of bubble point method and mercury intrusion porometry techniques for characterizing the pore-size distribution of geotextile, Geotextile and Geomembranes, Elsevier, 13, 679-702

Bhatia S. K. and Smith, J. L. (1995) Application of the bubble point method to the characterization of the pore-size distribution of geotextiles, Geotechnical Testing Journal, Vol. 18, No. 1, Mar., 94-105

Bhatia S. K. and Smith, J. L. (1996a) Geotexitle characterization and pore size distribution: part I, A review of manufacture processes, Geosynthetics International, Vol. 3, No. 1, 85 - 105

Bhatia, S. K. and Smith J. L. (1996b) Geotexitle characterization and pore size distribution: part II. A review of test methods and results, Geosynthetics International, Vol. 3, No. 2, 155-180

Bhatia, S. K., Smith J. L. and Christopher, B. R. (1996) Geotexitle characterization and pore size distribution: part III. comparison of methods and application to design, Geosynthetics International, Vol. 3, No. 3, 301-328 
Black, P. J. and Holtz, R. D. (1999) Performance of geotextile separators five years after installation, Journal of Geotechnical and Geoenvironmental Engineering, May, 404-412

Boller, M. A. and Kavanaugh, M. C. (1995) Particle characteristics and head loss increase in granular media filtration, Water Resource, Elsevier Science Ltd., Vol. 29, No. 4, 1139-1149

Bonala, M.V.S. and Reddi, L.N. (1998) Physiochemical and biological mechanisms of soil clogging - an overview, Filtration and Drainage in Geotechnical/Geoenvironmental Engineering, STP 78, ASCE, 43-67

Bourdeaux, G. and Imaizumi, H.(1977) Dispersive clay at Sobradinho dam, Dispersive clays, Related Piping, and Erosion in Geotechnical Projects, STP 623, J.L. Sherard and R.S. Decker, Eds.,ASTM,13-24

Calhoun, C.C. Jr. (1972) Development of design criteria and acceptance specifications for plastic filter cloths, Technical Report, S-72-7, US Army Engineer Waterways Experiment Station, Vicksburg, MS, 83

Carroll, R.G. (1983). Geotextile filter criteria, Transportation Research Record, No. 916, 46-53

Cazzuffi, D. A., Mazzucato, A., Moraci, N. and Tondello, M. (1999) A new test apparatus for the study of geotextiles behavior as filters in unsteady flow conditions: relevance and use, Geotextiles and Geomembranes, Elsevier, 17, 313-329

CGS (1992) Canadian Foundation Engineering Manual, Canadian Geotechnical Society, Canada

Chang H., Juang, A. M. and Holtz, R.D. (1986) Fabric, pore size distribution, and permeability of sandy soils, Journal of Geotechnical Engineering, ASCE, Vol. 112, No. $9,855-868$

Chapuis, R. P. (1992) Similarity of internal stability criteria for granular soils, Technical report, Candidian Geotechnical Journal, 29, 711-713

Chew, S. H., Zhao, Z. K., Karunaratne, G. P., Tan, S. A., Delmas, Ph. and Loke, K.H. (2000) Revetment geotextile filter subjected to cyclic wave loading, geotechnical STP.103, Advanced in Transformation and Geoenvironmental Systems Using Geosynthetics, Proceedings of the Geo Denver Conference, Denver, Aug., ASCE, 162175

Christopher, B. R. and Fischer, G. R. (1992) Geotextile filtration principles, practices and problems, Geotextiles and Geomembranes, Special Issue on Geosynthetics in Filtration, Drainage and Erosion control, Elsevier, Vol. 11, Nos. 4-6, 337-353 
Christopher, B.R. and Holtz, R.D (1985) Geotextile Engineering Manual, United States Department of Transportation, Federal Highway Administration, Washington DC, Report No. FHWA-TS-86/203

Christopher, B.R., Holtz, R.D and Berg, R.R. (1995) Geosynthetic Design and Construction Guidelines, U.S. Department of Transportation, Federal Highway Administration, Washington DC, Report No. HI-95-038

Corbet, S.P. (1993) The design and specification of geotextile and geocomposites for filtration and drainage In Geotextile in Filtration and Drainages, S. Corbet and J. King Eds., Thomas Telford, London, UK, 29-40

Dierickx, W. (1999) Opening size determination of technical textiles used in agricultural applications, Geotextiles and Geomembranes, Elsevier, 17, 231-245

Dimmick, K. and Bhatia, S. K. (1991) Geotextile edge drain design and specification by expert system, Geotechnical Conference, ASCE, Vol. 1, 281-297

Dullien, F. A. L. (1991) Characterization of porous media- pore level, Characterization of Porous Media, Kluwer Academic Publishers, Netherlands, 6, 581-606

Elisabeth, C., Etienne, G. and Stephane, R.(1987) Permeability of a random array of fractures of widely varying apertures, Transport in Porous Media, Kluwer Academic Publishers, Netherlands, 2, 31-43

El-Kadi, A. (1985) On estimating the hydraulic properties of soil, Part 1, Comparison between forms to estimate the soil water characteristics function, Advanced Water Resources, Vol. 8, 136-147

Elsharief, A.M. (1992) Laboratory Evaluation of Prefabricated Highway Edge Drains, Joint Highway Research Project, Final Report, FHWA/IN/JTRP-92/20, Purdue University, 283

Elsharief, A. M. and Lovell, C. W. (1996) A probabilistic retention criterion for nonwoven geotextiles, Geotextile and Geomembranes, Elsevier, 14, 601-617

Espinoza, R.D. (1993) Numerical Analysis of Unsaturated Flow in Porous Media, PhD Dissertation, School of Civil Engineering, Purdue University

Espinoza, D., Bourdeau, P.L. and White, T.D (1993) Pavement Drainage and Pavementshoulder Joint Evaluation \& Rehabilitation: Numerical Modeling of Infiltration and Drainage in Pavements, Joint Highway Research Project, Final Report, FHWA/JTRP/IN93-2, Purdue University 
Fannin, R. J., Vaid, Y. P. and Shi, Y. C. (1994) Filtration behavior of nonwoven geotextiles, Canadian Geotechnical Journal, 31, 555-563

Faure, Y.H. (1988) Approche structurale du comportement filtrantdrainant des geotextiles, Ph.D Thesis, L'Universite Joseph Fourier, L'Institut National Polytechnique de Grenoble, France, 352

Faure, Y. H., Gourc, J. P. and Gendrin, P. (1990) Structural study of porometry and filtration opening size of geotextiles, Geosynthetics: Microstructure and Performance, ASTM STP 1076, Peggs, I.D., Ed., ASTM, Philadelphia, 102-119

Faure, Y. H. and Kehila, Y. (1998) Filter behavior of hydraulically and mechanically damaged geotextiles, 6th International Conference on Geosynthetics, Vol. 2, 1017-1020

Fischer, G.R., Christopher, B.R. and Holtz, R.D. (1990) Filter criteria based on pore size distribution In Proceedings, 4th International Conference on Geotextiles, The Hague, The Netherlands, 289-294

Fleming, I. R. and Rowe, R. K. and Cullimore, D. R. (1999) Field observation of clogging in a landfill leachate collection system, Canadian Geotechnical Journal, 36, 685-707

Fluet, J. E. Jr. and Luettich, S. M. (1994a) Geotextile design using flow nets, Proceedings, Geosynthetics '93, NAGS Conference, Vancouver, B.C., Vol.1, 455-468

Fluet, J. E. Jr. and Luettich, S. M. (1994b) Geotextile filter criteria for gap-graded silty sands, Proceedings, Geosynthetics '93, NAGS Conference, Vancouver, B.C., Vol. 1, 469481

Fo, O. B. D., Marra, W. D. Jr., Kachan, G. C. and Coury, J. R. (2000) Filtration of electrified solid particles, Industrial and Engineering Chemistry Research, No. 39, 3884-3895

Forsyth, R.A., Wells, G.K. and Woodstrom (1987) Economic Impact of Pavement Subsurface Drainage, Transportation Research Record 1121, Washington, DC, Transportation Research Board

Fourie, A.B. and Addis, P.C. (1999) Changes in filtration opening size of woven geotextile subjected to tensile loads, Geotextiles and Geomembranes, Elsevier, Vol. 17, No. 5, Oct., 331-340

Fourie, A. B. and Kuchena S. M. (1995) The influence of tensile stresses on the filtration characteristics of geotextiles, Geosynthetics International, Vol.2, No.2, 455-471 
French Committee on Geotextiles and Geomembranes (1981) Recommendations for the Use of Geotextiles in Drainage and Filtration Systems (in French; draft translation in English, 1986)

Gabr, M. A., Akram, M. H. and Zayed, A. M. (1998) Field versus laboratory filtration performance of a non-woven geotextile with fly ash, Geotextiles and Geomembranes, Elsevier, 16, 247-255

Gardoni, M. G. and Palmeira, E. M. (1998) The performance of a geotextile filter in tropical soil, 6th International Conference on Geosynthetics, Vol. 2, 1027-1032

GEO (1993) Review of granular and geotextile filters, GEO Publication No. 1/93, Geotechnical Engineering Office, Civil Engineering Department, Hong Kong Government, 141

Giroud J. P. (1982) Filter criteria for geotextiles In Proceedings of the Second International Conference on Geotextiles, Vol.1, Las Vegas, Nevada, USA, August, 103108

Giroud J. P. (1988) Review of geotextile filter criteria, Proceedings of the First Indian Geotextiles Conference, Bombay, India, December, 1-6

Giroud, J. P. (1996) Granular filters and geotextile filters, Geofilters '96 Conference, Montreal, 565-680

Giroud, J. P., Delmas, P. and Artieres, O. (1998) Theoretical basis for the development of a two-layer geotextile filter, Sixth International Conference on Geosynthetics, Atlanta, Vol. 2, $1037-1044$

Govindaraju, R. S. (1997) Stochastic analysis for movement of fine particles in porous media, Journal of Hydrologic Engineering, Vol. 1, No. 4, Oct., 161-168

Guler, E. and Baran, E. (1998) Effect of cavities between soil and geotextile filter on permeability, 6th International Conference on Geosynthetics, Vol. 2, 1033-1036

Haegeman, W. and Van, I. (1999) Filtration performance testing of geotextile for vacuum consolidation drains, Geosynthetics International, Vol.6, No.1, 41-51

Harney, M. D. and Holtz, R. D. (2001) A Flexible wall gradient ratio test, Geosynthetics Conference 2001, Portland, Oregon, 409-422

Heerten, G. (1982) Dimensioning the filtration properties of geotextiles considering longterm conditions. 2nd international Conference on Geotextile, Las Vegas, Vol. 1, 115-120 
Hoffman, G. L. and Turgeon, R. (1983) Long Term In-situ Properties of Geotextiles, Research Project 82-83, Pennsylvania Department of Transportation Bureau of Construction Quality Control Materials and Testing Division

Honjo, Y. and Veneziano, D. (1989) Improved filter criterion for cohesionless soils, Journal of Geotechnical Engineering, Vol. 115, No.1, ASCE, 75-94

Hwang, G., Hwu, B. L. Hsing, W. and Lu, C. (1998) Manufacturing effects on the hydraulic properties of needlepunched nonwoven geotextiles, Geotextiles and Geomembranes, Elsevier, 16, 355-363

Indraratna, B. and Locke, M. R. (1999) Design methods for granular filters; critical review, Proceedings, Inst.. Civ. Engrs. Geotechnical Engineering, 137, Jul., 137-147

Indraratna, B. and Radampola, S. (2002) Analysis of critical hydraulic gradient for particle movement in filtration, Journal of Geotechnical and Geoenvironmental Engineering, Apr., 347-350

Indraratna, B. and Vafai, F. (1997) Analytical model for particle migration within base soil-filter system, Journal of Geotechnical and Geoenvironmental Engineering, Vol. 123, No. 2, Feb., $100-109$

Indraratna, B., Vafai, F. and Haque, A. (1998) Experimental and analysis modeling of filtration in granular media, Filtration and Drainage in Geotechnical/Geoenvironmental Engineering, STP 78, ASCE, 89-107

John, N.W.M. (1987) Geotextiles, Blackie and Son Ltd. Glasgow, UK, 347

Juang, C. H. and Holtz, R. D. (1986) A probabilitstic permeability model and the pore size density function, International Journal for Numerical ad Analytical Methods in Geomechanics, Vol. 10, 543-553

Karcz, D.A. and Holtz, R.D. (1988) Development of the IDOH Classification System for Geotextiles, Joint Highway Research Project, Final Report JHRP-88/14, Purdue University, 69

Kellner, L. and Matei, S. (1991) Criteria for geotextile filters in clayey soils, Geotextile and Geomembranes, Elsevier, 9, 79-88

Kenney, T. C., Chahal, R., Chiu, E., Ofoegbu, G. I., Omange, G. N., and Ume, C. A. (1985) Controlling constriction sizes of granular filters, Canadian Geotechnical Journal, $22,32-43$

Kenney, T. C. and Lau, D. (1985) Internal stability of granular filters, Canadian Geotechnical Journal, 22, 215-225 
Koerner, G.R. (1998). Designing with Geosynthetics, 4th Edition, Prentice-Hall

Koerner, G. R., Koerner, R. M. and Wilson-Fahmy, R. F (1996) Field performance of geosynthetic highway drainage systems, Recent Developments in Geotextile Filters and Prefabricated Drainge Geocomposites, ASTM STP 1281, Bhatia, S. K. and Suits, L. D. Eds., American Society for Testing and Materials, 165-181

Kossendey, T. (1999) Long-term performance assessed from compatibility tests, Geotextiles and geomembranes, Elsevier, 17, 281-298

Kossendey, T. and Karam, G. (1998) Large-scale performance tests to evaluate filtration process, 6th International Conference on Geosynthetics, Vol. 2, 1021-1026

Lafleur, J. (1984) Filter testing of broadly graded cohesionless tills, Canadian Geotechnical Journal, 21, 634-643

Lafleur, J. (1998) Particle washout associated with the retention of broadly graded soils by geotextile, 6th International Conference on Geosynthetics, Atlanta, Vol.2, 1001-1004

Lafleur, J. (1999) Selection of geotextiles to filter broadly graded cohesionless soils, Geotextiles and Geomembranes, Elsevier, 17, 299-312

Lafleur, J., Mlynarek, J. and Rollin, A.L. (1990) Filtration of broadly graded cohesionless soils, Journal of Geotechnical Engineering, Vol.115, No.12, 1747-1767

Lafleur, J. and Tetreault, M. (1986) Controlling constriction sizes of granular filters, Discussion, Canadian Geotechnical Journal, 23, 97-98

Laidlaw, W. G. and Wilson, W. G. (1993) A lattice model of foam flow in porous media, A Percolation Approach Transport in Porous Media, Kluwer Academic Publishers, Netherlands, 11, 139-159

Lambe, T.W. and Whitman, R.V. (1979) Soil Mechanics, S.I. version, John Wiley and Sons, New York

Lawson, C.R. (1986) Geotextile filter criteria for tropical residual soils In 3rd International Conference on Geotextiles, Vienna, Austria, Vol.2, 557-562

Lawson, C.R. (1987) Use of geotextiles for subsurface drainage in South East Asian context. In International Symposium on Geosynthetics, Kyoto, Japan, 145-165

Locke, M., Indraratna, B. and Adikari, G. (2001) Time-dependent particle transport through granular filters, Journal of Geotechnical and Geoenvironmental Engineering, Vol. 127, No.6, 521-529 
Loebotsjkov, E. A. (1969) The calculation of suffosion properties of noncohesive soils when using the non-suffosion analog (in Russian), International Conference on Hydraulic Research, Brno, Czeckoslovakia, Publication of the Technical University of Brno, Svazek B-5, 135-148

Luettich, S. M. (1993) Geotextile filters: designing for the application, Geotechnical Fabrics Report, Vol. 11, No. 1, 70-78

Luettich, S. M., Giroud, J. P. and Bachus, R. C. (1992) Geotextile filter design guide, Geotextiles and Geomembranes, Elsevier, 11, 355-370

Maier, R. and Laidlaw W. G. (1990) Fluid percolation in bond-site size correlated threedimensional networks, Transport in Porous Media, Kluwer Academic Publishers, Netherlands, 5, 421-428

Mannsbart, G. and Christopher, B. R. (1997) Long term performance of non-woven geotextile filters in five coastal and bank protection projects, Geotextiles and Geomembranes, Elsevier, 15, 207-221

Merwe, C.J.V.D. and Horak, E. (1989) Evaluation of soil/geotextile compatibility, Proceedings,11th Geofilter, Rio de Janero, Vol.3, Brazil, 1671-1677

Millar, P.J., Ho, K.W. and Turnbull, H.R. (1980) A study of filter fabrics for geotechnical applications in New Zealand, Central Laboratories Report, No. 2-80/5, Ministry of Works and Development

Mlynarek, J. (1985) Designing geotextiles as protective filters In 21th IAHR Congress, Melbourne, Australia, 154-158

Mlynarek, J., Lafleur, J. and Lewandowski, J.B. (1990) Field study on long term geotextile filter performance In 4 th International Conference on Geotextiles, Geomembranes and Related Products, The Hague, The Netherlands, Vol. 1, 259-262

Mlynarek, J., Lafleur, J., Rollin, A. and Lombard, G. (1993) Goetextile filter design based on the filtration opening size obtained by hydrodynamic sieving, Filters in Geotechnical and Hydraulic Engineering, Proceedings of the 1st International Conference “Geo-Filters'92”, Karlsruhe, Germany, 26-33

Mlynarek, J., Lewwandowski, J. B., Rollin A. L. and Bolduc, G. (1991) Soil-geotextiles system interaction, Geotextiles and Geomembranes, Elsevier, 10,161-176

Murty A. V. S. R., Mathur, S., Chandra, D. and Rao, K. N. (1994) Selection of geotextile filters wrapped around pipes in pavement edge drains, Geotextiles and Geomembranes, Elsevier,13, 519-529 
Nishigata, T., Fannin, R. T. and Vaid, Y. P. (2000) Blinding and clogging of a nonwoven geotextile, Soils and Foundations, Japanese Geotechnical Society, Vol.40, No. 4, $121-127$

Ogink, M.J.M. (1975) Investigations on the hydraulic characteristics of synthetic fabrics, Delf Hydraulics Laboratory, The Netherlands, Publication No. 146

OMT (1992) Guidelines for the design and quality control of geotextiles, Draft Engineering Material Report, Engineering Materials Office, Soils and Aggregate Section, Ontario Ministry of Transportation, Ontario, Downsview, Canada

Palmeira, E. M. and Fannin, R.J. (2002) Soil-geotextile compatibility in filtration, Proceedings, 7th International Conference on Geosynthetics, Nice, France, Sep., 853-872

Palmeira, E. M. and Gardoni, M.G. (2000a) Geotextiles in filtration: A state-of-the-art review and remaining challenges. International Symposium on Geosynthetics held as part of GeoEng 2000, M. Bouazza Ed., Melbourne, Australia, 85-110

Palmeira, E. M. and Gardoni, M.G. (2000b) The influence of partial clogging and pressure on the behavior of geotextiles in drainage systems, Geosynthetics International, Vol. 7, No. 4-6, 403-431

Qureshi, S., Kogler, R.M. and Bhatia, S.K. (1990) Long term filtration behavior of nonwoven geotextiles, 4th International Conference on Geotextiles, Geomembranes and Related Products, Vol.1, The Hague, Netherlands, 279-283

Ragutzki, G. (1973) Beitrag zur ermittlung der filterwitksamkeit durch-lassiger kunststoffe. Jahresbericht der Forschungstelle für Insel und Küstenshutz, Band XXV, Nordeney

Rankilor, P.R. (1981) Membranes in Ground Engineering, Wiley, 377

Rao, A. R. and Sitaram, N. (1999) Stability and mobility of sand-bed channels affected by seepage, Journal of Irrigation and Drainage Engineering, Vol.125, No. 16, Nov./Dec., $370-379$

Reddi, L.N. (1997) Particle transport in soils; review of significant process in infrastructure systems, Journal of Infrastructure Systems, Vol.3, No.2, $78-86$

Reddi, L. N. and Bonala, V. S. (1997) Analytical solution for fine particle accumulation in soil filters, Journal of Geotechnical and Geoenvironmental Engineering, Vol. 123, No. 12, Dec., $1143-1152$ 
Reddi, L.N., Ming, X., Hajra, M.G. and Lee, I.M. (2000) Permeability reduction of soil filter due to physical clogging, Journal of Geotechnical and Geoenvironmental Engineering, Vol.126, No.3, Mar., 236-246

Renault, P. (1991) The effect of spatially correlated blocking-up of some bonds or nodes of a network on the percolation threshold, Transport in Porous Media, Kluwer Academic Publishers, Netherlands, 6, 451-468

Richards, E. A., Scott, J. D. and Smith, D. W. (1998) Aquatextiles: use of non-woven geotextiles for filtration in a municipal water treatment plant, 6th International Conference on Geosynthetics, 1045-1048

Rigo, J.M., Lhote, F., Rollin, A.L., Mlynarek, J. and Lombard, G.(1990) Influence of geotextile structure on pore size determination, Geosynthetics: Microstructure and Performance, ASTM, 90-101

Rollin, A. L. and Lombard, G. (1988) Mechanisms affecting long-term filtration behavior of geotextile, Geotextiles and Geomembranes, Elsevier, 7, 119-145

Rollin, A.L., Mlynarek, J., and Bolduc, G.E. (1990) Study of significance of physical and hydraulic properties of geotextiles used as envelopes in subsurface drainage systems In 4 th International Conference on Geotextiles, Geomembranes and Related Products, The Hague, The Netherlands, Vol. 1, 363

Rowe, R.K. (1993) Some challenging application of geotextile in filtration and drainage, Geotextiles in Filtration and Drainage ; Proceeding of the Conference Geofad '92 ,1-12

Rowe, R.K., Armstrong, M.D. and Cullimore, D.R. (2000) Particle size and clogging of granular media permeated with leachate, Journal of Geotechnical and Geoenvironmental Engineering, ASCE, Vol.126, No.9, Sep., 775-786

Rowe, R. K. and Smith, J. D. (1991) Geosynthetics- environmental application in waste contaiment, 44th Canadian Geotechnique Conference, Vol.2, No. 75, 1 - 7

Ruckert, H., Uhlig, T., Kruse, G. and Zschernitz, P. (1991) Utilization of clogging in geotextiles for the sealing of earthworks, Geotextiles and Geomembranes, Elsevier,10, 103-113

Schoeber, W. and Teindl, H. (1979) Filter criteria for geotextiles. In 7th European Conference on Soil Mechanics and Foundation Engineering, Brighton, UK, Vol. 2, 123129

Scott, J.D., Wong, E.P. and Richards, E.A. (1991) Geotextile design for specialized filtration conditions, 44th Canadian Geotechnique Conference, Vol.2, No.77, 1-8 
Sek, J. P. (1996) Self-diffusion in liquids predicted by a theory of flow through granular media, AIChE Journal, Vol. 42, No. 12, 3333-3339

Sharma, H.D. and Lewis, S.P. (1995) Waste Containment Systems, Waste Stabilization, and Landfills, Johns Wiley \& Sons

Sherard, J. I. and Dunnigan, L. P. (1988) Critical filters for impervious soils, Journal of Geotechnical Engineering, Vol. 115, No.7, Jul., ASCE, 927-947

Sholji, I. (1987) Expansion of granular filters during backwashing, Journal of Environmental Engineering, Vol.113, No.3, Jun., 516-531

Silvera, A. (1965) An analysis of the problem of washing through in protective filters, Proceedings, 6th International Conference on Soil Mechanics and Foundation Engineering, Montreal, Vol. 2, 551-555

Siva, U. and Bhatia, S.K. (1994) Filtration performance of geotextiles with fine-grained soils, Proceedings, Geosynthetics '93, NAGS Conference, Vancouver, B.C., Vol. 1, 483499

Sluys, L.U.D. and Dierickx, W. (1990) Comparative study of different porometry determination methods for geotextiles, Geotextiles and Geomembranes, Elsevier, 9, 183198

Spearing, M. and Matthews, G. P. (1991) Modeling characteristic properties of sandstones, Transport in Porous Media, Kluwer Academic Publishers, Netherlands, 6, $71-90$

Stauffer, D. (1985) Introduction to Percolation Theory, Taylor \& Francis, London and Philadelphia, ISBN 0-85066-315-6

Stevenson, D. G. (1996) Flow and filtration through granular media; the effect of grain and particle size dispersion, Water Resource, Vol. 31, No. 2, Elsevier Science Ltd., 310322

Sweetland, D.B. (1977) The Performance of non woven fabrics as drainage screens in subdrains, MSc. Thesis, University of Strathclyde, Scotland, UK.

Taylor, S. W. (1990) Substrate and biomass transport in a porous medium, Water Resource Research, Vol. 26, No.9, Sep., 2181-2194

Terzaghi, K. (1922) Der grundbruch and stauwerken und seine verhutung, ForcheimerNummer der Wasserkraft, 17, 445-449 
Thevanayagam, S., Shentha, T., Mohan, S. and Liang, J. (2002) Undrained fragility of clean sands, silty sands, and sandy silts, Journal of Geotechnical and Geoenvironmental Engineering, Vol. 128, No. 10, Oct., 849-859

Tien, C. and Payatakes, A. C. (1979) Advances in deep bed filtration, AIChE Journal, Vol. 25, No. 5, Sep., 737-749

Tomlinson, S. S. and Vaid, Y. P. (2000) Seepage forces and confining pressure effects on piping erosion, Canadian Geotechnical Journal, 37, 1-13

Truesdail, S. E., Westermann-Clark, G. B. and Shah, D. O. (1998) Apparatus for streaming potential measurements on granular filter media, Journal of Environmental Engineering, Vol. 124, No.12, Dec., 1228-1232

Urashima, D. C. and Vidal, D. (1998) Geotextiles filter design by probabilistic analysis, 6th Internal Conference on Geosynthetics, Vol. 2, 1013-1016

USACE (1977) Plastic filter cloth, Civil Works Construction Guide Specification No. CW-02215, United States Army Corps of Engineers, Office, Chief of Engineers, Washington, DC, USA

USBR (1974). Earth Manual, $2^{\text {nd }}$ Ed., US Bureau of Reclamation, US Department of the Interior, 810

USBR (1994). Design Standards, Embankment Dams, No 13, Chapter 5, Protective Filters, US Bureau of Reclamation, US Department of the Interior

Vallejo, L. E. (2001) Iterpretation of the limits in shear strength in binary granular mixture, Canadian Geotechincal Journal, 38, 1097-1104

Vandervivere, P. and Baveye, P. (1992) Saturated hydraulic conductivity reduction caused by aerobic bacteria in sand columns, Soil Science Society of America Journal, Vol. 56, Jan./Feb., 1-12

Vigneswaran, S., Chang, J. S. and Janssens, J. G. (1990) Experimental investigation of size distribution of suspended particles in granular bed filtration, Water Resource, Vol. 24, No. 7, 927-930

Watson, P.D.J. and John, N.W.M. (1999) Geotextile filtration design and simulated bridge formation at the soil-geotextile interface, Geotextiles and Geomembranes, Elsevier, 17, 265-280

Wayne, M.H. and Koerner, R.M.(1993) Correlation between long-term flow testing and current geotextile filtration design practice, Geosynthetics '93 Conference, NAGS, Vancouver, BC, Canada, Vol. 1, 501-517 
Williams, N. D. and Abouzakhm, M. A. (1989) Evaluation of geotextile/soil filtration characteristics using the hydraulic conductivity ratio analysis, Geotextiles and Geomembranes, Elsevier, 8, 1 - 26

Wilson-Fahmy, R.F., Koerner, G.R. and Koerner, R.M. (1996) Geotextile filter design critique, Recent Developments in Geotextile Filters and Prefabricated Drainage Geocomposites, ASTM STP 1281, Shobha K. Bhatia and L. David Suits, Eds., American Society for Testing and Materials, 132-164

Witt, K. J. and Brauns, J. (1984) The influence of parameter variation on the reliability of filters, Proceedings of the International Conference on Safety of Dams, 23-28

Wu, J., Gui, S., Stahl, P. and Zhang, R. (1997) Experimental study on the reduction of soil hydraulic conductivity by enhanced biomass growth, Soil Science, Vol. 162, No.10, 741-748

Wukash, R. and Siddiqui, R. (1996) Remediation of Hazardous Effluent Emitted from Beneath Newly Constructed Road Systems and Clogging of Underdrain Systems, Joint Highway Research Project, Final Report FHWA/IN/JHRP-96/13, Purdue University, 196

Xiao, M. and Reddi, L. N. (2000) Comparison of fine particle clogging in soils and geotextile filters, Advances in Transportation and Geoenvironmental Systems Using Geosynthetics, Proceeding Geo-Denver 2000, Denver, ASCE, 176-185

Yanuka, M. (1992) Percolation theory approach to transport phenomena in porous media,Transport in Porous Media, Kluwer Academic Publishers, Netherlands, 7, 265282

Yao, K-M, Habibian, M. T. and O'Melia, C.R. (1971) Water and waste water filtration: concepts and applications, Environmental Science \& Technology, Vol. 5, No. 11, Nov., $1105-1112$

Zitscher, F.F. (1974) Recommendations for the use of plastics in soil and hydraulic engineering. Die Bautechnik, Vol. 52, No. 12, 397-402 


\section{Appendix A}

Geotextile Retention Criteria in Published Literature

(from Palmeira \& Fannin, 2002) 
Table 1. Geotextile retention criteria (modified from Palmeira and Gardoni, 2000).

\begin{tabular}{|c|c|c|}
\hline Source & Criterion & Remarks \\
\hline Ragutzki $(1973)^{(*)}$ & $\begin{array}{l}\mathrm{O}_{f} \leq 0.5 \mathrm{D}_{90} \text { to } 0.7 \mathrm{D}_{90} \\
\mathrm{O}_{f} \leq 0.5 \mathrm{D}_{9} \text { to } 1.3 \mathrm{D}_{9} \\
\mathrm{O}_{f} \leq 0.5 \mathrm{D}_{90} \text { to } 1.5 \mathrm{D}_{9}\end{array}$ & $\begin{array}{l}\text { Wovens and non wovens, dynamic/reverse flow, unconfined } \\
\text { soil } \\
\text { Wovens, dynamic/reverse flow, confined soil } \\
\text { Non wovens, dynamic/reverse flow, confined soil }\end{array}$ \\
\hline U.S. Corps of Engineers (1977) & $\begin{array}{l}0.149 \mathrm{~mm} \leq \mathrm{O}_{95} \leq 0.211 \mathrm{~mm} \\
0.149 \mathrm{~mm} \leq \mathrm{O}_{95} \leq \mathrm{D}_{85}\end{array}$ & $\begin{array}{l}\mathrm{D}_{50}>0.074 \mathrm{~mm} \\
\mathrm{D}_{50} \leq 0.074 \mathrm{~mm} \\
\text { Geotextiles should not be used if } \mathrm{D}_{85} \leq 0.074 \mathrm{~mm}\end{array}$ \\
\hline AASHTO Task Force $\# 25$ (1986) & $\begin{array}{l}\mathrm{O}_{95}<0.59 \mathrm{~mm} \\
\mathrm{O}_{95}<0.30 \mathrm{~mm}\end{array}$ & $\begin{array}{l}\text { If } 50 \% \leq 0.074 \mathrm{~mm} \\
\text { If } 50 \%>0.074 \mathrm{~mm} \\
\text { No limitations on geotextile type nor soil type }\end{array}$ \\
\hline Calhoun (1972) & $\begin{array}{l}\mathrm{O}_{95} \mathrm{D}_{85} \leq 1 \\
\mathrm{O}_{95} \leq 0.2 \mathrm{~mm}\end{array}$ & $\begin{array}{l}\text { Wovens, soils with } \leq 50 \% \text { passing no. } 200 \text { sieve } \\
\text { Wovens, cohesive soils }\end{array}$ \\
\hline $\begin{array}{l}\text { Zitscher, } 1974 \text { (from Rankilor, } \\
\text { 1981) }\end{array}$ & $\begin{array}{l}\mathrm{O}_{90} / \mathrm{D}_{90} \leq 1.7-2.7 \\
\mathrm{O}_{90}, \mathrm{D}_{90} \leq 2.5-3.7\end{array}$ & $\begin{array}{l}\text { Wovens, soils with } \mathrm{C}_{\mathrm{u}} \leq 2, \mathrm{D}_{50}=0.1 \text { to } 0.2 \mathrm{~mm} \\
\text { Non wovens, cohesive soils }\end{array}$ \\
\hline Ogink (1975) & $\begin{array}{l}\mathrm{O}_{9 / 2} \mathrm{D}_{9} \leq 1 \\
\mathrm{O}_{95} \cdot \mathrm{D}_{85} \leq 1.8 \\
\mathrm{O}_{f} \leq \mathrm{D}_{85}{ }^{(9)} \\
\mathrm{O}_{f} \leq \mathrm{D}_{15}{ }^{(m)}\end{array}$ & $\begin{array}{l}\text { Wovens } \\
\text { Non wovens } \\
\text { Dynamic/reverse flow, wovens and non wovens, with formation } \\
\text { of a natural filter } \\
\text { Dynamic/reverse flow, wovens and non wovens, without the } \\
\text { formation of a natural filter }\end{array}$ \\
\hline Sweetland (1977) & $\begin{array}{l}\mathrm{O}_{15} / \mathrm{D}_{85} \leq 1 \\
\mathrm{O}_{15} / \mathrm{D}_{15} \leq 1\end{array}$ & $\begin{array}{l}\text { Non wovens, soils with } \mathrm{C}_{u}=1.5 \\
\text { Non woven, soils with } \mathrm{C}_{\mathrm{u}}=4\end{array}$ \\
\hline Schober \& Teindl (1979) & $\begin{array}{l}\mathrm{O}_{90} / \mathrm{D}_{90} \leq 2.5-4.5 \\
\mathrm{O}_{20} \mathrm{D}_{90} \leq 4.5-7.5\end{array}$ & $\begin{array}{l}\text { Woven and thin non wovens, dependent of } C_{u} \\
\text { Thick non wovens, dependent of } C_{u} \text {, silts and sand soils }\end{array}$ \\
\hline Teindl \& Schober $(1979)^{(*)}$ & $\mathrm{O}_{f} \leq \mathrm{D}_{5}$ to $\mathrm{D}_{8 \mathrm{~s}}$ & $\begin{array}{l}\text { Dynamic/reverse flow conditions, wovens and non wovens, de- } \\
\text { pendent of hydraulic gradient }\end{array}$ \\
\hline Millar et al. (1980) & $\mathrm{O}_{98} \mathrm{D}_{85} \leq 1$ & Wovens and non wovens. \\
\hline Rankilor (1981) & $\begin{array}{l}\mathrm{O}_{95} / \mathrm{D}_{85} \leq 1 \\
\mathrm{O}_{15} / \mathrm{D}_{15} \leq 1\end{array}$ & $\begin{array}{l}\text { Non wovens, soils with } 0.02 \leq D_{85} \leq 0.25 \mathrm{~mm} \\
\text { Non wovens, soils with } D_{85}>0.25 \mathrm{~mm} \\
\end{array}$ \\
\hline Giroud (1982) & 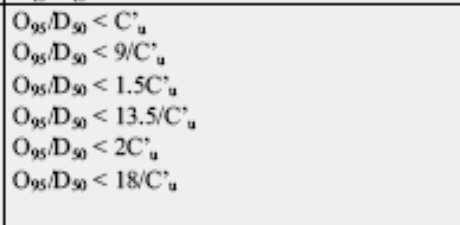 & $\begin{array}{l}\mathrm{I}_{\mathrm{D}}<35 \%, 1<\mathrm{C}_{\mathrm{u}}^{\prime}<3 \\
\mathrm{I}_{\mathrm{D}}<35 \%, \mathrm{C}_{\mathrm{u}}>3 \\
35 \%<\mathrm{I}_{\mathrm{D}}<65 \%, 1<\mathrm{C}_{\mathrm{u}}^{\prime}<3 \\
35 \%<\mathrm{I}_{\mathrm{D}}<65 \%, \mathrm{C}_{\mathrm{u}}>3 \\
\mathrm{I}_{\mathrm{b}}>65 \%, 1<\mathrm{C}_{\mathrm{u}}<3 \\
\mathrm{~b}_{\mathrm{b}}>65 \%, \mathrm{C}_{\mathrm{u}}>3 \\
\text { Assumes fines in soil migrating for large } \mathrm{C}_{\mathrm{u}}\end{array}$ \\
\hline Carroll (1983) & $\mathrm{O}_{95} \mathrm{D}_{85} \leq 2-3$ & Wovens and non wovens \\
\hline Hecrten (1982) & 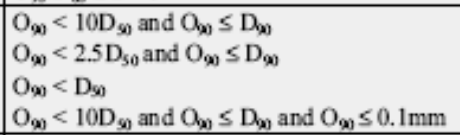 & $\begin{array}{l}\text { Cohesionless soils, with CU } \geq 5 \text { and static load conditions } \\
\text { Cohesionkss soils, with } \mathrm{CU}<5 \text { and static load conditions } \\
\text { Cohesionkss soils, dy namic bad conditions } \\
\text { Cohesive soils and all load conditions } \\
\end{array}$ \\
\hline $\begin{array}{l}\text { Mlynarek (1985), Mlynarek et al. } \\
\text { (1990) }\end{array}$ & $2 \mathrm{D}_{15}<\mathrm{O}_{95}<2 \mathrm{D}_{85}$ & Non wovens \\
\hline Lawson (1986) & $\mathrm{O}_{9} / \mathrm{D}_{\mathrm{n}}=\mathrm{C}$ & $\begin{array}{l}\text { Developed for residual soils from Hong Kong } \\
\text { Values of } \mathrm{n} \text { and C are obtained by a chart defining regions of } \\
\text { acceptable filter performance }\end{array}$ \\
\hline Lawson (1987) (from GEO, 1993). & $\begin{array}{l}\mathrm{O}_{9 /} / \mathrm{D}_{85} \leq 1 \\
0.08 \mathrm{~mm} \leq \mathrm{O}_{90} \leq 0.12 \mathrm{~mm} \\
0.03 \mathrm{~mm} \leq \mathrm{O}_{95} \leq \mathrm{D}_{85}\end{array}$ & $\begin{array}{l}\text { For predominantly granular soils with D }>0.1 \mathrm{~mm} \text {, e.g., resid- } \\
\text { ual soik which are granular in nature and alluvial sandy soils } \\
\text { For non-cohesive soils, e.g., silts of alluvial or other origin, and } \\
\text { for non-dispersive cohesive soils. } \\
\text { For dispersive cohesive soils }\end{array}$ \\
\hline John (1987) & $\mathrm{O}_{95} / \mathrm{D}_{90} \leq\left(\mathrm{C}_{4}^{\prime}\right)^{\prime \prime}$ & $\begin{array}{l}\mathrm{a} \text { is dependent of the of the size of the particle to be restrained } \\
\left(\mathrm{a}=0.7 \text { for } \mathrm{D}_{\mathrm{ss}} \text { ) }\right.\end{array}$ \\
\hline FHWA-Christopher \& Holtz (1985) & $\begin{array}{l}\mathrm{O}_{95} / \mathrm{D}_{85} \leq 1-2 \\
\mathrm{O}_{95} / \mathrm{D}_{15} \leq 1 \text { or } \\
\mathrm{O}_{90} / \mathrm{D}_{85} \leq 0.5\end{array}$ & $\begin{array}{l}\text { Dependent of soil type and } \mathrm{C}_{\mathrm{u}} \text {. } \\
\text { Dynamic, pulsating and cyclic flow if soil can move beneath } \\
\text { geotextile }\end{array}$ \\
\hline $\begin{array}{l}\text { CFGG (1986)-French Committee } \\
\text { on Geotex tiles and Geomembranes }\end{array}$ & $\begin{array}{l}\mathrm{O} / \mathrm{D}_{85} \leq 0.38-1.25 \\
\left.\mathrm{O}_{f} \leq 0.5 \mathrm{D}_{88} s^{*}\right) \\
\left.\mathrm{O}_{f} \leq 0.75 \mathrm{D}_{85} s^{*}\right)\end{array}$ & $\begin{array}{l}\text { Dependent of soil type, compaction, hydraulic and application } \\
\text { conditions } \\
\text { Reverse flow, wovens and non wovens, loose soil } \\
\text { Reverse flow, wovens and non wovens, dense soil } \\
\end{array}$ \\
\hline Fischer, Christopher \& Holtz (1990) & $\begin{array}{l}\mathrm{O}_{90} / \mathrm{D}_{85} \leq 0.8 \\
\mathrm{O}_{95} / \mathrm{D}_{15} \leq 1.8-7.0 \\
\mathrm{O}_{90} / \mathrm{D}_{90} \leq 0.8-2.0\end{array}$ & $\begin{array}{l}\text { Based on geotextile pore size distribution, dependent of } \mathrm{C}_{\mathrm{u}} \text { of } \\
\text { soil. }\end{array}$ \\
\hline Rollin et al. (1990) & $\mathrm{O}_{95}<1$ to $1.5 \mathrm{D}_{85}$ & $\begin{array}{l}\text { Tests with a fine sandy soil and } 3 \text { non woven, needle-punched } \\
\text { geotextiles using an upflow filtration apparatus. }\end{array}$ \\
\hline Luettich et al. (1992) & Design charts & $\begin{array}{l}\text { Based on geotextile void size, soil size and type, hydraulic } \\
\text { conditions and other factors }\end{array}$ \\
\hline
\end{tabular}




\begin{tabular}{|c|c|c|}
\hline CGS (1992) & $\begin{array}{l}\mathrm{O}_{4} / \mathrm{D}_{85}<1.5 \\
\mathrm{O}_{5} / \mathrm{D}_{85}<3.0\end{array}$ & \begin{tabular}{|l|} 
Uniform soils \\
Broadly graded soils
\end{tabular} \\
\hline OMT (1992) & $\mathrm{O} / \mathrm{D}_{85}<1.0$ and $\mathrm{O}_{f}>0.5 \mathrm{D}_{85}$ or $40 \mu \mathrm{m}$ & $\begin{array}{l}\text { Non wovens geotextiles preferred, } \mathrm{tor}_{\mathrm{r}}>1 \mathrm{~mm} \text {, avoid thermally } \\
\text { bonded geotextiles. }\end{array}$ \\
\hline $\begin{array}{l}\text { UK DTp - Murray and MoGown } \\
\text { (1992), from Corbet (1993) }\end{array}$ & $\begin{array}{l}\mathrm{O}_{N} / \mathrm{D}_{\mathbf{N}}=1 \text { to } 3 \\
\mathrm{O}_{\mathbf{N}} / \mathrm{D}_{\mathbf{N}}<1 \text { to } 3 \\
\mathrm{O}_{\mathbf{N}} / \mathrm{D}_{\mathbf{N}}<1.8 \text { to } 6\end{array}$ & $\begin{array}{l}\text { Soils with } 1 \leq \mathrm{C}_{u} \leq 5 \text {, wovens and non wovens. } \\
\text { Soils with } 5<\mathrm{C}_{u}<10 \text {, wovens and thin non wovens ( } \mathrm{t}_{0 \mathrm{r}} \leq \\
2 \mathrm{~mm} \text { ) - alternative criterion } \\
\text { Soils with } 5<\mathrm{C}_{u}<10 \text {, thick non wovens ( } \mathrm{t}_{\overline{\mathrm{T}}}>2 \mathrm{~mm} \text { ) - alterna- } \\
\text { tive criterion }\end{array}$ \\
\hline Fannin et al. (1994b) & 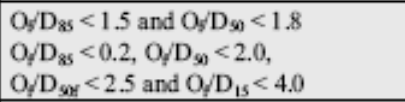 & $\begin{array}{l}\text { Non woven geotextiles, } 1<\mathrm{C}_{u}<2 \\
\text { Non woven geotextiles, } 3<\mathrm{C}_{u}<7\end{array}$ \\
\hline Bhatia and Huang (1995) & $\begin{array}{l}\mathrm{O}_{25} / \mathrm{D}_{85}<0.65-0.05 \mathrm{C}_{\mathrm{c}} \\
\mathrm{O}_{95} / \mathrm{D}_{\mathrm{ss}}<2.71-0.36 \mathrm{C}_{\mathrm{c}} \\
\mathrm{O}_{25}<\mathrm{D}_{85}\end{array}$ & $\begin{array}{l}\mathrm{n}<60 \% \text { and } \mathrm{C}_{\mathrm{c}}>7 \\
\mathrm{n}<60 \% \text { and } \mathrm{C}_{\mathrm{e}}<7 \\
\mathrm{n}<60 \%\end{array}$ \\
\hline Lafleur (1999) & $\begin{array}{l}\mathrm{O}_{/} / \mathrm{D}_{1}<1 \\
1<\mathrm{O}_{\mathrm{f}} \mathrm{D}_{1}<5\end{array}$ & $\begin{array}{l}\text { Stable soils }\left(C_{4} \leq 6 \text { and } D_{1}=D_{85} \text { in this case), soils with } C_{4}>6\right. \\
\text { but linearly graded }\left(D_{1}=D_{50} \text { in this case), gap graded }\left(C_{4}>6\right)\right. \\
\text { internally stable soils }\left(D_{4}=D_{0}\right) \text { and soils with } C_{u}>6 \text { with gra- } \\
\text { dation curve concave upwards and internally stable }\left(D_{1}=D_{90}\right) \\
\text { Unstable soils with: } \\
D_{1}=D_{30} \text { for gap graded internally unstable soils and for inter- } \\
\text { nally unstable soils with gradation curves concave upwards } \\
\text { (risk of piping of fines) } \\
\text { Criteria developed for cohesionless soils }\end{array}$ \\
\hline
\end{tabular}

Notes: $\mathrm{C}_{\mathrm{c}}=$ coefficient of curvature of the soil $=\mathrm{D}^{2}{ }_{\mathrm{s}} /\left(\mathrm{D}_{\omega 0} \mathrm{D}_{10}\right), \mathrm{C}_{u}=$ coefficient of uniformity of the soil $=\mathrm{D}_{60} / \mathrm{D}_{10}, \mathrm{C}_{4}{ }_{4}=$ linear coefficient of uniformity of the soil $=\left(\mathrm{D}^{\prime}{ }_{10 /} \mathrm{D}_{0}^{\prime}\right)^{\mathrm{as}}, \mathrm{D}_{0}=$ minimum soil gap size, $\mathrm{D}_{1}=$ indicative size of the protected base soil, $\mathrm{D}_{9 \mathrm{gf}}=$ mean particle size of the soil fraction smaller than the value of $\mathrm{O}_{f}$ for the geotextile, $\mathrm{D}_{Y}=$ soil particle size corresponding to " $\mathrm{Y}$ " percent passing, $\mathrm{D}_{\mathrm{Y}}=$ soil particle size corresponding to " $\mathrm{Y}$ " percent passing obtained from a straight line fitting of the central part of the soil gradation curve, $\mathrm{I}_{\mathrm{D}}=$ Density index (relative density), $\mathrm{n}=$ geotextile porosity, $\mathrm{O}_{f}=$ filtration opening size bas od on hydrodynamic sieving, $\mathrm{O}_{\mathrm{X}}=$ geotextile opening size corresponding to " $\mathrm{X}$ " partick size based on dry glass bead sieving, $t_{\pi /}=$ geotextile thickness, $\left({ }^{*}\right)$ from Faure (1988). 


\section{Appendix B}

Geotextile Survivability Specifications

AASHTO-AGC-ARTBA, Task Force 25 and AASHTO M288

(after Koerner, 1998) 


\section{How to determine geotextile properties required for survivability:}

Step A: In table 2.22 next page, enter level of ground pressure applied to geotextile through construction equipment (e.g. compaction equipment) and level of subgrade preparation prior to geotextile installation. Obtain from the table the required level of survivability.

Step B: Find the corresponding survivability class:

Very high to high survivability level $\rightarrow$ Class 1

High to moderate survivability level $\rightarrow$ Class 2

Moderate to low level of survivability $\rightarrow$ Class 3

Step C: In the following page, Table 2.2a, enter the survivability class and find the corresponding minimal requirements for grab, tear, puncture and burst strength. 
TABLE 2.22 REQUIRED DEGREE OF SURVIVABILITY AS A FUNCTION OF SUBGRADE CONDITIONS AND CONSTRUCTION EQUIPMENT*

\begin{tabular}{|c|c|c|c|}
\hline Subgrade Conditions & $\begin{array}{l}\text { Low ground- } \\
\text { pressure } \\
\text { equipment } \\
(\leqslant 25 \mathrm{kPa})\end{array}$ & $\begin{array}{c}\text { Medium } \\
\text { ground-pressure } \\
\text { equipment } \\
(>25 \mathrm{kPa}, \leqslant 50 \mathrm{kPa})\end{array}$ & $\begin{array}{l}\text { High ground- } \\
\text { pressure } \\
\text { equipment } \\
(>50 \mathrm{kPa})\end{array}$ \\
\hline $\begin{array}{l}\text { Subgrade has been cleared of all obstacles } \\
\text { except grass, weeds, leaves, and fine wood } \\
\text { debris. Surface is smooth and level so that } \\
\text { any shallow depressions and humps do not } \\
\text { exceed } 450 \mathrm{~mm} \text { in depth or height. All } \\
\text { larger depressions are filled. Alternatively, } \\
\text { a smooth working table may be placed. }\end{array}$ & Low & Moderate & High \\
\hline $\begin{array}{l}\text { Subgrade has been cleared of obstacles larger } \\
\text { than small to moderate-sized tree limbs and } \\
\text { rocks. Tree trunks and stumps should be } \\
\text { removed or covered with a partial working } \\
\text { table, Depressions and humps should not } \\
\text { exceed } 450 \mathrm{~mm} \text { in depth or height. Larger } \\
\text { depressions should be filled. }\end{array}$ & Moderate & High & Very high \\
\hline $\begin{array}{l}\text { Minimal site preparation is required. Trees } \\
\text { may be felled, delimbed, and left in place. } \\
\text { Stumps should be cut to project not more } \\
\text { than } \pm 150 \mathrm{~mm} \text { above subgrade. Fabric may } \\
\text { be draped directly over the tree trunks, } \\
\text { stumps, large depressions and humps, holes, } \\
\text { stream channels, and large boulders. Items } \\
\text { should be removed only if placing the } \\
\text { fabric and cover material over them will } \\
\text { distort the finished road surface. }\end{array}$ & High & Very high & $\begin{array}{c}\text { Not } \\
\text { recommended }\end{array}$ \\
\hline
\end{tabular}

*Recommendations are for 150 to $300 \mathrm{~mm}$ initial lift thickness. For other initial lift thicknesses:

300 to $450 \mathrm{~mm}$ : reduce survivability requirement one level;

450 to $600 \mathrm{~mm}$ : reduce survivability requirement two levels;

$>600 \mathrm{~mm}$ : reduce survivability requirement three levels

For special construction techniques such as prerutting, increase the fabric survivability requirement one level. Placement of excessive initial cover material thickness may cause bearing failure of the soft subgrade. Source: After Christopher, Holtz, and DiMaggio [159]. 
TABLE 2.2a AASHTO M288-96 GEOTEXTILE STRENGTH PROPERTY REQUIREMENTS

\begin{tabular}{|c|c|c|c|c|c|c|c|c|}
\hline & \multirow[b]{3}{*}{$\begin{array}{c}\text { Test } \\
\text { Methods }\end{array}$} & \multirow[b]{3}{*}{ Units } & \multicolumn{6}{|c|}{ Geotextile Classification *t } \\
\hline & & & \multicolumn{2}{|c|}{ Class 1} & \multicolumn{2}{|c|}{ Class 2} & \multicolumn{2}{|c|}{ Class 3} \\
\hline & & & $\begin{array}{c}\text { Elongation } \\
<50 \%\end{array}$ & $\begin{array}{c}\text { Elongation } \\
>50 \%\end{array}$ & $\begin{array}{c}\text { Elongation } \\
<50 \%\end{array}$ & $\begin{array}{c}\text { Elongation } \\
>50 \%\end{array}$ & $\begin{array}{c}\text { Elongation } \\
<50 \%\end{array}$ & $\begin{array}{c}\text { Elongation } \\
>50 \%\end{array}$ \\
\hline Grab strength & $\begin{array}{l}\text { ASTM } \\
\text { D4632 }\end{array}$ & $\mathbf{N}$ & 1400 & 900 & 1100 & 700 & 800 & 500 \\
\hline $\begin{array}{l}\text { Sewn seam } \\
\text { strength }^{t}\end{array}$ & $\begin{array}{l}\text { ASTM } \\
\text { D4632 }\end{array}$ & $\mathrm{N}$ & 1200 & 810 & 990 & 630 & 720 & 450 \\
\hline Tear strength & $\begin{array}{l}\text { ASTM } \\
\text { D4533 }\end{array}$ & $\mathrm{N}$ & 500 & 350 & $400^{4}$ & 250 & 300 & 180 \\
\hline Puncture strength & $\begin{array}{l}\text { ASTM } \\
\text { D4833 }\end{array}$ & $\mathrm{N}$ & 500 & 350 & 400 & 250 & 300 & 180 \\
\hline Burst strength & $\begin{array}{l}\text { ASTM } \\
\text { D3786 }\end{array}$ & $\mathrm{kPa}$ & 3500 & 1700 & 2700 & 1300 & 2100 & 950 \\
\hline Permittivity & ASTM & $\mathbf{s}^{-1}$ & \multirow{3}{*}{\multicolumn{6}{|c|}{$\begin{array}{l}\text { Minimum property requirements for permittivity, } \mathrm{AOS} \text { and UV stability are based on } \\
\text { geotextile application. Refer to Table } 2.2 \mathrm{~b} \text { for subsurface filtration, Table } 2.2 \mathrm{c} \text { for separa- } \\
\text { tion, Table } 2.2 \mathrm{~d} \text { for stabilization, and Table } 2.2 \mathrm{e} \text { for permanent erosion control. }\end{array}$}} \\
\hline $\begin{array}{l}\text { Apparent } \\
\text { opening size }\end{array}$ & $\begin{array}{l}\text { D4491 } \\
\text { ASTM } \\
\text { D4751 }\end{array}$ & $\mathrm{mm}$ & & & & & & \\
\hline $\begin{array}{l}\text { Ultraviolet } \\
\text { stability }\end{array}$ & $\begin{array}{l}\text { ASTM } \\
\text { D4355 }\end{array}$ & $\%$ & & & & & & \\
\hline
\end{tabular}

"Required geotextile classification is designated in Tables $2.2 \mathrm{~b}, \mathrm{c}, \mathrm{d}, \mathrm{e}$ for the indicated application.

'As measured in accordance with ASTM D4632. Woven geotextiles fail at elongations (strains) $<50 \%$, while nonwovens fail at elongation (strains) $>50 \%$. 'When sewn seams are required. Overlap seam requirements are application specific.

'The required MARV tear strength for woven monofilament geotextiles is $250 \mathrm{~N}$. 